\title{
INFLUENCES ON THE POLICY PROCESS \\ IN LOCAL GOVERNMENT IN VIETNAM: \\ THE CASE OF LOW-INCOME HOUSING POLICY \\ IN DA NANG CITY FROM 2005 TO 2013
}

by

NGUYEN THI HA VY

\author{
A thesis \\ submitted to Victoria University of Wellington \\ in fulfilment of the requirements for the degree of \\ Doctor of Philosophy
}

Victoria University of Wellington 



\begin{abstract}
There is a growing literature on the policy process at the central level in Vietnam but less attention is paid to exactly how policy gets shaped and implemented at the local level in the specific culture and context of Vietnam and the evolving role of the one-party state. Accordingly, this thesis examines the development of low-income housing policy in Da Nang City from 2005 to 2013 in order to understand the critical influences on the policy process at a local government. It employs qualitative techniques to analyse data collected from interviews and conversations with the participants in the policy process and a collection of published and unpublished documents relating to the process.

The findings show that it is possible to apply Hofferbert's (1974) funnel of causality model with some adjustments, based on insights from other theoretical approaches, to understand influences on the policy process. The significant influences include socio-economic conditions (particularly rapid urban population growth and the impact of urban renewal), which are shaped by some key historical and geographical features, institutional arrangements (especially the relationship between central and local government), and a network of policy actors centred on policy elites.

This study contributes to the literature in three ways. Firstly, although space for policy innovation was constrained by the authority of central government, the city government in fact enjoyed significant autonomy in policy implementation and the central-local relationship had room for policy experimentation and learning, which was still an effective way to change policy at both central and local levels. Secondly, local leaders in Vietnam could have a critical role in re-developing and implementing policies. This finding differs from the conventional wisdom that policymaking in Vietnam is collective and consensusbased. In this case, a strong policy leader could impose his will on the whole local state apparatus. Thirdly, the study also shed light on the opportunities for policy learning in the developing relationship between the state and private sectors in Vietnam. Faced with profit-driven private developers, the local government had to experiment with various incentives to ensure their participation in developing low-cost housing. Comparing the policy outcome before and after the private sector's participation suggests that low-income housing can be developed in partnership with the private sector, given appropriate government policies. The findings of this study offer some implications for people in and
\end{abstract}


outside Vietnam's party and government systems, who want to influence public policy in Vietnam. 


\section{Acknowledgements}

I would like to express my deep gratitude to people who participated in this study as interviewees, informants, and document suppliers who were or are working in various organisations and agencies in Da Nang City and beyond. This study would not have been completed without their generous and kind assistance.

I particularly wish to thank my supervisors, Dr Amanda Wolf and Mr Robert Laking. I owe them both a debt of gratitude for their guidance, inspiration, encouragement, dedication, and empathy during this journey.

My gratitude goes to Vietnam's Programme 165 and Victoria University of Wellington for their scholarships, which made this study possible. I thank my employer, Da Nang Institute for Socio-Economic Development, and its former director, Dr Ho Ky Minh, as well as my colleagues there for their assistance in many ways. I also wish to thank the staff and doctoral students of the School of Government for their support and sharing. I thank Madeleine Collinge for proofreading this thesis.

Finally, I would like to thank my family and friends who encouraged me to complete this study. I am indebted to my husband for two decades of love and sacrifice. I thank my daughter for the inspiration and love that made me stronger every day. I dedicate this thesis to them and to my mother, whose lifetime desire has been my academic success. I hope this work will make her proud and blissfully happy. Thank you, Dad, for always loving me and waiting for the day I come back.

My heartfelt thanks to you all. 
List of boxes, figures, and tables......................................................................... vii

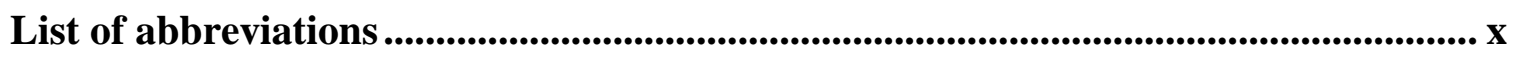

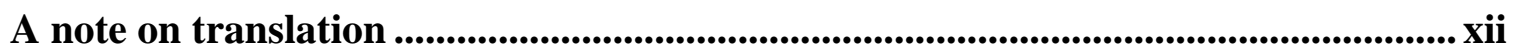

Chapter 1: Introduction ..........................................................................................

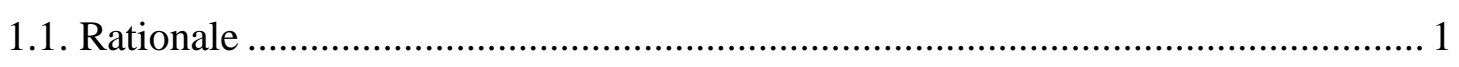

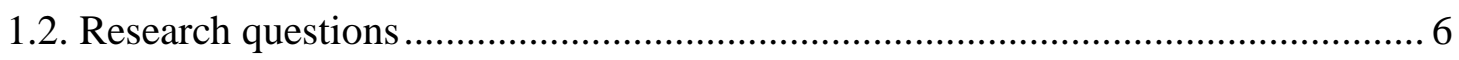

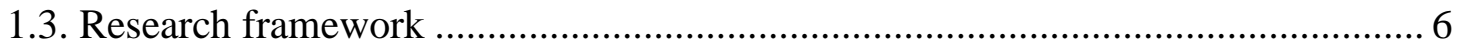

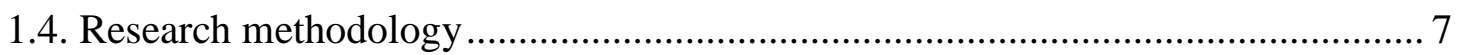

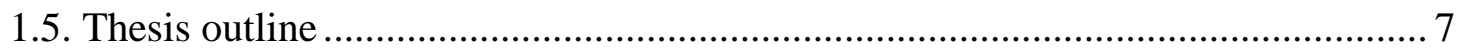

Chapter 2: Background context .................................................................................9

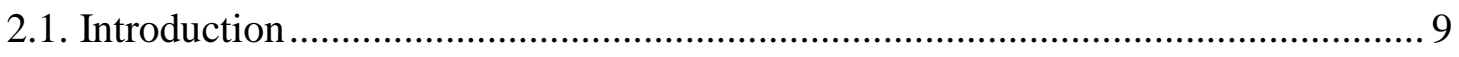

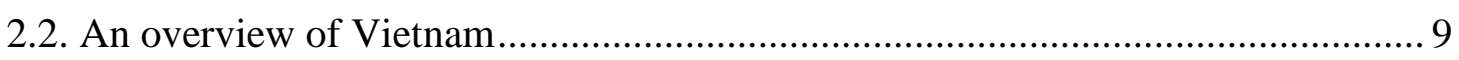

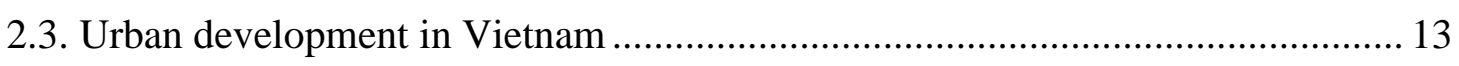

2.4. Urban housing and the development of LIH policy in Vietnam.......................... 15

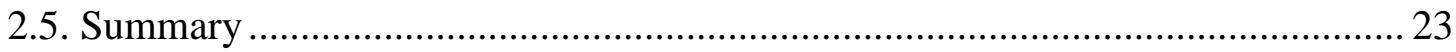

Chapter 3: Literature on public policy, policy process and determinants of public

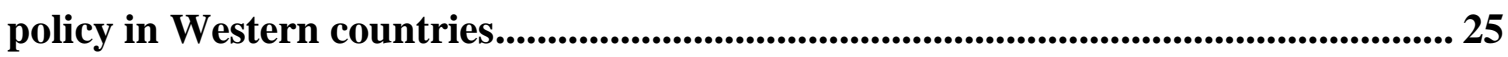

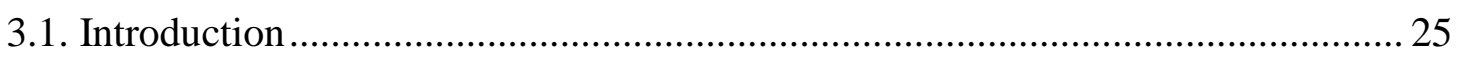

3.2. Public policy, policy process and determinants of public policy ........................ 25

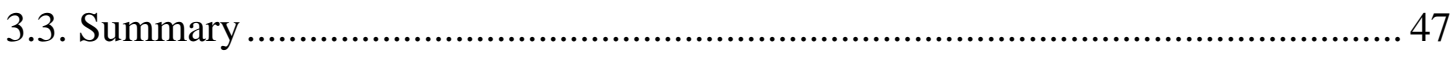

Chapter 4: Policymaking in developing countries and the single communist party

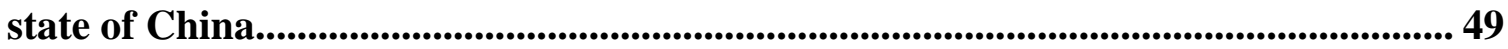

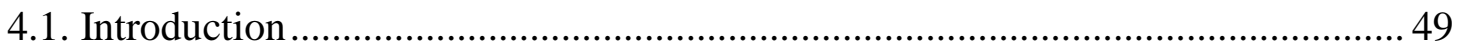

4.2. Grindle and Thomas's elite model of policy process in developing countries ..... 49

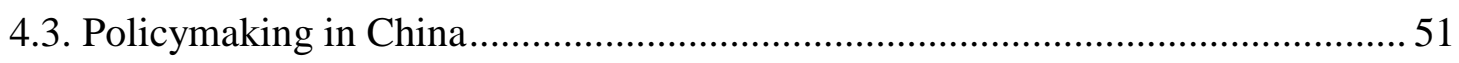

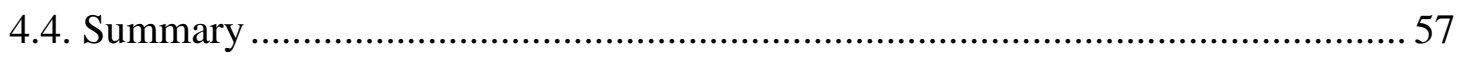

Chapter 5: Policymaking in Vietnam ..................................................................5 59

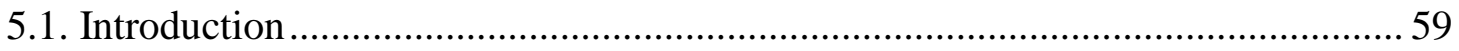

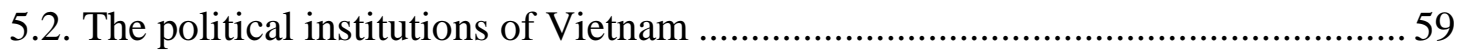

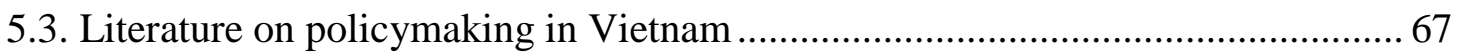

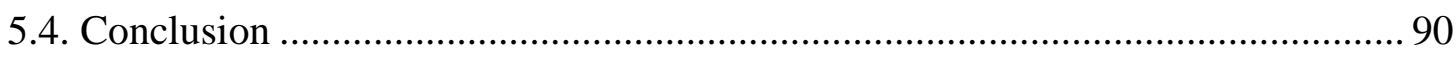


Chapter 6: Methodology ................................................................................................................93

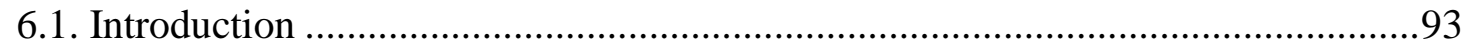

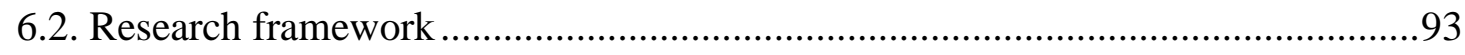

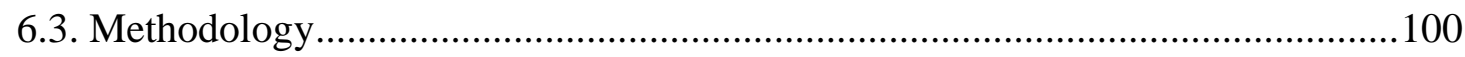

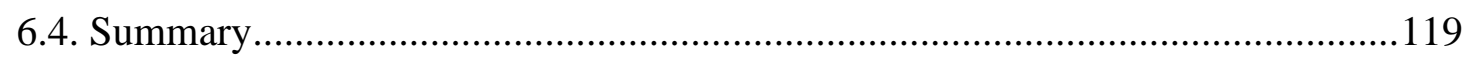

Chapter 7: An overview of Da Nang City ....................................................121

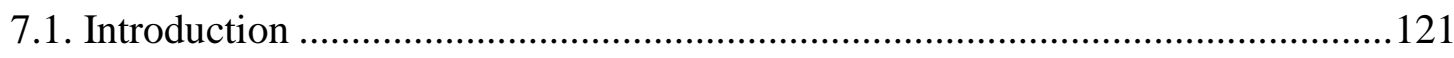

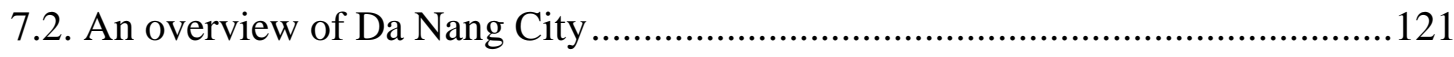

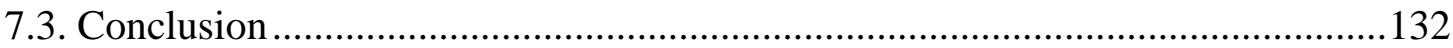

Chapter 8: A narrative of the policy process ...........................................................135

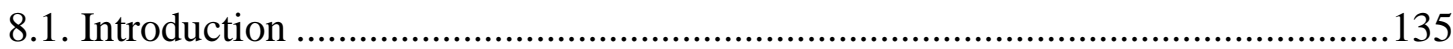

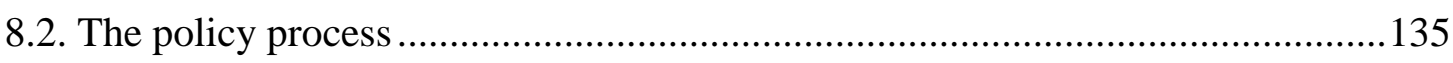

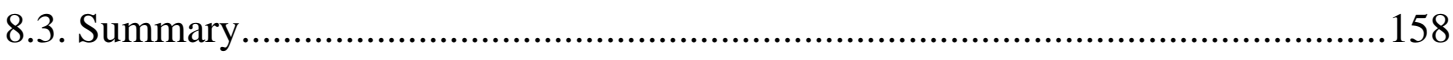

Chapter 9: The influences of the city's socio-economic conditions ............................161

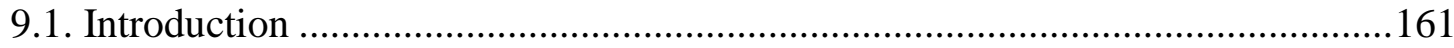

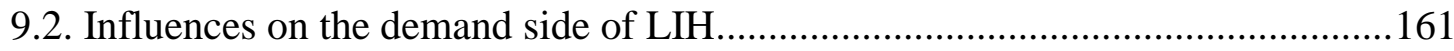

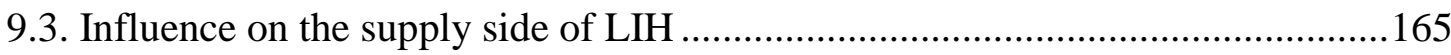

9.4. The indirect influences of historical and geographical features ........................170

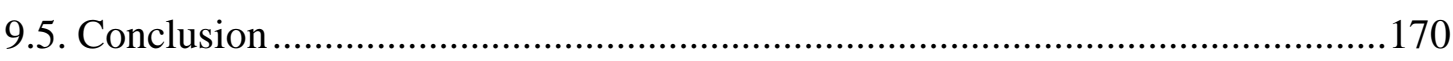

Chapter 10: The central and local government relationship ...................................173

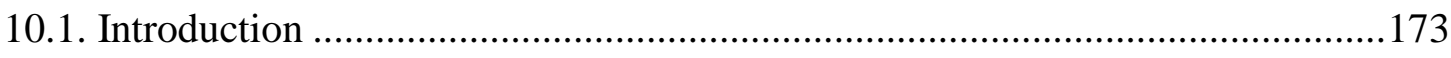

10.2. Evidence of the relationship throughout the case ..........................................173

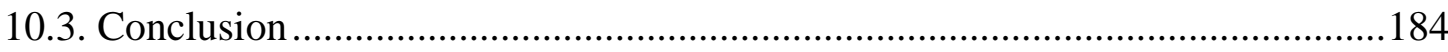

Chapter 11: The role of the city Party and the Party Secretary ..............................187

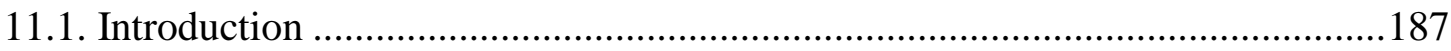

11.2. The role of the Party and the Party Secretary ..................................................187

11.3. Underpinning factors of the Party influences .................................................. 199

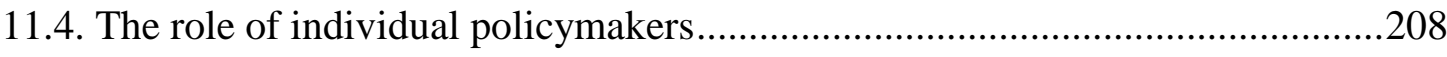

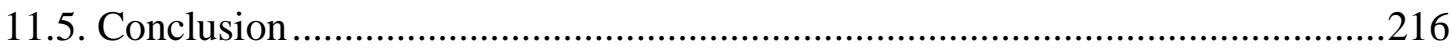

Chapter 12: Other influences on the policy process..............................................................217

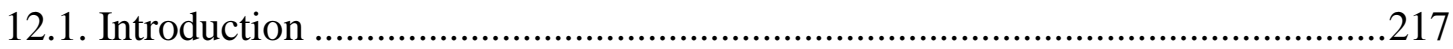

12.2. The role of the private sector and its relationship with the state .....................217

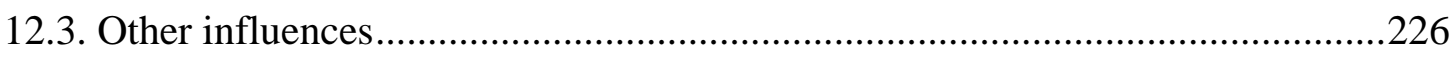

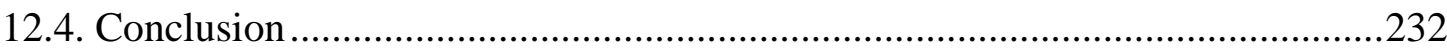


Chapter 13: Discussion and conclusion

13.1. Discussion

13.2. Contributions and limitations of the research 248

13.3. Conclusion 250

References................................................................................................................... 251

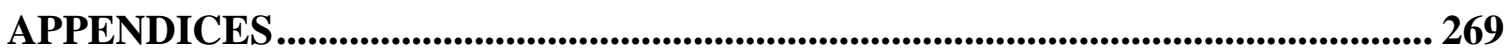

APPENDIX 1: INFORMATION SHEET FOR RESEARCH PARTICIPATION ... 269 APPENDIX 2: GUIDEPOST INTERVIEW QUESTIONS 271 APPENDIX 3: CODING OF INTERVIEW PARTICIPANTS AND INFORMANTS 274 APPENDIX 4: CODING OF DOCUMENTS 275 


\section{List of boxes, figures, and tables}

Box 10.1: Housing support for people in preferential categories in the first six months of 2008 177

Box 10.2: Housing support for poor people in the first six months of 2008 178

Box 11.1: Housing support for people under preferential treatment categories and poor people

\section{List of figures}

Figure 2.1: Share of investment by ownership in Vietnam .......................................... 10

Figure 2.2: Share of industrial output by ownership in Vietnam ................................... 10

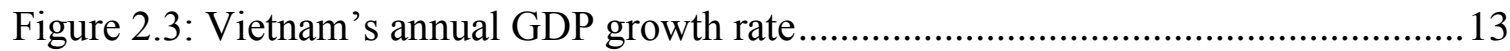

Figure 2.4: The percentage of urban population in Vietnam ......................................... 13

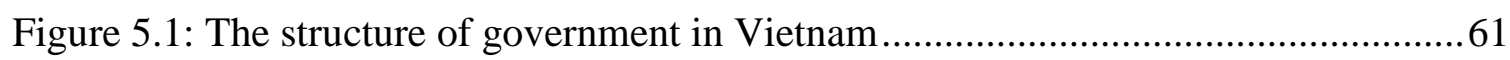

Figure 5.2: Policy documents and the hierarchy of their value........................................66

Figure 6.1: Hofferbert's (1974) funnel of causality model ..............................................97

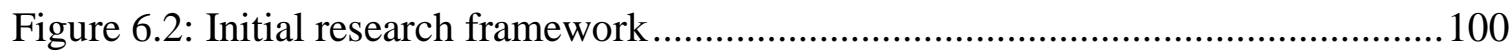

Figure 7.1: Sources of finance for investment in 2010 prices in Da Nang .................... 122

Figure 7.2: Contribution of economic sectors to Da Nang's GRDP in 2010 prices ........123

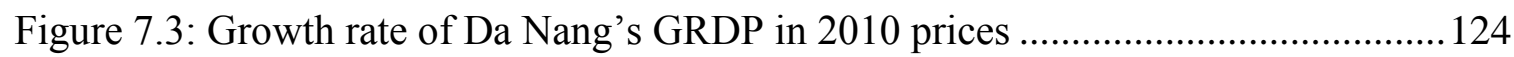

Figure 7.4: Contribution of economic sectors in Da Nang's GRDP in 2010 prices ........125

Figure 7.5: Number of jobs and unemployment rate in Da Nang ................................. 127

Figure 7.6: Contributions of economic sectors to total employment ............................. 127

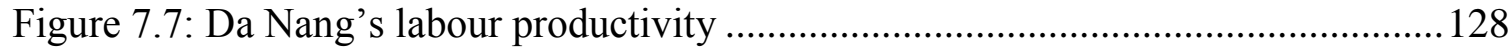

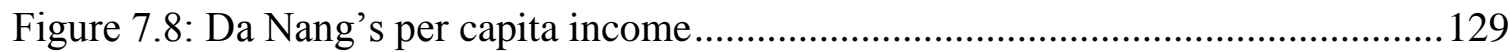

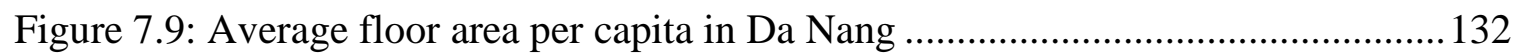

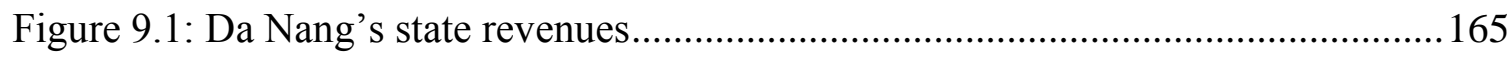

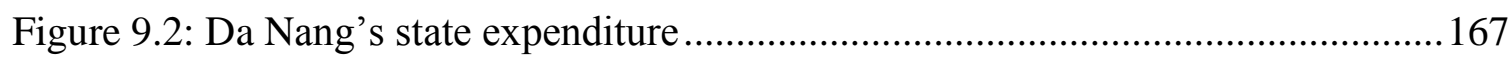

Figure 13.1: A framework of influences on the policy process in the case of LIH policy in

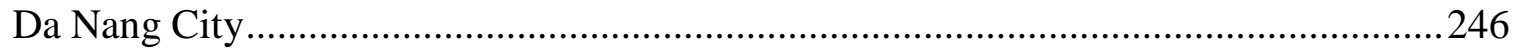

Figure 13.2: Influences on the policy process in the case of LIH policy in Da Nang ....247 


\section{List of tables}

Table 6.1: A summary of theories of the policy process and their implications for this study...... 94

Table 7.1: Number of households having housing by types in Da Nang 132

Table 8.1: Policy goals and estimated cost of the implementation plan..... 147

Table 9.1: Land acquisition and relocation in Da Nang .............................................. 162

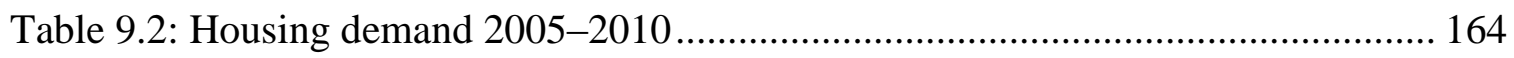

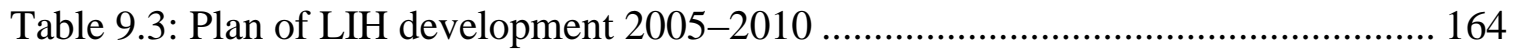




\section{List of abbreviations}

\begin{tabular}{|c|c|}
\hline CCOM & Central Committee of the Communist Party of Vietnam \\
\hline CIEM & Central Institute for Economic Management \\
\hline CIT & Corporate income tax \\
\hline $\mathrm{CCP}$ & Chinese Communist Party \\
\hline CPV & Communist Party of Vietnam \\
\hline DISED & Da Nang Institute for Socio-Economic Development \\
\hline DNIDF & Da Nang Investment and Development Fund \\
\hline DNPCe & Da Nang People's Committee \\
\hline $\mathrm{DNPCl}$ & Da Nang People's Council \\
\hline DOC & Department of Construction \\
\hline DOF & Department of Finance \\
\hline DOHA & Department of Home Affairs \\
\hline DOJ & Department of Justice \\
\hline DOLISA & Department of Labour, Invalids and Social Affairs \\
\hline DPI & Department of Planning and Investment \\
\hline FDI & Foreign Direct Investment \\
\hline FIEs & Foreign-invested Enterprises \\
\hline GDP & Gross Domestic Product \\
\hline GRDP & Gross Regional Domestic Product \\
\hline HMC & Housing Management Company \\
\hline
\end{tabular}




\begin{tabular}{|l|l|}
\hline LIH & Low-income housing \\
\hline MOC & Ministry of Construction \\
\hline NA & National Assembly \\
\hline ODA & Official Development Assistance \\
\hline PCe(s) & People's Committee(s) \\
\hline PCl(s) & People's Council(s) \\
\hline PCI & Provincial Competitiveness Index \\
\hline PIIP & Priority Infrastructure Investment Project \\
\hline SOEs & State-owned enterprises \\
\hline US-VN BTA & Bilateral Trade Agreement between the United States and Vietnam \\
\hline VAT & Value-added tax \\
\hline VCCI & Vietnam Chamber of Commerce and Industry \\
\hline VFF & Vietnam Fatherland Front \\
\hline VHLSS & Vietnam Household Living Standards Survey \\
\hline
\end{tabular}


A note on translation

In this thesis, references, interview data and documents in Vietnamese are translated by the researcher. 


\section{Chapter 1: Introduction}

This thesis enhances the knowledge of influences on the policy process in the one-party state of Vietnam. In doing so, it investigates a single case study of the low-income housing (LIH) policy in Da Nang City from 2005 to 2013. This introduction justifies the research rationale and the context of the research as well as the methodological approach to achieve the declared contribution.

\subsection{Rationale}

\subsubsection{Theoretical motivations}

Public policy has been extensively studied to answer some important questions, such as who makes policy decisions, how a policy has been made, what factors influence the policy process, and what evidence and criteria have been used in that process. Due to the complexity and ambiguity of the policy process, there are no common and right answers for those inquiries. However, the more we learn about them the better we can make policy effectively.

Since the 1950s, different theoretical approaches have been developed to explain and analyse the policy process. Some prominent approaches include stages heuristic framework (Anderson, 1975), institutional rational choice framework (Ostrom, 2007), multiple streams model (Kingdon, 1995), punctuated-equilibrium theory (True, Jones, and Baumgartner, 2007), advocacy coalition framework (Sabatier and Weible, 2007), diffusion model (Berry and Berry, 2007; Dolowitz and Marsh, 1996; Dolowitz and Marsh, 2000), and funnel of causality model (Blomquist, 2007; Hofferbert, 1974). Except for the stages heuristic framework, which focuses on describing and analysing different functional stages of the policy process, most of these models offer a different lens to understand the causes of public policy. According to these models, influences on the policy process include focusing events (the punctuated-equilibrium theory, the multiple streams theory and the advocacy coalition framework); external forces (the diffusion model); activities of individuals and interest groups as well as their underpinning belief and values systems (the institutional rational choice framework, the multiple streams theory, the punctuatedequilibrium theory, the advocacy coalition framework and the funnel of causality model); institutional constraints (the institutional rational choice framework and the funnel of causality model); and broad socio-economic conditions (the funnel of causality model). Recently, some scholars have suggested combining elements from different approaches to 
understand and explain the policy process (Howlett, McConnel, and Perl, 2017; Weible, Heikkila, deLeon, and Sabatier, 2012).

Determinants of public policy were also examined in different approaches that focus on either social factors (such as class struggle or group competition) or political factors (such as party competition or voter participation) or individual behaviour (Anderson, 1975; Borras, 2001; Dye, 1984; Genieys and Smyrl, 2008; Gilbert and Howe, 1991; Howlett and Ramesh, 2003; Przeworski, 1990; Skocpol, 1985). In sum, according to the literature, influences on public policy range from broad socio-economic conditions to institutional arrangements and policy actors. In a particular policy circumstance, some factors might be more influential than others. Nevertheless, policy outputs can be analysed as the result of the interactions of these different influences.

Most of the models and approaches mentioned above were developed to explain the policy process in relatively developed and democratic countries. Thus, they have not generally extended to consideration of the distinctive features of the policy process in developing economies or countries with different political system characteristics, such as one-party states. Their utility may therefore be limited in certain circumstances. In order to improve the generality of these models and approaches, some scholars have undertaken research to test their validity in different contexts. Examples include Grindle and Thomas (1991) about policymaking in developing countries, which focuses on the role of policy elites. Models have also been modified and developed to explain the distinctive features of the policy process in the single-party state of China, which focus on the role of the Chinese Communist Party (CCP) and also of policy elites (Airey and Chong, 2010, 2011; Heilmann, 2008; Lieberthal and Oksenberg, 1988; Mei and Liu, 2014; Schubert and Heberer, 2015; Tanner, 1995; Teets, 2015; Zang, 2006; Zheng, Jong, and Koppenjan, 2010). Similar efforts can also be seen in the literature of the policy process in Vietnam.

However, a striking feature of most research on the policy process in Vietnam is that it is funded by international aid organisations and primarily intended to map out the network of policy actors to serve the donor's goal of influencing the process (Datta and Pham, 2013; Shanks, Luttrell, Conway, Vu, and Ladinsky, 2004). The literature review for this thesis discovered only three studies that apply analytical models to explain the policy process in Vietnam. Painter (2005) and Bui, Mirzoev, and Mukhopadhyay (2015) employ Kingdon's multiple streams model, and Dang (2013) borrows some ideas from the punctuatedequilibrium theory to develop his own model of policy-making process at the centre. 
Studies on policymaking and politics in Vietnam highlight the crucial role of the Communist Party of Vietnam (CPV) in making key decisions, although they also emphasise the importance of line ministries in designing policy content and of local governments in actual implementation. However, although the role of local governments in re-developing and implementing policies has been recognised, none of the studies reviewed focuses on the policy process at this level. This study will address the gap in the literature by offering a description of a policy process in one typical local government in Vietnam and analysing the influential factors in that process.

\subsubsection{Empirical motivations}

To achieve the goal mentioned above, it is advisable to identify a case study in a significant policy domain that enables a fruitful investigation into the influences on the policy process in a local government in Vietnam. In this study, housing policy for low-income people has been chosen. Housing is an important domain for policy owing to its centrality in determining living standards. Access to decent housing faces challenges of availability and affordability. Responding to these challenges is a public policy issue for politicians and policymakers in most countries.

For many developed countries, housing affordability is a chronic problem. Governments in relatively affluent countries have embraced different approaches to tackle the problem for low-income people. Policy instruments range from supply-side assistance (state housing construction, tax treatment and credit assistance for private developers) to demand-side assistance (housing vouchers or housing supplements) as well as efforts to facilitate owner occupation (first-time buyers' grants, Homestart programmes, rights to buy, or shared ownership titles) (Goodlad and Atkinson, 2004; Hoffman, 2012; Housing New Zealand Corporation, 2004; Kempen and Priemus, 2002; NZHistory, 2016; Shester, 2011; The Housing Shareholders Advisory Group, 2010; Whitehead and Scanlon, 2002). Generally, most developed country governments have adopted a mix of direct provision of public housing and support on both supply and demand sides for access to affordable housing in the private sector (Blessing, 2015).

In many developing countries, governments have had to deal with great pressure on urban housing as a result of rapid urbanisation. Under this pressure, the role of the state in housing in some socialist countries has been changing. In China, housing used to be considered not a commodity traded in a free market but a privilege, provided only by the state in a subsidised system, especially in urban areas. During reforms the government retreated 
from direct housing provision. State housing units were gradually sold to tenants and a private housing market was facilitated (Chen, Yang, and Wang, 2014; Wang and Murie, 2000). However, privatisation led to a crisis of housing affordability that forced the state to reassert its role in providing public housing. In response, the government is now undertaking various housing programmes to assist the poorest households and low- and middle-income households (Chen et al., 2014; Wang and Murie, 2000).

Housing policy in Vietnam also shifted from direct provision of subsidised housing towards a relatively free housing market, resulting in similar problems of housing affordability. To support low-income people in accessing housing, as well as to stimulate real estate market development, in 2004, the central government included development of social housing in its housing development strategy to 2020.

The housing situation and housing policies in Vietnam in the pre- and post-reform periods have been well studied (Forbes, 1996; Gough and Tran, 2009; Nguyen and Kammeier, 2002; Pham and Parenteau, 1991; Phe and Nishimura, 1991; Trinh, Nguyen, Wiesman, and Leaf, 2000; World Bank, 2011; Yip and Tran, 2008). However, there is not much in the academic literature about the new approach to social housing announced in 2004. Recently, the World Bank published a report on affordable housing in Vietnam, which offers some assessments of the LIH situation at the time the study was conducted (Samad et al., 2015). However, this report focused on future housing policy reform and paid little attention to the development of LIH from 2004 to 2015. Therefore, there is still a gap in empirical knowledge of LIH development in Vietnam during this period. As mentioned in the World Bank report, there have been some innovative housing policy ideas in Vietnamese local governments but these efforts have encountered various difficulties, including gaining central government's approval. There is thus a need to understand how LIH policy developed in Vietnam during the past decade, especially from the perspective of local government.

To help fill the gap in the empirical knowledge mentioned above, I decided to investigate the case of LIH policy in Da Nang City from 2005 to 2013.

\subsubsection{Rationale for the case choice}

When the central government announced a new policy for housing assistance to lowincome people in 2004, there was not much guidance for local governments on how to implement it. Da Nang City actively supported the central government by introducing its own housing policy in the 2005 ' 3 -Haves' campaign (Chuong trinh 3 Co). This campaign 
consisted of three components: the Having Housing Programme (Co nha o) aimed to provide every resident a decent house to live in, targeting mostly poor and low-income people; the Having Job Programme (Co viec lam) set an objective of increasing employment; and the Having Civilised Behaviour Programme (Co nep song van minh do thi) aimed at boosting good behaviour in communities. The Having Housing Programme was the first official and explicit local social housing policy in Vietnam, following the central government's 2004 strategy. The city government further developed its LIH policy in the following decade in response to policy adjustments at central level. Officially at least, the Da Nang housing policies have been judged a success. The city's efforts were recognised and praised by the central government, and received support from the city residents. Studying the case of LIH policy in this city will improve knowledge of LIH development in Vietnam, and more generally how a local government starting with general policy guidelines from central government designed and implemented innovative policy ideas in reality.

Most importantly, studying this case can also address the gap in the literature about influences on the policy process in local government in Vietnam because the case offers enough evidence to understand how policy was developed and implemented. At the time of the case, Da Nang was undertaking a major urban renewal, which created significant demand on housing and housing policy. The changing social and economic circumstances of Da Nang over this period are relatively well documented. There is also reasonably good evidence on how the central and city governments worked to get the policy adjusted and implemented in two different periods. The first period was from 2005 to 2009 when the central government could only provide very general and vague directions in LIH policy. The second period was from 2009 to 2013 when there were more instructions from the central government as well as more cooperation between the central and the city governments. Finally, there is evidence on the role of policy elites in policy development and particularly on the influence of a distinctive local leadership style, which profoundly affected policy output and outcome. Availability of evidence on all these key influences mentioned in the policy literature indicates that this case is a suitable choice for study of a policy process.

To sum up, this study will address both the theoretical gap in the literature on the policy process and the current gap in empirical knowledge of LIH development in Vietnam. 


\subsection{Research questions}

Based on the context and motivations of the study, as well as considering the feasibility of data collection and analysis, this research focuses on the case of LIH policy process in Da Nang City from 2005 to 2013. The aim of the study is to address the primary research question:

What are the critical influences on the policy process in local government in the one-party state of Vietnam?

To answer this question, I will examine how the policy initiatives passed through different local government organs to be promulgated and implemented. The research will address some sub-questions as follows:

1. How has LIH policy process evolved in Da Nang City? What policy actors have been involved in the process?

2. During that process, what factors influenced policy actors? How and why are those factors important?

\subsection{Research framework}

To answer the research questions, the study adopts, and subsequently adapts, Hofferbert's funnel of causality model to understand the influences on the policy process. One merit of this model as a basis is its comprehensive capacity to embrace potential factors affecting the policy process of a case, including the background socio-economic conditions, the institutional arrangements and the policy actors. Other ideas from various models are also employed to complement Hofferbert's model. They include the role of policy entrepreneurs in Kingdon's multiple streams model and the special role of policy elites in Grindle and Thomas's model for developing countries' policy process. Additionally, the notion of a belief system or political core values in the advocacy coalition framework, and of underpinning personal interests and institutional constraints in the institutional rational choice framework are mobilised to examine the influences on policymakers' behaviour. Influences of policy learning from the past and other localities are also considered, as recommended by policy transfer and diffusion models. Moreover, reviewing previous literature on the policy-making process in China and Vietnam suggests an emphasis on other factors, including the paramount role of the communist party and its core values, as well as the relationship between central and local government in making local policy. Literature on stages of the policy process also helps analysis of the case's different phases. 


\subsection{Research methodology}

This study uses the single-case study of LIH policy in Da Nang City. The case is chosen because of its evidence on influences on the policy process as mentioned above. Evidence is available from 2005, when the city introduced the 3-Haves campaign, which was the first local attempt in social housing policy in Vietnam to 2013, when new policy ideas were introduced at central level (and when this study commenced). A single case study design was chosen instead of a multiple case study mainly because of the feasibility of data collection, particularly on the internal activities of party and government systems, which require access through extended networks and trusted relationships.

Documentary data and interviews with the policy participants were the main data sources. Triangulation across sources was employed to ensure the reliability of the findings. Qualitative techniques were used to analyse the collected data and produce the research findings.

\subsection{Thesis outline}

The thesis is organised as follows. This first chapter has introduced the study's context, the practical and theoretical motivations, and some brief explanation of the research questions and methodology used in the research. The second chapter provides the history and context of Vietnam's urban development and housing policy. Chapter 3 reviews the literature on policy process and determinants of public policy, mostly in Western and developed countries. Chapter 4 continues this review, with studies on policymaking in developing countries and particularly in the single-party state of China, while Chapter 5 focuses on policymaking in Vietnam and provides some basic understanding of the country's political systems. Together, Chapters 3 to 5 identify the gaps in the literature and establish a suitable approach to study LIH policy in Da Nang City. Chapter 6 justifies the researcher's philosophical stance and choice of the case; presents the initial analytical framework guiding investigation of the research questions; and discusses the methods used in collecting and analysing data. The research findings are presented in Chapters 7 to 12 , which cover Da Nang City and its housing development, a description of the policy process and an analysis of evidence for the set of influential factors in the case. Lastly, Chapter 13 discusses the findings in relation to the literature and the initial analytical framework; highlights contributions to the literature, points out limitations to the study and suggests ideas for further research. 


\section{Chapter 2: Background context}

\subsection{Introduction}

This chapter presents an overview of Vietnam and key events in the country's contemporary history, which have shaped urban development during the last three decades. Following that is a summary of the urban housing situation, which offers a basic understanding of the context in which LIH policy was initiated and developed at central level. The chapter serves as the context for investigation of the Da Nang case.

\subsection{An overview of Vietnam}

Vietnam was a small agrarian country, which suffered from continuous wars with and rule by the countries to its north from the 2 nd to 15 th centuries. The country went through several more centuries of civil wars before becoming a French colony from the late 19th century. When war with the French was ended in 1954, the country was divided at the 17th parallel. At that time, the North was under a Communist regime, which started a guerrilla war to reunite the country. The South was ruled by the Ngo Dinh Diem regime with support and involvement of the United States. The country was unified in 1975, with almost all national resources exhausted.

From 1975 to 1985 , the war-torn country followed the Soviet Union's centrally planned economy model, characterised by five-year plans based on collectivisation of agriculture and industry, in a subsidy-based and autarkic framework (Giang and Low, 2015; Lambert, 2015; Vuong, 2014). The economic model proved unsuitable, leading the country to a socio-economic crisis with hyperinflation at more than $700 \%$, hunger and poverty, outdated agriculture, stagnant industry and large foreign debt (Giang and Low, 2015; Vuong, 2014).

The Sixth National Party Congress in 1986 approved Doi Moi, a far-reaching policy of socio-economic renovation, which saw Vietnam gradually shift from a centrally planned economy to a socialist-oriented market economy. Doi Moi aimed to change the subsidised and relatively autarkic economy which relied on the state and collective economic sectors towards a multi-sector economy based on different types of ownership; foreign investments were welcomed and the private sector was recognised as the growth engine (Giang and Low, 2015). During the transition, a new legal system was adopted to create institutions appropriate for the market economy, including the Law on Foreign Investment (1987, 1996), the Corporate Law and Private Entrepreneur Law (1990), and the Enterprise Law (2000). The Enterprise Law was the most important achievement of institutional 
reform during Doi Moi, speeding up the business activities of the private sector (Tran and Bao Tram, 2013). Thanks to the legal reform in investment and doing business, foreigninvested enterprises (FIEs) and private enterprises significantly increased their contribution to the economy (Figures 2.1 and 2.2).

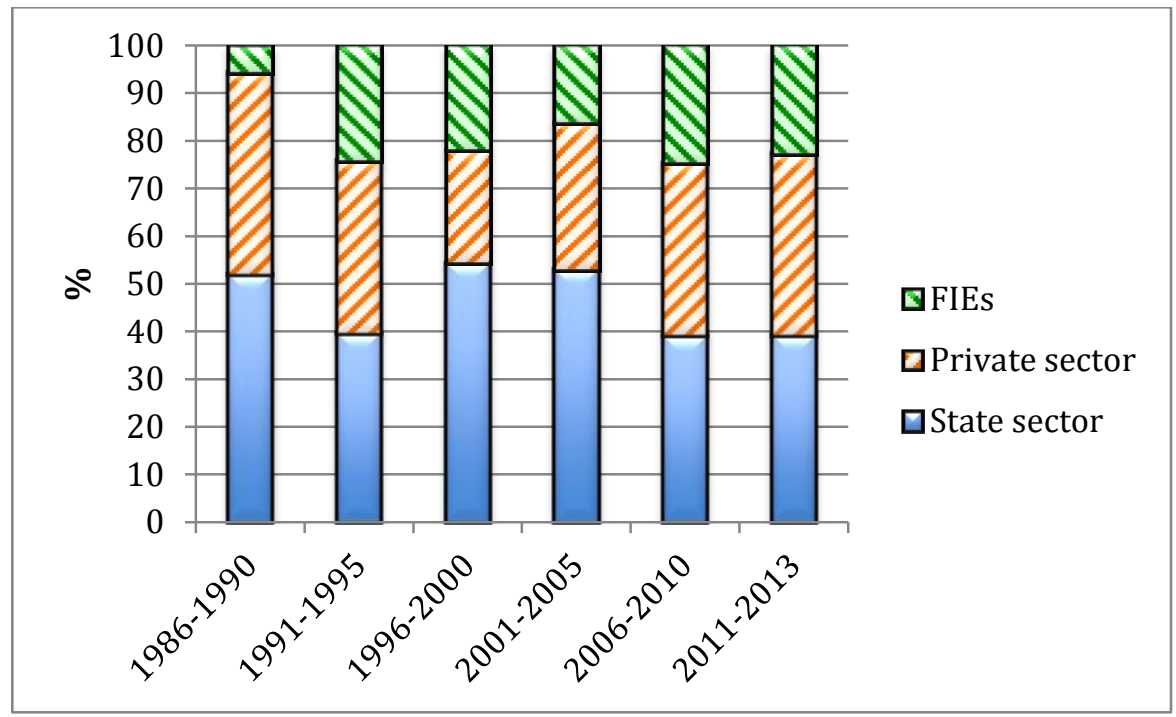

Figure 2.1: Share of investment by ownership in Vietnam Source: $\mathrm{Vu}(2015)$

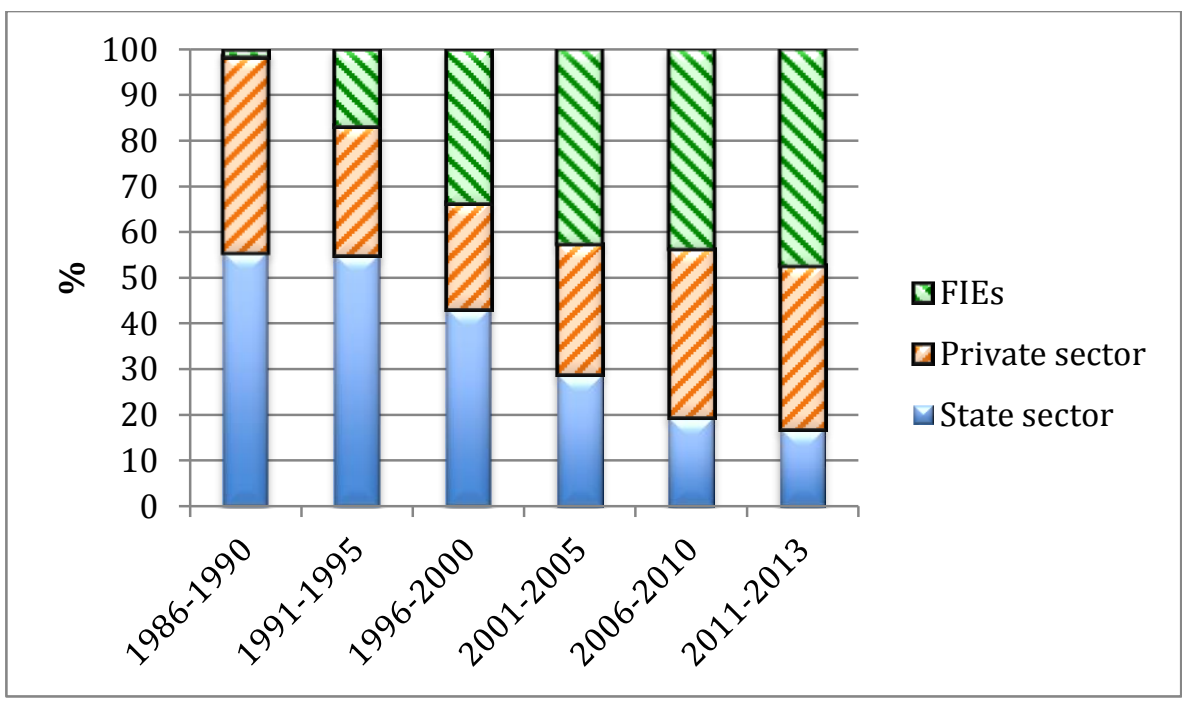

Figure 2.2: Share of industrial output by ownership in Vietnam

Source: $\mathrm{Vu}(2015)$

The legal framework on land was also reformed. The collectivisation of land started from the 1960s in the North and then extended to the South after 1975. The third Constitution in 1980 officially established the regime of people's ownership of all land in the country. This regime meant that there were no private rights in land and no property market. Land 
was considered as a free good, allocated by the state. There was therefore no notion of land price. The collectivisation of land and the subsidised and egalitarian economy discouraged farmers from investing in cultivating and trading activities. As a result, agriculture productivity decreased dramatically and food shortages became common.

The first 'fence-breaking' ${ }^{1}$ experiment in land use occurred in Vinh Phu province in 1966. The initiative involved allocating land to farmers and buying their products at higher prices than the state-set prices. The initiative was well supported by the people and led to a significant increase in agriculture productivity. It was first quickly terminated by the central government, but then revived in both the north and the south in the period 19791980 (Rama, 2008). The positive results of several other fence-breaking led to the socioeconomic renovation policy in 1986 (Rama, 2008). One year later, the first Land Law of the transitional period was enacted.

Though the law still provided that all land was owned by all the people and the state would act as an administrator of this resource, households and individuals were provided with agricultural and residential land for private use. Agricultural and residential lands were allocated to people, but the state set a ceiling on the area of rural and urban lands that could be allocated to any household or individual. Implementing this law helped change Vietnam from a country with persistent food shortages to one of the major rice exporters of the world (Dang, 2016).

At this time, all land transactions were still prohibited. Households and individuals could only use land for dwelling, and for cultivating and trading products from the land. After the enactment of the fourth Constitution (1992), which officially recognised the socialismoriented multi-sector market economy and the presence of private ownership, the second Land Law (enacted in 1993, amended in 1998, 2001, 2003, 2009) recognised five basic rights of agricultural and residential land users: exchange, transfer, lease, inheritance, and mortgage. This was also the first time the state regulated the price of land, though stateidentified prices were often at about 10-20\% of market prices (Dang, 2016). From then on, the state would lease out or allocate land to individuals, households and organisations. Organisations allocated residential land to build houses for rent and sale or households allocated land for building their houses had to pay a land levy (one-off payment), but households allocated agricultural land less than the area ceiling were exempted from the levy. In other cases, households and organisation had to lease land and pay rent. The

\footnotetext{
${ }^{1}$ A common description of local activities that breached central laws.
} 
elimination of the area ceilings of residential land in urban areas and the allocation of land to organisations for housing business enabled the development of the real estate market in Vietnam.

Other important laws were also enacted to strengthen the market economy. These included a system of tax laws and laws on bankruptcy (1993, 2005, 2014), credit institutions (1997, 2004, 2010), environment protection (1993, 2005), and labour (1994, 2002, 2007, 2012). With the enactment of this legal system, subsidies were replaced by a framework based on the principles of a market economy.

During the reform, the country's diplomatic relations were also expanded. Some milestones were when the United States lifted its trade embargo against Vietnam in 1994, and when the country joined the Association of Southeast Asian Nations (ASEAN) in 1995 and the Asia-Pacific Economic Cooperation (APEC) in 1998. Vietnam agreed a bilateral trade agreement with the United States in 2001 and became a member of the World Trade Organisation (WTO) in 2007.

An internationally integrated economy backed by a reformed legal system during Doi Moi has brought about remarkable achievements in the country's economy. Its gross domestic product (GDP) growth rate increased dramatically from $2.8 \%$ in 1986 to the peak of $9.3 \%$ in 1995, when its relationship with the United States was normalised. Though the GDP growth rate was affected by the Asian financial crisis in 1997 and dropped to $4.8 \%$ in 1999 , it soon recovered and remained at a relatively high average rate of $7 \%$ until 2007. As the country became more integrated into the world's economy, it was more easily affected by the global financial and economic crisis, which pulled its GDP down to 5.4\% in 2009. After two decades of reform some challenges arose, such as the inefficiency of state-owned enterprises (SOEs) and the real estate and stock bubbles, as well as mounting bad debt in the bank system (Vuong, 2014). In this situation, the country's GDP growth rate has recently fluctuated around 5 to $6 \%$.

Along with the GDP growth, the economic structure was transformed. The contribution of the agriculture sector to the total economy decreased from $37.2 \%$ in 1985 to $18.5 \%$ in 2008 while industry and service sectors increased their proportions from $26.2 \%$ to $43.2 \%$ and from $37 \%$ to $38.3 \%$ respectively (World Bank, 2011). Another noticeable achievement of Doi Moi was poverty reduction and income improvement. By the end of 2014, Vietnam emerged from its place as one of the poorest countries in the world to the ranks of the lower-middle-income countries, with per capita income of over 2,000USD and the 
percentage of households living in extreme poverty at 3\% (Rama, 2008; World Bank, 2015b).

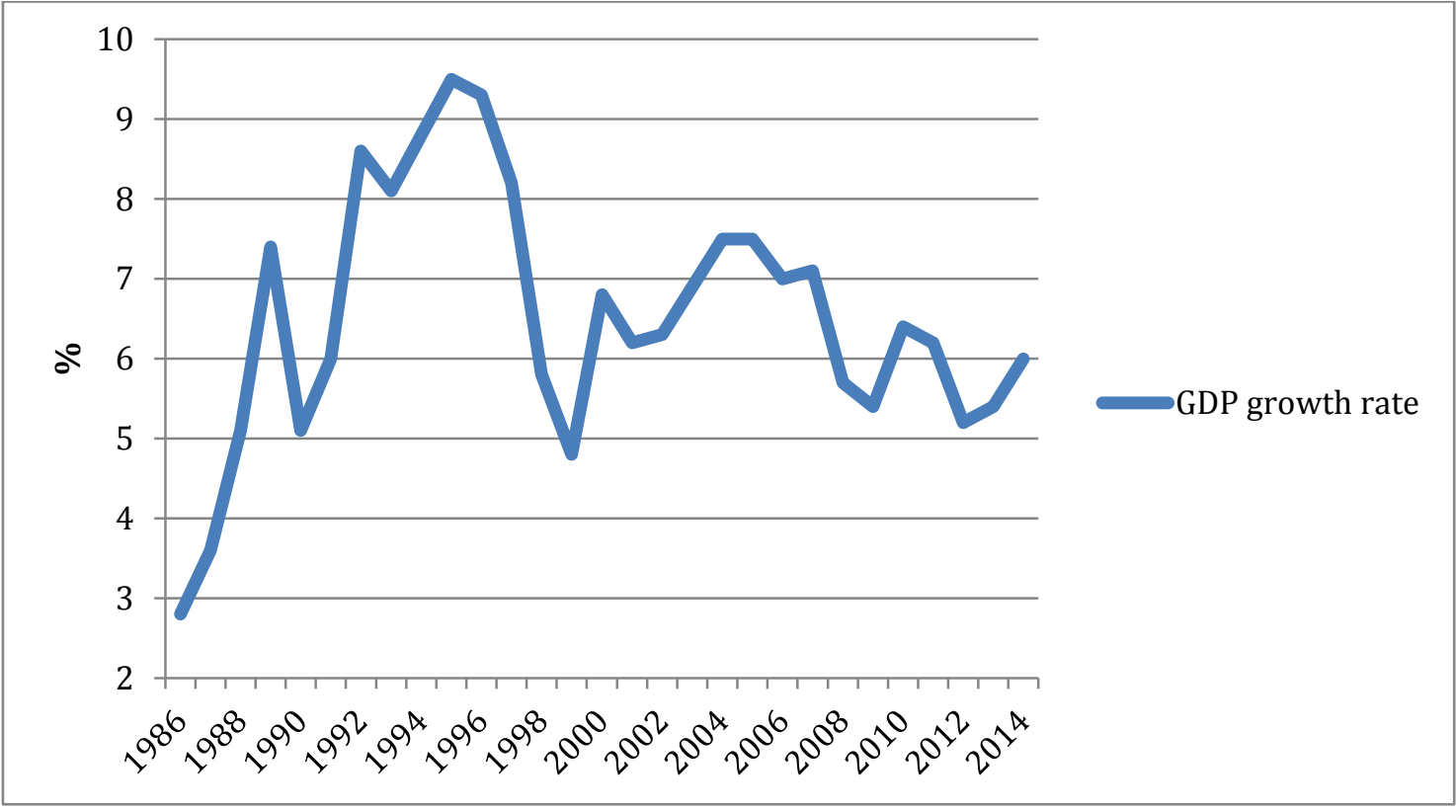

Figure 2.3: Vietnam's annual GDP growth rate

Source: World Bank

\subsection{Urban development in Vietnam}

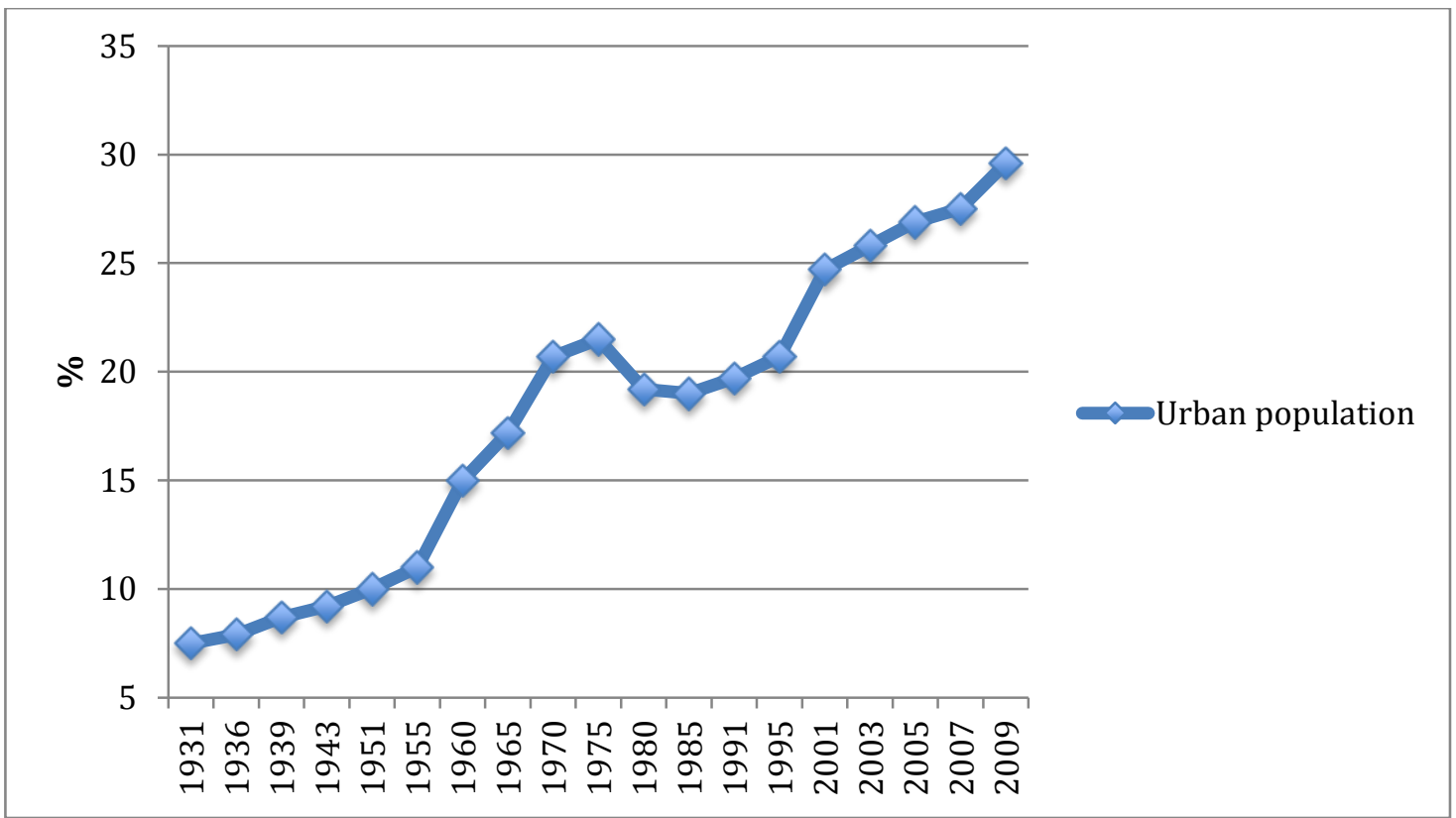

Figure 2.4: The percentage of urban population in Vietnam

Source: Vietnam General Statistics Office (2011)

In the $17^{\text {th }}$ and $18^{\text {th }}$ centuries, there were some urban areas in Vietnam such as Thang Long 
(Ha Noi), Hue, Hoi An, and Pho Hien (Forbes, 1996; Tran, 1993). Also in this time, settlers expanded the country's boundary to the south and built Saigon as an important trade centre (Ca Van Thinh, 1976, cited by Forbes, 1996). During the colonial period, the French developed some urban areas in three regions of Vietnam: Ha Noi, Hai Phong, Hue, Da Nang, Nha Trang, Sai Gon, Cho Lon, and Da Lat. At the end of the French colonial period, Vietnam was still mainly a rural economy with $11 \%$ of total population living in urban areas (Trinh et al., 2000).

Since 1954, the country's urban areas were developed in two opposite ways. In the North, urban areas were constructed following the socialist model with a focus on industrial investment especially in Ha Noi, Hai Phong, and Quang Ninh, which led to an increase in urban population from 1955 to 1964. However, from 1965 to 1972, the American bombing campaigns caused severe damage to urban areas. People had to be evacuated out of cities, reversing the urbanisation trend in the North. In stark contrast, in the South, the guerrilla war was mainly in the countryside, causing the flow of evacuees to urban areas (Forbes, 1996). Two major urban centres of the South were Saigon (urban population of about 4.5 million) and Da Nang (an important US military base with urban population reaching a peak of 600,000$)^{2}$ (Forbes, 1996). In the early 1970s, the percentage of the urban population in the South was between $40 \%$ and $45 \%$ of the total (Forbes, 1996; Trinh et al., 2000).

After the national unification, many evacuees returned to their hometowns in rural areas; a large number of people who worked for the old regime were sent to re-education camps; other people fled to foreign countries; and people in some northern provinces were encouraged and forced by the state to migrate to southern provinces and to New Economic Zones. ${ }^{3}$ All of these causes led to a sharp decrease in urban population. Also, during this period, the system of household registration books (so ho khau) made migration from rural to urban areas extremely difficult, leading to the relatively low rate of urbanisation in Vietnam in the post-war era, with urban population at about $18.4 \%$ (Trinh et al., 2000; Vietnam General Statistics Office, 2011).

\footnotetext{
2 There was another estimate of the highest level of urban population in Da Nang during this time. According to some recent city planners, the city was once occupied by about one million people (Dang, 2006; Forbes, 1996).

3 New Economic Zones are resettlement areas that were set up for people who migrated from northern Vietnam to southern Vietnam after 1975. These zones also welcomed rural immigrants, who had no place to return after the war, unemployed who sought new economic opportunities, and volunteers (legal city residents) to take pressure off southern cities and to extend settlement in non-used lands (mountainous areas) (Chandola, 1977). They were also used as a political means to deal with people working for the old regime (Huy Duc, 2013a). Thus, some were forced, while others volunteered to settle in these areas.
} 
From the start of Doi Moi, urbanisation in Vietnam accelerated again. The reforming economy created more job opportunities in urban areas, which attracted immigrants from rural areas. As a part of the institutional reform, from 1990 the government started to relax regulations on household registration (World Bank, 2011), which enabled free movement from rural to urban areas. As a result, the percentage of the urban population increased rapidly. According to the Vietnam Household Living Standards Survey (VHLSS) in 2009, $16 \%$ of the urban population (aged five years and over) was immigrants from rural areas. The percentage of the urban population in the whole country reached $29.6 \%$ (Figure 2.4). In the beginning of Doi Moi, the government still aimed to develop a network of urban areas with different sizes of cities. However, by 2009, this policy had to be altered to accept the presence of mega-cities and urbanisation was considered an essential tool to achieve the country's industrialisation and modernisation goals (World Bank, 2011).

In 2009, there were 752 urban areas, which were classified into six grades: 1) Specialgrade urban centres: Ha Noi and Ho Chi Minh City; 2) Grade I urban areas: 7; Grade II urban areas: 12, Grade III urban areas: 45, Grade IV urban areas: 41, and Grade V urban areas: 645 (Vietnam General Statistics Office, 2011, p. 132). Da Nang was among the Grade II cities. Da Nang was chosen as the key engine for the economic growth of the relatively poor central region. A 2011 World Bank report argued that the city was not strong enough to play that pivotal role because its urban population growth mainly came from short-distance migration from immediate neighbouring provinces and from ruralurban land conversion (World Bank, 2011). This meant that the attractiveness of the city was not high and it reflected the moderate potential for development.

In summary, Vietnam remained a predominantly rural economy during the French colonial period. Urbanisation accelerated in the period from 1954 to 1965, but then proceeded in two contrasting directions in the North and the South from 1965 to 1975 as affected by the war. This process stagnated in the first ten years after reunification, and then resumed rapid growth in the period following Doi Moi.

\subsection{Urban housing and the development of LIH policy in Vietnam}

\subsubsection{Housing prior to the socio-economic renovation}

Housing in the colonial era in urban areas was influenced by French architecture with necessary adaptation to suit local weather and purposes of use. Four typical types of houses at this time were traditional urban tube houses, improved tube houses, tube house-villas, and villas (Le, 2016; Tran, 2013). The poor in cities often built houses themselves, using 
temporary materials (wood or bamboo). Some of them occupied thatched houses along rivers, canals and dykes.

After the defeat of the French in 1954, the Democratic Republic of Vietnam (the North) took over all houses under the control of the old regime and distributed them to state employees. From 1965 to 1975, the state in the North used its funds to build Soviet-style apartment buildings. These were two- to five-storey buildings, consisting of units of 30 $40 \mathrm{~m}^{2}$. These houses were poorly supported by a limited-capacity infrastructure system and were constructed with little attention to urban space planning. They were leased out to government officials and employees at very low rents (about one percent of their monthly salaries) and poorly maintained by the government's housing office. In the early 1970s, housing in the North was greatly damaged by American bombing (Marshall-Cavendish, 2007; Phan, 2014; Trinh et al., 2000).

Housing development in the South was not well recorded. Indirect reference materials suggest that housing was developed in a market economy with a significant role of Chinese enterprises before 1975 (Ho Tuong, 2016). Another source stated that after unification, the state took over hundreds of thousands of houses. Some of these houses belonged to the Public Housing Fund of the Republic of Vietnam (South Vietnam), others were private houses abandoned by evacuees who left Vietnam before unification in April 1975 or were confiscated from people who stayed. In Ho Chi Minh City (Saigon), more than 70,000 housing units were taken over and allocated to state employees (Huy Duc, 2013b). According to an investigation on housing conducted in 1977, there were 393,849 housing units with total floor areas of about 31 million $\mathrm{m}^{2}$ in Ho Chi Minh City (Tran, 2015). With the recorded data on the percentage of the urban population in the South before 1975 (40$45 \%$ ), we can infer that housing was well developed in the South and presumably suffered much less damage than housing in the North before unification, at least in urban areas.

When the country was unified, housing stock in the south was taken over by the state and the subsidised housing policy in the north was extended to the south. A National Housing Programme was applied in the whole country (Trinh et al., 2000). The government wished to ensure the people's rights to shelter (Constitution 1980).

To realise this regulation, the government used its funds for building and improving public housing, particularly in big cities and industrial zones (Pham and Parenteau, 1991). State employees were allocated housing via their work units at extremely low rents. Due to limited budget capacity, however, the State could only allocate accommodation to about 
one-third of its employees, based on their rank and number of years of employment. Other households and individuals purchased their own construction materials and hired local builders to build their own houses (Department of Housing Management and Real Estate Market, 2013; Gough and Tran, 2009; Nguyen and Kammeier, 2002; Pham and Parenteau, 1991; Yip and Tran, 2008). Housing space per capita reduced significantly in the post-war era. In Ha Noi, this figure was $4 \mathrm{~m}^{2}$ per capita; 40,000 households were living in less than $2 \mathrm{~m}^{2}$ per person (Gough and Tran, 2009). In Ho Chi Minh City, average space per capita decreased to about $5 \mathrm{~m}^{2}$ (Huy Duc, 2013b).

In short, from unification in 1975 to Doi Moi in 1986, housing policy in urban Vietnam followed the communist style in which the state sector played the dominant role in housing production and distribution (Wang and Murie, 2011). Housing stock came from existing houses taken over from the old regime, new Soviet-style apartment blocks constructed by the state and owner-built houses (Department of Housing Management and Real Estate Market, 2013). The subsidised housing policy was unable to meet demand and created a careless attitude to housing maintenance by tenants. During this time, housing development in urban areas in the southern part of Vietnam, especially in Ho Chi Minh City, was not encouraged due to the state's intention to decrease the size and influence of these cities (Marshall-Cavendish, 2007; Trinh et al., 2000). From 1975 to 1985, city governments in the south focused only on the jobs of housing management and distribution; little or no new housing was built. From 1984 to 1985, the Ho Chi Minh City government started to invest in urban housing with about 12,000 housing units being developed. The state budget funded $62 \%$ of them (Tran, 2015).

\subsubsection{Housing in urban areas since the socio-economic renovation}

In the market-oriented economy after 1986, the Vietnamese government gradually put an end to the subsidised housing system and retreated from new housing production. The Land Law 1987 regulated the allocation of residential land to households in urban areas and recognised the right of transferring/selling houses on the land but not selling the land attached. In fact, when a house was sold, the land-use rights were transferred to the buyers implicitly. The actual effect of this regulation was to reduce the practice of trading empty land which, at the beginning of Doi Moi, was too sensitive. In reality, people did 'sell' and 'buy' land without official documents. Hand-written contracts for land purchase were popular until the 2000s. The official restriction lasted till the enactment of the Land Law in 1993. The Housing Ordinance in 1991 formally regulated the housing business activities 
of the private sector. The fourth Constitution (1992) replaced the citizens' right to housing with the right to build houses according to zoning regulations and laws and to be protected by the State in rent-lease contracts.

\subsubsection{Housing developed by the private sector}

\section{Owner-built housing}

Thanks to the increased income from Doi Moi, people started to invest in improving their dwelling conditions. There were many forms of self-help housing activities: some bought pieces of land from other land users to build new houses, including land designated for the relocated urban population, discussed below. Others re-built or repaired existing houses. In particular, tenants in old apartment buildings in Ha Noi extended their living spaces by occupying public space around their units or encroaching on public roads. There were also some illegal houses built on vacant land plots and legal construction on land allocated by local governments or state institutions (Gough and Tran, 2009; Trinh et al., 2000; Yip and Tran, 2008). Financial resources for these building activities came from savings, overseas remittances, and borrowings from friends and relatives (Trinh et al., 2000). In 1993, the estimated number of houses built privately by individual households with or without construction permits was about four times those built by the state (Trinh et al., 2000). In Ha Noi, 70\% of new constructed houses from 1985 to 1995 was funded by the private sector (Nguyen and Kammeier, 2002). Average living area per capita in Ha Noi increased from $4 \mathrm{~m}^{2}$ in 1993 to $10 \mathrm{~m}^{2}$ in 1999 (Gough and Tran, 2009). In Ho Chi Minh City, by 2005, total floor areas had increased to 69.5 million $\mathrm{m}^{2}$ (more than double the figure in 1977); the average living area reached $10 \mathrm{~m}^{2}$ per person (Tran, 2015). According to the World Bank, owner-built housing accounts for about $75 \%$ of the total stock of housing in Vietnam and is the most common housing supply for middle and low-income people (Samad et al., 2015).

\section{Commercial housing}

In general, for 15 years or so after Doi Moi, housing development by the private sector was to respond spontaneously to the urgent need of housing by households and individuals. Housing businesses at this time were mainly small scale, offering services such as design, construction, decoration, or material supplies. The activity of large-scale housing construction projects for sale or rent was limited, due to the strict and complicated regulations on land and the unavailability of long-term loans for housing development (Trinh et al., 2000). Former state-housing enterprises were still able to enjoy more 
advantages than their counterparts in the private sector (Yip and Tran, 2008), thus, largescale housing development by the private sector was not popular. Nevertheless, during this time, housing became a commodity traded in the market and housing prices increased dramatically, reflecting rapidly growing demand in urban areas. For example, real estate prices in central Hanoi rose at an unprecedented rate of 500\% from 1990 to 1993 (Drakakis-Smith and Dixon, 1997, cited in Gough and Tran, 2009).

The enactment of the Enterprise Law in 2000, the Land Law in 2003, the Law on Housing in 2005, the Law on Real Estate Business in 2006 and their subsidiary regulations enabled stronger participation by private investors in housing development for rent and sale. Foreign investment in the housing sector was also encouraged through favourable land lease schemes, tax breaks and increasing autonomy in running projects thanks to the increasing deregulation of business activities (Yip and Tran, 2008). These incentives spurred a flow of foreign direct investment (FDI); for example, FDI in the real estate sector took 35 percent of the total FDI registration in 2007 and increased to 54 percent in 2008 (Samad et al., 2015). Increased domestic private and foreign investment led to a significant increase in the number of private enterprises in the housing sector. For example, in Ho Chi Minh City, the number of enterprises in the land and housing sectors increased from about 300 in 1991 to almost 4,200 in 2006 (Le and Sajor, 2010). The engagement of these investors led to a proliferation of housing construction in all urban centres, especially $\mathrm{Ha}$ Noi and Ho Chi Minh City. In Ho Chi Minh City, for example, from 2005 to 2013, about 74,000 apartment units and luxury villas were constructed (Ho Chi Minh City People's Committee, 2013). The robust growth of the housing market was accompanied by a dramatic increase in housing prices, and ultimately a housing bubble burst in 2013, with a collapse in house prices, stagnation in transactions and slowdown in new investments. As a consequence, the commercial housing sector experienced some adjustments, with a redirection of some private investors to the LIH segment and an effort to convert some commercial housing into affordable housing in 2014 (Samad et al., 2015).

In addition to the permanent housing stock built by the private sector, many illegal housing areas sprang up for poor people. These houses were often built along canals, rivers, dumpsites or under bridges, using temporary materials and were entirely unconnected to infrastructure systems. Occupiers were urban poor residents, rural immigrants, and people returning from New Economic Zones (Trinh et al., 2000). The presence of these housing areas created pressure on city governments to replace these informal settlements with higher-standard permanent housing. 
The state also contributed to the growth in the private housing sector by selling old state housing units to tenants from 1994 (Decree 61) (Samad et al., 2015).

\subsubsection{Housing developed by the state}

In 1989, the Ministry of Construction (MOC) issued Circular 47 permitting the sale of state-owned houses to sitting tenants. In the meantime, the state continued some housing development activities. The state involvement included two main forms: housing development for relocated people and housing support for social-welfare beneficiaries.

Firstly, during the urban renewal process, city governments had to participate in housing development because they forcibly moved people out of their homes, with relatively low state-defined financial compensation. With this compensation, the affected people would not be able to buy property at market prices and therefore the government had to offer them plots of land or new apartment units for resettlement. Finance for this housing development came from local state budgets (compensation), property sales, international loans, and resettlers' saving and borrowing (Trinh et al., 2000).

Secondly, the state was also involved in social welfare housing projects. Under the supply and demand forces of the market-oriented economy, Vietnam has witnessed emerging inequalities in the housing sector. Affluent and better-off households have had greater opportunities to improve their living conditions, including housing, whereas poor families have been excluded from the housing market due to their limited purchasing capacity (Gough and Tran, 2009; Yip and Tran, 2008). The government offered housing support in different forms to people who contributed to the revolution, such as giving 'houses of gratitude' (houses built by local government or social organisations for such people or their next of kin to show gratitude) or giving financial support. Additionally, the government also provided housing support to poor people living in areas that were mountainous or prone to natural disasters, or to extremely poor households. For example, households in flood-prone areas in the Me Kong Delta, Highland areas, and in the Central Region were provided with 'houses of sympathy' and other financial support.

\subsubsection{The development of LIH policy}

LIH policy was first mentioned in the Prime Minister's Decision 76 in 2004, approving long-term objectives and primary principles for a Housing Development Strategy to 2020. In this decision, the state officially encouraged the establishment of a fund for LIH and set out the objective that average housing space should reach $15 \mathrm{~m}^{2} /$ person by 2010 and $20 \mathrm{~m}^{2} /$ person by 2020 . However, the Decision mentioned only general policy solutions to 
achieve the goals, such as to study and enact regulations relating to housing standards and architecture management in urban areas or complete credit procedures to support households and individuals in housing loans. The decision did however emphasise the need to issue new regulations for development and management of social housing in urban areas. In short, this was the first official acknowledgement of the need for LIH and outline of some policies for its development.

Following this Strategy, the Law on Housing (2005) officially recognised the need to develop social housing as a specific new category of state-supported housing. A new legal framework for social housing development was expected to be enacted in the near future [when] "the State works out procedures and policies for development of social housing funds" (Article 45). This law defined beneficiaries of social housing, including state employees, officials, military officers, professionals in the defence forces and workers working in economic zones, industrial areas, production areas, high tech areas and other groups defined by the Government, who have low-income and housing difficulties (Article 53). Gough and Tran (2009) criticise these target groups for excluding the most vulnerable people in society, such as members of small family businesses; workers in the informal sector and the private sector outside industrial zones, and the unemployed. Yip and Tran (2008) observe that the new 'social' housing policy was in fact an extension of the previous housing policy which prioritised government officials, state employees and people who contributed to the revolution, and the demands of other new emerging social groups "[were] received with a less enthusiastic response" (p.199). This was a political choice, partly to reward the loyalty of government officials to the state but partly because the Party and government did not have the resources to meet other housing demands (Yip and Tran, 2008).

The law has no definition of low-income people. In 2009, Circular 36 defined low-income earners as people whose monthly income was stable and high enough to pay off the rent or the value of a LIH unit (higher than local poverty line) but not above the local average income calculated by the provincial government. People in preferential treatment categories and poor people (whose income is below local poverty line) continued to receive housing support from the state.

The law also defined some quality standards for social housing, such as the maximum number of storeys (six) and the maximum space per living unit $\left(60 \mathrm{~m}^{2}\right)$. 
Three years after the law took effect, the government issued some subsidiary regulations and guidelines for social housing. Resolution 18/NQ-CP (20 April 2009) promulgated some policies on developing social housing for students at universities and colleges, workers in industrial zones, and low-income earners in urban areas. To implement these policies, the Prime Minister issued three decisions providing guidelines for housing for students (Decision 65), workers (Decision 66), and low-income earners (Decisions 67). In these directives, the most prominent measures applied to LIH were: lowering interest rates for LIH loans, assigning $20 \%$ of the land area of commercial projects to $\mathrm{LIH}$, setting the maximum area for $\mathrm{LIH}$ at $70 \mathrm{~m}^{2}$ per unit, limiting the profit rate from $\mathrm{LIH}$ projects to $10 \%$, and providing some incentives for private developers, such as exemptions from land-use fees, ${ }^{4}$ value-added tax (VAT) rate set at $0 \%$, exemption or reduction from corporate income tax (CIT) for some years and other credit support. However, due to the inconsistency of these three decisions with other laws, the Prime Minister had to amend the decisions, limiting the tax incentives to the year 2009 only.

The policies were implemented by provincial governments. For example, in Ho Chi Minh City from 2006 to 2012, the city government built about 800 houses of gratitude and repaired more than 3,000 houses for people who contributed to the revolution, built more than 7,000 units and repaired more than 6,000 units for poor people. The city also established a Housing Development Fund (HDF), which offered loans for housing to more than 1,200 city government officials (Ho Chi Minh City People's Committee, 2013).

To update housing policy again, the Prime Minister issued Decision 2127 in 2011, revising the national strategy on housing development through 2020, with a vision toward 2030. In 2013, the government issued a replacement resolution (Resolution 02) and the Prime Minister issued an updated decision (Decision 188), which provided more incentives to both the supply and demand sides of social housing. For example, Decision 188 allowed low-income people to re-sell their social housing units five years after buying (previously, they could only re-sell after 10 years provided that they paid back $50 \%$ of the land-use fee applying to the unit). This provision was designed to encourage low-income people to invest in housing by making properties easier to transfer. On the supply side, the Decision granted developers permission to assign $20 \%$ of the land area in a social housing project

\footnotetext{
${ }^{4}$ Land-use fees account for a large proportion of the cost of a housing project since prices of land in urban areas have been increasing dramatically after Doi Moi.
} 
to develop commercial housing. This regulation was designed to make social housing more attractive to developers.

In June 2013, after the housing bubble burst, the government launched a 30 trillion VND credit package to stimulate affordable housing and to stabilise the economy in general. The special feature of this package was that it provided assistance to both supply and demand sides of LIH. The package provided cheap loans to developers of social housing and mortgage loans to LIH buyers. According to a World Bank assessment, this package has been successful in redirecting the flow of capital into the affordable housing segment, but it also has come at a high cost to government and, thus, is not fiscally sustainable (Samad et al., 2015). Following the introduction of the new Law on Housing in 2015, social housing policy in Vietnam is still changing.

\subsection{Summary}

The socio-economic renovation in 1986 was the turning point when the country started to transform from a centrally planned economy towards a market-oriented economy. This transition enabled the new urban development strategy, which allowed the establishment of mega and big urban centres. In particular, the land reform during Doi Moi was the key element that enabled the development of the real estate market in Vietnam. During the transitional period, the state's retreat from subsidised housing policy and the vigorous participation of the private sector and foreign investors led to a proliferation of housing and accelerated housing prices in urban areas. However, new housing challenges in the market economy also appeared, including housing affordability for low-income people. Within this context, LIH policy was initiated for the first time by the central government in 2004. However, this policy was only actually implemented nationwide in 2009 when further guidelines were issued. New policy adjustments are, at the time of writing, on the way to provide housing assistance to low-income people in Vietnam. 


\section{Chapter 3: Literature on public policy, policy process and determinants of public policy in Western countries}

\subsection{Introduction}

This chapter reviews the literature on public policy, policy process and determinants of public policy to identify a suitable analytical framework for understanding the policy process in the Da Nang case. The chapter examines definitions of public policy, and prominent theories, models and frameworks developed to analyse policy process in mostly Western countries. In addition, it looks at different approaches in the literature on determinants of public policy to improve the utility of the chosen framework. Finally, the chapter reviews some key guidance on analysing different stages of a policy process, which will be useful for the case analysis.

\subsection{Public policy, policy process and determinants of public policy}

\subsubsection{Public policy}

Since 'policy sciences' were identified as a distinct academic discipline in the 1950s, there have been various definitions of public policy. Thomas R. Dye (1984) defines public policy as simply as "whatever governments choose to do or not to do" (p.1). This succinct definition highlights two important features of public policy. Firstly, the agent of public policy must be a government and secondly, public policy is the result of governmental choices (Howlett and Ramesh, 2003). This simple definition does not distinguish between daily operational decisions and influential public policy decisions made by government (Anderson, 1975; Howlett and Ramesh, 2003). Dye (1984) made it a little clearer by further explaining the purpose of public policy study, that it tells us "what governments do, why they do it, and what difference it makes" (p.1).

Jenkins (1978) offers a more comprehensive definition: public policy is "a set of interrelated decisions taken by a political actor or group of actors concerning the selection of goals and the means of achieving them within a specified situation where these decisions should, in principle, be within the power of those actors to achieve" (p.15). This definition emphasises the goal-oriented nature of public policy and the set of means to achieve those goals (Howlett and Ramesh, 2003). This emphasis helps to improve the weakness of Dye's definition in distinguishing public policy from daily decisions of government. More importantly, Jenkins's definition highlights that policy actors should make policy decisions within their power. That means policy is always made with available resources (Jenkins, 
1978) and within different constraints. Thus, understanding these constraints is crucial to understand a public policy.

Others define public policy as "a projected programme of goals, values, and practices" (Lasswell, cited in Dye, 1984, p.2) or "a purposive course of action followed by an actor or [a] set of actors in dealing with a problem or [a] matter of concern" (Anderson, 1975, p.3). According to Stewart, Hedge, and Lester (2008), these definitions share a view of public policymaking as 'a process' or 'a series' of governmental activities or decisions that are designed to address some public issues. Another merit of Anderson's definition is that it emphasises the perception of policy actors in defining what policy problem needs to be solved by a public policy.

\subsubsection{Policy process and prominent theories, models and frameworks for understanding policy process}

Various scholars have developed different theoretical approaches to explain and analyse the policy process. Each of them focuses on different aspects of public policy (Anderson, 1975). In a book about theories of the policy process, Sabatier (2007) selects and discusses seven promising theoretical frameworks that can be used to understand the policy process: stages heuristic, institutional rational choice, multiple-streams, punctuated-equilibrium, advocacy coalition, policy diffusion and funnel of causality and other frameworks used in comparative studies between states in the United States.

\subsubsection{The stages heuristic framework}

To simplify the complexity of the policy process, the stages heuristic framework disaggregates the process into a series of discrete stages (Anderson, 1975, Howlett and Ramesh, 2003). Though there are differences in the number, names and order of stages in the policy cycles constructed by different authors, the most common stages are agenda setting, policy formulation, decision-making, policy implementation, and policy evaluation (Howlett and Ramesh, 2003). This framework is criticised for many reasons, one being that it oversimplifies the complexity and interactive nature of the policy process (Sabatier, 2007b). In reality, policy stages do not occur in a systematic and linear fashion as mapped in the models, rather they can be skipped, change order or be repeated in unpredictable ways (Howlett and Ramesh, 2003). More importantly, the stages heuristic does not mention any causal factors affecting the policy process (Howlett and Ramesh, 2003; Sabatier, 2007b). As a result, its capacity for explaining the actors and influential factors of the policy process is limited. Thus, many other models have been constructed to 
replace this stage heuristic model. However, breaking down the policy process into stages is still useful for policy analysts in outlining different groups of related activities in a specific policy process, even though they do not occur in a linear order. That is why this approach has been in use in policy studies during the last six decades (Howlett et al., 2017) and why I use this approach to separate the stage logic of my case study, especially in the agenda setting and implementation stages, before recombining them into a whole policy process, while also keeping in mind the limited nature of this disaggregation.

\subsubsection{The institutional rational choice framework}

Based on rational choice theory, the institutional rational choice framework postulates that individuals behave to maximise their personal benefits, but they do so under the constraints of institutional rules (McGinnis, 2011; Sabatier, 2007b). According to institutional analysts, individuals always have to make decisions within certain constraints. The "rules, the state of the world, and the nature of the community" (Ostrom, 2007, p.35) will determine the actions that individuals can take and the resulting outcomes. Thus, to conduct an institutional analysis, one must understand the "working rules" (Ostrom, 2007, p. 36) that individuals reference in making decisions. Then one ought to trace back to the origin of those rules. Ostrom (2007) notes that in a government directed by the rule of law, those rules can be found in official, legal documents. However, in other systems that do not follow the rule of law, both 'rules-in-form' and 'rules-in-use' are significant. Ostrom (2007) also advises institutional analysts to be aware of the limit of language in conveying the whole meaning of rules and the fact that many rules-in-use are not written down or even conceptualised by participants themselves (they are just implicitly understood). In addition to working rules, the framework also pays attention to the attributes of states of the world and the attributes of the community (or the community's culture). The policy process, as described by the author of the institutional analysis and development framework (a specific body of the literature on institutional rational choice [Ostrom, 2007]), is where contextual factors (biophysical conditions, attributes of communities, and rules-in-uses) are processed by policymakers in an 'action situation' to produce outcomes, which can be evaluated to generate feedback and learning for any stage of consecutive processes (McGinnis, 2011; Ostrom, 2011).

The framework's focus on the role of rules (both implicit and explicit) is useful in my case to examine the constraints that local leaders faced when making policy decisions, especially the formal institutional arrangements between central and local government, the 
norms in local autonomy and also the implicit rules within the case's action arena. Its concepts of other contextual factors and the role of policymakers in processing inputs to generate policy outputs are also useful for this case study. Finally, the framework's proposition of maximising individual interests can be used to examine whether or not policy actors in my case pursued their personal benefits in making policy.

\subsubsection{The multiple streams theory}

John Kingdon (1995) develops the multiple streams theory based on the approach of the 'Garbage Can Model of Organisational Choice' by Cohen, March, and Olson (1972). This theory explains why a policy idea is advanced onto the agenda of a government and then becomes policy. The multiple streams theory views policy outputs as the result of three main streams: problems, policy and politics, which meet at a point when a 'window of opportunity' appears and policy entrepreneurs work hard to join those streams together (Kingdon, 1995; Sabatier, 2007b).

According to Kingdon (1995), a problem exists and people might know it does but policymakers need some indicators to make sure it is a problem, what its magnitude is and whether government should address it. A problem needs a little push (maybe from a crisis, a disaster, or personal experiences of decision makers) to call for the policymakers' attention. All of the push factors need to be accompanied by other supporting evidence, such as a pre-existing perception of a problem, a subsequent condition that catches policymakers' attention, feedback from implementation, or budget constraints. In sum, indicators, focusing events and feedback bring problems to decision makers' attention. However, not every condition is seen as a problem; people need to be convinced that something should be done to change it. People within and outside the government make that judgement by evaluating conditions in the light of their values, by comparisons among localities and by classifying conditions into categories (Kingdon, 1995).

As for the policy stream, Kingdon (1995) notes that proposals are generated, debated, redrafted, and accepted mostly within communities of specialists. Proposals go through a strictly selective process and only some prominent ideas survive after being well considered. Policy entrepreneurs play an active role in this process to promote their favourite ideas. A proposal that survives has to meet several criteria such as technical feasibility (capable of being implemented) and value acceptability (compatible with decision makers' values, suited to national culture/traditions or dominant ideology, in harmony with the principle of equity or principle of efficiency, reasonable in cost). The 
proposal must also be viable within anticipated future constraints (budget, public acquiescence). In sum, ideas must get through a long process of consideration, floating up, discussion, revision and trying out before being the chosen proposal (Kingdon, 1995).

The last stream, politics, might consist of swings in national mood, changes in pressures from interest groups, the results of elections, partisan or ideological distribution in representative bodies and changes of administration. The political stream is the most important stream for "making some things possible that were impossible before, making things out of the question, and creating a receptivity to some ideas but not to others" (Kingdon, 1995, p.145).

According to the multiple streams theory, policy change occurs when the three streams couple at the right time, that is, when a policy window opens. Policy entrepreneurs, who are willing to invest their resources (time, energy, reputation, money) to promote a policy initiative in return for anticipated future benefits, play a critical role in the coupling when the window of opportunity opens (Kingdon, 1995).

The multiple streams theory has been widely used to study various cases in the United States and Europe (Howlett et al., 2017). Kingdon's theory is also applied by some scholars to explain policymaking in Vietnam (Bui, Mirzoev, and Mukhopadhyay, 2015; Painter, 2005).

Based on the earlier overview, it is possible that the three streams can be detected in the Da Nang case. Kingdon's (1995) notion of policy entrepreneur, who has “expertise", "an ability to speak for others" (a leader of a powerful interest group or an authoritative decision-making position), "political connections or negotiating skill" and who was "persistent" (pp.180-181), also appears of potential interest, given the prominent role of local Party secretaries in Vietnam and the high public profile of Da Nang's leader. Kingdon (1995) also notes that when studying any specific case, one can nearly always pinpoint a particular person or persons who were central in advancing a policy idea onto the agenda and getting it past the decision-making stage, or the "central figure in the drama" (Kingdon, 1995, p.180). This observation is helpful in examining the role of the city's Party Secretary. The multiple stream theory also offers a useful proposition that it is difficult to pinpoint a single origin of a policy idea. However, it is not the source of the idea but the climate in the government in which the idea becomes prominent that is important. Thus the key to understanding a policy change is not where the idea comes from but what made it take hold and grow (Kingdon, 1995). 
However, since the multiple stream theory is developed to explain how policy ideas are advanced onto the agenda in the American policy context, there are many concepts, especially in the political stream, that need to be reconceptualised, such as political competition or turnover of key personnel, to explain what happened in the single-party state of Vietnam. The theory is also not suitable to explain the next stages of the policy process, for example the implementation in my case, when the relationship between central and local government, the participation of the private sector and the role of policy elites were very significant.

\subsubsection{Punctuated-equilibrium theory}

Punctuated-equilibrium theory describes the policy process as the accumulation of incremental changes during a long period (or policy stasis), which is then punctuated by a major policy change (Sabatier, 2007b; True et al., 2007). Punctuated-equilibrium theorists believe that a political system cannot simultaneously deal with all policy issues that confront it, so policy issues are disaggregated into policy subsystems. Each of these policy issues is parallel-processed within its own community of experts, which results in incremental change and policy adjustment. Then, one or a few issues get heightened attention from media, broader public and decision makers and get onto the macro-political agenda for serial processing. This is when major change might occur (True et al., 2007). A policy subsystem creates a so-called 'policy monopoly' where its institutional structure is dominated by a policy image ("beliefs and values concerning a particular policy" [Baumgartner and Jones, 1991, p.1045]), which is affected by core political values. Policy monopoly obstructs major policy change in the subsystem (that is why the theorists consider this policy state as demonstrating a negative feedback process). However, stability will not last forever. When pressure for change is sufficient (because of focusing events, crisis or an accumulation of small pressures), new policy actors step into the subsystem and make change in the policy image, which finally leads to major policy change (positive feedback process). After a major policy change, there will be a new equilibrium in the policy area (Jones and Baumgartner, 2012; True et al., 2007). In a recent reflection, the authors of the punctuated equilibrium theory reinforce that policy changes can occur when information is accumulated enough to gain governmental attention and the allocation of attention is one of the 'microfoundations' of this theory (Jones and Baumgartner, 2012). The theory has recently been applied to understand policy changes in local governments that lead to policy changes at central level (McNew-Birren, 2015) and 
to explain the influence of local political institutions on policy change (Kwon, Choi, and Bae, 2013) in the United States.

Dang (2013) borrows the concept of 'policy image' in the punctuated-equilibrium theory to explain the importance of a change in how policy elites perceive policy problems and possible solutions before any major policy change can occur in Vietnam. He also uses the ideas of bounded rationality (that individuals' decision-making is bounded by the information and the time they have and within their limited intellectual capacity) and institutional constraints to construct the concept of political predisposition of policy elites. Dang (2013) explains that policy elites in Vietnam have to refer to some principles and priorities as guidelines for their policy decisions to avoid unexpected consequences. This practice explains the 'gradualism' and 'incremental' features of policy change in Vietnam. Finally, Dang (2013) finds some resemblance between the supreme power of the CPV and the concept of policy monopoly in dampening major policy change.

As will become clear in subsequent chapters, in this case policy change did occur, but it was not a radical or major policy change. Policy image was adjusted but not replaced and the case has more features of a policy adjustment than of a radical policy change. In addition, it is difficult to find a focusing event or a crisis that lead to policy punctuation in this case. Rather, the policy improvement was a result of many factors that will be investigated in the next chapters. Thus, punctuated-equilibrium is not an ideal model to explain what happened in my case. However, bounded rationality and institutional constraints, as explained by Dang (2013), are useful to shed light on the influences on policymakers in making policy. Moreover, the incremental characteristic of policy process in the stasis stage suggested by the punctuated-equilibrium theorists is quite similar to the 'gradual' feature of the policy process in my case, especially for explaining what happened after a significant policy improvement had been adopted. Finally, understanding the allocation of policy makers' attention is useful in studying the flow of information that influenced policymakers in making their decisions.

\subsubsection{The advocacy coalition framework}

Sabatier and Jenkins-Smith (2007) developed the advocacy coalition framework to explain policy processes that deal with complicated policy issues which involve "substantial goal conflicts, important technical disputes and multiple actors from different levels of government" (p.189). The framework is based on the foundations of some key concepts such as policy subsystems, belief systems, advocacy coalitions and external perturbations. 
The advocacy coalition framework assumes that the policy process occurs mainly in a policy subsystem, which is composed of participants such as legislators, agency officials, interest groups, researchers and journalists. Since these participants share some particular policy beliefs, they cooperate to form an advocacy coalition to compete with opponents in influencing the policy outcome within a policy subsystem. The belief system in the advocacy coalition framework is organised into a three-tiered hierarchical structure, namely deep core beliefs, policy core beliefs and secondary beliefs (Jenkins, 1978; Sabatier, 1986; Sabatier and Weible, 2007). At the highest level, deep core beliefs reflect participants' fundamental values and perceptions. They are established from childhood and thus are very difficult to change. The next level is policy core beliefs that consist of perceptions and assumptions about some policy-related values, the roles and authorities of different policy actors, and the causes and seriousness of policy problems. These beliefs are difficult to change since they reflect the participants' fundamental principles about policy choices. Change in policy core beliefs can occur when experience reveals serious problems. The final level is secondary beliefs, which affect the participants' approaches to a specific policy problem in a specific locale. These are the beliefs that can be changed. The authors of the advocacy coalition framework distinguish the concept of a beliefs system in their framework from the material self-interests in the institutional rational choice framework by explaining that the beliefs system glues allies in purposive groups, motivated by an ideological position rather than in material groups, which are motivated by economic self-interest (Sabatier and Weible, 2007). The advocacy coalition framework explains policy change as a result of a change in the beliefs system (mostly the secondary beliefs) or of a replacement of a dominant advocacy coalition. Since internal change of the beliefs system is difficult, it needs some external factors such as policy-oriented learning or external perturbations or shocks (Sabatier and Weible, 2007).

The advocacy coalition framework is criticised for not identifying the conditions in which policy learning and external shocks can translate into policy changes, for not explaining the internal change within the advocacy coalitions themselves, and for some difficulties in collecting enough data for analysis (Rozbicka, 2013). Although the framework is considered "one of the most promising frameworks" (p.849) to understand the policy process in the European Union, especially to comprehend the information flows between coalitions and the participation and influences of interest groups, it still needs to combine with other theoretical approaches to fully explain the policy process in the European Union (Rozbicka, 2013). The framework also suffers frequent criticism that it is designed to 
explain the policy process in pluralist and democratic politics, such as the United States. Scholars particularly doubt the ability of the framework to be applied in non-democratic countries. Thus, it would be difficult to identify and analyse the advocacy coalitions within Vietnamese political elites, particularly in my case study. However, the concept of policy beliefs system is helpful in examining the core values that influence policymakers in Vietnam. In addition, policy-oriented learning from implementation is also a possible factor that might affect policy adjustment in my case. The policy history of Vietnam shows that, although deep core values were unchanged in the period of Doi Moi, new approaches have been applied to reform the country. The process mostly happened as a result of policy learning from implementation reality.

The modifications of the advocacy coalition framework after 1999 offer some extra benefits for students of policy process. For example, Sewell (2005) developed a set of resources that might affect the policy process, including formal legal authority to make policy decisions, public opinion, information, mobilisable troops, financial resources and skilful leadership (Sabatier and Weible, 2007). Many of these resources can be traced and examined for their influences in studying the policy process in local government in Vietnam.

\subsubsection{The policy diffusion models and policy transfer}

Policy transfer, lesson drawing, policy innovation, policy emulation, or policy diffusion are among various terms to conceptualise the spread of policy from one political system to another, such as from one state of a country to other states of the same country (Berry and Berry, 2007; Dolowitz and Marsh, 2000) or from one country to others (Dolowitz and Marsh, 2000; Rose, 1991).

To understand policy transfer, various studies have been undertaken to answer some key questions, such as who learns what from whom and where, why policy transfer occurs, what elements of policy are transferred and at what scale, as well as what facilitates and constrains the transfer (Benson and Jordan, 2011). Actors involved in policy transfer can be elected officials, political parties, bureaucrats/civil servants, pressure groups, policy entrepreneurs and experts, transnational corporations, think tanks, supra-national governmental and nongovernmental institutions and consultants (Dolowitz and Marsh, 1996). 'Hard' transfer might include the emulation of policy goals, structure and content, instruments, institutions and programmes, while 'softer' transfer can consist of the diffusion of ideas, attitude, ideologies and concepts. Policy can be transferred across time 
and space (between cities, states, nations, or from the own past of one organisation) (Rose, 1991). The degree of policy transfer varies from copying to emulation, combination and inspiration (Dolowitz and Marsh, 2000). Policy transfer can be constrained by various factors, including past decisions, institutional and structural constraints, different ideologies, or insufficient technological, economic, bureaucratic and political resources (Dolowitz and Marsh, 1996). Benson and Jordan further conceptualise the constraints into four categories: demand side (for example, policymakers' tendency to remain in the status quo); programmatic (for example, the uniqueness of policies); contextual constraints; and application related constraints (for example, transaction cost, institutional changes) (Benson and Jordan, 2011).

When explaining the underpinning reasons of policy diffusion within the United States, Berry and Berry (2007) argue that the emulation happens because states tend to learn a promising policy idea from other states to make a shortcut in dealing with complex policy problems, or to compete with neighbouring states (that have already adopted a policy) in order to steer themselves from being in a disadvantaged position, or to ensure that the adopted policy conforms to national rules. Meanwhile, Rose (1991) assigns the stimulus of voluntary lesson-drawing to dissatisfaction with the status quo. Dolowitz and Marsh (2000) explain voluntary or coercive policy transfer among countries as a result of global economic pressures, the development of international communications and the intervention of international organisations. Benson and Jordan (2011) summarise the underpinning reasons in "the role of dissatisfaction among policymakers, public disquiet, perceptions of policy failure, political competition, the need to legitimate particular policy actions, and uncertainty" (p.369-370).

According to Berry and Berry (2007), there are several models that give different weight to external influences on the process of policy emulation. Additionally, internal determinant models focus on internal factors, such as political, economic, and social characteristics of the state to explain whether and when a state adopts a policy innovation. In reality, no state can escape from influences of external forces (as explained in the diffusion models) and all policy adoption must consider the effect of internal factors. Thus, Berry and Berry (2007) offer a unified model of state government innovation by combining factors examined in both diffusion models and internal determinant models. Their model is elaborated in this equation: 


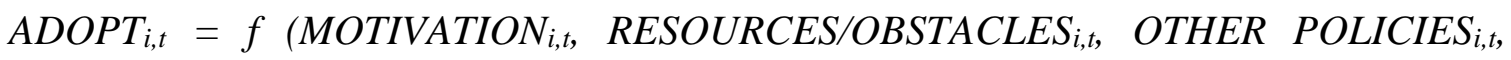
EXTERNAL $L_{i, t}$ ) [Equation 3]. (Berry and Berry, 2007, p.237)

According to this equation, policy adoption is a dependent variable, representing the probability that state $i$ will adopt the policy in year $t$, which is determined by independent variables, including motivation, resources, obstacles, other policies, and external forces. Though this innovation and diffusion model is designed to examine the policy process at state governments in a federal system characterised by a high degree of political competition, as the authors suggest, this can be modified to apply to local governments within a unitary system. The authors point out the imitation of this model in explaining the complexity of the policy process, since it does not take into account the role of intergovernmental influences and key policy actors. In addition, the most challenging problem when applying this model is the requirement of pooled data measuring important variables over time of many analysis units (states). To solve this problem, Berry and Berry (2007) suggest using intensive analysis of case studies or small-sample comparative designs.

My case study does not aim to measure the probability of adoption of a specific policy; rather it attempts to explain the factors affecting a policy process in a certain case. Thus, Berry and Berry's (2007) innovation and diffusion model does not fit well into my study purpose. However, the model's independent variables are helpful as a suggested lens on the Da Nang case. Among the critical factors that affect the policy process in this case are motivation (the housing problem), financial resources, and innovative leaders. More importantly, the model suggests attention to the possible influences from other policies, including complementary policies (Berry and Berry, 2007) (such as the 5-Nos ${ }^{5}$ as an influence of the 3-Haves campaign) and substitute policy (Berry and Berry, 2007) (such as previous housing subsidy policy in the centrally planned economy, housing support policy prior to 2005), and external influence from the other localities and from central government (vertical influence model). Other studies on policy transfer among countries have focused on treating policy transfer as a dependent variable to explain why and how policy transfer happens, but few have examined how policy transfer acts as an independent variable which affects the policy process (Benson and Jordan, 2011). However, the literature still offers ideas that might be of relevance for my case study. They include a suggestion to look for

\footnotetext{
${ }^{5}$ The 5-Nos campaign, implemented in the city from 2000 to 2005, includes five components: no hungry households, no illiterate people, no begging, no drug users living in communities, and no robbery murder (defined as killing people for money) (Chuong trinh 5 Khong: khong ho doi, khong nguoi mu chu, khong an xin, khong co nguoi nghien ma tuy song trong cong dong, khong cuop cua giet nguoi).
} 
evidence of policy transfer from other countries during the case's time period or if there was any demand or opportunity for policy transfer within and outside the case. Similar to Berry and Berry's (2007) policy diffusion model, literature on policy transfer in general also directs my attention to the role of policy experience in the past, especially the housing policies prior to 2005 in Da Nang City.

\subsubsection{The funnel of causality models}

In 1963, Dawson and Robinson asked one of the most interesting questions in policy studies: whether environmental or political variables matter more in determining public policy (Blomquist, 2007). Their findings from 46 states of America showed that political variables are less influential than environmental variables (Blomquist, 2007). Thomas Dye, Ira Sharkansky, and Richard Hofferbert were among many other scholars who followed Dawson and Robinson's path and produced research findings to support the claim that environmental conditions matter more. In a 1965 study, Dye concluded: "Most of the policy differences which do occur turn out to be a product of socio-economic differences among the states rather than a direct product of apportionment practices" (cited in Blomquist, 2007, p.263).

In his book The Study of Public Policy (1974), Hofferbert argues that the policy-making process is mainly determined by environmental conditions of the country and only marginally influenced by political actors. By using a metaphorical image of a funnel, he describes public policy as a result of a flow of factors, starting with the three key determining factors, historic/geographic conditions, socioeconomic composition and mass political behaviour, which enter at the open end of the funnel, are then filtered through two less important factors, namely governmental institutions and elite behaviour, to form policy outputs at the formal policy conversion point (Hofferbert, 1974, p.228). Hofferbert claims that the role of political institutions and elites is less influential than that of underlying historical, social and economic conditions. Dye (1984) supports this claim by suggesting similar propositions that "economic development is an important determinant" (p.313) of public policy (especially policies related to taxing, spending and services) while political features are less influential factors. If the political system has any influence on public policy, it is because of the indirect effect of economic conditions on the political system. Economic resources can directly and indirectly affect public policy, while a political system can only facilitate or obstruct the relationship between economic resources and public policies. Dye also argues that a local government can only be relatively 
independent from economic conditions when it receives financial support from central government. Dye's and Hofferbert's approaches were extensively applied in the 1960s and 1970s to understand state welfare expenditure, and policy and legal changes, especially in the United States (Blomquist, 2007). These models and empirical studies based on them share the same basic approach to depict policy outputs as dependent variables, which are influenced by independent variables such as socio-economic conditions and political behaviour and institutions.

This model is utilised by Jenkins and Sabatier (1993, as cited in John, 2013) when they argue that sudden change in economic and social conditions gives a shock to policymakers, breaking down existing policy advocacy coalitions and creating new relationships which lead to new policy (John, 2013). Wilensky (cited in Parson, 1995) supports Hofferbert's argument by examining the determining factors shaping welfare policy. According to Wilensky, economic development leads to affluence and results in a growing capacity to provide social welfare, while political factors such as party competition or voter choices have less influence (Parsons, 1995).

The funnel of causality model receives strong criticism from other scholars due to its neglect of the role of human agency in policymaking (Blomquist, 2007). Blomquist (2007) particularly criticises this approach for downgrading the role of information, ideas, beliefs and interests in guiding individuals' actions. He also denounces the model for its failure to incorporate the influence of the relationships between different levels in multigovernmental systems and for its inability to recognise the existence of multiple decisionmaking entities (including formal and informal arrangements) in a multi-organisational government like that of the United States. As a result, according to Blomquist, the model is unable to reflect the institutional rules that define the roles of different individuals in political communities and misses out the complicated and multiple levels of actions and conflict within the system. However, the model's emphasis on socio-economic conditions has its own merits and did influence other theorists in constructing their theories about policy change (Blomquist, 2007). When commenting on the discussion of whether environmental or political factors matter more in determining public policy, Anderson (1975) draws a fair conclusion that to understand how and why policy decisions are made, one must consider both social-economic and political factors. However, he notes that the question of which set of factors is more important is still open (Anderson, 1975). 
In fact, in the funnel of causality models, especially in Hofferbert's (1974) model, the factors of institutional arrangements and policy actors were not missed out. They were mentioned at the end of the funnel though with less emphasis than historical, geographical, social, and economic conditions and mass political behaviour. If the weaknesses of the model can be fixed by taking into account the importance of institutional arrangements and policy actors, this model offers a comprehensive analysis framework to understand determinants of public policymaking. Thus, I will modify the variables of this model to build up my own analysis framework for my case study. More details on this modification are presented in Chapter 6.

In sum, different theoretical approaches offer different lenses to understand public policy. Depending on the key features of a particular policy situation, one approach might have more utility than other. Those approaches used to be viewed as 'mutually exclusive' or 'competitive' (Howlett et al., 2017). Weible et al. (2012) assert that different approaches help to understand "the complexity and diversity" (p.2) of the policy process. They incorporate insights from those approaches to suggest a set of factors affecting the policy process, including individuals (their cognitive characteristics), context (policy subsytems and macro-systems) and other supporting factors, such as internal and external events, learning, and negotiation and cooperation. Based on this understanding, the authors propose three strategies for understanding and influencing public policy: developing deep knowledge in a policy subsystem, investing in networks and participating for a long time (Weible et al., 2012). In a similar effort, Howlett et al. (2017) suggest combining some key elements of the stages heuristic frameworks, the multiple streams theory and the advocacy coalition framework to develop a reconciling framework to explain all stages of the policy process. Their framework consists of five streams (problem, policy, politics, process, and programme) with influences from key policy actors' ideas and beliefs at key conjunctures of the policy process (Howlett et al., 2017). Although the idea of bringing insights from different models together to enhance our understanding of the policy process is great, Howlett et al.'s suggested framework does not seem to suit this case study, especially the separations of political stream after agenda-setting and of policy stream in implementation. Instead, as argued above, the funnel of causality model seems to be a suitable one for studying this case because it embraces significant policy factors, ranging from broad socioeconomic conditions to institutional arrangements and policy actors. It also allows an incorporation of insights from other approaches, which will be elaborated on later in 
Chapter 6. In the following sections I examine the literature further to enhance the utility of this model in my case study.

\subsubsection{Determinants of public policy}

This section focuses on the body of the literature on determinants of public policy according to society-centred, state- and individual-centred approaches. The aim of this review is to further examine the possible factors affecting policy process in order to construct an initial analytical framework to understand the policy process in my case study, based on Hofferbert's funnel of causality model.

Howlett and Ramesh (2003) note that studying public policy is not easy because there are many different approaches to policy study. They outline the main approaches based on the levels of analysis (macro, meso or micro), methods of analysis (deductive or inductive), and units of analysis (individuals, groups, or social structures). From another perspective, there are two main approaches to explain determinants of public policy that gain the attention of many scholars, namely society-centred and state-centred approaches.

Society-centred approaches focus on society's classes and groups in explaining policymaking. Marxist theorists believe that the state is an instrument in the hands of the dominant social classes and thus public policies are determined by the interests of those classes. For example, public policies in capitalist societies aim to maintain the capitalist system and increase the profits of the capitalists at the expense of the working class (Howlett and Ramesh, 2003). Other group theories (pluralism and corporatism) assume that societies consist of different groups of individuals with similar interests and concerns. Public policy, according to pluralists, is a result of competition and collaboration among groups in order to maximise their members' collective interests while corporatists assume that policy is a result of interaction between the state and the interest groups or groups recognised by the state (Howlett and Ramesh, 2003). In other words, the state is just an arena within which different groups struggle and contend in shaping public policy (Dye, 1984; Skocpol, 1985) and public policy reflects the interests of dominant groups (Anderson, 1975). That means the state and policy actors have no autonomy in making policies and their decisions can be predicted by analysing the class and group formulations (Borras, 2001). This assumption is criticised severely. The common criticism about Marxist theory is its incapacity to provide the evidence that the state follows the capitalists' instructions in making public policies and to explain why the state adopts many policies that are against the interests of the capitalists (such as social welfare policies) (Howlett and 
Ramesh, 2003). Another criticism targets the theory's underestimation of the role of public officials in policymaking (Anderson, 1975).

As for pluralism, Howlett and Ramesh (2003) point out that this theory does not reflect the various capacities of different groups in affecting policies and ignores the interests of government officials in controlling government activities. Neo-pluralists acknowledge that some groups may have more power in influencing policies than others but they are still unable to fix the inherent flaw of pluralism: its lack of attention to other important factors such as the state and contextual conditions. Howlett and Ramesh (2003) also point out the problem of applying pluralism in other countries outside the United States due to the limited role of interest groups in those countries, especially in authoritarian states. Similarly, although corporatism takes into account the role of the state in interacting with interest groups, its greatest weakness is still the ignorance of other important factors such as political arrangements within the state.

While society-centred approaches downplay the role of institutional arrangements and individual policymakers, state-centred approaches grant more recognition to these factors. The central role of the state is claimed by Max Weber in an argument that states are compulsory associations claiming control over territories and the people within them (Skocpol, 1985). Actor-centred institutionalism, including the institutional analysis and development framework, starts with the belief that individual policy actors aim to maximise their interests in making policy decisions. However, these theorists pay more attention to institutional arrangements that constrain policy actors' behaviour. Rules, norms, and culture will influence policy actors and ultimately affect the state's decisions (Howlett and Ramesh, 2003). Statism theory goes even farther by eliminating social factors such as norms, informal rules and culture; instead it emphasises the role of formal rules, procedures and standards that constrain individuals' behaviour and the operation of politics and the economy. According to these theorists, only states have the absolute power to "create, organise and regulate societies" (Przeworski, 1990, p.47). Some state-centred theorists argue that the state is autonomous from society (Hall, 1993), others even claim that the state dominates society and has the power to define the culture and economy (Przeworski, 1990). Skocpol (1985) offers a more balanced view on the role of states: they may be viewed as organisations through which different social groups seek to compete for their collective interests, but the states can also be perceived as configurations of organisations and actions that influence the politics of social groups and classes. 
There is also a stream of studies that focus on the role of individuals in policymaking. Elitists argue that public policy is shaped by the values and preferences of policy elites and that, due to the general conservatism of elites, changes in public policy will be incremental rather than revolutionary (Anderson, 1975; Dye, 1984). Elites, as defined by Genieys and Smyrl (2008), "are people who already hold positions of power and influence" (emphasis in the original) (p.22). They are "a minority of individuals whose preferences regularly prevail in cases of differences of preference on key political issues" (Dahl, 1958, p.464). Elite theory claims that the masses are passive, ill-informed and influenced by the elites, and thus public policy is seldom decided by their preferences. Elitists pay attention to personal motives and the pursuit of authority of elite actors in making policy change (Genieys and Smyrl, 2008).

Since Genieys and Smyrl (2008) focus on contemporary policymaking in Europe and North America, they highlight the competition for power among elites as the principal force for policy change. By this, the authors do not mean to reject the role of institutional structure. Instead, they claim that institutional structure can limit, slow down and redirect change (p.32). The notion of power competition might not fit well into an authoritarian state. However, their proposition that elites, who have 'legitimate authority' or dominant power, the power that enable them to issue orders and make others to obey, is quite useful to apply in my case. They note, "That a small number of individuals, regardless of time or regime, make decisions in the name of the great majority of their fellows is, we submit, self-evident" (Genieys and Smyrl, 2008, p.27).

Focusing on the key feature of elite model, that a minority can prevail over the majority, Anderson (1975) proposes that elite theory is of more value when it is used to explain policy formulation in developing and communist countries than in pluralist democracy states. This proposition suggests an emphasis on the role of policy leaders in my case study. In addition to the elite model, rational choice theory focuses only on the role of individual policy actors who make policy decisions. The theory assumes that policy actors pursue their self-interest and aim to maximise their benefits in making political decisions and policies. Thus, institutions should be structured to steer this self-serving tendency to serve the common interest of the society as a whole. This theory may fit into the politics of the United States where the fierce competition between the two major parties is critical in determining important public policy strategies. Again, this theory will not be as useful in other political systems, especially in authoritarian states where there is no formal 
institutional competition for executive power. However, the theory's notion of the underlying interests that guide policy actors' behaviour should be taken into account when analysing policymaking in my case.

In summary, both the state- and society-centred approaches to determinants of public policy have their limitations. Overemphasis on or downgrading the role of any factors of the state or social configurations will limit our understanding of public policy. In reality, there are situations when public policies, made by strong political will, regardless of social conditions, fail. States can sometimes also make autonomous decisions against the interests of dominant classes in society. A balanced view acknowledges the interdependence of state and society (Borras, 2001; Gilbert and Howe, 1991). Additionally, while some studies were quite ambitious for establishing causal theories and models of determinants of public policy, especially by quantitative methods (Dye and Robey, 1980; Hofferbert, 1974), recent studies takes a more cautious approach to comprehending influences on policymaking and implementation (Airey and Chong, 2011; Munira and Fritzen, 2007; WeaverHightower, 2014; Weible et al., 2012). Due to the involvement of 'mental states' (Berg, 2001) in policy process, this study will not make claims on determinants of public policy; rather it aims at an understanding of the interaction of influences on the policy process. Accordingly, this study draws on studies reviewed in this and the previous sections for key and relevant policy concepts and influences, while not always following the configuration of influences as described by the original authors.

Finally, a review of an individual-centred approach in this section suggests that attention should be paid to the role of policy elites when examining the policy process in a developing and communist country, like Vietnam.

\subsubsection{Literature on different stages of policy process}

To understand the influences on the policy process in the Da Nang case, I will need analytical devices to guide my examination of different stages of the process. Thus, this section will review the literature on policy agenda setting, formulation, decision making, implementation and evaluation in order to garner key guidance for my research.

\subsubsection{Agenda setting}

Except for the stage heuristic model, other models and frameworks mentioned in section 3.2.2 focus on the agenda setting, policy formulation and decision making stages of policy process. The institutional rational choice framework highlights the importance of individuals' interests while taking into account the influences of rules, norms and culture 
in explaining why a policy idea gets attention from policymakers and gets adopted. The multiple stream model emphasises the role of policy entrepreneurs in coupling different streams at the right time to produce policy outputs. The punctuated-equilibrium theory focuses on the pressure of change (focusing events or crises) to change the policy image in a policy subsystem and thus shift to a new policy equilibrium. The advocacy coalition framework postulates that change in policy belief systems or replacement of dominant coalitions will produce policy change. Diffusion models pay attention to policy learning. Finally, the funnel of causality models focus on socio-economic conditions in making policy. In sum, they all attempt to explain why policy change happens and what gets a new policy idea onto the policy agenda. Some of them are very useful and relevant for my case study, including the multiple streams theory and the funnel of causality models. In addition, the Outside Initiative Model, Mobilisation Model and Inside Access Model (Cobb, Ross, and Ross, 1976) are also useful to understand the relationship between state actors and the public in agenda building. The Outside Initiative Model captures a process where a policy issue is initiated in a nongovernmental group, then extended to the public for popular support before getting on formal agenda. The Mobilisation Model describes a process when a policy decision has been made inside a government and then is brought to the public to mobilise support for implementation. The Inside Access Model characterises a process where a policy issue is discussed and decided within the government sphere without any involvement of the public (Cobb et al., 1976).

\subsubsection{Policy formulation}

Policy formulation is a stage when different solutions for addressing the problem are identified and discussed (Howlett, 2011). Policy formulation is conducted with a consideration of technical and political constraints (Howlett, 2011; Howlett and Ramesh, 2003). Technical constraints include the feasibilities of technologies, financial, human and information resources while political constraints can consist of institutional arrangements, power capacity and political feasibility (Howlett and Ramesh, 2003). Policy actors involved in this stage are various (Howlett, 2011). Common actors include societal and state actors (iron triangles, issue networks, policy networks, policy communities, or advocacy coalitions) (Howlett and Ramesh, 2003) and especially policy advisers. Participants in this stage often have specific knowledge of the policy issues and thus usually belong to the policy subsystem. This stage of a policy cycle can consist of many activities, such as appraisal (collecting and considering data and evidence), dialogic (formal and informal communications among policy actors for solution discussion), 
assessment (evidence is considered to come up with some proposals), and consolidation (key policy actors select final solutions, taking into account all controversies, consensus and disagreements) (Howlett, 2011). These activities are aimed at tasks such as problem characterisation, problem evaluation, specification of objectives, policy options assessment and policy design (Turnpenny, Jordan, Benson, and Rayner, 2015). Some common tools used by policy actors in this stage are brainstorming, consultation exercises, risk analysis, checklists, cost-benefit analysis, scenario analysis, expert judgment and elicitation, financial impact analysis, cost-effectiveness and focus groups (Howlett, Tan, Migone, Wellstead, and Evans, 2015; Turnpenny et al., 2015).

These aspects of policy formulation will be given attention when studying my case, especially the technical and political constraints, the activities of policy formulation (discussion among policy actors relating to evidence, data and proposals) as well as analytical tools used in this case.

\subsubsection{Decision-Making}

Decision-making used to be considered as a result of a rational calculation by a decision maker assuming that he or she has no opponent in making the decision and is a rational calculator, while the setting is simple, the problem is well-defined, information is perfect and there is no time constraint. In this ideal condition, the final decision is the rational choice, the best option, the optimisation through careful calculations (unboundedly rational decision-making) (Forester, 1984; Howlett and Ramesh, 2003; Simon, 1955). In reality, there is no such perfect condition for decision-making. Policymakers always have to encounter many 'bounds', and, depending on "the types of boundedness of rationality" (Forester, 1984, p.26), different models of decision-making are developed. In real and complex decision-making conditions, decision makers might face the risk of miscalculation and suffer the constraint of time and information deficiency. They might as well have to negotiate with rivals or deal with complicated problem in an open environment. Thus, the decision-making can ultimately be a "satisfice", a "hedge", a "bargain", or an "incremental" choice (Forester, 1984, p.26). Incrementalists assert that policymaking is not merely a technical decision but a political one, and thus the chosen solution might not be the best technical option; rather it is a compromise of different political constraints. According to the author of the incrementalism model, policymakers tend to choose the option that is not substantially different from the status quo because radical changes might need too many resources and involve uncertainties that might be 
beyond the control of policymakers (Howlett and Ramesh, 2003). These models will guide the examination of decision-making in my case study.

\subsubsection{Policy implementation}

Two popular approaches are used to study implementation, namely top-down and bottom up (Sabatier, 1986). The top-down approach posits that once a policy is adopted, it is simply transferred to the bureaucracy for carrying out according to the preferences of politicians. A study conducted in a top-down approach will start with the policy decision and examine the extent to which the policy objectives have been achieved through implementation and what factors affect the policy outcomes. This approach assumes that policy goals and directions are clearly set by politicians and the administrators just need to faithfully implement them (Howlett and Ramesh, 2003). In reality, things do not happen in such an easy way. Policy can be vague, unclear and even contradictory; thus, it requires an interpretation by implementers who may be able to substitute their own preferences and interests for those of the decision-makers. This is when other policy actors (such as the public, target groups, the private sector, interest groups, street level bureaucrats) have chances to negotiate how policy is implemented in reality (bottom-up approach). The bottom-up approach pays more attention to the policy actors participating in the implementation and their strategies to pursue their objectives rather than the policy itself.

Sabatier (1986) attempts to combine the strengths of both approaches and suggests a synthesis: the starting point of this approach is the policy problem, then working further to identify the policy networks and their strategies to deal with the policy problem (a feature of the bottom-up approach). However, during this process, one needs to take into account the effect of changes in socio-economic conditions and legal constraints on policy actors' resources and strategies, as well as the way policy actors try to influence the policy decisions and adjust their strategies through policy-oriented learning (features of the topdown approach) (Sabatier, 1986).

In addition to the top-down and bottom-up approaches, studies of policy implementation also pay attention to the relationship between the politicians and administrators, in which the administrators are considered as the agents who carry out the principal's (politicians') decisions. In this relationship, the administrators often enjoy some discretion that leads to the separation of the realities of policy implementation from the objectives of policymakers (Howlett and Ramesh, 2003). Jenkins (1978) posits that administrators can affect or even control political actors, and thus influence the policy outcomes. He cites Ostrom's note: 
"Public administration rests squarely within the domain of politics. The public servant in a democratic society is not a neutral and obedient servant to his master's command" (Jenkins, 1978, p.64).

This principal-agent relationship is influenced by the nature of the policy problem, the target group and changes in social, economic, technological and political contexts (Howlett and Ramesh, 2003). If the policy problem is complex and the target group is large and diverse, policy implementation will be difficult, and thus the discretion of the administrators will be increasingly significant. During the implementation stage, if changes in policy context occur, they will affect how implementers perceive the problem and the way they carry out the politicians' decisions.

The top-down/bottom-up approaches and principal-agent theory in studying policy implementation suggest that students of public policy should pay attention to all relevant policy actors in the implementation stage and factors affecting their behaviour. Implementation should be considered not only as a stage where implementers put effort to achieve desired policy outcomes, but also a process in which policy learning occurs and becomes feedback for new policy cycles. An understanding of policy actors involved in this process and context factors (social, economic, political changes) is essential to understand policy implementation. These notes will be guiding lights for the examination of my case study.

\subsubsection{Policy evaluation and policy learning}

"Policy evaluation assesses the effectiveness of a public policy in terms of its perceived intentions and results" (Gerston, 2004, p.119). Once a policy is implemented, some type of evaluation will be undertaken. According to Howlett and Ramesh (2003), there are three types of evaluation: administrative, judicial and political. Administrative evaluation receives greater attention from students of public policy because it consists of comprehensive assessments of the performance, efficiency, effort, process and impact of the policy implementation (Howlett and Ramesh, 2003; Sharaput, 2012) and its outcome can be inputs for other policy cycles (policy learning) (Sanderson, 2002).

Policy learning, as Bennett and Howlett (1992) assess, "has been overtheorised and underapplied" (p.288). Many authors have attempted to examine policy learning from different perspectives. Their studies ultimately support the statist theory that policy change can be a result not only of societal conflicts but also of policy learning or, in other words, of knowledge and ideas (Bennett and Howlett, 1992). Sharaput (2012) asserts that 
"evaluation is most significant when it plays a role in policy learning" (p.247-248) and good policy evaluation can help policy actors to design better policy and improve policy implementation. My examination of the policy process will pay attention to the policy learning through policy evaluation within the case.

\subsection{Summary}

This chapter has reviewed relevant literature on public policy and policy process in Western countries. The review has showed that to understand public policy and policy process it is advisable to examine a range of influences, including the broad socioeconomic conditions, institutional arrangements and the network of policy actors involved in the process. Different models and approaches might place different emphases on a certain set of influences in different policy circumstances. However, the recent tendency in policy studies is to acknowledge the interdependence of various influences. Among prominent reviewed theories, models and frameworks, Hofferbert's (1974) funnel of causality model emerges as one that, with suitable elaboration, can embrace all potential influences on public policy and policy process. This model is therefore utilised to guide the investigation in my case study. However, it is worth noting that all the models discussed here were developed to understand and analyse policy process in relatively developed and democratic countries. Thus, it is necessary to modify them when applying to poorer countries and less democratic systems. This literature review has also indicated that the policy process in different political structure systems might be characterised by some special features and certain models can be more useful in examining the policy process in developing and communist countries, such as the elitist model. 


\section{Chapter 4: Policymaking in developing countries and the single communist party state of China}

\subsection{Introduction}

As noted in the summary of Chapter 3, there is a need for some modifications to Hofferbert's funnel of causality model to develop a sensitive research framework for a policy study in the developing economy and single party state of Vietnam. Grindle and Thomas's (1991) elite model is chosen as a good reference for policymaking in developing countries because this model has been empirically developed and utilised by scholars of policy studies in Vietnam, such as Dang (2013). This chapter will also review studies on policymaking in China. This body of the literature is selected as a comparative point of reference for two reasons. Firstly, Vietnam and China share many similarities in politics and policymaking since they are both influenced by Confucianism and have a common socialist background. Secondly, there is quite a large literature on policymaking in this country, which might yield significant suggestions for studying the policy process in Vietnam.

\subsection{Grindle and Thomas's elite model of policy process in developing countries}

By examining 12 case studies of policy reform in developing countries, Grindle and Thomas (1991) developed a model that pays significant attention to the role of policy elites in explaining "how, why and when policy and institutional changes occur" (p.2) in developing countries. Their model systematically combines two sets of variables: the policy elites (their values, experiences, perceptions, motivations, skills, and opportunities) and the contextual factors (historical, cultural, and constitutional contexts, coalitions, conflicts, opposition and support, constraints and opportunities) to explain policy reform. In this combination, the role of policymakers is more decisive than contextual factors, especially in developing countries where "information is limited, needs are great, resources are scarce, and responsibilities are extensive" (p.49). According to Grindle and Thomas, information for policymaking in developing countries is often inadequate and unreliable. As a result, policymakers have to rely on intuition and experience rather than data and evidence when making decisions. The condition of underdevelopment (a large proportion of the population living in rural areas, lack of communications, low levels of literacy) contributes to low public participation in policymaking and enhances the power of policymakers. The legacy of colonisation in most developing countries also strengthens the tendency of centralisation in politics and policymaking. These conditions lead to a 
consequence that policy elites play a much more decisive role in developing countries than in developed ones. Policy elites' perceptions can influence the content, timing and sequence of reform initiatives (Grindle and Thomas, 1991).

In an effort to combine the state- and society-centred approaches, the authors acknowledge that historical, political and institutional contexts also influence policy initiatives. These factors are important because "they shape the perceptions, options and actions of policymakers" (p.7). In brief, to understand the force of a reform we need a "systematic understanding of the values, experiences and perceptions of policy elites and the historical, political and institutional context within which they operate" (p.5).

Grindle and Thomas (1991) argue that when making decisions, policy elites will not only be affected by external factors but will also have their own evaluation within their 'policy space'. Their policy space can be narrow or wide, depending on decision makers' ability to utilise information and resources available to them. To understand policy elites, the authors suggest the need to understand their perceptions and the factors that affect their perceptions, which include "personal attributes and goals", "ideological predispositions", "professional expertise and training", "memories of similar policy experience", "position and power resources", "political and institutional commitments and loyalties" (pp.33-37). However, the authors argue that it is not easy to obtain information from inside the government in developing countries because their policymaking is not open to public scrutiny and thus it is difficult to assess the perceptions of policymakers. Still, Grindle and Thomas suggest that students of policymaking in developing countries should not focus only on examining policy elites' self-interest. Rather they should analyse policy elites' personal and professional values as well as their serious concern for public interest and social welfare (Grindle and Thomas, 1991).

In evaluating the relevance of this model in the Vietnamese context, Dang (2013) notes that the model reflects the fact that policymakers and managers in developing and transitional countries are relatively autonomous in the policy process. Their independent policy spaces mainly come from the underdeveloped conditions of the economy and the lack of policy coalitions, interest groups or strong civil society as well as the absence of competitive political rivals. Dang (2013) appreciates that 'ideological predisposition' can strongly influence policy elites' perceptions since ideological commitment to a socialist state and regime's core values are extremely important in Vietnam's political and policy 
environment. These values will largely determine what issues will be policy priorities, how they will be dealt with and what objectives the policy will aim to achieve (Dang, 2013).

Grindle and Thomas's (1991) model is particularly appropriate for the case of LIH policy in Da Nang City because it examines the role of policy elites "who have official positions in government and whose responsibilities include making or participating in making and implementing authoritative decisions for society" (p.59). Early evidence shows that the city leader demonstrated strong political will and personal characteristics that might greatly affect the making and implementation of policy. In addition to ideological predispositions, factors such as personal values and goals, memories of past policies or power resources can also be used to effectively explain the policy decisions of Da Nang City's leaders.

Dang (2013) also mentions some limitations of Grindle and Thomas' model. The first is that the model does not separate critical factors from non-critical factors as required for a good model. It also lacks an explanation for the interactive process of those causal factors (Dang, 2013). However, Grindle and Thomas indicate that while policymakers consider a wide range of criteria in making their decisions, only one or some play an important role in a specific decision context. In addition, the set of factors influencing policy initiatives is unique in any particular reform (Grindle and Thomas, 1991). This might be why the authors did not designate any specific factor as the most critical for all 12 case studies. However, it is worth noting that Grindle and Thomas's study is based on 12 case studies in 11 countries, none of which were governed by a communist party. Thus, party cadres, the most important politicians in communist party states, were not examined in Grindle and Thomas's study. This gap will be filled by examining the policy-making process in China and Vietnam. A further examination serves to build up a sensitive theory of policymaking in the Da Nang case.

\subsection{Policymaking in China}

\subsubsection{Different models have been modified and developed to study public policy in China}

Policymaking in China has been well studied. Different models have been applied to understand the process, including the rationality model, pluralist model, or institutional model (Lieberthal and Oksenberg, 1988; Zang, 2006). Tanner (1995) argues that it is not fruitful to use any particular theory to explain the policy-making process in China. Rather, he postulates that different models can be applied to understand different stages of the process. For example, the multiple streams theory is an appropriate framework to 
investigate agenda-setting stage. Meanwhile, the 'organisational politics model' best describes the incremental and consensus-building features of the drafting stages (Tanner, 1995).

Noticeably, an elitist model was utilised to emphasise the crucial role of top political leaders who drive the dynamics and directions of major policy changes, such as the Hundred Flowers campaign, the Great Leap Forward, the Cultural Revolution, or the postMao reforms (Lieberthal and Oksenberg, 1988; Zang, 2006). Lampton (2014) notes that Chinese government and leadership are affected by the traditional dynastic system and a strong culture of leadership. Leaders in China are expected to "understand, define, and act upon society's enduring interests"; they are even expected to "educate, persuade and perhaps even change popular inclinations" (Lampton, 2014, p.50). Due to this expectation, Chinese political philosophy pays particular attention to the nature and character of leaders. It is believed that the welfare of the people depends on the wisdom, capacities, and compassion of the leader, as well as of people working next to him. It is the leader's job to discern the people's interests and to adopt policies that serve those interests (Lampton, 2014).

Studies of policy elites in China have been divided into two schools. One claims that top leaders (such as Mao) aim for a completely dominant role over the CCP while the other asserts that top-level politics is factioned and no single leader or single group can dominate the whole party (Shih, Shan, and Liu, 2010). Shih, Shan and Liu's (2010) study findings show that a single leader can obtain absolute power during critically difficult times, such as when the country is under threat from external forces. However, after the 'life-and-death struggle' is over, no one single leader can continue to maintain such dominance. Instead, factional division becomes a typical pattern, reflected in political promotion of followers and purges of rivals and their supporters. However, the current leader, $\mathrm{Xi}$, is said to have returned to Mao's leadership style in wielding strong power. In fact, he is claimed to have consolidated more power than other previous top leaders, including Dang and Mao, and to have aimed for an authoritarian rule (Nathan, 2016). Nathan's analysis on Xi's leadership and Chan's (2010) examination of late Premier and General Secretary Zhao Ziyang's case show that Chinese leadership is complicated and nuanced. Chan asserts that informality is a special characteristic of Chinese politics and elites. Moreover, cultural dimensions, characterised by "ambiguities, contradictions and non sequiturs" (Chan, 2010, p.718) can affect elite politics more than other factors, such as personal power maximisation or constraints of rules and institutions. 
All of the models mentioned above are state-centred, emphasising political factors in determining public policy in China. Recently, new approaches have been applied to study the policymaking, including network theory (Zheng, Jong, and Koppenjan, 2010). According to these scholars, in addition to the decisive role of elites, new policy actors such as civil groups, think-tanks and intellectuals, the public, and international forces have participated in or influenced policymaking in China. In addition to political interests and policy network's influences, other studies also argue that efficiency in the use of resources in the market economy has become one of the critical criteria in making policy choices in some policy issues (Zang, 2006).

\subsubsection{Key characteristics of policymaking in China}

In a study of energy policymaking in China, Lieberthal and Oksenberg (1988) offer some observations about the characteristics of policymaking in China, which are also of value for studying public policy in other communist party states. Their findings suggest that the CCP plays a critical role, but that the structure of authority in the country is highly fragmented. As a result, policy initiatives often need the cooperation of different authorities. Consensus building, both vertically and horizontally, is therefore a feature of the process, requiring constant negotiations, bargains, and deals among agencies. Thirdly, policy process is often protracted, disjointed, and incremental. That means that policy matters often take a very long time to process and pass through many different agencies and policy changes occur gradually. The authors note that policy in China is not reflected in a single decision, rather, it is located in a string of decisions made by different levels of the authority structure (Lieberthal and Oksenberg, 1988). Tanner (1995) confirms the crucial role of the CCP, the decisive influence of a top leader's endorsement for a policy idea, the influential effect of a successful local experimentation on national policymaking, and the incremental and consensus-building features of the process. He also adds the feature of increasing participation of new policy actors in policymaking in China.

Similar to Lieberthal and Oksenberg (1988), Zheng, Jong, and Koppenjan (2010) highlight the dominant role of the CCP and the hierarchical but fragmented structure of authority in policymaking in China. In addition, they note that personal networks are very important in Chinese politics and acknowledge the limited role of independent civil groups in the country. According to these authors, a closed policy process allows policy elites to push their pet policy ideas through the system without encountering serious opposition. The 
authors note that the country has a "long history of elites leading the public" (Zheng, Jong, and Koppenjan, 2010, p.414).

Overall, the policy process in China is characterised by the crucial role of the CCP and elites, a fragmented structure of authority that requires consensus building vertically and horizontally, a slow and incremental process of change and influences of informal relationships.

\subsubsection{Policy studies on the relationship between central and local government in policymaking in China}

Among the key characteristics of policymaking in China, the role of policy elites and the relationship between central and local government gained great attention from scholars. While the elitist model has been reviewed in section 4.2.1, this section will examine the second important characteristic.

Lieberthal and Oksenberg's (1988) findings on the relationship between the central and provincial levels in China are similar to Vietnam's system. Firstly, the top leaders of provinces and cities in China are very powerful and skilful in dealing with the centre. Since directives from the centre are numerous, diverse, and sometimes contradictory or vague, provincial leaders have to choose carefully the ones to follow and the ones to neglect safely (Lieberthal and Oksenberg, 1988). Secondly, some provincial leaders choose to be agents of the centre, leading their localities in ways intended to please their central bosses, while others can be local defenders, protecting their local interests. The middle strategy is trying to survive between the pressures from both the centre and the local people. Thirdly, the centre can impose some control on the provincial level by using their authority in personnel arrangements, military strength, propaganda apparatus and economic resources. At the same time, the provincial level can also enjoy some autonomy, supported by local resources such as culture, human, land, and local enterprises. However, it is noted that the balance between the centre and provinces varies significantly among localities. The degree of local autonomy depends on the characteristics of local leaders, their personal relationships with top leaders in the centre, the level of economic development and the proximity to Beijing. Although this study is relatively dated, its findings, especially about the power of local leaders and the resources for local autonomy, are still relevant and applicable for my case study. Recent trends in central-local government relationships in China are further discussed below. 
Zheng, Jong, and Koppenjan (2010) assert that the Chinese political system is "comparatively centralised" so that local activities and initiatives are not very important but local governments do enjoy some discretion, reflected in "passive resistance and unspoken refusal" (p.413). Like Lieberthal and Oksenberg, Zheng, Jong and Koppenjan (2010) postulate that relative independence in financial issues gives local authorities some autonomy in expenditure and policy initiatives.

The study of central-local relationships helps explain policy changes in China. There has been a debate about whether policy is a result of conscious and goal-attaining policy design made by the central government or of an experiment-based policymaking initiated mainly by local actors (Mei and Liu, 2014). Heilmann (2008) offers a balanced view by proposing an 'experimentation under hierarchy' model to explain the important role of both central and local levels and the interaction of the two. According to this model, the central government sets out the general policy objectives, while local levels will work out what policy instruments work. Local experiments will be selectively developed by central policymakers to scale up into national policies (Heilmann, 2008; Mei and Liu, 2014). In a study of underlying incentives of local policy innovation, Teets (2015) presents two popular approaches in explaining what motivates local policymakers to experiment with new policy ideas, namely the 'experimentation under hierarchy' and the 'local needs' or 'pragmatic motivations' approaches. The experimentation under hierarchy approach explains that local policy experimentation is driven by local officials' desire to please central bosses, to be promoted or to obtain other career success. The local needs approach postulates that local policymakers try out new ideas when facing governance difficulties. Teets argues that the number of local policy innovations is increasing because local officials are learning that policy innovation is a good strategy to get promoted and to solve local problems. They learn from others' successes that adopting policy innovation can help in career advancement because these experimentations are good signs to "distinguish oneself from the other cadres" (Teets, 2015, p.95). Meanwhile, the central government also signals its encouragement for local policy innovation by using policy experimentation as one of the criteria for promotion when designing the cadre evaluation system (Schubert and Heberer, 2015; Teets, 2015).

In short, the relationship between central and local government is complicated and varies among localities. Local authorities can enjoy some room for manoeuvre and their experiments can be scaled up to be national policies. The extent of local autonomy largely depends on the local leaders and geographical and economic position in relation to Beijing. 
Local policy experimentation has become one of important criteria in political promotion and thus, pushed policy innovation in lower levels in China.

\subsubsection{Other useful studies}

Among various studies investigating policymaking in China, Airey and Chong (2011) might be the one that focuses most similarly to my case. The authors use the case of tourism-policymaking post-1978 to understand the factors affecting the policy process in China. According to them, tourism-policymaking in China is affected by an 'interactive coalescence' of different factors, including ideological orthodoxies, the normalisation of diplomatic relationships with other countries, the need for foreign exchange, the initiatives of top leaders, and a shift in the tourism policy paradigm from political and diplomatic orientation towards economic ends (Airey and Chong, 2011). Airey and Chong use Hofferbert's (1974) funnel of causality model to explain the interaction among factors. However, the authors do not use Hofferbert's terminology of policy influences, instead they invent their own variables for the investigation. The authors highlight the important role of ideology, the tourism policy paradigm, tourism institutions, and policymakers. According to Airey and Chong, the relationship between ideology and the tourism policy paradigm is 'interdependent' while that of the tourism policy paradigm and institutions is 'synergistic'. In addition, in the hierarchical but fragmented authority structure of China, policymakers play a crucial role. They construct ideas from policy-oriented learning, "within which ideological orthodoxies, the policy paradigm and organisational roles form the interpretation prisms for them to understand their surroundings and to shape the policy initiatives" (Airey and Chong, 2011, p.259). The authors also mention the need for coordination among different authorities in making policy in China. Policy-oriented learning and cooperation are the "two independent but interrelated and indispensable components" (Airey and Chong, 2010, p.311) of the policy process in this case. In a context when ideological orthodoxies, policy paradigms and institutions change rapidly and new ones are not fully established, the role of elites becomes critical in initiating new policy ideas and policy paradigms, and trying out institutional experiments. Overall, the authors emphasise the interaction of those factors in driving tourism-policymaking in China. This study also confirms the appropriateness of Grindle and Thomas's (1991) elite approach in studying factors affecting policy process in developing countries. 


\subsection{Summary}

Consistent with Anderson (1975), Grindle and Thomas's (1991) elite model suggests that studying public policy in developing countries should pay special attention to the role of policy elites. This model also offers some suggestions on factors affecting policy elites' decisions, which is useful for studying the role of policy elites in the Da Nang case. They include personal values and goals, political will and determination, memories of past/similar policies, power resource and personal characteristics. In addition, studying policymaking in China reinforces a proposition that studying factors affecting the policy process should take notice of a combination of different factors and the interaction of them in driving policy changes. Moreover, the literature also suggests some crucial points in studying policymaking in a single-party and Confucius-influenced country, including the important role of the communist party and its ideologies as well as the decisive role of political leaders. Finally, the interaction of central and local government in the unitary but fragmented China is also a good lesson to apply in studying the policy process in Vietnam. 


\section{Chapter 5: Policymaking in Vietnam}

\subsection{Introduction}

This chapter will examine the literature on policymaking in Vietnam in order to finalise a framework for the investigation of policy process in the Da Nang case. Before doing so, it is useful to have a look at the formal structure of the country's political institutions (at the time of this case study) and then further examine previous studies of the country's politics and policymaking in order to capture key characteristics of the system for constructing the initial analytical framework. This examination also pinpoints the gaps in the literature on policy studies in Vietnam which this study can address.

\subsection{The political institutions of Vietnam}

The state in Vietnam in a broad sense consists of the CPV, the state apparatus and the network of Party-directed mass organisations (London, 2014) (Figure 5.1).

\subsubsection{The Communist Party of Vietnam}

The CPV's origins can be traced to 1925 when Ho Chi Minh established the Vietnamese Revolutionary Youth League in China. This organisation had many changes in its names, organisation and operation styles (clandestinely or publicly) before being renamed the CPV. Its unarguably crucial role in leading the country through two consecutive wars with the French and the Americans, in protecting the southwest border from the Khmer Rouge and in fighting against the aggression from China, secured its prestige and legitimacy in Vietnam. Though its chosen economic development model in the post-war period proved ineffective, the CPV retained its supremacy by directing the country to undertake economic renovation. The supremacy of the CPV has been guaranteed in the country's constitutions (1980, 1992, and 2013). According to these fundamental laws, the CPV is 'the leading force of the State and society'.

So far, the CPV has monopolised all economic and political decision-making (Abuza, 2001). It has maintained absolute power in "access, use and allocation of resources", in "redistribution of economic benefits", and in "granting political perquisites and social status" (Vu, Dapice, Nguyen, and Do, 2016, p.11).

The CPV's highest organ is the Party National Congress, which decides important policy issues and chooses the central leaders of the Party. The Central Committee of the CPV $(\mathrm{CCOM})$ is elected by the National Congress to implement the latter's decisions between the congresses. The CCOM is the most powerful institution in the Party. It elects the 
Politburo, the General Secretary, the Secretariat and the Central Inspection Commission.

The Politburo is the highest leadership institution of the Party between the CCOM's plenums. Its responsibility is to implement resolutions and policies of the National Congress and the CCOM. Members of the Politburo hold the most important positions in the government system.

The General Secretary is the highest post within the CPV and is elected by the CCOM. The General Secretary and the Politburo are the most powerful groups in Vietnam (Dang and Beresford, 1998). Under the Politburo are the Party Secretariat that deals with daily Party issues and some Party committees. Before Doi Moi, Party committees were organised in parallel with ministries. Each committee closely oversaw the activities of one or several ministries. Since Doi Moi, the number of these committees has shrunk. They are also no longer able to intervene deeply in the ministries' activities. The Party system's operation is funded by the state budget. This expenditure does not require approval by the NA. Some Party business enterprises also contribute finance for the Party's activities (Dang and Beresford, 1998).

According to London (2014), the Politburo and its Standing Committee have the "preeminent decisional" power in Vietnam (p.6). However, Malesky Abrami, and Zheng (2008) point out that Politburo's decisions have sometimes been overruled by the CCOM. Former Prime Minister Vo Van Kiet described the CCOM as a legislature and the Politburo as an executive of the CPV (Malesky, Abrami, and Zheng, 2008). Thus, Malesky et al. (2008) claim that the CCOM is a relevant forum for decision-making in Vietnam.

\subsubsection{The state apparatus}

\subsubsection{Central level}

At central level, the state apparatus consists of the NA, exercising constitutional and legislative powers; the President, acting as the Head of the State and representing the Socialist Republic of Vietnam internally and externally; the Government, led by the Prime Minister, holding executive power; and the Supreme Court and Supreme Prosecution, exercising the judicial power. All these bodies are under the leadership of the CPV. Although the constitution states that the NA decides fundamental issues of the country and exercises the supreme power of supervision over all state activities, this institution used to be described as the 'rubber stamp' of the Party's policies (Thayer, 1993, cited in Gainsborough, 2005) because all of its decisions were pre-arranged (N. T. Nguyen, 2015). Since the Party retreated from intervening in the government's administration from Doi 
Moi, it has encouraged a more powerful NA to put a check on the administrative system, particularly on the Prime Minister (Schuler, quoted in Ives 2016). Livelier debates and closer supervision of the administration have been conducted by some of the NA's deputies. Some out-of-plan decisions have been passed (N. T. Nguyen, 2015), thanks to the increasing number of full-time deputies, longer sessions, and more substantive deliberations (Vasavakul, 2014). However, in general, the NA has less real power than the executive branch and is still struggling to increase its legislative capacity. Its composition of deputies remains problematic, with too many deputies from the CPV and administrative system and with deputies who lack of knowledge, experience and an active attitude toward participating in debates (Huu Kha, 2016). Overall, the NA is still considered a deliberative body under the control of the Party (London, 2014).

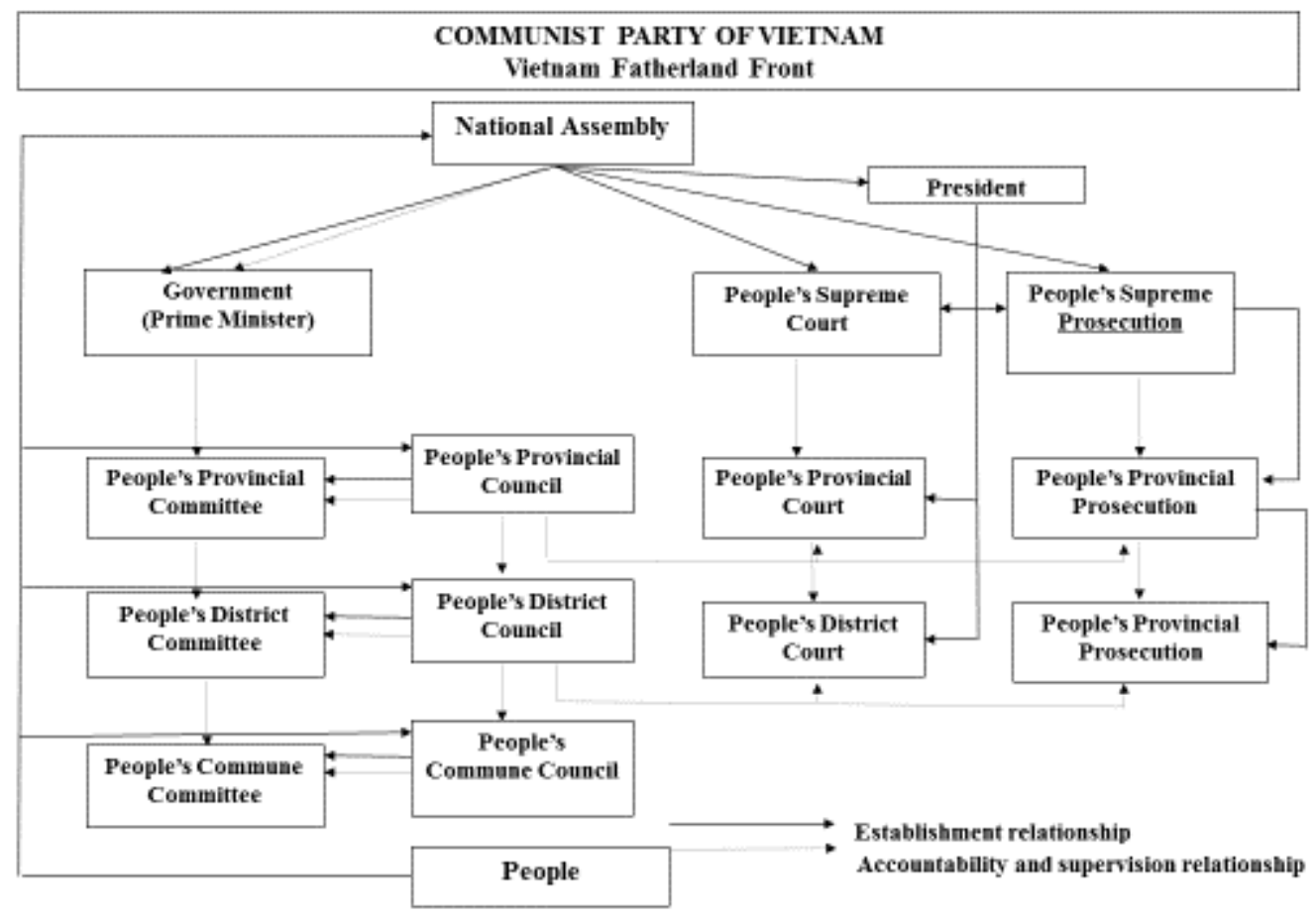

Figure 5.1: The structure of government in Vietnam

\subsubsection{Local level}

At provincial and district level, the state apparatus consists of the People's Council (PCl), the People's Committee (PCe) and local branches of People's Court and Prosecution. The $\mathrm{PCl}$ and $\mathrm{PCe}$ are organised to commune level but there are no judiciary organisations at this lowest level.

\section{The People's Council}

The Constitution 1992 states that "the $\mathrm{PCl}$ is the state authority institution at local level; it 
represents the will, aspirations, and mastery of the people $;{ }^{6}$ it is elected by the local people and is accountable to them and to the superior State institutions" (Article 119).

The $\mathrm{PCl}$ practises its role through its meetings, the activities of its Standing Committee and other special committees and its deputies' work. Meetings are the most important form of the PCl's activities. Regular meetings are held twice a year. The PCl's meetings are public; some sessions of them are broadcast on local television channels.

The Standing Committee of the $\mathrm{PCl}$ is elected by the $\mathrm{PCl}$ and consists of a Chairperson, a Vice-Chairpersons and members. These people must not hold any position in the parallel $\mathrm{PCe}$ at the same time. The provincial PCl establishes three committees, responsible for economic and budget issues, social and cultural issues, and legal affairs. There may be a committee for ethnic issues where residents are diversified by ethnic groups (Law on Organisation and Activities of the $\mathrm{PCl}$ and $\mathrm{PCe}$ ).

The PCl's deputies' official responsibilities are to collect and present the will and aspirations of local people to the $\mathrm{PCl}$, protect the people's legitimate rights and interests, and report their activities to the people and answer their questions and recommendations (Law on the Organisation and Activities of the PCl and PCe). Most of the PCl's deputies work part-time (Vasavakul, 2014). This fact significantly affects the quality of the PCl's activities, because too many part-time deputies have not been able to devote enough time to the job; some of them lack necessary knowledge and experience in making local polices and undertaking supervision.

\section{The People's Committee}

The PCe is the executive agency of the PCl; elected by the PCl. Its responsibility is to implement the regulations of higher state organs and execute the PCl's resolutions. It is accountable to the $\mathrm{PCl}$ and the higher-level administrative agencies.

A provincial PCe is led by a Chairperson, Vice-Chairpersons and other members. A PCe decides major local issues by collective discussion and majority voting (Constitution 1992). This collective decision-making mechanism makes the role of the Chairman of the PCe quite limited (Dinh, 2013). As a result, it is not easy to distinguish the responsibility of the PCe as a collective body and the responsibility of the individual leader (Bui, 2013).

A PCe has an administrative office and some functional divisions, such as Division of

\footnotetext{
${ }^{6}$ The Constitution 1992 provided that all the state authority belongs to the people. Thus, people are often referred as the masters of the country.
} 
General Affairs, Division of Economic and Budget Affairs, Division of Social and Cultural Affairs, Division of Urban Management, Division of Personnel and Organisation, or Division of Legal Affairs and other supporting teams. These divisions are the professional and administrative assistant teams of the PCe's members.

Provincial PCes' functional agencies comprise departments and other agencies that directly exercise the administration in certain sectors. They are accountable both to the local PCe and to the line ministries.

All local state agencies are under the leadership of the local Party. Each provincial Party unit is organised in the same pattern as the central level: the most important decision maker is the Provincial Party Congress, which is held every five years; the Provincial Committee of the CPV (Thanh uy/Tinh uy), which exercises the Party leadership between the Provincial Party Congresses; and the Party Secretary. The Provincial Party Secretary is often a member of the CCOM.

\section{The legal framework for making policy at provincial level in Vietnam}

\section{The procedures of issuing resolutions by the provincial $\mathrm{PCl}$}

According to the Law on the issuance of legal regulations of PCls and PCes (2005), the $\mathrm{PCl}$ passes resolutions on 1) policies and measures to implement superior state agencies' regulations; 2) plans of socio-economic development, local budget execution and local issues of national defence and security; 3 ) measures to stabilise and improve the people's living conditions; 4) local initiatives to promote the locality's development within its authority; and 5) other issues regulated by superior state agencies.

The PCl's resolutions are drafted by administrative agencies, based on the Party's policies, superior state agencies' regulations, local situations; and other relevant information. Resolution drafts must be appraised by the Department of Justice (DOJ) and functional committees of the $\mathrm{PCl}$ before being discussed and voted on at the PCl's meetings following the simple majority rule.

As presented above, the $\mathrm{PCl}$ seems to play an important role in local politics with the decision-making power on key issues. In reality, the extent of the PCl's authority is not always as stipulated by the law, because the PCl's activities are constrained by limited resources of finance and information, which are supplied mainly by the administrative system (Vasavakul, 2014). The PCl's skills and capacity in policymaking are also still inadequate (United Nations, 2004). The fact that the PCl meets only twice a year with 
limited working time to cover many issues further undermines the quality of the PCl's activities (Wit, 2007). Above all, the PCl is closely controlled by the local Party. Its decisions, in fact, are the legal form of the Party's policies and, as Vasavakul (2014) comments: "Under one-party rule, there remains a gap between the legal stipulation of powers and authority on the one hand and actual practice on the other" (p.52).

In any $\mathrm{PCl}$, there is a Party unit whose members hold key positions in the PCl. This Party unit meets and discusses important issues before any $\mathrm{PCl}$ session. In addition, a member of the Standing Committee of the provincial Party units holds the position of Chairperson of the PCl. Thus, the space for the PCl to make any decision that is out of the Party's control is not significant. The $\mathrm{PCl}$, as perceived by Vasavakul, is increasingly supported by the Party to become a real accountability agency "to curb the rising power" (Vasavakul, 2014, p.62) of the executive branch, but the outcome of this task remains problematic.

In a report, the $\mathrm{Ha}$ Noi $\mathrm{PCl}$ admitted that its formal power and responsibilities as regulated by the constitution were very significant but its actual power was very limited. The Ha Noi $\mathrm{PCl}$ was sometimes unable to exercise legal power in reality. In addition, its supervision power was not effective due to the formal nature of this activity (Ha Noi People's Council, 2013).

The procedures of issuing decisions and directives by the provincial PCe

The PCe is responsible for the implementation of laws and regulations, the approved plans for socio-economic development, the execution of budget, and other assigned duties in its locality. The PCe issues decisions and directives to exercise its budgetary and administrative responsibilities. The drafts of these documents can be prepared by the PCe's offices and functional divisions within the PCe. However, most of them are prepared by functional departments and agencies. These drafts are also appraised by the DOJ and the PCe's functional divisions before being voted on by the PCe (Law on the issuance of legal regulations of $\mathrm{PCl}$ and $\mathrm{PCe}$ in 2005).

PCes have recently been granted more authority in planning, budgeting and human resource management. This autonomy coupled with economic development opportunities has led to some cases of fence-breaking. As mentioned above, to control this trend, the central government required PCls to promote their role in holding PCes accountable through reporting activities, appraising the legal validity of local regulations, and supervising implementation of PCes' plans and budgets (Vasavakul, 2014). However, Vasavakul asserted that this increasing role of the $\mathrm{PCl}$ does not really strengthen the $\mathrm{PCl}$ 
as a local representative body to protect the people's interest. Rather, it is promoted to ensure that decentralisation of government management will not lead to uncontrollable local autonomy. In any event, the power of the local executive branch should arguably not be exaggerated because in fact the administrative system is deeply penetrated by the Party apparatus (London, 2014). The fact that the Chairpersons and Vice-Chairpersons of the $\mathrm{PCl}$ and the PCe are members of the parallel Party's Standing Committee proves that the Party can overwhelmingly control the activities of the $\mathrm{PCl}$ and the PCe. The same pattern can also be found in other state agencies, including functional agencies of the PCe. With Party members holding the key positions of all state agencies, the Party, in fact, controls the whole state apparatus and has a critical role in determining key policies. Meanwhile, the PCe has some increasingly significant power in implementing polices in reality.

In sum, though formal regulations identify the legislative authority of PCls and the executive power of PCes at local level; in reality, the real power is held by the Party Standing Committee and Party Secretary. Thus, when examining the policy-making process in a local government in Vietnam, it is advisable to pay great attention to the role of the local Party and its head. Also, it is commonly agreed that, though the authority of the PCls, as regulated by law, is significant, the actual authority is informal and less tranparent than formal declarations.

\subsubsection{A brief note on the value of these institutions' legal documents}

Though the Party's resolutions have no legal authority, in reality, their value underpins all legal documents. Most policy initiatives are introduced by resolutions of the Party National Congress or CCOM. These resolutions are then often cited in the preamble of the NA's constitutions, laws or ordinances. The constitution and its amendments are the fundamental laws of the legal system, which provide primary principles in political, economic, and social relations as well as basic rights of citizens in the country.

In each policy sector, the NA's laws or ordinances of its Standing Committees are the highest legal documents, providing principal regulations in a specific policy area. However, laws and ordinances cannot be applied directly by local government, organisations and citizens. They need to be guided by the Government's resolutions, decrees or decisions. In their turn, government regulations are often elaborated by ministries' directives or circulars. Since the legal system is still developing, there are also some policy issues that have not been covered by any NA law or ordinance. In this case, the government might promulgate resolutions, decrees or decisions to regulate the issues. 
These documents are also usually followed by guidance for implementation by relevant line ministries. The Prime Minister's decision or directives often regulate a specific policy issue that is not important or popular enough to be regulated by a law, an ordinance or a decree. Based on these central legal documents, local governments will issue resolutions and decisions to implement them in their localities.

A typical general policy issue is regulated by a framework of an NA law, some Government decrees, several line ministries' circulars and, locally a PCl resolution and some PCe decisions or directives (Figure 5.2). The detailed contents of a policy are mainly prepared by line ministries in the form of draft government and NA regulations. These drafts are discussed and approved collectively at the cabinet and then ratified by the NA.

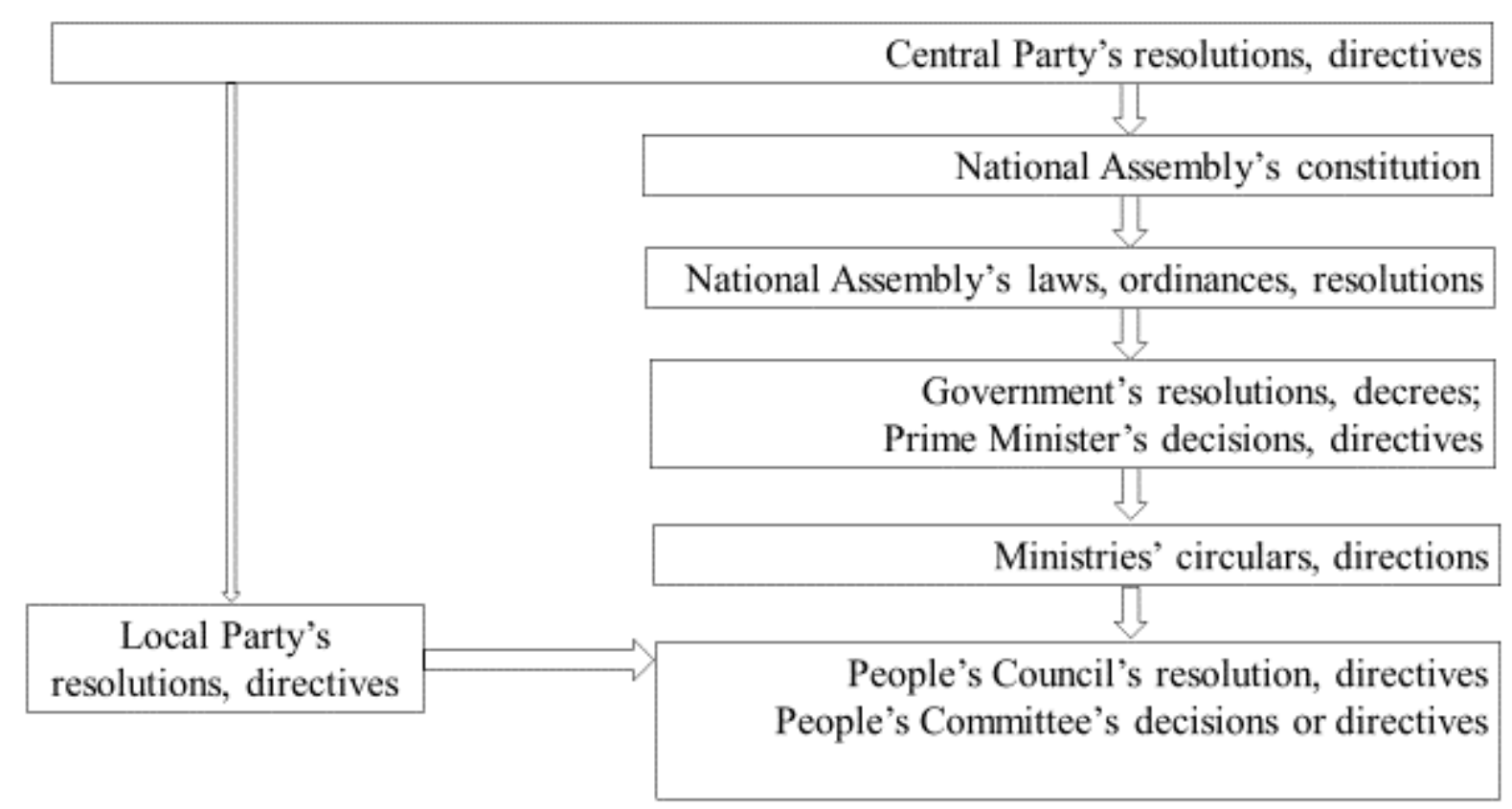

Figure 5.2: Policy documents and the hierarchy of their value

\subsubsection{The mass organisations}

The Vietnam Fatherland Front is the broadest mass organisation in Vietnam. Its members include socio-political organisations (the General Federation of Labour, the Farmer's Association, the Communist Youth League, the Women's Union, and the War Veteran's Association) and other social, professional, religious organisations as well as individuals. The CPV and the Vietnamese People Armed Forces are also members of the VFF, but the VFF is under the leadership of the CPV. 
The VFF and its five socio-political members are organised at central and all local levels, in parallel with the government apparatus. These mass organisations present the people's voice to the Party and the state and participate in the task of propaganda and mobilisation (Law on the VFF). The VFF has a significant role in elections of parallel legislative bodies because almost all candidates for the NA and local PCls have to be nominated by the VFF. This nomination is also required for other key personnel of those bodies. Another important role of the VFF is that its President and local heads can be invited to attend and contribute opinions in meetings of parallel legislative and executive bodies. Local PCls and PCes have to report their activities to parallel VFFs and respond to VFF questions and requests.

\subsection{Literature on policymaking in Vietnam}

The above section sketched out the government structure consisting of formal actors of policy-making process in Vietnam. It also reviewed the official procedures for policymaking at provincial level. In reality, the process can involve other policy actors and might be characterised by other informal norms and rules. The following section consists of a summary of key characteristics and other actors involved in the process, a review of some studies on policymaking in Vietnam, and an examination on the relationship between central and local government. They all serve to identify the knowledge gap for my investigation as well as to garner sufficient knowledge guiding my research.

\subsubsection{Key characteristics of policy-making process in Vietnam}

\subsubsection{The paramount role of the CPV}

As presented in the previous section, Vietnam is a one-party state under the rule of the CPV. The CPV exercises its leadership in policymaking mainly through its personnel arrangements and outlining key policies. Its personnel arrangements are based on the principles that all key positions in the government system must be held by Party members and that all organisational and personnel issues, especially promotion, must be approved by an authorised Party unit. The Party organises its 'units' within every single state agency. With this extended network of members that deeply penetrates into the state apparatus, no policy issue is actually discussed without the Party's observation and intervention when needed. As a result, "anything being submitted to the CPV for formal approval could hardly come as a surprise" (McCarty, 2001, p.13).

Equally important, the Party plays a crucial role in adopting major policy changes. All important policy initiatives must be approved by Party resolutions before being legalised by state laws and regulations. "The government is viewed as a structure through which 
Party agreed policy is implemented" (McCarty, 2001, p.4). The Party also undertakes a close supervision of the operation of the government and applies all necessary sanction measures to maintain the Party's desired orders.

Since Doi Moi, the CPV claims that it has retreated from intervening in the government's activities by reorganising Party committees that oversee the government's activities, changing leadership style and respecting the legalisation of Party resolutions by government's legal documents (Vasavakul, 2002). The Party also aimed to correct the situation when Party cadres operate regardless of laws and "ride roughshod over" (Gainsborough, 2012, p.35) the government, especially representative bodies. This shift was reflected in a Party motto: "The Party leads, the state manages and the people exercise their mastery" (Dang lanh dao, nha nuoc quan ly, nhan dan lam chu). Studies of Vietnamese politics record changes in some areas. For example, the NA has become more important in making laws and regulations. It is "no longer a rubber-stamp institution" (Gainsborough, 2005, p.9) of Party policies. Instead, livelier debates can be observed in the debating chamber. In addition, decentralisation also decreases the overarching role of the central Party and grants more authority to lower level governments. There is also an increasing independence of people from the Party and state, thanks to the emergence of the private sector. However, Gainsborough (2005) claims that those changes do not reflect the whole nature of Vietnamese politics. To him, the 'continuity' is still present in many aspects of political life and the Party will never trade off its supremacy for any reform. Elite political culture and a paternalistic approach in treating the people are still dominant in the Party's leadership. All conflicting political ideas will be suppressed and treated as 'anathema' (Gainsborough, 2005).

In general, the distinction between the Party's leadership and the government's administration in Vietnam is still very opaque (Arkadie and Mallon, 2003; McCarty, 2001). The activities of the Party and the state sometimes overlap. Recently, under the threat of corruption and economic mismanagement, the Party re-established the Committee of Internal Affairs and the Committee of Economic Affairs in 2012 to monitor the government's activities (Vu, 2015).

\subsubsection{Collective leadership and consensus-based decision making}

Before Doi Moi, the role of individual leaders was dominant in Vietnamese politics. Ho Chi Minh and his successor, Le Duan, were the two most prominent figures in Vietnam because of their pivotal roles in the wars. In Rama's (2008) study of the policy process of 
Doi Moi decisions, Le Duan, though having some reformist views, was implicitly blamed for the mistake of the autarkic approach in the centrally planned economy. ${ }^{7}$ Thus, after he died in 1986, several months before the $6^{\text {th }}$ Party National Congress was convened, "strong individual leadership" (Rama, 2008, p.20) was no longer dominant since it embodied a risk of making incorrect policy choices. The death of prestigious leaders and the decline of the Party's legitimacy due to the economic crisis and the Cambodian war led to the emergence of a new 'checks and balances system' to control the Party's policy-making process (Malesky et al., 2008). From 1986 onwards, individual leaders could no longer impose their decisions on the whole Party. Instead, collective and consensus-based leadership became the primary mechanism in policymaking in Vietnam.

This style of leadership requires that all decisions must be collective: discussed and decided based on the will of the majority of members of authoritative bodies. At central Party level, no major policy change can be adopted without a consensus of top leaders who have veto power ( $\mathrm{Vu}$ et al., 2016). In addition to the decisive role of several key politicians on stage, retired top leaders, who shifted to hold positions in the 'Advisory Commission of the CPV', also had veto power in major policy changes (Vu et al., 2016). This type of leadership was expected to achieve "solidarity over division" (Rama, 2008, p.21). Rama (2008) notes that collective leadership was a key factor that made the reform process in Vietnam quite politically peaceful.

Following the collective leadership principle, the NA, the Government, the PCls and PCes at all levels are required by law to make key decisions by a majority vote. The consensusbased principle is also reflected in cooperation among government agencies. If an issue relates to several ministries or departments, there should be a consensus of these organisations before sending a recommendation to the authorised person, such as the Prime Minister or the Chairperson of a PCe, to make a decision.

Consensus-based policymaking also involves a process of "opinion collecting" (Arkadie and Mallon, 2003, pp.57-58). This requires that relevant and affected organisations and individuals must be consulted before the issue is concluded. However, it is worth noting that these opinions are definitely scanned and filtered through the Party's ideologies and policies before being taken up for revising the drafts. The opinion collecting process is one of some limited methods the Party applied to show the democratic features of the regime

\footnotetext{
${ }^{7} \mathrm{He}$ was the author of the slogan 'every district is a fortress' which reflected the autarkic approach in the centrally planned economy.
} 
(Gainsborough, 2012), which McCarty calls a "managed democracy" (p.5), a special feature of "consensus governance Vietnam-style" (McCarty, 2001, p.4). This managed democracy enables the voice of the masses to be heard in a fashion that will not threat the Party's control. In addition, McCarty also points out that, under the leadership of the CPV, the tripartite style of government structure became irrelevant. There is no need to separate the powers of legislature, executive and judiciary branches when the Party is the ultimate decision maker, mobilising all available suggestions through extensive consultations. The three branches of state power are still organised but they are 'decentralised' to exercise state power within their jurisdictions in a cooperative style instead of a competitive spirit. This is the most striking characteristic of "consensus governance Vietnam-style" (McCarty, 2001, p.3-4).

Collective leadership is encouraged because it works in sharing responsibility and reducing risk in making difficult choices; it also maintains political stability and involves some societal elements in making decisions (Arkadie and Mallon, 2003). However, this consensus-based principle also slows down the policy process, especially in implementation stages when cooperation and coordination among agencies is often difficult to achieve (Arkadie and Mallon, 2003; McCarty, 2001). Evidence shows that an objection of even one leader could delay a policy idea for years (Vu et al., 2016).

\subsubsection{Secret nature of the policy process}

The CPV had a history of working clandestinely for some periods during the wars. This secretive style continues to dominate the regime's operation at present. Contemporary studies about the relationship among authorities and policy process are mostly based on secondary data available in the media (subject to the censorship of the CPV) and from selectively published governmental documents and Party statements. Some more detailed insights into state activities can be found in studies funded by donors and aid agencies who have been provided information for their policy consultancies. However, knowledge about what actually happened within the Party is still rare. Two exceptions are a study conducted by Rama (2008) who was able to interview one of the prominent leaders in Vietnam about the Doi Moi policy process, and Huy Duc's The Winning Side (2012) which provides ample insights into Vietnamese politics, thanks to the time the author served in the army and his work as a well-known journalist in Vietnam, although his attitude to some politicians and his political tendency are still controversial matters. As Arkadie and Mallon (2003) observe, in a closed regime discussion is often going on behind the scenes, thus, it 
is hard to know what is said. The policy-making process is not well understood, even by people within the government system (Arkadie and Mallon, 2003).

\subsubsection{The role of other policy actors in the policy-making process}

\subsubsection{Role of elites}

Vietnam went through centuries of feudalism with the rule of royal families. It was also led by a paramount leader: Ho Chi Minh. Thus, “elitism and paternalism” (Gainsborough, 2012, p.38) are undeniably persistent remnants of Vietnamese politics. Vietnamese people still expect and believe in the benevolence of leaders in governing the country. Ho Chi Minh has always been considered 'the father of the country'. However, in the two decades after Doi Moi, praise of individual leaders became less common. Gradually, Vietnamese politicians became colourless. It is difficult to identify a single dominant political figure since their public appearances were mainly attached to their formal roles. Even when some prominent reformers appeared in media, their existing formal responsibilities rather than their personalities were in focus. In recent years, the country's media has given a lot of space to the daily work of two provincial leaders, namely Mr Nguyen Ba Thanh (Party Secretary of Da Nang City before 2003) and Mr Dinh La Thang (Party Secretary of Ho Chi Minh City from 2016 to 2017). Their personal characteristics were given attention and their actions were publicly praised, even though many of their decisions are far from being classified as special for their jobs. A writer called these appraisals "a fever in the society" (Nguyen, 2016), or a hot trend. The trend reflect the Vietnamese people's tacit desire for a leader who seems to truly serve the people (whether they actually do or not) and their aspiration (if not illusion) that individual elites could make radical changes to a city or even the country. This increased attention to individual politicians indicates a possibility that individuals could gain suffient popular support to enable them to bypass collective decision-making bodies. However, in a study about the relationship between public profile and promotion in autocracy, its is plausible that an exceptionally well-known politician can be a threat to a single-party system and thus, "conspicuously low or high public profiles are harmful for promotion prospects" (Gueorguiev and Schuler, 2016, p.107).

There has been and will always be unspoken competition between individuals inside the CPV. During Doi Moi, there was an implicit classification of reformists (or progressives) and conservatives among CPV elites. They competed in deciding key policy changes (Dang, 2013; Rama, 2008). The final decisions were a compromise between the two groups, and also indicated that sometimes one faction could dominate the political 
decision-making. Recently, the country's politics has become very complex and complicated because it is a mixture of survivalists, conservatives, reformists, modernisers, moderates and rent-seekers (Vuving, 2016). Thus, any simplistic conclusions about the Party and government should be avoided. With that caution in mind, when studying the policy process in Vietnam, in addition to the collective leadership that has been an explicitly prominent feature of the country's policy process, it is advisable to take notice of individual figures because they might have played significant roles.

\subsubsection{Influence of business}

The political ideology of a communist state requires that SOEs must be regarded as the main actor of the economy. SOEs in Vietnam have enjoyed great advantages over other economic sectors in doing business. SOEs are entitled to many privileges such as free or easy access to land and natural resources, free or low-rate loans, monopoly or dominant positions in important industries and opportunities to win investment projects funded by the state budget. Managers of SOEs have very close ties with CPV cadres and government officials, which enable them to influence policymaking in their favour $(\mathrm{Vu}, 2015)$. Though the degree of favour shown by the state to the SOEs has been reduced under pressure from international integration and domestic economic growth, SOEs still enjoy special treatment in comparison with other sectors (Vu, 2015).

Doi Moi led to the proliferation of FIEs. Foreign investment has been encouraged to develop in Vietnam in competition with neigbouring countries. However, because of the diversity in their countries of origin and as foreign actors, they have had not much opportunity to influence policymaking except for formal dialogues between the state and the investors' representatives ( $\mathrm{Vu}, 2015)$.

As for the private sector, at the begining of Doi Moi, doing business was extremely difficult for private enterprises due to state discrimination in favour of SOEs and the risk of being out-competed by FIEs. However, when Doi Moi accelerated, the role of the private sector became significant. The goverment at both central and local levels sometimes held meetings with the business community, creating an official channel of communication between the state and the private sector. Through these policy dialogues, the business community can significantly affect policymaking on issues such as tax, customs, import and export, land, credit, investment, and administrative procedures ( $\mathrm{Vu}, 2015)$.

In the 'opinion collecting' process mentioned above, business people are consulted on market reform. One prominent business representative, the Vietnam Chamber of 
Commerce and Industry (VCCI), has a significant role in policy formulation. It presents the business interest in policymaking. The VCCI even established an online forum to discuss drafts of law and regulations. Leaders of this organisation have close ties with the Party and the government (Datta and Pham, 2013). The state often invites business representatives to participate in the agenda setting or implementation stages of the policy process on issues pertaining to their business activities. Evaluation of governance capacity by the business sector, reflected in the Provincial Competition Index (PCI), has been highly respected by both the Party and the State.

Gainsborough (2005) offers some explanations for the increasing influence of the business sector in Vietnam's politics and policymaking. Firstly, the economy is still dominated by state enterprises whose managers have close relationships with politicians and government officials or were even transferred from the state sector to manage state assets. Secondly, a significant proportion of private enterprises are established or run by people who are closely connected to the state (for example, old colleages, classmates, friends, relatives or crony enterprises of the the latter). In addition, many people in Vietnam are willing to invest in getting a state position with an expectation that the job will bring about opportunities to enrich themselves later on (by doing some private business relating to their state job or by exploiting their power to gain financial benefits from the private sector) (Gainsborough, 2005).

Recently, a concern has emerged about the unclear relationship between the state and the private sector. It is said that instead of focusing on technical inprovements and extending markets, private enterprises nowadays invest on building ties with key governnment officials. In the 2013 PCI survey, private enterprises were asked to confirm if it was true that contracts, land and other economic resources mostly fall into the hands of enterprises that have strong connections to local authorities ( $\mathrm{Vu}, 2015)$. The issue was also raised in a recent conference organised by the CPV's Central Economic Committee, the World Bank and the VCCI. In this conference, a private enterprise representative highlighted a phenomenon of "commercialising the relationship between private enterprises and the state" (H.G, 2016). ${ }^{8}$ He referred to the fact that private enterprises can make fortunes by having an underground relationship with powerful state agencies or officials rather than by their own competitive capacity. Gainsborough (2012) asserts that in Vietnamese political culture, connections and relationships are key factors. Businesses can exploit this feature

\footnotetext{
${ }^{8}$ H.G. is the penname of the reporter.
} 
to earn profit and especially to conduct some behind-the-scenes lobbying to shape regulations in their favour. Some business people can even make their way to political careers by being nominated to be deputies in elected bodies. As McCarty (2001) notes, "the line between state and private is blurred" (p.21). Since the true relationship is carefully concealed, outsiders would be puzzled in any effort to understand it. However, although business's influence on policymaking in Vietnam has not been examined in detail, it is likely that it plays a significant role.

\subsubsection{Role of research community}

To formulate its policies, the CPV mobilises intellectual resources from its own institutions (such as Party committees, the Party's Central Theoretical Council, and the Ho Chi Minh National Academy of Politics and Public Administration) and government agencies and institutes (Arkadie and Mallon, 2003; Datta and Pham, 2013). Mobilising the state's resources in making Party policies is a way to ensure that the Party's resolutions will accord with the state's demands (Dang and Beresford, 1998).

The government has a network of research institutes providing professional consultancy for policymaking. For example, the Institute of Legislative Studies is a knowledge pool and a subunit of the NA. The Prime Minister can establish an advisory unit to provide him with policy advice. There is at least one research institute organised under every ministry. These institutes can be considered as subunits of those ministries and often operate as semiautonomous state agencies, for example, the Central Institute for Economic Management (CIEM) of the Ministry of Planning and Investment.

Policymaking at national level also receives 'technical support' from donors and aid agencies that supply 'good practices' from international experience for local policy problems. The result of this intervention is often described as 'hybridisation', referring to adaptations to suit the local context in Vietnam (Datta and Pham, 2013; Gainsborough, 2005; Painter, 2005).

At a local level, Ha Noi, Ho Chi Minh City, Da Nang and Can Tho have established their own research institutes. Like national research institutes, these local ones provide policy advice and recommendations by completing policy studies or directly participating in drafting local regulations and policies. However, the contribution of these institutes varies and is not well-recorded. Local governments also use research services from national institutes, particularly from the institutes of the line ministries that govern the policy issues. A recent study showed that in spite of a broad network of national and local research 
institutions, informal consultancy is still dominant in making policy (Datta and Pham, 2013). Policy leaders might rely on senior or retired officials or a group of trusted advisers rather than on formal knowledge sources in addressing complicated policy problems. Policymakers prefer to learn lessons from neighbouring countries but are very cautious about imported ideologies. Also, according to these authors, economic research is rich in value but the uptake of this value is limited. Researchers sometimes see themselves as "flowers" (Datta and Pham, 2013, p. 25) to enhance the credibility for policymakers. The supply of knowledge and information for policymaking comes mainly from national research institutes. Local consultancy is not important. Central government sometimes ignores the conditions for effective policy implementation from a local perspective. This leads to poor implementation of many policies in reality (Datta and Pham, 2013). In general, knowledge has been mobilised only to a limited extent.

It is also worth noting that most existing research institutes in Vietnam, other than independent research institutes that focus on technical and social issues, have close relationships with their state governing agencies. Their staffing and budgets depend partially on the state. Above all, their activities are subject to the leadership of the CPV. As a result, even prestigious researchers must carefully articulate their advice and recommendations and be alert to politically sensitive issues. Rama (2008) notes that during the Doi Moi process, reformist local leaders had to find some 'bullet-proof' figures to gradually transfer reform ideas to the top leaders of the CPV. Directly relating to policy research activities, there was once an attempt to establish a research institute (the Institute of Development Studies) by some scholars in 2007. However, it was dissolved two years later. It was said that the dissolution was in response to the existing Prime Minister's decision on governing science and technology organisations.

\subsubsection{The media}

The role of media in policymaking in Vietnam has been examined by some scholars such as Shanks et al. (2004) and Datta and Pham (2013). According to these authors, media can be regarded as a forum for policy debate. Drafts of legal documents might be published in the media for comments. The media helps to spread information about policy issues to the people and thus to influence their political knowledge and values. In return, people can also express their opinions in the media. Their insights can be transferred to policymakers and potentially influence policy output. Open discussions in the media about a specific policy's implications can be a good source of knowledge for policymakers such as deputies 
of the NA or PCls. For example, in 2016, in a discussion about the task of solving citizen's complaints, one NA deputy cited a controversial issue on media and suggested a better response from the state (Pham, 2016). Sometimes, the media can keep government officials under surveillance and report their wrongdoings publicly. These activities are a source of feedback for policy modification. The development of the Internet and social media is increasingly influencing the political environment and policymaking in Vietnam. However, the CPV applies strict censorship to media and social media. Discussion of sensitive issues is monitored and some bloggers have been prosecuted for their criticisms of the state and the CPV. Freedom of the press is a principle in the constitution but exercised within prescribed limits in reality. Most newspaper editors maintain close ties with the Party's Ideology Departments and receive the CPV's instructions and directions for their publications' contents. A large part of the country's media is considered as the mouthpiece of the CPV and as the propaganda and mobilisation tools of the state (Datta and Pham, 2013).

\subsubsection{The people as a whole}

As presented in section 5.2.3, the VFF and its members provide the communication mechanism through which the CPV and the state inform the people about policies and mobilise their support. The VFF also officially represents the people to the state, expressing their interests and opinions on policy issues. The media also provide communication between the state and the people. In addition, policy history in Vietnam shows that people as a whole can influence policymaking through mass resistance (Shanks et al., 2004). When a policy is unpopular and against the interests of most people in society and when legal complaints do not work, people may respond with disobedience. One example is the popular violation of complicated and costly construction regulations in urban areas. If the resistance accumulates to a great extent, policymakers must reconsider and modify the policy. As Kerkvliet (as cited in Shanks et al., 2004) notes, this resistance is spontaneous and the people do not mean to affect or subvert government policy. However, when the resistance becomes widespread, it may ultimately affect policy. Particularly if the resistance extends to public protests, it can be a primary force for policy changes, as in the case of farmers' protests in Thai Binh in 1997, which led to the enactment of a decree on grassroots democracy in Vietnam (H. H. Nguyen, 2014). Nevertheless, public protests are still not a regular force in policymaking in Vietnam. 


\subsubsection{Policy process}

According to McCarty (2001), the policy process in Vietnam is quite confusing because of the lack of clarity in power allocation between the CPV and the state, among agencies within the state, and between the state and the private sector. He quotes Donge, White and Nghia (1999):

The policy making process in Vietnam is diffuse and does not follow the structures that a political scientist may map out. The system is one of consultation and consensus, with many different bodies being involved in a single decision - not just ministries but also agencies, such as Women's Union, and the multitude of thinktanks (overlaying which is the government/party divide and the relationship between the two). (McCarty, 2001, p.22)

Painter (2005) might be the first scholar who attempts to depict the policy-making process in Vietnam in a Western-style policy process framework. Applying Kingdon's (1984) multiple streams model, Painter attempts to identify the three streams of the reform policy process. In addition, he manages to incorporate Watson's (2001) notion of transplantation and borrowing of policy ideas and utilises the importance of the "problem solving" practice (Painter, 2005, p.271) to understand the policy process in Vietnam. By analysing the case of salary reform within the Public Administration Reform, the author notes that there is a stream of problems that is mostly identified by local authorities; while the policy stream (or solutions) might come from international experiences as 'good practices' introduced by donors and aid agencies. However, Painter does not elaborate the politics stream in his analysis. Instead he argues that adaptation and transformation of international experiences to suit the local situation might lead to inevitable consequences which are not what the state expects. Bui et al. (2015) is another study that employs Kingdon's model to explain the case of a safe motherhood policy in Vietnam (Bui et al., 2015).

Shanks et al. (2004) offer some insights about policy change in Vietnam and its implications for pro-poor policymaking. Firstly, the authors assert that the policy process is consensus-based. However, they do not mention the consensus among elites within the Party or any particular state agencies. Instead, they emphasise the combination of the horizontal consensus among the Party, the legislature, and the executive and the vertical consensus between the central and local levels. Taking into account this key feature, Shanks et al. (2004) advise that a simplistic approach of top-down or bottom up should not be applied in studying policymaking in Vietnam. Rather the process should be examined 
as a complex of many negotiations between different wings and levels. The report also highlights the diversity of actors and institutions involved in the process. Coupled with the consensus-based system, this feature leads to an implication of establishing a broad network of contacts to influence policy in Vietnam.

Secondly, Shanks et al. (2004) note that the policy-making process in Vietnam produces a large amount of published and unpublished legislation and the real content of policy might not lie in the laws or ordinances but in the follow-up guidelines and instructions by line ministries and local governments. Thus, it is necessary to be informed of the whole system of legal documents at all levels to comprehensively understand the policy position. It also indicates that a policy might get changed in its interpretation and implementation by lower levels.

Shanks et al. (2004) particularly emphasise the extremely important role of provincial governments in interpreting and implementing policy. The authors assert that the provincial level is a second critically important point in the policy process, in addition to the overall investment and financing mechanism decided by the central level. The report also highlights the iterative and diverse nature of policy interpretation and implementation at local levels. It proposes some factors explaining the variation in policy implementation in local government, including the style of local leadership, local budget capacity, local attitude and sanctions towards local resources and corruption and local human resources, as well as external forces, such as whether or not there are significant international aid projects, which associate with policy conditions in the locality. The role of local government is more important when local re-interpretation of policy becomes a new policy initiative, which can be later adopted as national policy. That means local government can sometimes have an indirect influence in central government's agenda setting stage.

Another noticeable feature is that the policymakers at central level tend to favour targeted programmes and campaigns. An official explanation for this tendency is that it helps to "concentrate and focus policies and resources", to "increase efficiency" and to reduce "the points of contact" (p.65) in implementing policy. However, the authors suspect that it is influenced by the tradition of exhortation and popular mobilisation through the 'campaign' approach in socialist countries. These explanations might be useful to understand the practice of using 'campaigns' in Da Nang's policymaking.

In sum, Shanks and his co-authors (2004) highlight two important features of policymaking in Vietnam, namely the horizontal and vertical consensus among state agencies and the 
crucial role of local government in interpreting and implementing policy. As for the consensus principle, Shanks et al., like several other authors, are unable to provide any empirical evidence of how it actually works within the system. The lack of specific, empirical evidence suggests nuances of the principle may be missed in reality. The authors' suggestions on factors affecting a local government's interpretation of policy can be useful for my investigation into the Da Nang case.

Among studies on policymaking in Vietnam, Dang's (2013) is one that borrows ideas from Western-style theories to develop his own model of four critical factors interacting to produce innovative policy change. Dang draws on data from four policy case studies: institutional autonomy for higher education institutions, the Bilateral Trade Agreement between the United States and Vietnam (US-VN BTA), the SOEs' management reform, and the radical change in foreign investment policy. His thesis offers explanations of why some policies experienced radical reform while others could only be changed incrementally. His findings show that several conditions are required for radical policy change to occur: when stressors are strong, the CPV's predisposition to reform is intensive and clear (reflected in Party resolutions or leaders' statements), a significant change in policy image of the CPV and government exists (also reflected in the CPV's resolutions) and a consensus is reached within the Party. Dang notes that, in the Vietnamese context, stressors can be disasters, crises, structural changes, national mood, international pressures or a command from superior Party or government unit. The leadership's predisposition to reform refers to the readiness of the CPV for policy change, which is affected by their ideology, political commitments and institutional constraints. The third factor, 'a change in policy image and belief', was borrowed from the punctuated-equilibrium theory, to describe how policy is perceived, the policy issues that need to be addressed, the causes of the issues, and why certain solutions should be adopted. The last factor is 'the consensus on the Party's political core values and contemporary priorities', such as political stability and the absolute leadership role of the CPV. If one or more of these factors was absent, the process would produce different policy outputs, such as policy maintenance (the existing policy's goals, objectives and instruments are still maintained) or policy succession (a new policy retains some features of the old one).

Dang's thesis emphasises four key characteristics of policymaking in Vietnam: firstly, the process is gradual and experimental in nature; secondly, policy reform is increasingly affected by external factors (such as international integration and donors' influences); thirdly, the absolute leadership of the Party, which decides the political acceptability of a 
policy idea, while the state is responsible for technical issues; and finally, the consensusbased policy process, meaning a policy idea must accord with core values of the CPV and achieve a consensus among top leaders to be advanced in agenda setting.

However, Dang himself identifies some limitations of this thesis. First of all, his model does not cover the implementation and evaluation stages of the policy process. Even in the agenda-setting stage, the author is unable to examine how policy actors actually interact with each other. He aggregates policy actors into two main groups, on the one hand is the CPV and on the other hand is the state (the NA, the government and line ministries), but sheds very little light on the interaction or communication between two groups and among agencies within those groups.

Secondly, Dang admits that he is unable to get detailed information about internal deliberation and discussion within the CPV and the government (except for some limited information about the case of the US-VN BTA). As a result, his explanation about the change in policy image is unclear. The thesis is also unable to distinguish the policy beliefs of the CPV as a whole from those of individual elites due to the strict principle of democratic centralism, which prohibits an individual leader from speaking against a collective decision. The author also mentions the difficulty in isolating core values and principles of the CPV. Many of these limitations are the result of the limited data collection method: the author was unable to access internal information within the system. The research was based mainly on secondary data which has been censored and is patchy.

Due to these limitations, some of the author's explanations sound implausible. For example, given that human resource is one of key elements in economic reform, the thesis is unable to provide a convincing explanation of why the need to reform the higher education system (particularly through institutional autonomy) could not obtain a priority place within the CPV. Dang argues that a lack of trust in the administrative capacity of educational institutions is the main reason. However, this argument is not convincing enough to explain the case. In the other two examined cases: the WTO accession and the US-VN BTA, we can see that the CPV's sceptical view did exist and possibly at a higher level because these cases relate to external forces. However radical change is still achieved because they were seen by the CPV to be inevitable choices and consistent with Party policy to enhance economic development. In fact, what makes education reform slow is the core ideology of the Party. Education is an essential means to control the younger generation's thoughts and the Party cannot afford to set the education system free from its 
ideological boundaries. Similarly, SOE reform also encountered a fundamental ideology of the CPV: the role of the state sector in a socialist country. The state sector is the macroeconomic instrument and resource for the Party to control domestic and foreign economic forces. These issues are both mentioned and analysed in this thesis, but the author did not push them to a pivotal position, where they can claim their decisive role in making or inhibiting policy change. Instead Dang uses them as the conditions that lead to lack of a significant change in policy image in the CPV and leaders. Nevertheless, the author admits that due to the lack of information about the internal debates within the state agencies on the Investment Law, the factor 'policy image change' is quite ambiguous in this case (p. 287). In short, the last three factors of the model (leadership predisposition, a significant change in policy image and a political consensus) all relate to the political acceptability of policy issues and solutions.

Relating to the fourth factor, Dang uses the case of the US-VN BTA to show the important of political consensus in policymaking. In 1999, when all technical assessments and feasibility studies were in favour of signing the agreement, the US-VN BTA still had to wait one more year to be signed because consensus was not achieved within the CPV. Dang explains that by that time, the then General Secretary was unable to lead the Party to a consensus among top leaders in conservative and reformer groups. Only when a reformers gained the leadership and the then General Secretary was about to step down, was a consensus reached: the agreement was signed in July 2000 and only ratified by the NA in November 2001. Looked at another angle, this case showed that an individual leader on top of the hierarchy could have absolute power to make the final decision. Under the leadership of the conservative General Secretary, the agreement could not be signed. However, when his reformist successor was about to gain the leadership (officially in April 2001), he was able to change the final decision. The fact that the agreement was only ratified in November 2001 supports the proposition that the new General Secretary needed time to reinforce his power and get his decision done.

In another case of radical change (legal reform for investment activities), Dang does not explain the role of political consensus. He admits that Party consensus was not "fully documented and explained" (p.278) in this case. In the remaining two cases (higher education reform and SOE reform), the author attributes the incremental policy change to the third factor (the lack of significant change in policy image) and thus he stops examining the fourth factor (the political consensus). In sum, the consensus-based feature in policymaking process has not been explained clearly in this study. This lacuna leads to a doubt 
about the consensus in policymaking in Vietnam: whether it is just a dressed-up name for actual individualism in a regime that praises collectivism or a public face on internal faction and competition.

In short, Dang (2013) is prominent in admittedly limited studies on policymaking in Vietnam. This work shows that it is possible to utilise and develop Western theories, models and frameworks for understanding policymaking in a developing and single party state. He also identifies various concepts that might be of useful for my study, including policy image, bounded rationality, institutional constraints, gradualism and incrementalism. In addition, Dang advocates using Grindle and Thomas's (1991) model in policy studies in Vietnam. His study also offers some valuable insights into the case of the US-VN BTA, which help understand the role of individual leaders in policymaking. Particularly, Dang gives great emphasis to the role of the CPV in the policy-making process. His suggestions on the core values of the system are quite similar to Lucius's assertion that three core values strictly protected by Vietnamese political system are regime stability, national independence, and social order (Lucius, 2009). The study's limited scope on agenda setting at central level leaves space for my study to investigate policymaking at local level and in other stages of a policy process.

Recently, in a study about the knowledge base of policymaking in Vietnam, Datta and Pham (2013) describe the policy process in a linear order, starting with agenda setting, leading to drafting and consulting, then implementation and learning. This approach allows the authors to introduce relevant policy actors and their roles as well as key features of each policy stage (similar to the approach of Shanks et al., 2004). According to this report, the agenda-setting stage happens mainly at the Party's CCOM where important decisions are made, based on the principle of collective leadership. However, the legal process starts in line ministries, where drafts of laws and regulations are prepared and then passed to the government for discussion before sending to the NA for consideration and approval. Although the NA has the highest power to approve a law, its capacity to decide the content of policy independently is limited as a result of limited time, human resources and low quality of law-making skills and experiences. Thus, major policy ideas are primarily decided by the Party's CCOM, while the detailed content of policy is mainly structured by relevant line ministries.

As the drafting agency for most laws and regulations, line ministries have significant power in determining policy content. In each ministry, the general departments are the most 
influential actors in making policy because they are responsible for specific policy areas and have practical experience and expertise in their areas. When it needs to draft up a new legal document, a ministry will often establish a drafting committee to prepare the drafts of the regulations. The drafting committee comprises representatives from relevant departments, agencies and at times from research institutes and mass organisations. Sometimes a research institute is assigned the task of drafting up the regulations for the ministry. The drafting team is required to collect comments from concerned parties to complete the draft. The draft is reviewed by the Ministry of Justice and an ad hoc council, or both, before being sent to the government for approval.

Datta and Pham (2013) note that national policies, particularly economic policies, are often not implemented uniformly throughout the country. They offer some explanations for this situation. The first possible reason is the disagreement between central and local leaders, which will delay implementation. Secondly, the large number of often highly complicated and contradictory regulations requires business people to seek guidance from local officials. This leads to formal and informal rent-seeking activities. Poor implementation is also a result of local discretion enjoyed by local government. The amount of discretion varies depending on the local capacity and resources, as well as the level of bureaucratic control and discipline. Poor implementation can also happen when local government waits for detailed guidelines from central government.

In sum, Datta and Pham (2013) offer a good map of the policy process at national level in Vietnam. The report provides rich information on how policies are discussed and revised before being approved by authorised institutions. It also offers reasonable explanations of why some policies are poorly implemented at the local level. However, since this report focuses mainly on the knowledge sources that policymakers at different levels often draw on, the policy actors as well as the actual process are not systematically described. For example, like many other scholars in Vietnamese policy studies, Datta and Pham mention the consensus principle in making policy decisions at the CCOM, but do not provide evidence about how this principle is applied in any specific case. Similar to Dang (2013), this report does not analyse how different policy actors interact with each other and the implementation section was mainly a discussion from the perspective of poor implementation cases and the limited growth of the private sector. How policy is actually implemented at the local level is not covered. Policy actors participating in this stage are also not discussed in detail. 
In conclusion, the literature on policy-making process in Vietnam is limited in empirical case insights and detailed analysis of the inner workings of policy actors as well as interactions among them. Previous studies highlight some key characteristics of the process, such as the important role of the CPV in making key decisions and major policy changes; the consensus-based system and collective leadership style; the diversity of actors and institutions participating in the process; the substantial role of line ministries in deciding policy's detailed content; and the important role of local government in reinterpreting and implementing national policies. However, due to limited access to internal discussions within the CPV and the state, little is known about how the consensus-based principle actually works in reality. Moreover, though all of these studies recognise the importance of local government in implementation, none has studied how the policy process plays out at this level. My study will fill this gap in the literature by offering evidence on how the consensus-based principle and collective leadership work in a specific case. More importantly, it will offer insights into a policy process and an analysis of influences on that process at local level.

\subsubsection{The relationship between central and local government in Vietnam}

As the literature review on China policymaking indicated, in a unitary country, the relationship between central and local government can have significant effects on policymaking. Since this study is of a policy process in a local government in Vietnam, it is essential to examine previous studies of this relationship.

\subsubsection{The principle of democratic centralism}

Vietnam is a unitary country in which democratic centralism is a fundamental principle in governing the organisation and activity of all state organs (Constitution, 1992). The principle of democratic centralism requires that all policy decisions must be democratically discussed and decided following the majority rule (democratic perspective). However, once a collective decision is achieved, it requires an unquestioning obedience by all Party members and government officials. Nobody in the system is allowed to speak against the approved policy even if they have a different opinion (centralism perspective). In the relationship between central and local government, the principle is to ensure that central Party's policies and central government regulations are faithfully implemented in the whole country. That means all local government decisions and policies must be issued within the boundaries of the central government legal framework (centralism perspective). The democratic perspective of the principle allows local governments to propose policy 
changes that suit practical conditions, but those proposals will be subject to approvals from the central level.

Vietnam's policy history provides plenty of examples of how this principle works within the relationship between central and local government. In the development of Doi Moi, fence-breaking activities in land, foreign trade, manufacture and distribution played an important role in instigating formal national policy change but were undertaken in a cautious and gradual manner to avoid confrontation (Rama, 2008). Local leaders, under the pressure of the practical situation, secretly initiated fence-breaking activities. Once the experiments produced positive results, they would then work out an appropriate strategy to access central elites to lobby for their approval. Local leaders would come to Ha Noi or invite a central leader to visit their localities to witness the urgency of the practical situation and the necessity of the new initiative. Once they received support from the most accessible elite, local leaders would repeat the strategy with the others and use the "cross-referencing" (Rama, 2008, p.19) technique, meaning using the support of this elite to persuade the others. By this approach, the Doi Moi process in Vietnam happened peacefully and did not involve any replacing of top leaders. All heated debates happened behind the scenes. Thus, to outsiders, it seemed that reform policies came gradually from inside the CPV and were decided by a consensus among top leaders of the CPV.

\subsubsection{Decentralisation and local autonomy}

Doi Moi led to the need to reform the relationship between central and local government. In 1986, for the first time, The CPV mentioned the need for "decentralisation of management in accordance with the democratic centralism principle" (CPV National Congress's Resolution, 1986, p.5). However, the Party was also cautious of unorganised freedom, regionalism and factionalism. At this time, the decentralisation was just in the economic sphere, meaning decentralising business management to enterprises and eliminating the administrative intervention of the government in business operations. As for central-local government relations, the Party's resolution encouraged "the active role of local government in socio-economic management at localities" (CPV National Congress's Resolution, 1986, p.5). However, the CPV retained central authority in deciding important policy issues. Until the early 2000s, decentralisation in Vietnam was still very limited: mainly in the form of economic management decentralisation with no aspect of political or personnel decentralisation, due to the lack of regulations about how decentralisation was exercised in reality ( $\mathrm{Vu}, 2012)$. 
In the early period of Doi Moi, due to limited decentralisation, fence-breaking activities became popular and reflected the local autonomous tendency. Malesky's (2004) study about fence-breaking in Vietnam proposes that leaders in better-off provinces had more opportunities to access innovative ideas and were more active in grasping chances of reform. Malesky also notes that provinces with revenues mainly from FDI and large central state companies were among the most autonomous localities, while provinces heavily influenced by the private sector were less autonomous. The least autonomous were those that depended on the local state sector. Coincidentally, these were provinces with poor socio-economic conditions. The author concludes that no single explanation accounts for the degree of autonomy of a certain province, and suggests a combination of geographical location, initial conditions and the dominant source of revenues to explain autonomy. According to his data, provinces in the southern part of the country with highly favourable initial conditions, high levels of FDI and less dependence on the state sector were the most autonomous localities (Ho Chi Minh City, Dong Nai, Binh Duong and Da Nang) (Malesky, 2004). Fritzen (2006) also asserts that localities with better economic development status and an ability to collect their own revenue for their spending purposes can enjoy more discretion than less prosperous localities. Fritzen's thesis shows that localities with good levels of some explanatory factors (administrative capacity, facilitative socio-economic conditions [with an emphasis on fiscal capacity] and incentive structure) are likely to successfully implement the reform on the National Programme of Action for Children, while localities with poor levels of those factors uniformly fail to respond to the reform, although fiscal capacity is not a determining factor because this reform is administrative in nature and does not require heavy fiscal investments (Fritzen, 2000).

To deal with local resistance, reflected in fence-breaking activities, the central government promoted decentralisation. With its political aspect (devolution), decentralisation was mentioned for the first time in a Party resolution in 2004 (M. P. Nguyen, 2013). Along with this resolution were many relevant laws and regulations which included decentralisation provisions, such as the Law on Organisation and Activities of the $\mathrm{PCl}$ and PCe 2003, the Budget Law 2002, Law on Investment 2005.

The Budget Law 2002 is the most important document relating to fiscal decentralisation. According to this law, local governments can increase their budgets from revenues that are fully assigned to local governments, such as revenues from land and natural resources (excluding petroleum). Local governments are also able to share other substantial revenues (such as CIT, VAT, income tax on high income earners, special consumption tax) at rates 
set by the central government and fixed for each province for a 'stability period' of three years. In addition, local governments can enjoy a 'bonus' if their actual collected shared revenues are in excess of estimated amounts. Some provinces and cities that are rich in land and natural resources or have had a strong economy could generate more revenue than others and became more independent from central government ( $\mathrm{Vu}, 2015)$. In some cities and provinces where the share rates are less than $100 \%$, local governments can increase their overall revenue by putting more effort into collecting fully retained revenues and paying less attention to shared revenues (Nguyen and Schroeder, 2010). Local government can also enjoy some 'off-budget' revenues, which are not disclosed to central government. Also, according to the Budget Law 2002, provincial governments are decentralised to determine how local revenues are distributed among different sub-national levels within their jurisdictions. With all of these resources, some provinces became relatively rich and their voices were more respected in the relationship with the central government. Cities like Ha Noi, Ho Chi Minh City or Da Nang could lobby for more incentives from central government thanks to their large contributions to the state budget.

Local government autonomy in budget revenue is restrained mostly by the fact that all tax rates are set by central government. Even the authority to set user charges and fees is mostly assumed by central government. In addition, the model of state budget limits the local fiscal autonomy. Vietnam's budget system is organised in a nested model ('Matrioska'), which means the communal budget is a component of the district budget; the district budget, in its turn, is a part of the provincial budget and the provincial budget is an element of the national budget. As a result, the local budget is subject to approval by the NA every year. There is argument that, due to these constraints, local government is not independent in fiscal issues (Phan, 2012). However, most students of decentralisation in Vietnam agree that provincial governments enjoy considerable discretion in fiscal decision-making (Arkadie and Mallon, 2003; Fritzen, 2006; Nguyen and Schroeder, 2010).

Relating to budget expenditure, the Budget Law 2002 gives local governments more flexibility in determining local spending. They also have autonomy in distributing expenditure responsibilities among sub-national levels and especially in assigning capital investment responsibilities. The share of local spending has been continuously increasing from 2004 (Truong, 2014). However, high levels of local expenditure also present some problems, such as inefficiencies in capital investment in badly planned facilities, including seaports, airports, and industrial zones, and escalating costs in many projects in a number of provinces. In addition, some local governments exploited land and natural resources to 
increase revenue by converting agricultural land into residential and commercial land and using the money from selling land-use rights for infrastructure development and rent seeking ( $\mathrm{Vu}, 2015)$. This practice affected farmers' interests and led to social unrest. According to $\mathrm{Vu}$ (2015), some local governments also even supported companies to lobby central government for more budget and financial benefits. Some central government elites are also willing to grant more benefits to localities in return for their support in the NA, CCOM, and Politburo.

Decentralisation in investment creates more scope for local autonomy in FDI attraction. However, some local authorities abused this autonomy. For example, in a competition to attract more FDI, governments in 32 less-developed provinces had to fence-break and offer extra incentives (more land rent reduction or tax holidays) to foreign investors, a practice that caused clashes with central regulations and was called a 'race to the bottom' ( $\mathrm{Vu}, \mathrm{Le}$, and Vo, 2007) during the period from 2001 to 2005. In a response to the situation, the central government issued a decision to suspend all extra incentives and ordered local governments to report details of their violations as well as measures to correct wrongdoings. However, many local governments did not obey this reporting directive (Vu et al., 2007). In another attempt to push up local economic growth, under the pressure of capital constraints, Ba Ria-Vung Tau province experimented with the Land-ForInfrastructure Mechanism in 1993. In this experiment, an investor agreed to construct a new road for the province; in return the local government would expropriate the agricultural land adjacent to the road and offer it to the investor for commercial use. The initiative was followed by other localities; it produced mixed outcomes because many investors did not fulfil their promises and these bargains were carried out at the expense of the enforcement of official urban plans (Labbé and Musil, 2014). The initiative was nevertheless later adopted as national policy in the Land Law 2003, and controlled by many other national regulations.

In personnel decentralisation, the Law on Organisation and Activity of PCl and PCe (2003) provided that local government officials have dual accountabilities: vertical accountability to central government and horizontal accountability to local authorities. For example, rovincial line departments are under the personnel mamangent of the local PCe (horizontal accountability), but also have to follow professional instructions and inspection from central line ministries (vertical accountability). In practice, government officials tend to focus on the horizontal relationship because their political careers mainly advance within 
the localities while shifting positions in different localities or to central level was limited to local Party leaders only (Arkadie and Mallon, 2003).

From some aspects of decentralisation, it can be said that Vietnam is continuing to devolve more economic, fiscal and administrative responsibilities to lower levels. Though in the rules and regulations the scope for manoeuvre by local governments is not big, in practice, local governments can enjoy a significant discretion and autonomy. While decisionmaking power is not clearly transfered to lower levels (political decentralisation), under the pressure of growth and development, local governments sometimes go beyond the boundaries set by the central government. If a local government's decision aims to deal with local issues, using local sources of finance, and does not move ahead of central government's policy or threaten the legitimacy of the CPV, then the central government might not use its intervening power (Vasavakul, 2002). Local governments can delay the implementation of central government policies if they find those policies unpopular or against the local benefits and interests. Local officials can also deliberately re-interpret national policies to protect their own interests as a result of poor salary and incentives, lack of transparency and clarity or overlapping in authorities (Koh, 2001; Shanks et al., 2004). Finally, the large number of complicated legal documents pertaining to a policy issue or a delay in issuing guidelines from central government agencies might also lead to poor implementation of national policies at localities (Datta and Pham, 2013).

The local resistance to national policies in Vietnam originated from the feudal period, reflected in Vietnamese sayings such as: "The emperor's rule stops at the village gate" (Phep vua thua le lang). Recently, there is a new saying: "The Party has policies but the people have ways" (Dang co sach con dan thi co cach) (Koh, 2001, p.279). The policy process leading to Doi Moi shows that local initiatives played a significant role in national policy changes. It proves that local experiments should be given attention and encouraged because local governments are close to the people and have more pratical experience for policy ideas. However, local response is relatively diverse. Some provinces might be more active in innovating and pursuing new policy ideas, while others might be slow and cautious in policy experiments (Arkadie and Mallon, 2003). Similarly, when functioning within their relative autonomy, some provincial governments demonstrate a strong commitment to local development while others might follow rent-seeking purposes. While explanations for diversity in local initiatiaves and autonomy have been examined by many authors, such as Malesky (2004), Shanks et al. (2004), Fritzen (2006) and Datta and Pham (2013), little is known about why some local governments are more development-oriented 
than others (Vu, 2015). A possible explanation might rest in local leadership style and the incentives behind leaders' decisions, and on whether they seek material benefits or to establish their reputation in history. The resources available for them to implement decisions are equally important.

Central responses to local initiatives and fence-breakings are also diverse. If the actions are taken at an inappropriate time, they might be criticised and even punished, such as early fence-breakings in land management. However, in many cases, local resistance does cause the central government to re-examine and alter its policies. In transition from an unworkable model of a centrally planned economy to a not-yet-defined model of a socialist-oriented market economy, policy experiment is inevitable and has become a policy-making model in Vietnam. In this model, the role of local government is essential because they know in reality what works and what does not.

To sum up, many students of the relationship between central and local government in Vietnam agree that Vietnam has never been as centralised as it may appear in rules and regulations and that local leaders have always had substantial room for manoeuvre. In addition, national policies can be interpreted in different ways to best suit local interests (Arkadie and Mallon, 2003; Datta and Pham, 2013; Fritzen, 2006; Lucius, 2009). There are, of course, still some factors obstructing further decentralisation, especially political decentralisation, in the near future. The primary obstacle is the principle of democratic centralism that assigns central government agency to local governments and requires an absolute obedience from the local to the central (Fritzen, 2006; Painter, 2005). In addition, Fritzen also mentions some other obstructing factors, such as the tendency of power to concentrate in the central government; the governance structure in a unitary state with the executive branch having more real power than legislature and judicial branches; the weak voice of civil society and the private sector; limited multi-sectoral (horizontal) coordination; and an attitude of mistrust of local government from central officials (Fritzen, 2006).

\subsection{Conclusion}

This chapter shows that though policies are made at central level in Vietnam, their actual effect is largely determined by the policy process at local level because local government can enjoy a significant autonomy in interpreting and implementing policies. While there have been some studies dedicated to the policy process at central level, little is known about how policy gets shaped and implemented at local level and the main influences on 
this process. The research question set out in Chapter 1 (What are critical influences on the policy process in local government in Vietnam?), focuses on this process and will help fill this gap in the literature. Examining previous studies on policymaking in Vietnam also reinforces the need to examine the role of policy elites and their underpinning core political values as well as other policy actors in policymaking at local level. In addition, the review on the relationship between central and local government in Vietnam shows that this relationship can be an important factor affecting the policy process in the Da Nang case. 


\section{Chapter 6: Methodology}

\subsection{Introduction}

Chapter 5 showed that there is an existing gap in the literature on the influences on the policy process in local government in a developing economy and single party-state of Vietnam. The literature review also indicated that Hofferbert's (1974) funnel of causality model would appear to be a useful model for examining the influences on the policy process in the Da Nang case, if further modification is undertaken to improve the model's utility. This chapter develops a research framework to answer the research questions identified in Chapter 5, and will elaborate a research design and its data requirements. Finally, this chapter will outline the methods and techniques for data collection and data analysis during this investigation.

\subsection{Research framework}

This section develops a research framework that helps address the gap in the literature on the influences on the policy process in local government in Vietnam. The framework is based on Hofferbert's model and insights from other theories, models and frameworks as well as from previous knowledge about policymaking in China and Vietnam. Table 6.1 summaries prominent theories and their insights of relevance to this study.

This summary of the literature on theories of the policy process shows that each can offer different lenses to examine the influences on the policy process in the Da Nang case. They direct attention to the benefit of disaggregating the policy process into stages; the role of focusing events and policymakers, as well as institutional rules and constraints on them; the influence of relevant policies that were implemented in the city within and outside the case and from the central government or other localities; and the possibility of policymakers pursuing their personal interest in making policy or influenced by their core values and beliefs. 
Table 6.1: A summary of theories of the policy process and their implications for this study

\begin{tabular}{|c|c|c|}
\hline Theories & Summary & Relevance to this study \\
\hline $\begin{array}{l}\text { The stages heuristic } \\
\text { framework }\end{array}$ & $\begin{array}{l}\text { The disaggregation of } \\
\text { policy process into stages }\end{array}$ & $\begin{array}{l}\text { Recognising and } \\
\text { distinguishing different } \\
\text { groups of activities } \\
\text { reflecting various stages } \\
\text { of the policy process. }\end{array}$ \\
\hline $\begin{array}{l}\text { The institutional } \\
\text { rational choice } \\
\text { framework }\end{array}$ & $\begin{array}{l}\text { Individuals tend to } \\
\text { maximise their benefits } \\
\text { under the constraints of } \\
\text { institutional rules }\end{array}$ & $\begin{array}{l}\text { Rules and constraints on } \\
\text { local leaders in making } \\
\text { decisions; } \\
\text { Underpinning personal } \\
\text { interests of policy } \\
\text { makers while making the } \\
\text { policy. }\end{array}$ \\
\hline $\begin{array}{l}\text { The multiple streams } \\
\text { theory }\end{array}$ & $\begin{array}{l}\text { Three streams of problem, } \\
\text { policy and politics meet } \\
\text { when the window of } \\
\text { opportunity opens, } \\
\text { supported by the activities } \\
\text { of policy entrepreneurs }\end{array}$ & $\begin{array}{l}\text { The important role of } \\
\text { policy entrepreneurs; } \\
\text { The origins of the policy } \\
\text { problems and solutions; } \\
\text { The political context that } \\
\text { facilitates the coupling of } \\
\text { the streams. }\end{array}$ \\
\hline $\begin{array}{l}\text { The punctuated- } \\
\text { equilibrium theory }\end{array}$ & $\begin{array}{l}\text { Policy is adjusted } \\
\text { incrementally over time } \\
\text { and then changes radically } \\
\text { when pressures are high }\end{array}$ & $\begin{array}{l}\text { Focusing events that led } \\
\text { to policy change. }\end{array}$ \\
\hline
\end{tabular}




\begin{tabular}{|c|c|c|}
\hline Theories & Summary & Relevance to this study \\
\hline $\begin{array}{l}\text { The advocacy coalition } \\
\text { framework }\end{array}$ & $\begin{array}{l}\text { Policy change is a result } \\
\text { of a change in the beliefs } \\
\text { system or of a replacement } \\
\text { of a dominant advocacy } \\
\text { coalition }\end{array}$ & $\begin{array}{l}\text { The belief system/core } \\
\text { values of policy makers } \\
\text { in Vietnam; } \\
\text { Policy-oriented learning; } \\
\text { Influential factors of the } \\
\text { policy process: authority, } \\
\text { information, finance, and } \\
\text { leadership. }\end{array}$ \\
\hline $\begin{array}{l}\text { The innovation and } \\
\text { diffusion models }\end{array}$ & $\begin{array}{l}\text { Policy adoption is affected } \\
\text { by various domestic and } \\
\text { external factors, including } \\
\text { motivation, resources, } \\
\text { obstacles, other policies, } \\
\text { and external forces }\end{array}$ & $\begin{array}{l}\text { The influence of } \\
\text { complementary policies } \\
\text { and substitute policies; } \\
\text { The external influence } \\
\text { from the central } \\
\text { government and from } \\
\text { other localities. }\end{array}$ \\
\hline $\begin{array}{l}\text { The funnel of causality } \\
\text { models }\end{array}$ & $\begin{array}{l}\text { Factors affecting the } \\
\text { policy process, including } \\
\text { background context, } \\
\text { governmental } \\
\text { arrangements and elite } \\
\text { behaviour. Policymaking } \\
\text { is strongly influenced by } \\
\text { environmental conditions } \\
\text { and only marginally } \\
\text { influenced by political } \\
\text { factors }\end{array}$ & $\begin{array}{l}\text { Factors affecting the } \\
\text { policy process, including } \\
\text { background context, } \\
\text { governmental } \\
\text { arrangements and policy } \\
\text { actors. }\end{array}$ \\
\hline
\end{tabular}

Hofferbert's funnel of causality model is chosen as the starting point for a framework to examine the influences on the policy process in this study for several reasons. First of all, this model offers a relatively full set of potential factors that can influence the policy process, including policy-relevant incidents (or focusing events), the general background context, defined by historical and geographical features, socio-economic conditions and 
mass political behaviour, governmental institutions and elite behaviour in shaping policy changes. However, the set of influences is modified to best fit the Da Nang case.

Another advantage of this model is that it places 'elite behaviour' at the end of the funnel, indicating the key position of policy elites in making policy change. As Hofferbert (1974) notes, his model image suggests that a good strategy to examine "the determinants of public policy would be to begin with elite behaviour and work backward through factors conditioning them" (p.229). Although he asserts that to start with 'elite behaviour' is a frustrating task since elite behaviour is difficult to measure, he also points out that this issue can be solved by the sensitive analysis of case studies. This emphasis on policy elites is likely to be a suitable approach in studying the policy process in developing countries, supported by various scholars, including Anderson (1975), Grindle and Thomas (1991), Sabatier (2007) and Airey and Chong (2011). According to Grindle and Thomas (1991), policy elites play a decisive role in policymaking in developing countries, where information and resources for policymaking are limited, while the need is great and policymakers' responsibilities are extensive. Similarly, Sabatier (2007a) considers individuals to be the "linchpin" (p.329) of the policy process, and Airey and Chong (2011) note that policy actors should be placed at the core of the policy process since they formulate and implement policies in reality. This elitist approach is also supported by other studies in the literature on policymaking in China and Vietnam. 


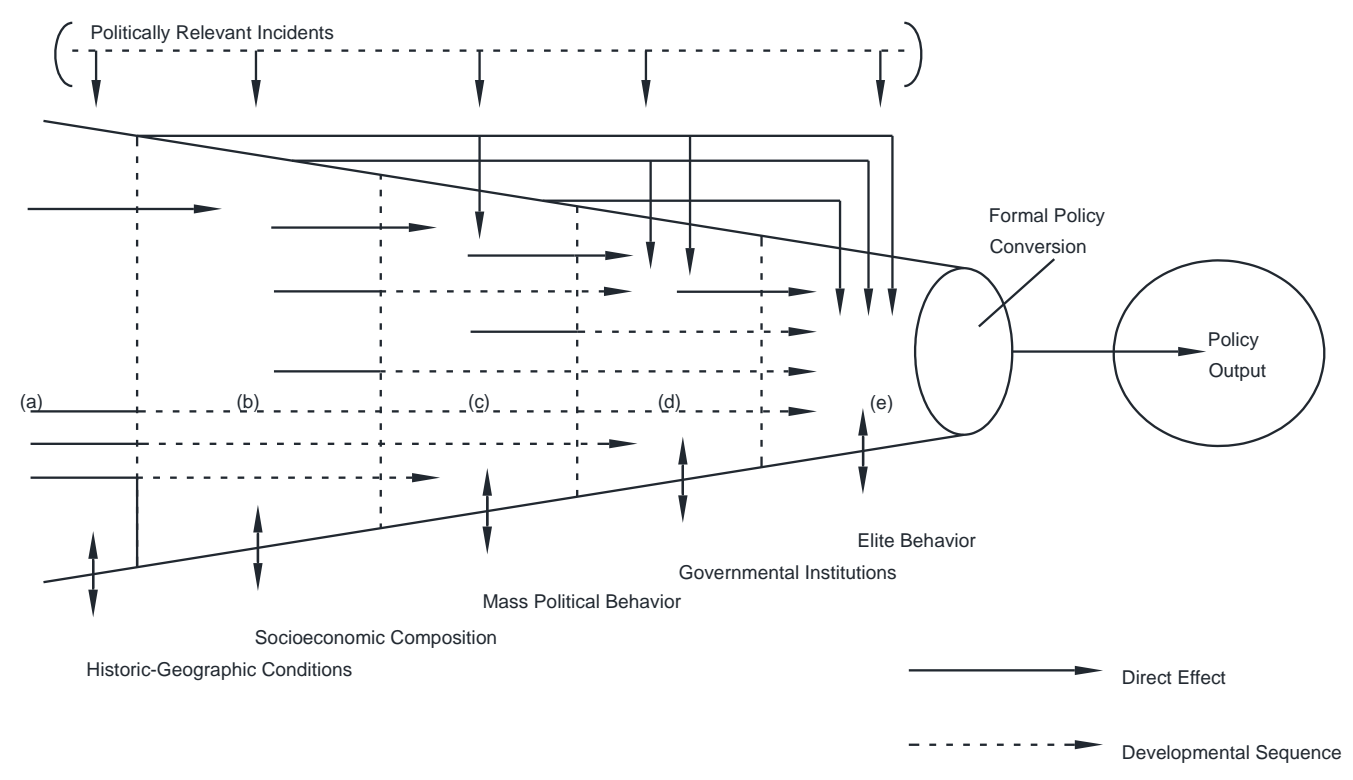

Figure 6.1: Hofferbert's (1974) funnel of causality model

Finally, Hofferbert's model illustrates both the independent effect between factors and the cumulative effects that they create collectively on the policy elites in shaping policy output. The cumulative effects are reflected by the dotted arrows inside the funnel (Figure 6.1). They mean that historic-geographic conditions can affect socio-economic compositions and the combined effect of these two factors will affect the mass political behaviour. The combined effect of the three factors will influence governmental institutions, and together determine elite behaviour. The independent effect is represented by the straight arrows between two sequential factors and the straight 'by-pass' arrows outside the funnel. For example, historical conditions can affect socio-economic composition and governmental institutions can influence elite behaviour. In some cases, historical conditions can directly affect governmental institutions irrespective of socio-economic composition. However, Hofferbert does not mention the reversing effect of factors near the closing end of the funnel on factors at the opening end. Acknowledging the possibility of mutual and combined effects among influences on the policy process, while developing a research framework for the Da Nang case, all of the arrows will be combined into one set of twoended arrows to reflect the interaction of influences on final policy output (Figure 6.2).

Some other adjustments to the model are also made to suit this case study. Firstly, for the first set of influences, the 'historic-geographic conditions', Hofferbert asserts that depending on one's perspective, socio-economic conditions can be classified as 'historical', because "nothing happens that is not in some sense a function of prior 
circumstances" (p.229) and these two factors are mutually dependent. Thus, analysing the 'socio-economic composition' might include the influences of relevant historical and geographical impacts (if any). To incorporate these two set of influences, my research framework will name the first set of influences as 'socio-economic conditions' with a note for historical and geographical impacts (if any) to remind the researcher to pay attention to the question of why socio-economic conditions have become what they are (Hofferbert, 1974)

Secondly, with relation to 'mass political behaviour', in a one-party state like Vietnam, voter turnout or party structure does not direct impacts on the policy-making process. Hence, this factor will be omitted. Instead, my proposed research framework will pay attention to factors that drive policymakers in making their decisions. These include the pressure from citizens' demands and the core values of the system and the underpinning personal interests (if any).

Thirdly, since this study focuses on the policy process in a local government and the literature review showed that the relationship between central and local government in Vietnam can exert significant influence on the policy process at both central and local levels in Vietnam, it is necessary to place an emphasis on this relationship while designing the research framework. Therefore, Hofferbert's fourth factor, 'governmental institutions', is replaced by the term 'institutional arrangements' with a focus on the 'central-local government relationship'.

Fourthly, while Hofferbert only mentions elite behaviour in his model, I will adjust this last factor into 'policy actors' behaviour' to embrace the influences from other actors involved in the policy process. Meanwhile, the role of policy elite will be highlighted by placing the 'policy elite' at the centre of 'policy actors' behaviour'.

In Hofferbert's model, the term 'formal policy conversion' is used to indicate the point where all influences meet and produce policy output. In my framework, the conversion point is named policy output.

Finally, a review of the literature on the 'debate' between society-, state- and individualcentred approaches indicated that it is tricky to place emphasis on any particular set of factors while ignoring other ones when studying determinants of public policy. Airey and Chong (2011) also assert that any single policy factor cannot determine policy alone and a workable framework should include a combination of multiple factors and indicate the interrelationships among them. Thus, while Hofferbert places more attention to 
background context factors than political factors, my proposed research framework will not downgrade the importance of any influence; instead it aims to understand the interaction of them in shaping policy changes.

In my research framework, socio-economic conditions (including historical and geographical features) act as a background context. This context couples with the centrallocal government relationship to affect policy actors in shaping policy output. For each of these three main factors, this study examines why they are important, what aspects of them are important and what influences them. For example, to understand the influence of policy actors, based mostly on Grindle and Thomas's model and previous knowledge about policymaking in China and Vietnam, focus is placed on the crucial role of the CPV and key politicians. It is also advisable to look at factors that shape their perceptions (Grindle and Thomas, 1991) about housing policy for low-income people, including regime core values or belief system (as also suggested by the policy advocacy coalition framework), political will and determination, memory of past/similar policies (diffusion models), and personal characteristics. Evidence is also considered to identify whether policymakers were driven by any personal interest as suggested by the institutional rational choice framework.

In addition to the policy elite, it is also necessary to examine the influence of the network of policy actors, "who share common interests with regard to a policy and who exchange resources to pursue these shared interests acknowledging that co-operation is the best way to achieve common goals" (Börzel, 1997; cited in Besussi, 2014, p.2). In this study, the policy network can include government officials, the media, the research community, the people and their mass organisations, and, particularly, the private sector.

Regarding institutional arrangements or the role of rules-in-use (institutional rational choice framework), the literature on policymaking in China and Vietnam suggests a focus on the impact from central government on local government behaviour as well as the backward influence from local government to central policies. More specifically, the literature on the relationship between central and local government in policymaking in Vietnam shows that it is necessary to examine how the democratic centralism principle and the tendency of autonomy in local government work in this case.

For the influence of socio-economic conditions, factors that are relevant to housing policy for low-income people are examined, including the effects of urbanisation and population growth on the housing situation, the pressure on housing demand caused by urbanisation 
and the flow of immigrants into urban areas as well as the availability of financial resources for housing policy implementation.

Finally, as suggested by the diffusion model, attention is paid to relevant policies to see what effect they have on the process, including housing policy implemented before the introduction of the Having Housing Programme in 2005 and other relevant policies that were initiated and implemented during the case's timespan, not only in the city but also on other localities and from the central government.

Taking into account all of those considerations above, the following initial research framework is designed to examine influences on the policy process in the Da Nang case:

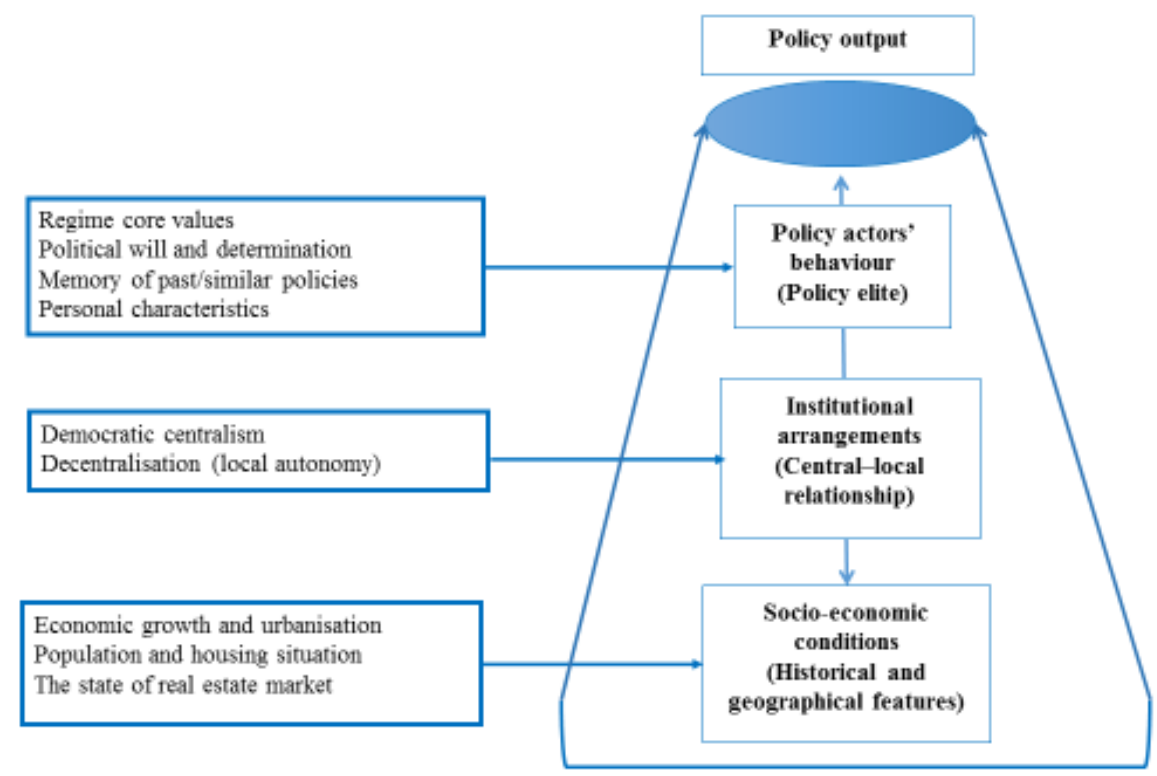

Figure 6.2: Initial research framework

\subsection{Methodology}

\subsubsection{Research paradigm}

This section justifies my choice and use of methodologies and methods, answering the questions of what kind of knowledge I believe to be obtainable through this study and what is the nature of that knowledge (Crotty, 1998). Answering these questions relies on a "basic belief system or worldview that guides the investigator" (Guba and Lincoln, 1994, p.105). A researcher's basic belief system consists of three pillars: ontology, epistemology and methodology - the "three musketeers of metaphysics" (Moses and Knutsen, 2007, p.4). Ontology defines the nature of reality; epistemology explains the relationship between the knower and what can be known; and methodology refers to the way of knowing or how 
the investigator gathers and analyses data in order to find the answers for his or her inquiry. The epistemology is determined by the researcher's ontological stance and, in turn, will constrain the methodology.

In the methodological literature, there are numerous ways to label different theoretical perspectives in social science. Orlikowli and Baroudi (1991) classify research approaches into three schools: positivist, interpretive, and critical studies. Later, Guba and Lincoln (1994) categorise research paradigms in social sciences into four main streams: positivist, post-positivist, critical theory and constructivist. Crotty (1998) also identifies some prominent schools in social science, including positivism, constructivism, interpretivism, critical inquiry, feminism, and postmodernism. Moses and Knutsen (2007) simplify all those complicated terms by dividing all research paradigms into two main schools: naturalism and constructivism. Naturalists assume that there is a real world, existing independently of our experiences (naturally); and we can gain knowledge about that real world by 'sensual perceptions', such as observing or recording. Naturalistic inquiry aims to capture the world "as it is"; logic and reasoning still can be used but they must be based on evidence and we can "distinguish between the value-laden and factual-statements" (Moses and Knutsen, 2007, p.9). Naturalists only claim knowledge when it "accurately corresponds to a state of affairs in real world" (Moses and Knutsen, 2007, p.50). Thus, knowledge about the world must be able to be tested and confirmed or falsified.

My philosophical assumptions are on the side of constructivists, as described by Moses and Knutsen, since I believe that each of us sees the world differently, and our perceptions are shaped by social and contextual influences and presuppositions (Moses and Knutsen, 2007). Reality can be classified into natural reality and social reality. In social science, social reality is the focus. Social reality is regarded as the product of negotiation among social actors about the meanings of actions and situations (Blaikie, 1993, cited in Crotty, 1998). Undertaking this research, I aim to shed light on a policy process at the local government level in Vietnam. That policy process is a social reality, which is "contingent on human practices" and is "constructed in and out of interaction between human beings and their world" (Crotty, 1998, p.42; Moses and Knutsen, 2007). I assume that the policy process did happen in a certain way and was affected by certain influences to reach a final outcome. In other words, a world was already there (Crotty, 1998). However, we can never tell exactly how and why things happen, because when we strive to make sense of that world, we start to use the experience of our minds to understand what we have observed (Moses and Knutsen, 2007). As Wilhelm Dilthey (1910) claims, we understand things 
when we transfer our own lived experience into expressions (cited in Stake, 2009). Perceptions of the world come to our mind and then are processed, organised, interpreted, and assessed in our mind, which is affected by our own ideas, foreknowledge, and lived experience, including experience on what we once were, how we developed, what decisions we made or why we made those decisions (Kant, cited in Moses and Knutsen, 2007; Dilthey, cited in Stake, 2009). From the perspective of a constructivist, I believe that even my participants see that process differently and I, as an outsider, perceive it in my own way. Ultimately, I question the capacity of social scientists to understand the world wholly 'as it is'. To put it in another way, the world exists, but there are multiple perceptions of the world (Moses and Knutsen, 2007). As conveyed by Crotty, the views we have to work with are far from being objective (Crotty, 1998) and people's perceptions of reality are altered by changing reality.

The knowledge that I will obtain is an understanding about a policy process in local government in Vietnam and influences on that process. A description of the process is achieved by interpreting the stories shared by participants and recorded documents. It is also important to note that attempting to assess influences on that process is different from striving to produce a causal relationship explanation. My understanding of influencing factors is obtained by interpreting participants' perceptions of what can impose effects on the LIH policy process in Da Nang City. Different participants at different positions can provide different evaluations. Moreover, we can never gather all possible evaluations from all participants in that process and the unavoidable missing pieces of data will make a statement of a causal relationship inadequate and illegitimate. The final understanding is the result of my personal evaluation based on carefully analysing obtainable data. It is not an absolute truth and cannot be used to predict other policy processes, even those that happened in the same government and concerning the same policy issue but at different times. What it can offer are some confirmations or better-established arguments regarding influences that have been claimed in previous research. Where my understandings are less well grounded, I will provide new hypotheses for subsequent researchers to pursue.

Since I am faced with a constructed social reality, my methodology requires me to understand the meanings and perceptions of people participating in that reality, taking into account the social, cultural and historical contexts. In doing so, I draw knowledge from society by interacting with people in that society, listening to them and reading texts written by them (Moses and Knutsen, 2007). In addition, before starting the investigation, I was equipped with some prior knowledge about potential influences on a policy process 
in Vietnam. Although I took steps to avoid imposing that prior knowledge on participants' responses, I still relied on it when seeking to understand participants' interpretation and documents. Thus, the ideas and foreknowledge that I brought into my investigation are not the sort of bias researchers must seek to avoid; rather they helped me to make sense of my data (Moses and Knutsen, 2007). Ultimately, I targeted the best understanding of the set of influences on the policy process in its contextual situation or a closest understanding of reality.

\subsubsection{Research design}

To answer the research questions, this study examines the case of LIH policy in Da Nang City to comprehend influences on the policy process in local government in Vietnam. A case study as defined by Simons (2009), is "an in-depth exploration from multiple perspectives of the complexity and uniqueness of a particular project, policy, institution, programme or system in a 'real life' context" (p.21). A case study is also described as an empirical inquiry that examines a contemporary phenomenon (the 'case') in-depth and within its real context, especially when the boundaries between the phenomenon and its context are not clear (Yin, 2014). In short, a case study is an intensive study of an analysis unit in its real context.

Case study research is a widely used research method in social science (Flyvbjerg, 2011; Rowley, 2002; Yin, 2014). It is sometimes regarded as not an ideal way of doing research. However, this perception may be due to some popular misunderstandings. Some people argue that case studies cannot be used for generalisation, especially single-case studies. Others believe that case studies are suitable for pilot research or in exploratory stages of an investigation while other types of research methods are more appropriate for the descriptive and explanatory phases. Case studies have also been criticised for lacking rigour and objectivity (Flyvbjerg, 2006, 2011; Rowley, 2002; Yin, 2014). These misconceptions have been rejected by many successful and famous case studies conducted in the past (Yin, 2014). Flyvbjerg (2011) argues that a case study is a valuable scientific method; can be generalised from to contribute to scientific development; can be used for generating and testing hypotheses, building and testing theory and other research activities; contains no greater bias than other methods of research; and enables researchers to summarise and develop general propositions and theories. According to Flyvbjerg, the primary strengths of a case study are that it can provide deep and detailed knowledge and enable researchers to understand the background context and process of the case. Most 
importantly, the case study is suitable for studying the causes of a phenomenon as well as the relationships between causes and consequences (Flyvbjerg, 2011).

To increase the rigour of case study research and enhance the value of this research method, Yin (2014) suggests researchers should avoid some common mistakes such as not following systematic procedures, and accepting equivocal evidence. Since biases in case studies occur quite frequently, he advises researchers to pay more attention to this matter and try to present all evidence fairly. Regarding the ability to generalise, Yin contends that case studies can be generalised to theoretical propositions and not to populations or universes. A researcher should consider his or her study as an opportunity to shed empirical light on some theoretical concepts and principles rather than as a sample to represent any larger population (Yin, 2014). Stake (2009) further explains that single case studies can be generalised to other similar cases rather than a population of cases.

In social science research, the case study is a more appropriate research method than other methods, such as experiments, surveys, histories, and archival analyses, provided that the study has the main research questions in the form of 'how' or 'why' questions (Yin, 2014). Rowley (2002) also notes that case study is a suitable method for descriptive and explanatory research. Descriptive research aims to make complicated things understandable by collecting, organising and summarising information about them, while explanatory research not only makes things understandable but also finds the reasons for things, to answer the questions: "why and how they have come to be what what they are" (Punch, 2014, p.19). This study is both descriptive and explanatory since it answers the questions of how a policy process happened and which policy actors were involved in this process (descriptive nature) and why proposed factors influenced the process (explanatory nature). Hence, using a case study is a proper choice to address the research questions identified in Chapter 5 and to assess the research framework designed in section 6.2. In addition, as Stake (2009) claims, a case study is best used to enhance existing experience and understanding of the social world, which is exactly what this study aims to do. Finally, applying a case study approach is also appropriate because this study focuses on a temporary phenomenon and the researcher has no control over behavioural events of the case.

Case study research can be single or multiple (Rowley, 2002). A single case study is chosen when the case is special and unique and there is no need for any comparison between different cases (Rowley, 2002; Thomas, 2011). In my proposed research framework, the 
role of the city's leader in Da Nang is unique. With early evidence drawn from media and from my working experience in Da Nang City, it is not overstated to say that the city's leader was a special politician who could profoundly influence the policy process in this locality. Thanks to this leadership, Da Nang has always been considered a special case of local governance in Vietnam by media and people around the country. The city also has some distinctive socio-economic conditions, which led to the introduction of the Having Housing Programme in 2005. This was the first local LIH policy adoption in the country. With this early engagement, the case of LIH policy in Da Nang City is the only case that enables an investigation of the development of the central-local government relationship through two different periods. The first period is from 2005 to 2009, when the central government just had some general ideas about LIH policy, and the second period is from 2009 to 2013, when the central government issued more detailed guidelines for local governments to follow. Additionally, the city's effort has been appreciated and praised by the central government. These special and unique features of the case recommend the single case study as the research design. Since the collection of data relates to a past phenomenon, this study will be classified as a retrospective study (Thomas, 2011) that examines the introduction of the Having Housing Programme and the development of the LIH policy to find out the influences on that process. In this case study, the LIH policy process in Da Nang City from 2005 to 2013 is 'the subject of the case', which is used to exemplify the research framework refined in section 6.2 or 'the object of the case' (Thomas, 2011), which serves the ultimate object of understanding the influences on the policy process.

The time boundary of the case starts at the point when Da Nang City government enacted the Having Housing Programme (2005), which followed the long-term targets set by the central government to develop affordable housing for low-income people. It continues to examine the development process of the housing policy to 2009 when the central government issued detailed guidelines for LIH policy and the city's response to these instructions. The case continues forward, and ends around 2013 when the central government issued more detailed guidelines for social housing policy. Since the implementation of these new guidelines is still in progress, it is too soon to assess their impact. This end point of the case also marks the commencement of this study. This case is selected and determined with considerations of the research questions and framework as well as other constraints such as data accessibility and time availability (Rowley, 2002).

\subsubsection{Data collection}




\subsubsection{Interviews}

This study uses semi-structured interviews (Myers, 2009; Olsen, 2012) to collect experiences and knowledge from the participants in the policy process. In semi-structured interviews, some guidepost questions are prepared but the interviewer does not need to adhere strictly to the order of the guide questions. Some prepared questions might be skipped if interviewees' responses have covered the expected issues while other new ones might emerge during the talks for further understanding of respondents' answers or for new ideas. The advantages of this data collection method are two-fold, as it helps interviewers cover pre-determined themes, and allows interviewees to tell their stories freely and gives space for interviewers to follow new lines of inquiry.

\section{The advantages of interviews}

According to Myers (2009), interviews are an almost mandatory data collection method for case studies in business and management. Though no research has showed that this method is compulsory for public policy studies, Rubin and Rubin (2004) claim that qualitative interviews are "especially good at describing social and political processes" to find answers for the questions "how and why things change" (p.3).

Through interviews researchers can understand experiences and reconstruct events in which they did not participate (Rubin and Rubin, 2004). An in-depth interview helps portray ongoing social processes (Rubin and Rubin, 2012). In interviews, researchers have the opportunity to gently direct the discussion so that they can get the insights they need from the subjects that they are studying. They also can develop the conversation based on new ideas given by interviewees during the conversation. The results of qualitative interviews are primary data, which are unique to the research and can be used to contribute added value to the literature (Myers, 2009).

\section{The disadvantages of interviews}

Although interviews have those advantages in drawing out rich insights of research subjects, Myers (2009) has noted some potential difficulties, problems and pitfalls of this method. First is the risk of incomplete data and artificial information due to the lack of trust, lack of time or interviewees' intentional distortions. The sample of people who are willing or able to talk to the interviewer also contributes to the incompleteness of the collected data. In this research, once interviewees agreed to participate in the study, they mostly seemed to open up and were willing to tell their stories. Time pressure was sometimes an actual constraint and I might have missed some segment of the data due to 
this constraint. However, the potential threat of 'creating' stories can be minimised by crosschecking with other sources of data.

Myers (2009) also raised the problem of 'level entry', meaning that once people at lower levels have been interviewed, it is more difficult to get access to higher-level informants. In another case, interviewing some people in one group (for example the labour union) might affect the possibility of interviewing people from other groups (such as the management board). Interviews might also have an elite bias: an interviewer might aim to access people of high status and ignore other informants. For this study, I tried to interview as many knowledgeable people as I could. The process is described in detail later in the section on interview participants.

Another disadvantage of this type of interview is that when respondents are allowed to talk freely, the conversations might last too long with too much irrelevant data or might finish too early if respondents are not talkative or do not open up (Myers, 2009). This happened once in this research and I had to slightly re-direct the conversation to remain on track.

The next two problems raised by Myers were about the potential influences that interviewers might have on their respondents through interacting and prompting interviewees. It is true that interviewers should be aware of this potential risk in order to avoid any deep intervention on their respondents' stories. However, as Myers (2009) points out, the role of interviewers is to listen, prompt, encourage, and direct. Through these actions, they co-construct the reality with interviewees and therefore the interviewer's effect on the dialogue is unavoidable but controllable. The interviewer can channel the flow of the narratives but cannot create or adjust the content of the answers. In this case, although I designed interview questions based on an initial research framework, the responses did not always confirm my propositions. Acknowledging these risks, nevertheless, is helpful in choosing questions and analysing data.

With the last two pitfalls, Myers mentions the mistakes made by inexperienced interviewers. They perhaps unconsciously use jargon or ambiguous language that may cause difficulties for interviewees in understanding the question. Some might unintentionally insult the interviewee, which may lead to the abandonment of the interview. Interviewers need to be aware of these mistakes and may only overcome them with experience. 


\section{Interview Participants}

Before commencing the data collection, I planned to conduct about 22 interviews. When actually conducting the fieldwork, things turned out to be more difficult than expected. I managed to conduct interviews with ten people in total. They had previously been or were currently working for the city Party, the Da Nang People's Council (DNPCl), Da Nang People's Committee (DNPCe), the Department of Construction (DOC), the Department of Labour, Invalids and Social Affairs (DOLISA), the Housing Management Company (HMC), two private companies, a research group, and the Da Nang Newspaper during the case timespan. In addition, I held some conversations (some via emails) with twelve knowledgeable people who were not willing to participate as formal interviewees but were happy to give me some information for my research. These informants worked for the DNPCl, the DOJ, the Department of Finance (DOF), the DOC, the Da Nang Statistics Office, the Priority Infrastructure Investment Project (PIIP), the Women's Union, and the Da Nang Newspaper (Appendix 3). These interviews and conversations were undertaken in the period from October 2014 to January 2015 in Vietnam, except for one in July 2015 in New Zealand during the interviewee's business trip to New Zealand and another two via email in 2016. I also had some conversations via Facebook message with people who posted statuses relating to my study's subject. In all cases, participants were informed about my research and agreed with me on their terms for using their opinions for my study.

Most of those I planned to interview are policy elites. Elite interviewing in policy studies is a desirable data collection method since it can yield valuable insights of policy processes. Elite interviews can produce 'confidential' or 'behind the scenes information' that nonelite interviews cannot (Schoenbergee, 1991, cited in Darbi and Hall, 2014). However, this method presents many challenges.

The greatest difficulty is gaining access to policy elites, which is a daunting exercise (Darbi and Hall, 2014). There are always barriers that distance policy elites from the public, including researchers. As Darbi and Hall (2014) point out, the most common barrier is their personal or executive assistant. This was what I encountered when I tried to access leaders of the city Party and the DNPCe. All effort to contact their assistants by phone, via email, through networking or even their relatives, failed. One assistant advised that meeting the new Party Secretary was impossible because the Party Secretary never met media for interviews. However, this leader was still often quoted in local media regarding important events or when introducing some policy decisions. He even organised a meeting 
with the media in 2015 to express his gratitude to the media for their contributions to the development of the city. On this occasion he also mentioned the fact that sometimes media news is inaccurate and "leads to the distraction in the job of directing people's minds" (Hai Chau, 2015). It seems that the policy elites in Vietnam will come to the media when they need to mobilise support from the general public (mobilisation model [Cobb et al., 1976]) and will stay away from them if it comes to talks for other purposes. One interesting observation in the response of the assistant above was that he did not want to distinguish between research interviews and media interviews. He simply put 'interview' as a prohibited activity. Perhaps policy elites and their assistants were afraid of uncontrollably negative consequences to their political images from talking to outsiders that they do not trust. From my own experience, some politicians did consider journalists to be 'troublemakers'. Additionally, it is not easy to find an incentive for those politicians to be involved in media or research activities.

In another case, through networking, I had successfully obtained the support from one elite's assistant (one Vice-Chairman of the DNPCe), but the elite himself refused to meet and advised (via his assistant) that I should interview his staff rather than trying to meet him. His refusal can be understood as a matter of power distance. I guessed he found no reason to meet an ordinary government official just for her own study. After this, with his relative's assistance, I got the elite's agreement to meet but then he cancelled the appointment when receiving my description of issues to be discussed, including questions about the relationship between the policymakers and the private sector. The assistant of the elite claimed that his boss had not promised to meet but then revealed that the elite said those issues were too sensitive to be addressed. I understand this second refusal as the avoidance of being involved in interviews and disclosing internal political stories of the system as mentioned above. This experience confirms the challenges of gaining access and trust in elite interviews, as described in the literature (Darbi and Hall, 2014; Drew, 2014; Mikecz, 2012).

The attitude of avoiding interviews was shown in many other cases. One Director of an important department refused to meet because she was retired and afraid of getting involved again in those working issues. Another difficulty in accessing policy elites in Vietnam is that their contact information is not public. Even when I managed to obtain their contact numbers or email addresses, I was sometimes unable to gain their responses. 
Moreover, accessing policy elites is stressful partly because they are genuinely busy. During the three months of my data collection in Da Nang, I struggled to find a good time to contact a member of the DNPCl and also a member of the city's NA Delegation, who was my acquaintance. I was quite optimistic that getting access to him would be easy. However, as a member of the city delegation to the NA, he spent a lot of time in Ha Noi. When he came back to the city, his schedule was always full. When I eventually contacted him, he told me that he had nothing to say about the policy.

As Darbi and Hall (2014) point out, luck and chance are vital in elite interviewing. The Party Secretary during the time of my case study, Mr Nguyen Ba Thanh, an informant that I most desired to interview, was critically ill at the time I conducted my data collection; and then he passed away. All efforts to access two of his assistants had no success.

In spite of those difficulties, I managed to access two elites and some non-elite but knowledgeable people. Access to these interviewees was assisted mostly by local informants (Fontana and Frey, 1994), including the former director of my employer, my colleagues, and friends and acquaintances working in various Party and government agencies in Da Nang City.

One of them was among key policymakers of the case. Another interviewee used to work at the DOC at the time of my case. These two respondents were deeply involved in the decision-making process and the preparation of the policy documents. They therefore offered unique insights about the policy process. Both of them were accessed through personal and professional networking.

Since calling and sending letters to governmental agencies is often met with silence, I decided to directly come to all relevant administrative agencies to ask for information and access to informative people. This was quite awkward but it did help me to arrange an interview with one department's Vice Director. It took me three attempts to meet this informant and luckily he agreed immediately to participate in the study. On the day of the interview, I noticed that there were some journalists around his office with a big camera imprinted with the logo of a well-known television broadcaster. He was a little late for our appointment, excusing himself as being stuck in a media interview. This suggested that people who had had experience working with media are more accessible. This man was the easiest to access in my case. Nevertheless, this strategy did not work for other people. Another interviewee used to work for the DNPCe. I made several phone calls to his number but he never picked up the phone. Through my professional network, I found his home 
address. After being refused entry by one of his family members, I was fortunate to meet that informant while he went for a walk around his house. Then we made an appointment over the house's fence. On the day of the interview, he still did not pick his phone up to confirm the appointment until receiving my message explaining again who I was and why I called. As discussed above, government officials at a reasonably high level seldom take a phone call from an unfamiliar number. In addition, their email addresses were not public and some of them do not even use email. It therefore seems impossible to contact them except by a direct encounter or by making arrangements through someone they trust. Another respondent came from the DNPCl. His first question for me when I called to ask for an appointment was to ask who gave me his phone number and who recommended contacting him. Both the fourth and the fifth respondents had close relationships with the late Party Secretary as a long-time friend or an executive assistant.

The sixth interviewee was a senior Party cadre. He therefore obtained some very special information that was retrieved from his diaries. Unfortunately, my interview with this informant was interrupted and finished early because he had to chair a meeting that was not in his schedule.

Two other respondents were representatives from private construction companies that were developing in LIH in Da Nang City. These were both easily contacted by phone and email. The last two interviewees answered my questions via email, including one researcher (who later became one of the city leaders) and one journalist.

Though it was difficult to access interviewees, once they agreed to participate in the study, all of them were open and willing to disclose their knowledge and experiences. They all felt comfortable in expressing their opinions.

Overall, I could not manage to interview some key elites who were directly involved in the policy process and had the power to make final decisions, such as the late Party Secretary, the Chairman of the DNPCe, and some Directors of the city's departments. As a result, I am unable to report their own understanding of influences on the policy process. However, my interviewees are representatives from all important Party and government agencies; two of them were policy elites and some others were working closely with policy elites as a technical professional or executive assistant or leader of implementation team. They were directly involved in the process and could offer explanations for the justification of the policy content. Moreover, they had local knowledge about the cultural, economic, social and political context of the housing policy decisions in Da Nang City, which can be helpful 
in interpreting the influences on the process. Some general observation from this interviewing experience are that: 1) personal and professional networks are an essential element in conducting policy interviews in Vietnam; 2) a direct encounter might be more useful than sending an email or making a phone call; and 3) there are always exceptions: some people are very easily accessed, open and helpful.

In summary, although the number of interviews was less than I had hoped, the ones that I conducted yielded valuable information for my investigation and significantly contributed to the trustworthiness of the findings. In addition, I have been able to supplement this information with some formal conversations and a range of informative documents to construct a story of my case.

\section{Interview Schedule}

Most of my interviews happened at interviewees' offices; only one was at an interviewee's house and another one was in New Zealand.

All of my interviews were opened by an expression of gratitude to the interviewee for participating in my research. This aimed to make interviewees feel welcomed and comfortable for the coming conversation. A brief introduction of my research and the purpose of the interviews would be presented though in some cases my interviewees had read the information sheet and consent form in advance (see Appendix 1). Then I would ask for the interviewee's permission for recording. Though I had always explained that the recordings would only accessed by my supervisors and myself, most of my interviewees refused to be recorded. One interviewee explained that he had been involved in a media interview and the journalist had reported his opinions inaccurately. That led him to some trouble and made his boss and the city leaders disappointed. Therefore, he did not want to be recorded while promising to speak slowly so that I could take good notes.

Another respondent agreed to be interviewed with a condition that his participation in this study must be strictly confidential. He wanted no one to be informed about his participation. One respondent from a private company explained that he would mention some sensitive issues in the conversation and it was safer not being recorded. Only three interviewees agreed to be recorded, including one policy elite. One interviewee refused to go further in a sensitive matter while he was recorded but was willing to elaborate the issue when the recorder was stopped. I found that the conversations with people who refused to be recorded were more informative than ones with people who were recorded. It is likely that when the conversations were recorded, the interviewees tended to be more cautious in 
their responses and held back from disclosing any sensitive information or any 'behind the scenes' stories. It may be that they knew there would be nothing risky in their response and therefore agreed to be recorded. Those conversations were quite formal. Meanwhile, interviewees who refused to be recorded seemed to be more comfortable and sometimes could talk to me as if to a friend with all their personal feelings expressed freely.

The main body of the interviews were the conversation between me and interviewees around some pre-determined guidepost and follow-up questions. Since most of my interviews were not recorded, I had to listen attentively and take notes simultaneously. Some interviewees deliberately spoke slowly so that I could capture the content of the conversations. Most interviews started with some tour questions (Rubin and Rubin, 2012), asking interviewees about their working positions at the time of my case study, about their and their organisations' roles in the policy process. Then I started on the main questions, which were adjusted to suit the interviewee's knowledge area and their roles in the process. When interviewees mentioned some new ideas, I would follow up to obtain more relevant detail. The length of interviews ranged from thirty minutes to one and half hours. All interviews were closed by another expression of gratitude and asking whether interviewees would like a report of the content of the interview. All interviewees agreed that they would continue to help via phone call or email to clarify the content of the interview. Applying a snowball technique, I asked my interviewees to recommend other informants. With one exception, this did not generate any further useful leads.

Some interviewees wanted a summary of their interview, others just asked for a copy of my thesis's summary. For long interviews with much information, I re-wrote my notes right after I finished the interviews.

\section{Interview Questions}

Before commencing my data collection, I had prepared some guidepost questions based on the proposed research framework in order to find data to verify my propositions. I also kept my mind open to new ideas emerging during the interviews. The pre-determined questions were around the two research questions:

1. How has LIH policy process evolved in Da Nang City? What policy actors have been involved in the process?

2. During that process, what factors influenced policy actors? How and why are those factors important? 
Depending on the role and position of each interviewee, I would adjust my list of questions. Based on their response I would follow up with more questions to clarify my previous assumption or new emerging ideas.

A list of prepared guidepost questions is presented in Appendix 2.

\section{Interview Transcription}

All interviews were conducted in Vietnamese. There were only three interviews recorded and transcribed. Other interviews were recorded with written notes.

\subsubsection{Document collection}

“... if an event happened, some record of it exists ... [if one] knows how the world works ... one can imagine the tracks that must have been left by the action ... [and] if one knows one's way around the world of records, one knows where to look for the tracks" (authors' emphasis) (Lincoln and Guba, 1985, p.278)

These assumptions answer the question why non-human sources can be used as data for qualitative research. Non-human sources, as defined by Lincoln and Guba, include documents and records. My study works on a social phenomenon involving many local government agencies' activities. Thus, documents were essential tools for communication among stakeholders. Collecting documents, therefore, was an important method for collecting data for my study. Collected documents include official documents circulated among government agencies during the policy process (such as resolutions, decisions, plans, state letters, reports); documents as evidence of activities of a process's participants (meeting minutes, preparation for media conferences, and preparation for policy elite's public speeches); and records of the result of the policy's implementation. State letters, meeting minutes, preparations for media conferences, preparations for policy elite's public speeches and reports provide rich insights into the policy process and influences on that process.

According to Lincoln and Guba (1985), using documents and records (written materials) as data sources has many advantages. First of all, compared to collecting data from interviews, focus groups or observation, collecting documents can be easier and achieved at lower cost. Secondly, written materials are stable and durable over time. Thus, they may accurately reflect past situations and can give historical insight. Unlike human memory, documents are particularly useful in providing accurate information relating to numbers and time. Another advantage of written materials is that many of them cannot be modified; 
especially those that are certificates or official records of events. Written data is also rich in information and contextually relevant. They can bring about the "knowledge of the history and context surrounding a specific setting" (Marshaw and Rossman, 2006, p.107). Finally, they are nonreactive sources (Marshaw and Rossman, 2006). This means that there will be no deliberate change in the data sources to respond to an investigator's enquiry though the investigator still makes an interpretation when working with them.

My collected documentary data embody all those advantages. If interviewees could make mistakes in remembering some activities in the past, documents could help fix that problem. Documents were particularly helpful to sort activities of the policy process in chronological order, and hence are useful to construct the narrative of the story. Documents also contain a great deal of numerical data which interviewing data cannot offer. They provide rich information and reflect the case context to complement the incomplete oral data.

Despite those advantages, using documents as a data source has also been criticised for being possibly unrepresentative, lacking objectivity, of unknown validity, and possibly deliberately deceptive (Lincoln and Guba, 1985). Silverman (2011) also suggests that documentary data need to be cautiously treated since they are constructed realities made by organisations and sometimes do not reflect the whole story. Nevertheless, Lincoln and Guba explain that dealing with atypical and objective data is a part of constructivist research and the risk of being deceived should be carefully considered in analysing any type of data, including observational and interview data. The problem of validity can be addressed by applying some recommended techniques in collecting and analysing data, such as checking the credibility of the writer; testing the value of the document against other forms of evidence; or checking for internal consistency and coherence within the document (Hodder, 1994; Lincoln and Guba, 1985). Text materials should also be understood in the context of production and circulation to infer implicit information and attached values (Silverman, 2011). Even with some disadvantages, documentary data should be treated as important as other types of data (observational and oral data) since they are documentary versions of reality and reflect the setting in which they are produced and circulated (Silverman, 2011). They are also evidence of interactions, which are subjects of social studies (Silverman, 2011).

Reflecting on my documentary data, the most obvious disadvantage was that formal documents do not reflect some aspects of the process, such as the actual conflicts, the 
personal calculation while making decisions, or behind the scenes activities. However, interpreting activity could help to infer some meaning between the lines in those documents.

Regarding the availability of data, my collected documents can be divided into two main types: published and unpublished. Published documents include the DNPCe's decisions, DNPCl's resolutions, information on the city's expenditure and revenue available on the website of the Ministry of Finance, newspaper articles and statistical yearbooks. Obituaries in newspapers and social media after the death of the city's former Party Secretary as well as a book about him were also a source of information for interpreting the role of this policy elite in housing policy in Da Nang.

It is more difficult to gain access to unpublished documents. Accessing these documents needs professional network support. The sources most difficult to access in my research were documents from the city Party because most of them were circulated only inside the Party system. One of my acquaintances who worked at the city Party provided me with some important documents relating to LIH policy. This person was informed about my research and explained the purpose to his colleagues when collecting the documents for me. Some other documents were from the city Records and Archives Agency. Though they are not limited use or secret documents according to the Law on Archives (2001), I still needed assistance from officials at the DNPCl and the DNPCe to gain copies.

I was also very lucky to be given a collection of great number of electronic and hard copy documents relating to LIH policy, maintained by two officials of the DOC. One official simply copied all of his relevant electronic files for me; the other let me choose any documents I wanted from his personal collection of housing policy documents. Given that they are people who directly managed the LIH issue in the city, their unpublished written materials were very informative and important. They covered various events relating to LIH policy, including interactions among different policy actors. Therefore, they helped me to understand some aspects of the policy process, which I could not get from my interview data.

I also collected unpublished documents from the DNPCl, the DNPCe, the DOLISA, the DOF, the Department of Home Affairs (DOHA), the Department of Planning and Investment (DPI), the Da Nang Investment and Development Fund (DNIDF), the PIIP, the Women's Union, and the Da Nang Institute for Socio-Economic Development (DISED). One lesson from collecting documents in this study is that a very good relationship with 
some officials at those government agencies is needed to access their documents. Some other experiences led me to an assumption that those government agencies were able to trace documents in the past but they were not always willing to do so for an outsider. The main reason was that they had no motive to spend time on it. Finally, when looking for a document, it is better to obtain detailed information about its provenance, such as its number and date, otherwise it is unlikely to be tracked down.

In summary, in addition to published documents that could be accessed online, I collected a great number of unpublished documents. Among them, I analysed and translated 105 documents to produce the data findings (Appendix 4). The remaining documents helped me picture the background context and the role of various actors and other aspects of the policy process. They enhanced my knowledge about the case and the interpretation of the data.

\subsubsection{Data analysis}

This section presents the procedures and techniques used to interpret the collected data.

\subsubsection{Documentary data}

Before analysing the collected data, I had identified some key themes for data analysis based on my initial research framework and published information about the policy in the media. The themes were 'policy process', which would be used to label any piece of data that reflected different stages of the process; 'city Party and Party Secretary', 'the private sector', 'research community', 'media', 'PIIP', 'mass organisation', and 'the people' - all were used to label data of policy actors; 'central-local government relationship' and 'socio-economic conditions' were used for the two remaining potential influences in the framework; and 'influences of other policies' and 'other influences' were themes for coding the influences of other relevant policies and other factors that have not been foreseen in the initial research framework.

I read each document thoroughly to determine if there was any part that could be used for data analysis (sampling [Bernard and Ryan, 2010]). If so, I extracted that part and translated it into English. The extract was stored in a Word file. At this point, I coded the original document by a number (for example, D1), reflecting its order in my analysis process and serving for the purposes of citation, storage, and retrieval. The file was placed in a separate folder for data management. 
After finishing the translation of all relevant parts of one document, I would make my comments for that document. The comments include my interpretation of the meaning and value of that document for my investigation as well as thematic labels for those chunks of data (marking texts [Bernard and Ryan, 2010] or coding [Myers, 2009]). One or several themes can be assigned to a piece of data. This translation, interpretation and thematic labelling (coding) were conducted for 105 documents.

Next, in an Excel file, I entered the pre-identified themes in a table. When a document was analysed, I put the key meaning of that document in the column of the relevant theme. This can be considered the sub-theme of the thematic analysis (identifying [sub-] themes, [Bernard and Ryan, 2010]). For example, one document was about the 'legal constraints' from the central government while another one showed the 'financial assistance' from the central government. They both belong to the 'central-local government relationship' theme but reflect two different sub-themes. By the end of the analysis, I had a table of themes and sub-themes (building codebooks [Bernard and Ryan, 2010]). While themes were identified prior to the data analysis (deductive approach), sub-themes were developed along with the analysis (inductive approach [Bernard and Ryan, 2010]) and served for organising my data report on each theme.

After finishing the steps of sampling, translation, interpretation and thematic labelling, I started my thematic analysis. All pieces of data and my interpretation relating to a certain theme were placed in one file in a chronological order. Reading the file thoroughly and referring to the table of themes and sub-themes helped me understand the meaning of data. I also considered whether they supported my initial propositions (Rowley, 2002) and how they were linked to each other (Bernard and Ryan, 2010). The chronological order of the data was very helpful in organising my data report on the narrative of the policy process and the sub-themes were useful for presenting data on the influences.

In my document analysis, I did not apply quantitative techniques, such as counting the frequency of themes or measuring the proportion of text dedicated to a theme. It is partly because the analysed documents are neither a complete record nor a representative sample; and partly because I believe those quantitative techniques would serve little in helping me gain insights into this case.

\subsubsection{Interview data}

As presented in section 6.2.3.1, due to the small number of interviews, interview data were mainly used for corroborating, complementing and triangulating the larger amount of 
documentary data (Bernard and Ryan, 2010; Myers, 2009). For example, missing documentary data on activities and discussions within the city Party were complemented by transcripts and notes from interviews with two senior Party cadres. Interviewees were assigned a number (for instance, R1).

\subsubsection{Interpretation}

My interpretation process started at the very beginning of this research, reflected in my choices of case and initial framework to answer my research questions. These choices indicated partly what I expected to learn from this inquiry. The interpretation continued in my selection of interviewees and documents to ensure the best possible collection of relevant evidence. It was also reflected in the expansion of my data collection after I had finished the fieldwork to fill the gaps in my construction. Further, I interpreted when coding and categorising segments of data, making sense of them and grouping them into themes as well as choosing extracts to include in reporting the themes in this thesis. Interpretation was also at play in my effort to triangulate data from different sources to assess the authenticity of collected data and to enhance the credibility and worthiness of my construction. The process finished when I turned back to the literature to identify my findings and specify the research contributions. Since the interpretation was a result of my judgment on a collection of facts and opinions based on an integrated theoretical framework, it was indeed "an act of imagination and logic" (Peshkin, 2000, p.8).

\subsection{Summary}

To answer the questions of how a policy process happened in local government in Vietnam and what were the influential factors of that process, I decided to design a research framework, based on Hofferbert's funnel of causality model and insights from other theories as well as from prior knowledge about policymaking in developing countries and single-party states of China and Vietnam. This framework guided the investigation of the case of LIH in Da Nang City from 2005 to 2013, which has potential to exemplify the initial research framework. Data were collected from interviews with policy participants and documentary sources. Collected data were analysed using qualitative techniques. Triangulation across data sources was used to ensure the validity and enhance the comprehensiveness of findings. 


\section{Chapter 7: An overview of Da Nang City}

\subsection{Introduction}

This chapter presents some key historical, geographical, social and economic conditions of Da Nang City before the enactment of the Having Housing Programme in 2005 and during the case's timespan. This is the background context for understanding the policy process and its influences.

\subsection{An overview of Da Nang City}

Da Nang is a coastal city, located in Central Vietnam, 766km south of the capital, Ha Noi, and $957 \mathrm{~km}$ north of the biggest city of Vietnam, Ho Chi Minh City. The city is located on National Route 1A and the North-South Railway and has a well-developed airport and an easily accessible seaport. This location makes the city a transportation hub for Central Vietnam. It is also the exit to the sea of the East-West Economic Corridor, connecting Vietnam, Laos, Thailand, and Myanmar.

\subsubsection{Area and population}

Da Nang has an area of $1,285 \mathrm{~km}^{2}$ and a population of almost one million people with $87 \%$ living in urban areas as of 2013. The population grew at an average rate of about $2.2 \%$ in the period from 1997 to 2013, mainly from immigration. According to the 2009 Population and Housing Census, Da Nang was one of the provinces that had the highest net migration, ranking fourth in the country. By June 2012, about 19\% the city's population was immigrants from other provinces (Da Nang Home Affairs Department, 2012).

The population density increased from 545 people $/ \mathrm{km}^{2}$ in 1997 to 772 people $/ \mathrm{km}^{2}$ in 2013 . However, the population distribution was uneven among districts. For example, the population density in Thanh Khe Districts reached 19,192 people $/ \mathrm{km}^{2}$ in 2011, while that of Hoa Vang District was just 167 people $/ \mathrm{km}^{2}$. In 2012, the two central districts, Hai Chau and Thanh Khe, with only $3.1 \%$ of the city's area, had $41 \%$ of the total population (Da Nang Home Affairs Department, 2012).

\subsubsection{Economic development}

Doi Moi produced positive effects on the city's economic development as in other localities in Vietnam. However, the impact it generated on the city from the late 1980s to 1997 was not as impressive as in the other two urban hubs of Vietnam (Ha Noi and Ho Chi Minh City). The reasons for this, as according to X. T. Nguyen (2003), were two-fold. First, the city's 'low-valued industry sector' with weak linkages to other industrial centres, 
'unsophisticated service sector', and low-purchasing power population could not act as strong engines to boost economic development. The second but more important reason was that until 1997, the city had been part of the poor Quang Nam-Da Nang province and therefore had no freedom in budget management or setting development strategies.

Once it had the advantage of provincial status, the city enjoyed more independence in budgetary matters. Its budget increased more than 3.4 times in the period from 1997 to 2003 (Da Nang Statistics Office, 1997-2013), Gross Regional Domestic Product (GRDP) in 2010 prices grew at $9.9 \%$ annually in this period (Figure 7.3). During this period, the city's economic development relied heavily on the state sector, especially in 2002 and 2003 (Figure 7.1).

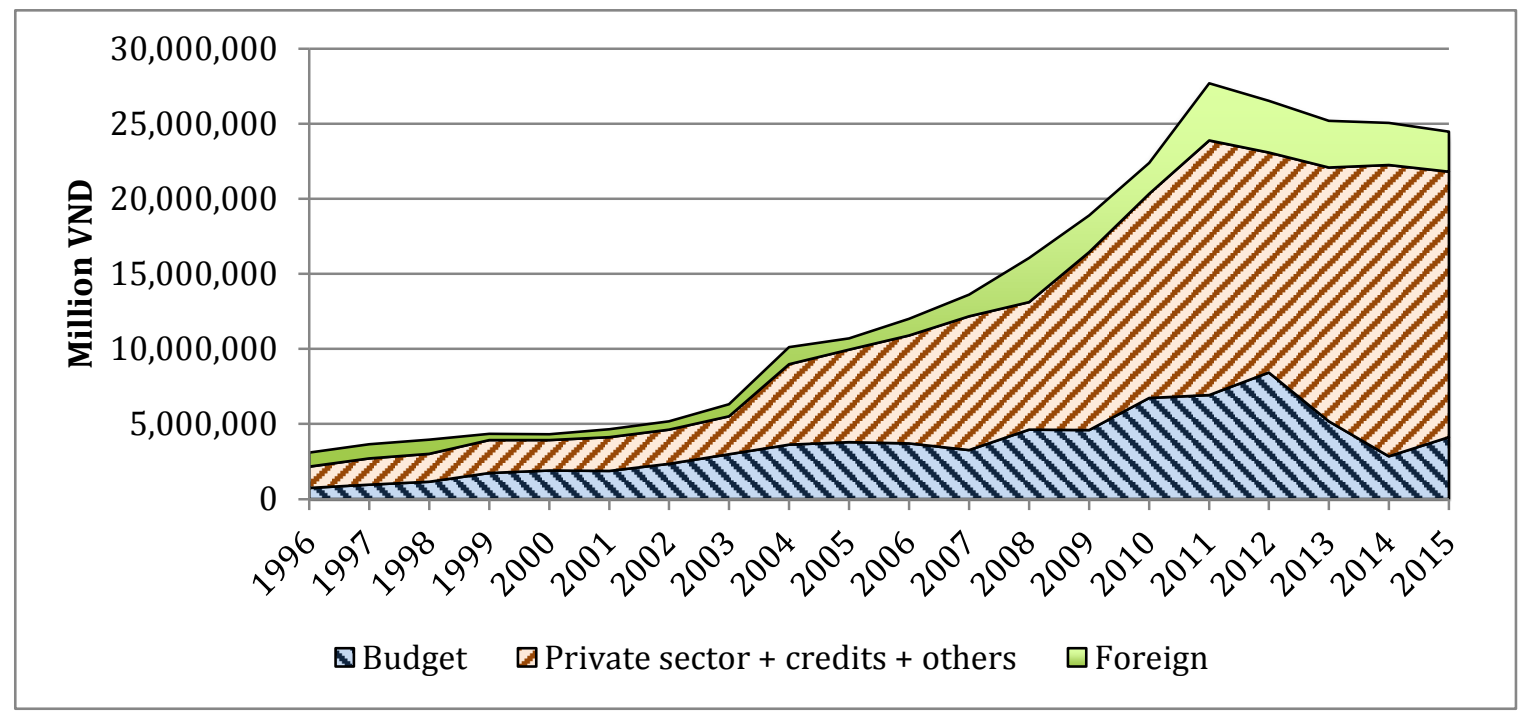

Figure 7.1: Sources of finance for investment in 2010 prices in Da Nang

Source: Da Nang Statistics Office (1997-2013), private update in 2017

In 2003, Da Nang was classified as a Class 1 city by the Prime Minister. This status enabled an increase in infrastructure development supported with central government finance, which led to land price escalation. It also elevated Da Nang into the group of key urban areas in Vietnam (other important cities were Ha Noi, Ho Chi Minh City and Hai Phong). Also in this year, the Politburo issued Resolution 33 on Da Nang's industrialisation and modernisation to facilitate the development of the city (the Politburo only issued specific resolutions about the development of important cities). In this document, the central Party expected that Da Nang should become an economic centre and a motivating force for the Central Region of Vietnam (meanwhile, Ha Noi was chosen as the centre of the north focal economic zone and Ho Chi Minh City was the centre of the South focal economic zone 
[X. T. Nguyen, 2003]). Da Nang was also expected to be one of the localities leading national industrialisation and modernisation, to become an industrial city before 2020 . The resolution also approved development of some key city infrastructure projects, financially supported by the central government and with the central Party influencing central government to speed up progress. Followed this resolution was the Prime Minister's Decision 13 (2006) on preferential financial and budgetary policies for Da Nang City, which legalised the key infrastructure projects approved by the Politburo and offered some preferential policies on rewards when actual revenue collections exceeded estimates and for mobilising financial resource for development investment.

From 2003, the status of a city of level 1 and Resolution 33 as well as the effect of the Law on Enterprises in 2000 increased the attractiveness of Da Nang to private investors. The introduction of the PCI (Provincial Competitiveness Index) in 2005, which measures the competitiveness of provinces in the country, might also have encouraged private sector investment. Da Nang ranked first in the PCI in five years (2008, 2009, 2010, 2013 and 2014) and at other top positions in other years (VCCI and USAID, 2015). With these achievements, from 2003, the private sector's contribution to the total city's GRDP growth increased dramatically (Figure 7.2). Meanwhile, the city government also began equitisation ${ }^{9}$ of SOEs, which shrank the proportion of the state sector in the economy, following the common trend in the whole country.

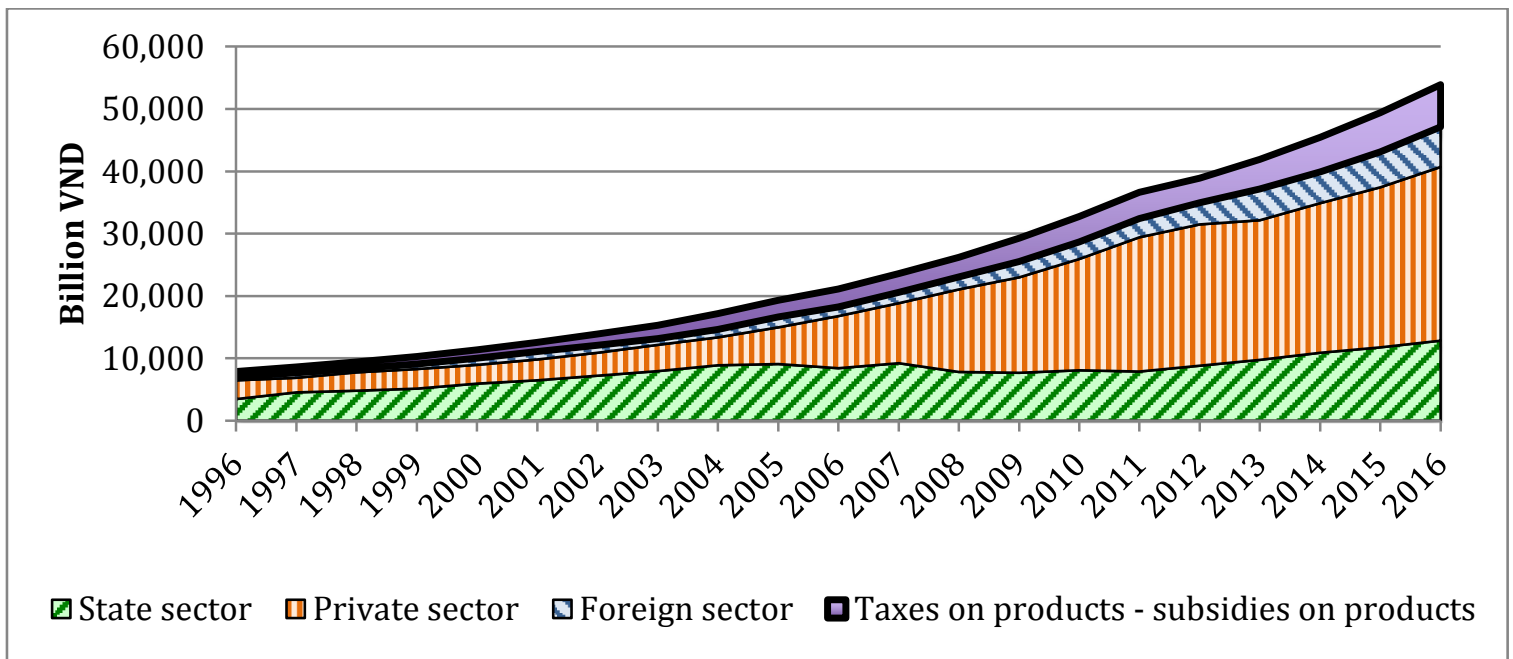

Figure 7.2: Contribution of economic sectors to Da Nang's GRDP in 2010 prices

Source: Da Nang Statistics Office (1997-2013), private update in 2017

The contribution of the city budget to total investment in the city increased steadily from

\footnotetext{
${ }^{9}$ Due to its political sensitivity, privatisation of SOEs was called equitisation in Vietnam.
} 
2003 to 2012 but then decreased significantly as a result of the contraction of budget revenue from land from 2012 and the increasing role of the private sector from 2003 onwards (Figure 7.1).

The city's official annual GRDP growth rate averaged about 10.3\% from 1997 to 2013 (Figure 7.3). ${ }^{10}$ GRDP in Vietnam is not very reliable; Nguyen (2003) advises that when interpreting this number we should reduce it by about $2 \%$. Nevertheless, this GRDP growth rate was still much higher than the average growth rate of Vietnam (about 6.5\%) (World Bank, 2015a). The city's high GRDP growth rate is similar to other big cities, though not as much as Ha Noi and HCM City (World Bank, 2015a).

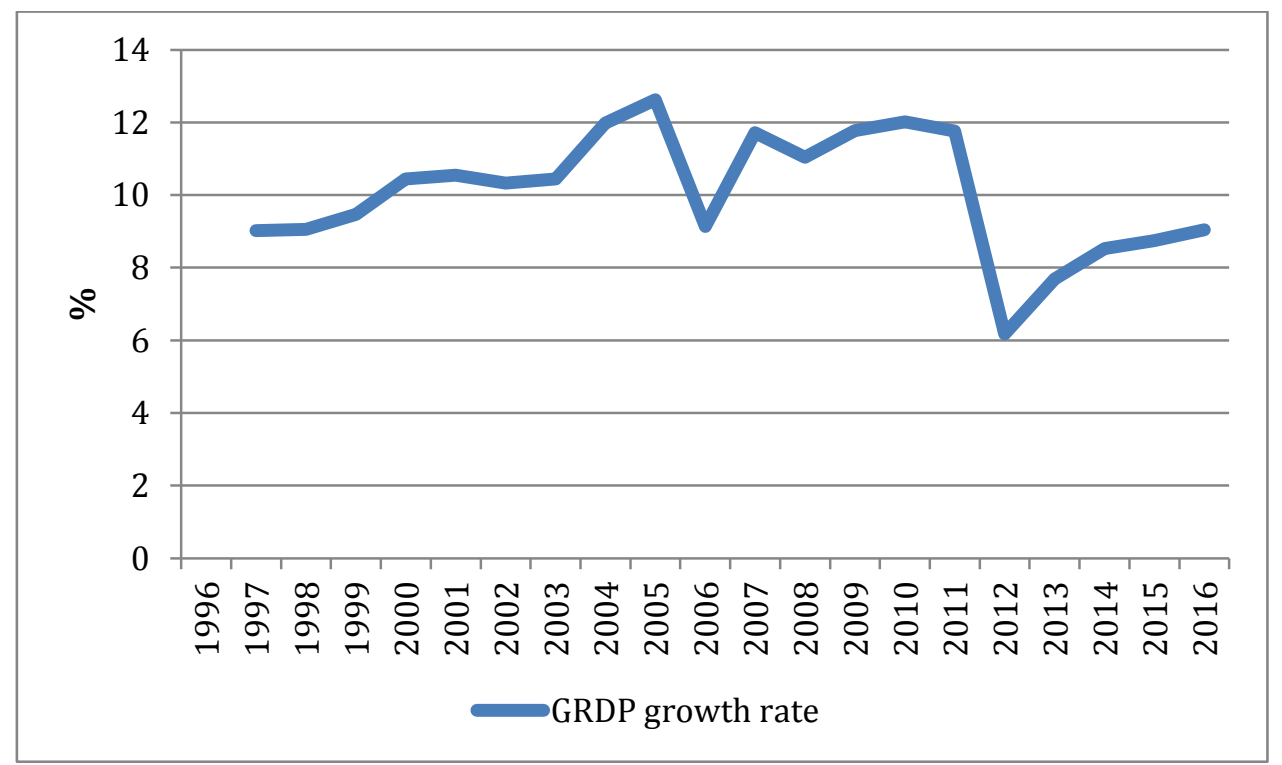

Figure 7.3: Growth rate of Da Nang's GRDP in 2010 prices

Source: Da Nang Statistics Office (1997-2013), private update in 2017

\footnotetext{
${ }^{10}$ According to the city Statistics Year Books, from 1997-2009, real GRDP was calculated in constant prices of 1994; from 2010 to present, real GRDP was calculated in constant prices of 2010. Due to the inconsistency in the series of data, in 2017, the Da Nang Statistics Office provided me with a united series of GRDP from 1997 to 2016 (the figures of 2015 and 2016 are not finalised). Therefore, the data used in this section are slightly different from those in the Year Books.
} 


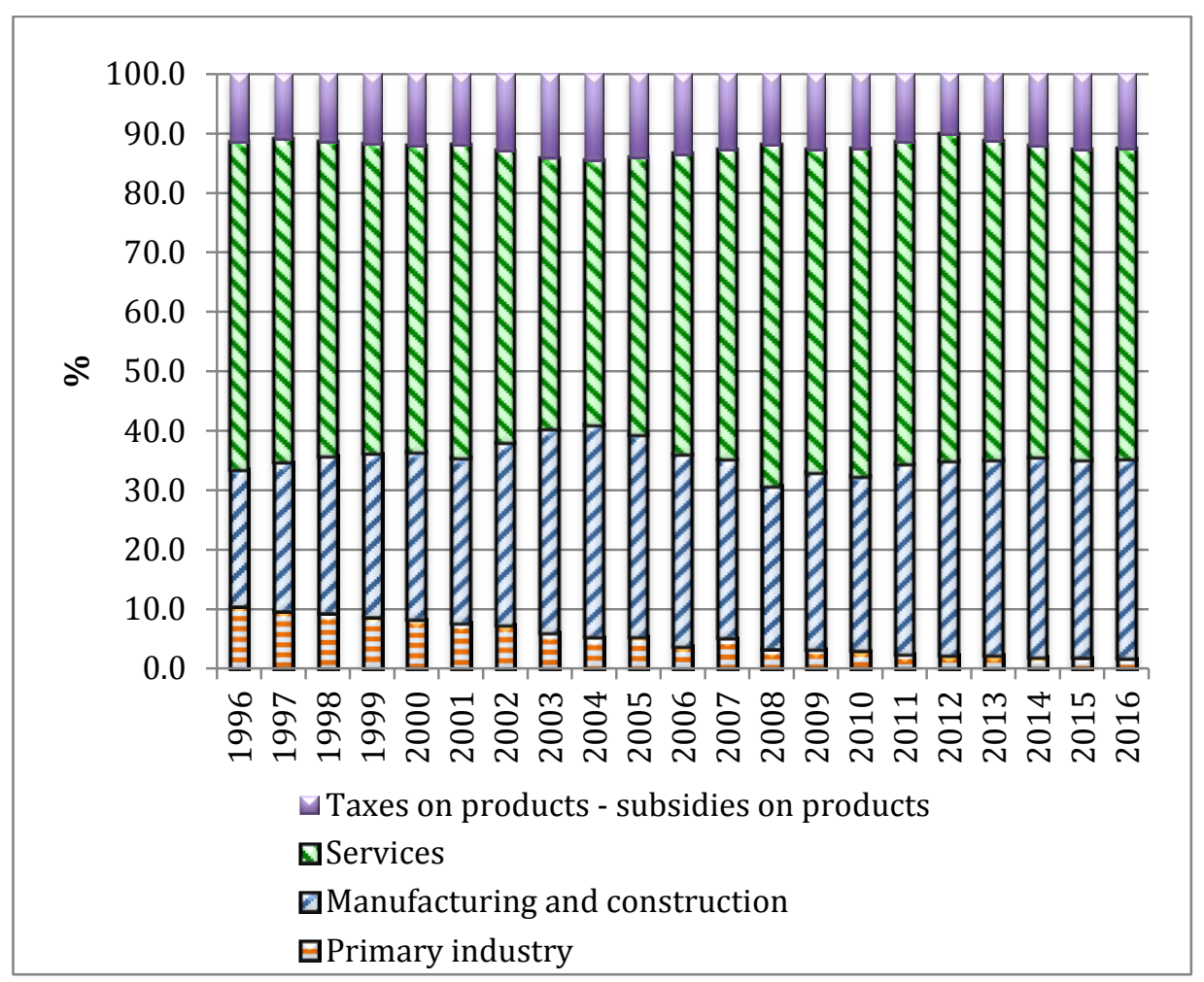

Figure 7.4: Contribution of economic sectors in Da Nang's GRDP in 2010 prices

Source: Da Nang Statistics Office (1997-2013), private update in 2017

The city's economic growth was also reflected in the changes in the economic structure. From 1997 to 2013, the share of the primary sector (agriculture, forestry and fisheries) to the city's economy steadily reduced, reflecting the average high growth in manufacturing and construction and in services (Figures 7.2 and 7.4).

A major state sector investment activity was in infrastructure. Total investment for development in the city from 1997 to 2009 reached 82.2 trillion VND, of which investment for infrastructure took 61\%, increasing from 1.1 trillion VND in 1997 to 7.4 trillion VND in 2009 (Da Nang People's Committee, 2010). Total state investment for development in Da Nang City in the period from 1997 to 2009 was 23.3 trillion VND, or about $50.3 \%$ of total local budget expenditure (Da Nang People's Committee, 2010).

In a speech to celebrate 30 years of liberation of Da Nang City, the Party Secretary stated that the biggest success of the city was city planning, infrastructure building and urban upgrading. He compared the city to a construction site, which was always in a rush for a better city image (D92, p.8). The city applied two fundamental principles in infrastructure improvement: the first was "The state and the people work together" (Nha nuoc va nhan dan cung lam). This principle has been followed widely in Vietnam when the state invests budget in infrastructure upgrade projects (especially for rural roading). Since the local 
people would benefit from the improved infrastructure, they were expected to contribute some resources to the project. For example, they could agree to give a part of their land for free because the remaining part would be more valuable when the project finished; or they could also contribute some labour and financial resources. One typical example of this situation was the construction of the Han Bridge in Da Nang City, where local people contributed more than $28 \%$ of the total cost of the bridge (X. T. Nguyen, 2003).

The second principle was "Exploit the land fund to create capital for infrastructure improvement" (Khai thac quy dat tao von xay dung co so ha tang): the city government would provide land to investors in return for land-use fees, which would be used for infrastructure improvement in the whole city. By 2012, the city had cleared out all temporary houses and slums; developed hundreds of apartment blocks and condominiums; built seven bridges over the Han River (valued at more than 5,000 billion VND); established six industrial parks, a High Technology Park and a Concentrated Information Technology Park; built up a network of schools all over the city, constructed many new hospitals and some district clinic centres; and upgraded several cultural landmarks such as theatres, museums, and sport centres (D101). Many other huge projects that contributed to the city's development, such as highways, an airport, a seaport, and a tunnel, were funded by the central government's budget and Official Development Assistance (ODA). The effect of urbanisation was reflected in the increase in the city's land for non-agriculture purposes (built area), which rose from around 31\% $\left(390 \mathrm{~km}^{2}\right)$ in 1997 to over $41 \%$ $\left(530 \mathrm{~km}^{2}\right)$ in 2013 , while the city's total area remained roughly unchanged (Da Nang Statistics Office, 1997-2013).

\subsubsection{Labour and employment}

Da Nang has a young population, with $62.5 \%$ of the population of working age during the period from 1997 to 2013 (Da Nang Statistics Office, 1997-2013). ${ }^{11}$ The city's workforce grew at an average annual rate of $3.7 \%$ and the city's economy added an annual average 14,400 new jobs during this period. The overall unemployment rate fell over the period but still averaged about 5.2\% from 1997 to 2013. According to an official at the Da Nang Statistics Office, Da Nang's unemployment rate is among the highest in the country (second to Ho Chi Minh City), due to the increasing number of immigrants, the concentration of tertiary education institutions, and the low demand of labour from local

\footnotetext{
${ }^{11}$ There is no data on population of working age in the Year Book 2013; this data is provided by an official from the Da Nang Statistics Office in 2017.
} 
enterprises, especially during the economic recession. This relatively high rate could also reflect the high proportion of low-skilled workers in the total labour force $(65 \%)$ and the high number of farmers whose land was acquired in the urbanisation process and who could not find suitable jobs in other sectors (Figure 7.5). Employment growth mostly came from the service sector, which is consistent with the change in economic structure of GRDP (Figure 7.6).

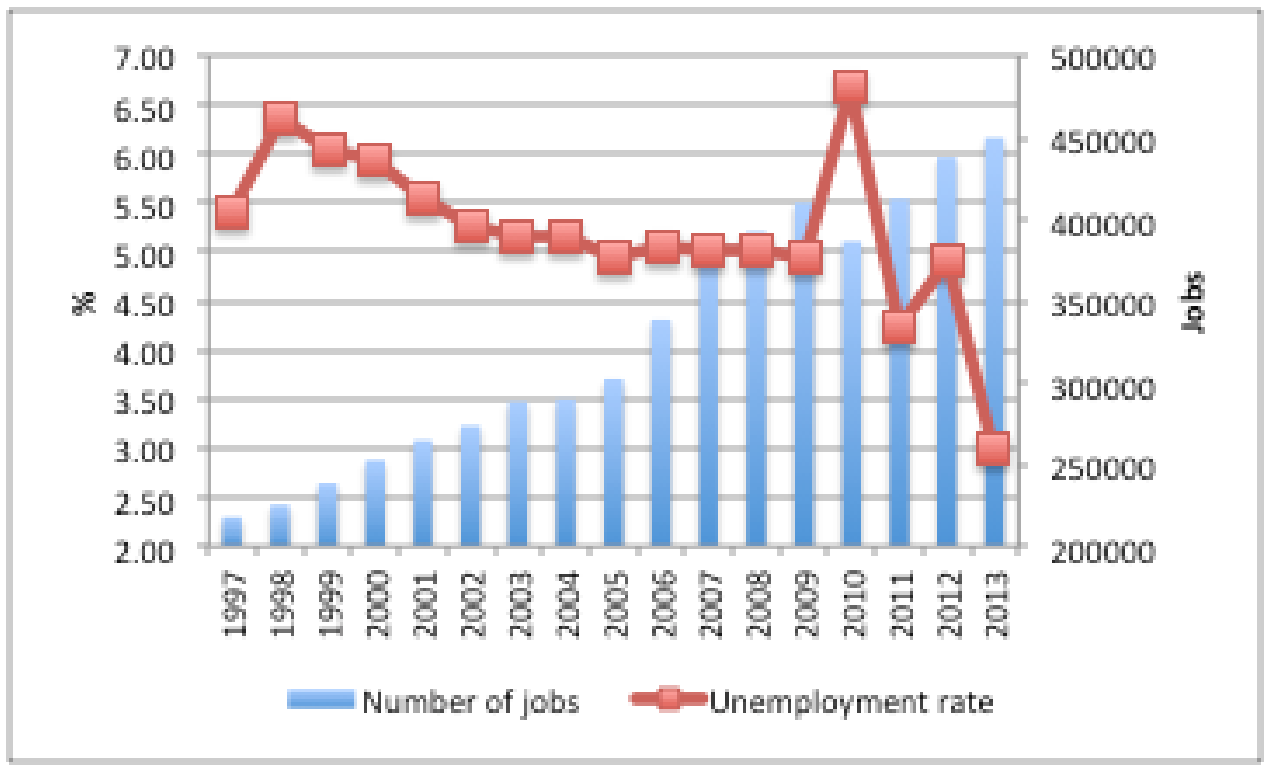

Figure 7.5: Number of jobs and unemployment rate in Da Nang

Source: Da Nang Statistics Year Books from 1997 to 2013

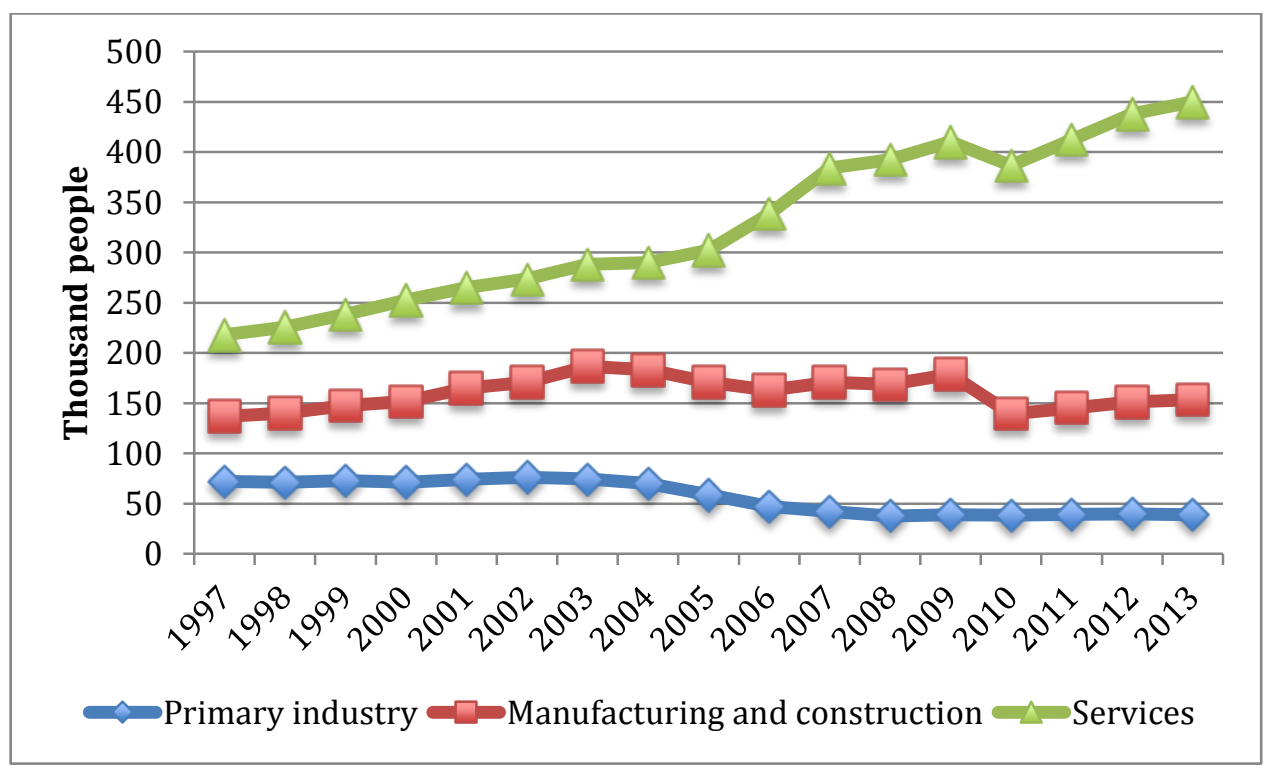

Figure 7.6: Contributions of economic sectors to total employment

Source: Da Nang Statistics Year Books from 1997 to 2013 


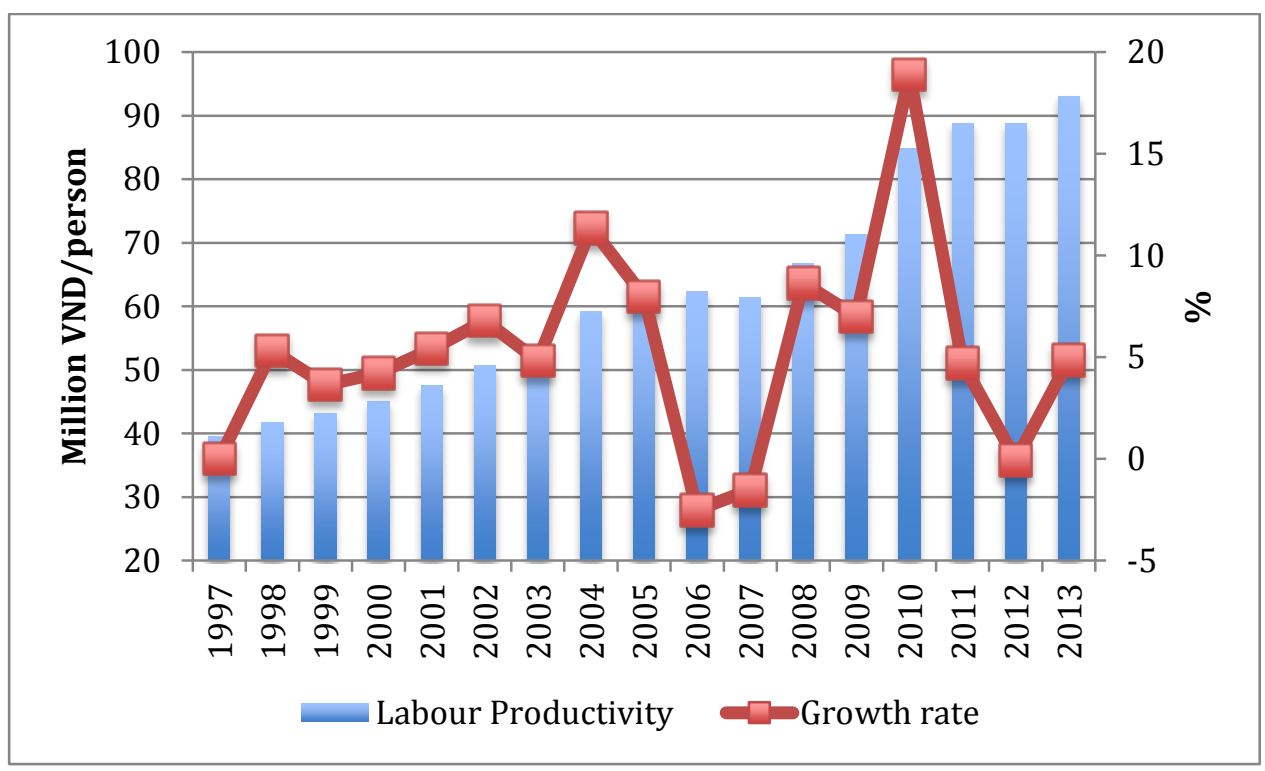

Figure 7.7: Da Nang's labour productivity

Source: Da Nang Statistics Year Books from 1997 to 2013

Urbanisation and economic restructuring also helped to increase labour productivity. ${ }^{12}$ The labour productivity growth rate averaged about 5.6\% annually during the period from 1998 to 2013 (Figure 7.7).

\subsubsection{Income}

Economic growth led to increased household income. Per capita income ${ }^{13}$ in the city increased about three-fold in the period from 1997 to 2013 (Figure 7.8). However, the gap between the richest and the poorest groups also increased. That ratio in Da Nang was 5.5 times in 2004 and 6.4 times in 2012 (Vietnam General Statistics Office, 2006, 2012).

\footnotetext{
${ }^{12}$ Labour productivity $=$ GRDP in 2010 prices/total employed labour .

${ }^{13}$ Per capita income $=$ GRDP in 2010 prices/total population .
} 


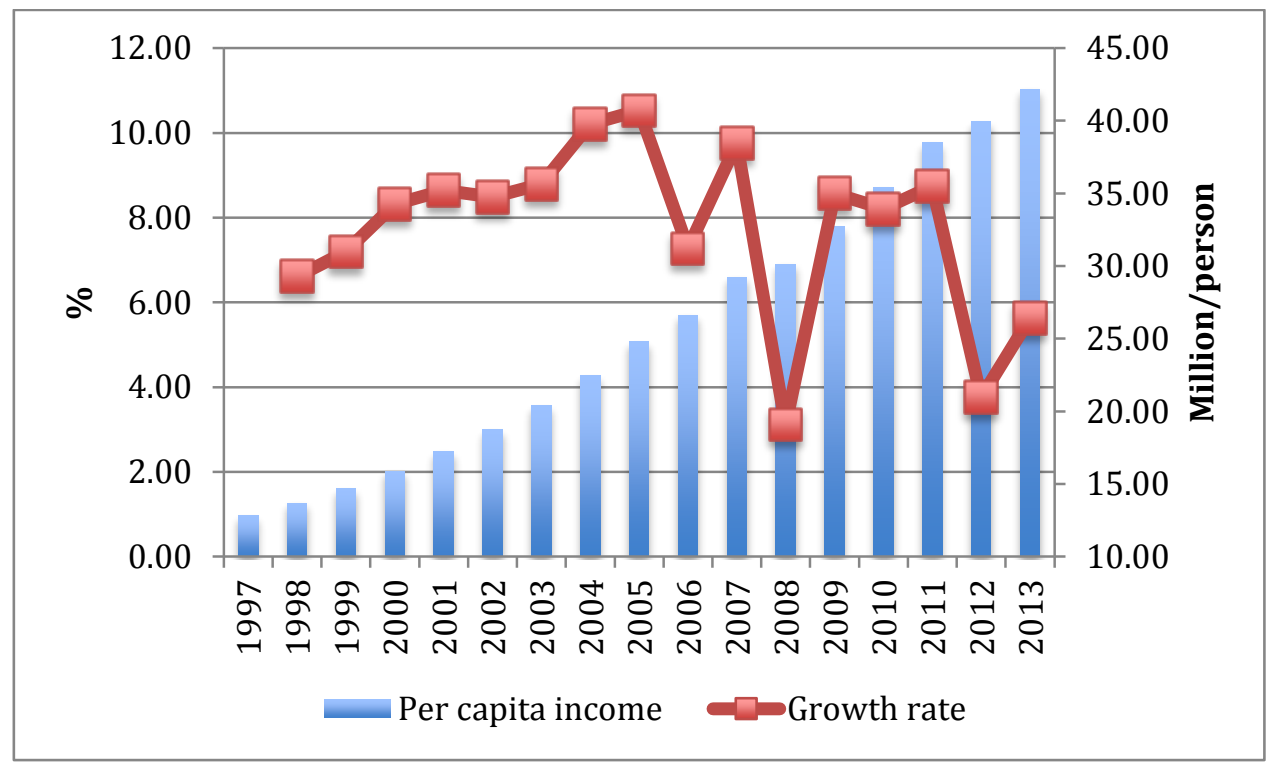

Figure 7.8: Da Nang's per capita income

Source: Da Nang Statistics Year Books from 1997 to 2013

\subsubsection{Housing}

\subsubsection{Before 1975}

Before 1975, Da Nang was the second biggest city of South Vietnam, with a population of about 600,000 people (Dang, 2006). Housing in the city before 1975 consisted of two main groups: (1) people's houses $\left(100-150 \mathrm{~m}^{2}\right)$ along some main streets and soldiers' houses, and (2) temporary houses erected by evacuees, who fled the war in the countryside during the period from 1965 to 1975 . These houses were mostly along riverbanks, under the bridges, along the railway tracks, or within some public car parks (Dang, 2006). They were temporary and unconnected to infrastructure systems such as electricity, clean water and waste treatment. These houses were built without regard for legal plan or regulations, mainly in response to the demand of people in the war, and were the main sources of the city's slums. The old regime also built some apartment blocks.

\subsubsection{From 1975 to 1986}

After 1975, many houses were acquired by the government from people who used to work for the old regime and who had left the country as refugees or had to go to 'education camps' (Cima, 1987; Dang, 2006). Most evacuees also returned to their homes in the countryside. These abandoned or acquired houses were re-distributed, mostly to government officials. Among them were 22 old apartment blocks, which were still in use recently. The living conditions in these buildings were poor and there was almost no 
maintenance (Dang, 2006). The government collected a nominal rent which was not enough for maintenance (Dang, 2006; World Bank, 2006). During this period, some state employers also built houses for their employees. The newly built houses made up about $31.8 \%$ of the total number of houses in the city at that time, including owner-built houses (Dang, 2006). However, according to the World Bank (2006), although there was housing developed by employers or government offices during the 1980s and 1990s, there is no reliable statistical information about public housing in Da Nang City due to poor administrative records. Newly built houses were few due to the difficult economic conditions. Generally, housing was in very poor condition. The average housing area was about $6 \mathrm{~m}^{2} /$ person (Dang, 2006).

\subsubsection{From 1986 to 1997}

Doi Moi led to economic development and increased income. The legal recognition of private ownership encouraged people to improve their dwelling conditions. Many better houses were built and mainly financed by personal savings. The flow of immigrants seeking economic opportunities in the city increased housing demand. To respond, many local landlords extended their existing construction areas to lease out some living spaces to immigrants. These rental-housing units were mostly of very low quality with an average area each of about $15 \mathrm{~m}^{2}$, cooking areas included in the units and shared bathroom.

Some employers continued to build houses or provide plots of land to their employees to build houses. Two examples were the housing complex developed by the Chemical Industries Joint Stock Company on Le Dinh Duong Street and the residential area in Hoa Cuong Ward. These housing complexes were relatively small and of low quality, and poorly connected to infrastructure (Dang, 2006). Following the enactment of the Land Law 1993, which granted households and individuals the right to permanently use land and the right to sell and transfer their land rights, owner-built houses were improved significantly.

\subsubsection{From 1997 to 2004}

After 1997, the city government further invested in urban development. It exploited the land to develop infrastructure systems and build some apartment blocks for people in preferential categories and for the purpose of slum clearance. Many temporary houses and slums along the Han River banks and Thanh Binh beachfront were cleared and converted to public spaces; areas were also cleared in the city centre to create space for commercial activities and along the My Khe Beach for the tourism industry (World Bank, 2006). Urban development also required the city government to build housing for relocated people. 
During the period from 2000 to 2005, the city built approximately 2,000 housing units for resettlement purposes. Some apartment blocks were also built for government officials based on their rank, income and other criteria (World Bank, 2006).

The Land Law 1993 allowed organisations and individuals to rent land from the state to conduct business, including housing development. Thus, during this period, some housing complexes were developed by the private sector, but they mainly attracted high-income customers. Some investors rented a large area of land from the government, developed infrastructure systems, and then divided the land into many small plots to sell to customers who would build their own houses (Dang, 2006). While undertaking urban renewal projects, the city government agencies provided plots of land to people who were relocated by the projects. Most of them used the compensation money from the government to build their new houses. Some others chose to sell their plots of land and moved to less-valued areas, leaving the new occupiers to build on the land. These new houses were constructed under very general regulations about building and housing in the city (Dang, 2006).

Some other activities contributed to the city's housing improvement, such as the infrastructure system improvement in old housing areas or housing refurbishment by occupiers. Generally, people who could improve their dwelling conditions during this time were mostly high- or middle-income people. Meanwhile, many relocated people, government officials, people in preferential categories, and immigrants were poor people who could not afford to purchase or rent housing at market prices (Dang, 2006). The city's Poverty Reduction Programme recorded that in 2004, there were 1,867 poor households living in permanent houses; 12,106 poor households living in semi-permanent houses ${ }^{14}$ (of them, 685 houses were deteriorated); 1,737 poor households living in temporary houses; and 2,680 poor households renting or sharing shelters (D27). That meant there were 5,102 poor households living in sub-standard houses.

In sum, by 2005, the start of the period of this case study, the need both to expand the stock of housing and to refurbish or replace existing stock in the city was high. The 1999 and 2009 Population and Housing Censuses showed that housing condition in Da Nang improved significantly (Table 7.1 and Figure 7.9) as a result of the housing policy for lowincome people. However, it should be noted that there was difference in the housing quality among income quintiles. Most of permanent houses belonged to affluent households while

\footnotetext{
${ }^{14}$ Categories of houses were decided by the materials used
} 
temporary houses were mainly occupied by the poorest people.

Table 7.1: Number of households having housing by types in Da Nang

\begin{tabular}{|c|c|c|}
\hline Types of houses & 1999 & 2009 \\
\hline Permanent & 21,242 & 51,953 \\
\hline Semi-permanent & 102,493 & 168,217 \\
\hline Less-permanent & 9,826 & 993 \\
\hline Simple & 11,604 & 660 \\
\hline Not stated & & 56 \\
\hline Total & 145,165 & 221,879 \\
\hline
\end{tabular}

Source: Vietnam General Statistics Office $(1999,2009)$

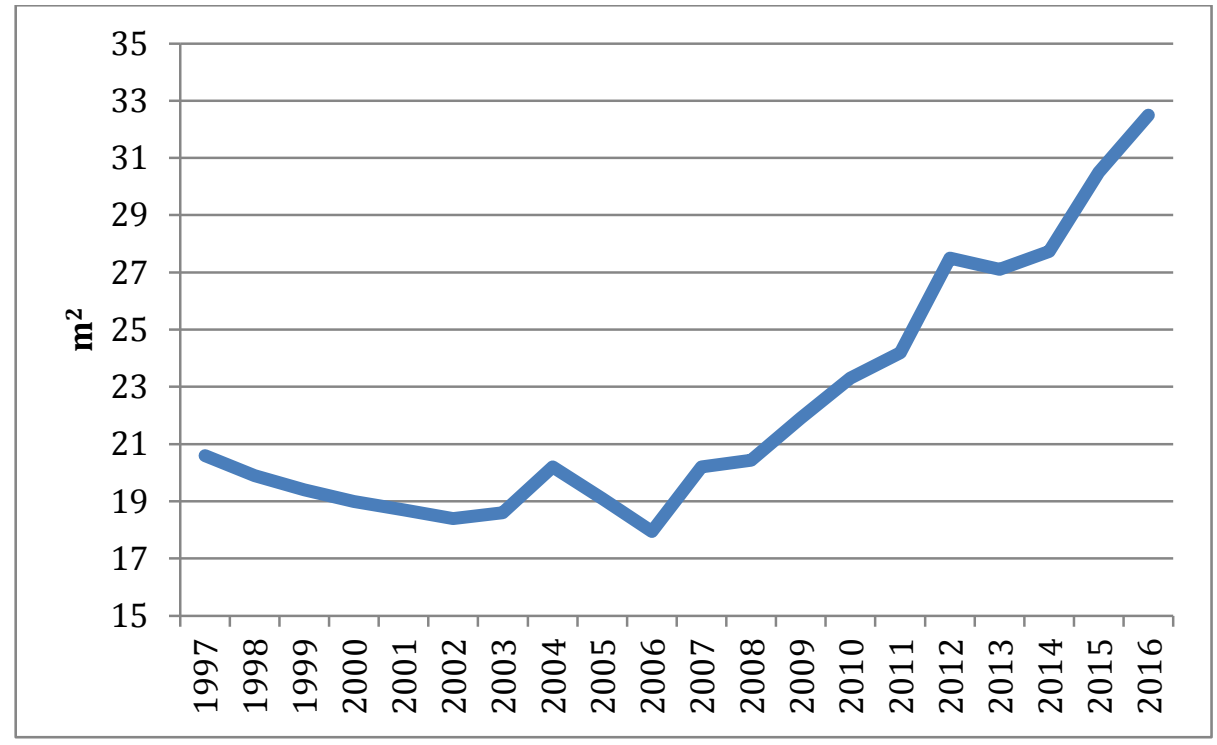

Figure 7.9: Average floor area per capita in Da Nang

Source: Private update from Da Nang Statistics Office, 2017

\subsection{Conclusion}

During the period from 1997 to 2005, after being separated from Quang Nam-Da Nang province, Da Nang City underwent a major period of economic development and urban renewal. These processes had led to increases in the city's GDP growth, population, employment, labour productivity and per capita income. At the same time, the city government was investing in its infrastructure, with associated requirements for resettlement and replacement of temporary accommodation. People's increased income 
also led to more investment in dwelling conditions. However, most of the housing improvement was enjoyed by high- and middle-income people. There were still a great number of low-income people in need of housing assistance from the government. This was the context of the introduction of the Having Housing Programme in 2005. 


\section{Chapter 8: A narrative of the policy process}

\subsection{Introduction}

This chapter is a narrative of the policy process in the Da Nang case, in chronological order with some descriptive analysis. The narrative highlights key events, which will be further analysed in the following chapters using different lenses to understand the influences on the process.

\subsection{The policy process}

Before presenting the events of the policy process, it is useful to summarise key turning points of the housing policy in Da Nang City. Before the starting date of the case, the city government was providing some housing support for people in preferential categories and poor people, following national policies. The policy process in this case started in 2005 when the city government adopted the Having Housing Programme to enhance the effect of those existing policies and extend its housing support to other beneficiaries. The declared ultimate goal was that every household in the city would have a decent house to live in. In 2009, the city adjusted its policies to offer incentives to the private sector participating in social housing development. In 2013, the endpoint of the case, new policies were adopted to provide housing support to both supply and demand sides of LIH.

\subsubsection{May 2004: the central government issued the national Housing Development Strategy}

In May 2004, the Prime Minister issued Decision 76 approving the Housing Development Strategy through 2020, in which the central government set out the long-term objectives and primary principles of housing development. Of those, the central government announced its commitment to improving housing conditions for people, especially lowincome people. This decision was one important legal foundation for the city government to enact the Having Housing Programme in 2005. It signalled that the central government would issue policies on housing for low-income people and encourage local governments to provide housing support to low-income people by using revenue from the sale of landuse rights. It also specified some responsibilities of local governments in LIH although it did not provide detailed guidelines to implement those tasks. More details will be discussed in Chapter 10. 


\subsubsection{Late 2004: Framing a housing policy for the urban poor}

Housing support was an essential component of social security programmes in Vietnam. In 2004, the DNPCe issued Decision 184 enacting the Poverty Reduction Programme from 2005 to 2010. This document is the earliest record in the data collected for this case of the policy idea of providing housing support to low-income households in urban areas in the city. The Programme set out a goal of clearing all temporary houses by 2007 and initiated a solution for households living in urban areas: "if they do not have houses, the city will issue policies to support them buying apartment units by instalments or renting houses at preferential prices" (D27). At this point, the problem of housing for low-income people in urban areas had officially come to the attention of the government. Policymakers perceived a need for solutions for that issue. However, while the problem was well perceived, solutions for it were still not clear. The document said only that: "the city will issue policies", which probably meant that the city government acknowledged that this problem was urgent but needed more time to decide a suitable solution. The city government might be waiting for guidelines from the central government, as stated in Decision 76. In the implementation section of the document, the DOC was assigned a task of drafting a housing programme for poor people to submit to the DNPCe. However, a deadline for the submission was not clear. We can infer that, from this point on, the policy ideas and solutions would be further discussed within the system, especially by policymakers, technical experts and officials at the DOC.

\subsubsection{To May 2005: Getting the '3-Haves' campaign onto the agenda}

On 29 March 2005, in a speech delivered on the $30^{\text {th }}$ anniversary of the city's independence, the city's Party Secretary, Mr Nguyen Ba Thanh, pointed out the weaknesses and challenges faced by the city, including three urgent needs: supporting lowincome people with housing, solving the unemployment problem, and building up civilised behaviour in communities (D92).

To solve these challenges, the city leader publicly introduced the 3-Haves campaign:

Based on the success of the 5-Nos campaign, we are going to implement a new campaign, 'A city of 3-Haves': 'Having Housing, Having Jobs, and Having Civilised Behaviour', so that every citizen has a shelter, every worker has a job, every Da Nang person has good behaviour, is nice and kind in communication, protects the environment and urban security, and treats each other well. (D92) 
One official working at the DNPCl claimed that this anniversary was the first time the idea of the 3-Haves campaign was publicly stated by the city leader (R16). After this first introduction, the idea was probably discussed within the city Party and then orally directed to the administrative agencies in meetings before any written order was made by the city Party to put the policy on the government's agenda. According to one interviewee: "In our political system, all new policy ideas must be discussed within and directed by a city Party before being officially put on the government's agenda" (R11).

In this case, the policy idea was discussed in meetings of the Standing Committee of the city Party. Since the Party Secretary held the position of the Chairman of the DNPCl and other members of the Standing Committee were also the Chairman and Vice Chairpersons of DNPCe, the policy ideas and solutions were easily transferred to the administrative system. Hence, after Mr Thanh's speech, the DNPCe started directing relevant departments, especially the DOC, to prepare the drafts of the 3-Haves campaign.

According to Interviewee R11, while the policy idea was discussed within the Standing Committee of city Party, some people worried about the feasibility of the Having Housing Programme, predicting that the city budget would not be able to support all people, especially immigrants from other provinces. However, acknowledging that the programme was a good social policy, all members of the Committee supported the ideas and focused on discussing policy solutions.

The idea was discussed not only within the Standing Committee but also in other extended meetings of the city Party. For example, in a meeting chaired by the Party Secretary on 4 May 2005, the Vice President of the city's VFF suggested that "to clear all temporary houses (slums) by 2007 we need to set up a prioritised campaign". At this same meeting, Mr Tran Van Minh, Standing Vice-Chairman of the DNPCe, spoke to a suggestion that the DNPCe should "build a 3-Haves campaign to submit to the DNPCl". After an agreement was reached within the city Party, the Standing Committee of the city Party issued Letter 960 dated 12 May 2005, ordering the DNPCe to evaluate the results of the earlier 5-Nos campaign and to draft the content of the coming 3-Haves campaign. The letter indicated that the drafts of the 3-Haves campaign needed to be approved by the Standing Committee of the city Party before being submitted to the DNPCl. So, after about seven weeks of discussion within the city Party, the policy idea officially got on the government's agenda. 


\subsubsection{Spring 2005: Preparing the Having Housing Programme}

According to interviewee R5, once the DNPLe had received the official order from the Party, it brought the issue to its weekly meeting and issued letters to relevant departments, assigning responsibilities for drafting programmes of the 3-Haves Campaign. The respondent assumed that there was probably a letter from the DNPCe requiring the DOC to draft the Having Housing Programme. It is likely that other departments and agencies would have received orders from DNPCe to support the DOC in developing the draft.

The meeting record of the $\mathrm{DNPCl}$ on $25 / 07 / 2005$ shows that in fact the preparation of the Housing Programme started four months before the meeting (D87). This means that the DOC started the preparation from April 2005, after Mr Thanh's speech in March 2005 and before the issuing of Letter 960. It can therefore be surmised that through the city Party's meetings with the participation of the DNPCe's representatives, and the PNPCe's meetings with the participation of the DOC's representatives, the idea of developing a programme to support housing for low-income people was discussed among the city leaders and relevant agencies around April 2005. However, it could only be legalised after an official written direction from the city Party.

According to interviewee R1, to prepare for the content of the Having Housing Programme, the DOC collected necessary information from relevant agencies. For example, the DOLISA provided information on the numbers of poor households, and households with members who had contributed to the revolution; the DOHA supplied information on the numbers of government officials; the Management Board of Industrial Zones and Export Processing Zones provided information on the numbers of workers; the Department of Education and Training provided information about the numbers of students; district PCes provided other information. In the respondent's judgment, "the data provided by these agencies was informal; they were mostly based on the estimates of the relevant departments" (R1).

The DOC also invited representatives of these agencies to comment on at least three versions of the policy draft before submitting it to the DNPCe (R1). Also, according to this informant, there was no available advice from the research community at that time, except some opinions from the Da Nang Young Officials Club. The Club was established in 2004 based on Mr Nguyen Ba Thanh's idea. The club's members were government officials under 40 years old who had potential for management positions in the government system. 
One of its main activities was contributing ideas and opinions on the city's policies. Another interviewee recalled:

Perhaps the Young Government Officials Club had some discussions and ideas ... When there were some policy issues, they discussed [them] and came to some ideas and then they sent their opinions to the DNPCe. Anyway, the Young Government Officials Club did not focus on one specific issue, they gave opinions on many issues and policymakers might have a look at. (R11)

The DOC also looked to other localities in Vietnam for ideas, but found no relevant experience to follow except the information that housing dominantly relied on the private sector. They also studied Singapore's and South Korea's policies but could not make use of them. Therefore, the content of the policy was mainly based on the city's socioeconomic conditions, its existing housing situation, application of national standards on construction, and city leaders' ideas (R1).

\subsubsection{Mid-2005: communicating the policy to the people}

Meanwhile, the Party and the government used media as a tool to communicate the policy ideas to the people and collect responses from them. On 26 June 2005 the city government organised a press conference with the participation of the Party Secretary Nguyen Ba Thanh and the Standing Vice Chairman of the DNPCe Tran Van Minh, broadcast live in a television programme Talk to Us (Cung chung toi doi thoai). ${ }^{15}$ In this programme, the Party Secretary explained the meaning of the Having Housing Programme in the 3-Haves campaign:

Having a house does not mean having resident land, because there will be apartment buildings for people. Yesterday, the city decided to build 4,000 housing units. Also, we decided to assign 4,000 plots of land in Hoa Xuan for low-income households. (Tran, 2005)

According to this explanation, some households would be allocated plots of land so that they could build their own houses while others would have to live in apartment buildings, which was not a favoured type of accommodation for Vietnamese people. The tape of this programme could not be traced, so there is no record of viewers' questions. What we can infer from this step is that the people were informed about the policy idea, and if they had

\footnotetext{
${ }^{15}$ Talk to Us was an interactive television programme focusing on political commentary, on air from 2001 to 2014 . It was a rare direct form of communication between the government and citizens at the time. In this programme, politicians, government officials and professionals were invited to discuss and answer questions from viewers (via phone or email while the programme was on air) about particular issues.
} 
any concerns about the policy, they could raise questions directly via this programme or through their representatives in the DNPCl or via the city VFF.

\subsubsection{July 2005: Discussion in the DNPCl}

After the draft was discussed within the administrative system, according to Letter 960, it would have been sent to the Standing Committee of the city Party for approval before being presented to the DNPCl in its meeting from 25 to 27 July 2005.

During the three-day meeting of the DNPCl, four deputies commented on the content of the Having Housing Programme draft. The first deputy questioned the accuracy of the data on the numbers of households having no housing in the city. He also expressed his support for the policy idea but suggested more clarification in the documents. One deputy from a Catholic church (a parish priest) said that, in his area, there were many families sharing a house; and suggested a need to examine the real housing situation of every household to generate suitable solutions. Another deputy expressed a concern that building dormitories for students would be difficult since it required a large investment while the payback was small and slow. He suggested that the city government should issue a special housing policy for students and consider it a way to invest in human resources. The last deputy supported the 3-Haves campaign, but was worried that the policy's objectives might be too ambitious. He believed that the policy should focus on people in preferential categories, vulnerable poor households, and low-income people having no stable housing. ${ }^{16} \mathrm{He}$ said: “The [policy's] objectives should not be too ambitious". He also suggested the need to take care of tenants who were renting low-quality state apartments and to take into account the costs for infrastructure projects around future apartment buildings. He suggested learning experiences from other provinces' policies to attract private companies into building housing.

Four opinions on such a major policy are not many. One of the possible reasons for few deputies offering views was that the DNPCl was discussing many issues and the time constraint might have limited the number of opinions. It is worth noting that all deputies having opinions expressed their polite support for the policy idea. The potential of a policy which improves the quality of housing for many poor people could explain this consensus. In addition, with such an important policy idea, all deputies probably understood that there had been approval from the city Party and whether the city should or should not enact it

\footnotetext{
${ }^{16}$ There is no definition of vulnerable poor people. In this context, the deputy emphasised a priority for poor people with many difficulties.
} 
was almost certainly not up for discussion. Speaking against a policy idea, which has been approved by the city Party, is not only unlikely to bring about change but might also negatively affect deputies' political careers. Therefore, it is not unusual to see a high consensus in the DNPCl's discussions.

There were also few comments on the technical issues of the policy. Only two people raised questions concerning the accuracy of the data, the ambitious objectives, and the financial estimates of the Programme. Technical issues might be too complicated for some of the representatives but finance was an important issue that could have received more comments. One explanation for this lack of attention to finance is that deputies who had enough knowledge and information to question the cost of the programme and the financial resources mainly came from the DNPCe and relevant departments, who submitted the Programme. One deputy did, however, mention the idea of mobilising the participation of the private sector, which was later discussed further when the policy was being implemented.

In response to the four opinions, the Director of DOC reported that during the previous four months, his department had collected comments from relevant agencies for the draft of the Having Housing Programme and organised one press conference. Regarding the accuracy of the data, he admitted that they were not totally accurate and needed to be adjusted and supplemented.

He also explained: "the short-term goals were focusing on people in preferential categories; finance would come from loans provided by the World Bank; and the city would lease or sell housing units by instalment". The meeting minutes can be understood as summaries of his answers. For example, the programme prioritised not only housing demand of people in preferential categories but also addressed demand from other beneficiaries. Also, the explanation on finance was quite incomplete because the only assured source of funding for the Programme was in fact the city's budget. The Director's response might have been an effort to justify the vague financial estimates of the Programme draft, which will be discussed in the next section on the content of the policy document. However, this answer also showed that at this point, the policymakers did believe that they could mobilise financial resources from the World Bank's PIIP. This belief may have encouraged the policymakers and drafting team in designing the policy's ambitious goals.

The Party Secretary, also the Chairman of the DNPCl, further explained that the city would not give away houses for free but would lease them out at different rental rates, depending 
on the types of beneficiaries. He repeated this statement twice during the meeting. It seems that the policymakers were worried about a potential misunderstanding from citizens that the new housing policy would provide them houses for free, which might lead to unwillingness to pay rent. This can also be understood as an explanation for the ambitious goal of the policy, to generate substantial finance for re-investment. However, the Secretary also admitted that the city would offer some support in subsidised rent. $\mathrm{He}$ claimed:

The city can partly subsidise [rents]. Once the city is developed, its people should be able to enjoy social benefits. It is normal. It is a social policy. It means taking care of our people. (D87)

Given that the meeting was broadcast live to the city people, this was obviously a good opportunity for the Party Secretary to win popular support by claiming that the city government was taking care of the people's demands with this social security policy.

In his concluding speech, the Party Secretary emphasised that in the short term, the city would prioritise people in preferential categories who were having housing difficulties, relocated people in housing need, and poor people with no stable housing. The emphasis shows that though the Having Housing Programme set out some ambitious and broad goals, its implementation would be staged and targeted at different prioritised beneficiaries in each stage.

By these explanations, the Party Secretary set out to justify the necessity, feasibility and rationality of the Programme. He also called on the city's VFF and other organisations to provide information to the people so that they could understand the city's policy.

By the end of this meeting, the DNPCl issued Resolution 25 approving the vision of "A city of 3-Haves: Having Houses, Having Jobs and Having Civilised Behaviour". The resolution asks the DNPCe to revise the drafts based on the comments of the DNPCl's representatives and departments, and to obtain approval from the Standing Committee of the DNPCl before issuing the Programme.

Now that the policy idea had been passed by the DNPCl, the city's legislative institution, some administrative steps would be required to enact the final decision. The meeting minutes indicate that the discussion at the DNPCl was not very contentious. No deputy questioned the policy idea. Some concerns about the policy's goals were raised, relating to the capacity of the city budget, but the concerns were addressed by the Party Secretary, who advocated the enactment of the policy. 
The DNPCl's resolution, a legal document, ratified the policy already approved by the city Party. Due to the lack of technical expertise, the DNPCl did not propose any specific changes to the policy details. In other words, it left all technical issues to the DNPCe. Thus, the main import of the meeting was that it formally legalised the Party's policy and provided an opportunity for the DNPCl's deputies to help prepare understanding for smoother implementation.

The Resolution also suggests that the city VFF and its members participated in providing information and encouraging the people to support the 3-Haves campaign. Again, the role of these organisations in mobilising public support was emphasised, showing that the city Party and government did regard mobilisation of public support as a part of the process of legitimising policy decisions.

\subsubsection{August 2005: legal verification}

As required by law, the draft was further verified by the DOJ. In a verification letter, the DOJ affirmed 1) the legal requirement for the document; 2) the scope and objects of the regulations; and 3) the relevance of the draft document to the Constitution and the existing laws, as well as its consistency with the existing legal system. The department provided some comments on the document's language and drafting techniques and suggested incorporating into the document the responsibilities of the lead drafting agency, reorganising some parts of the document, and concretising the solutions of the policy. The DOJ's suggestions on the solutions of the policy can be inferred as a criticism that the policy was not specific enough, especially on technical and financial aspects. The DOJ also advised the removal of a section relating to buying, purchasing, leasing and delegating the management power of state housing because these matters had been regulated in other legal documents (D91).

In fact, once the policy idea was approved by the city Party and the DNPCl, there was not much room for the DOJ to make changes to the draft, except on some technical drafting issues. A former official of the DOJ, who was involved in preparing the DOJ's verification, explained that the DOJ did not have much to say in the official letter because the policy idea was not against any central government regulation. However, he recalled another policy idea relating to the establishment of a local force to protect the city's social order and security, which the DOJ believed was inconsistent with the current constitution, laws and central government regulations, even though it proved unable to change the city leaders' will. It can be inferred from this counter-example that when the city leaders have 
made up their minds, technical departments will not be able to change their decisions. This claim was confirmed by another case when the $\mathrm{DNPCl}$ issued a regulation that "Underage students driving motorbikes would get their motorbikes seized for 60 days". When the central government required the regulation to be abrogated, the Director of the DOJ publically defended himself by claiming that he had reported and given legal advice to the Chairman of the DNPCl but could not change the DNPCl's resolution (D77). These examples show that functional agencies can contribute technical advice but cannot alter the substance of policy made by city leaders. As a local researcher quoted the Party Secretary in a meeting with him: "criticising is acceptable but objecting is prohibited" (Tran Duc Anh Son's Facebook on 13 February 2015, quoted with the author's consent).

After receiving clearance from the DOJ, the DNPCe organised a meeting to discuss the implementation of the 3-Haves campaign. At this meeting, the DOC received final decisions from the Vice Chairwoman of the DNPCe on the draft of the Having Housing Programme. Then, the DOC revised the draft and submitted it to the DNPCe for enactment. At the same time, a draft of the implementation plan for the Having Housing Programme was also being prepared.

\subsubsection{October 2005: The Having Housing Programme was enacted}

The draft of the Having Housing Programme was approved and issued on 03 October 2005 in Decision 140. The official Programme justified the reasons for enacting this housing policy, using data of the city's housing and population as evidence for the policy decision. It is estimated that the city would need about 1,154,000 square metres of housing in the next five years, and set out an objective of meeting this demand. According to this document, people in preferential categories, poor households and relocated people would be prioritised first. High-level government officials, professionals, and government officials working for the city under the city's talent-attraction policy would also be supported. Other beneficiaries would be considered later. The prioritised groups showed that, when designing the policy, the city policy followed current national housing policy and also reflected the city's urgent need for housing to support resettlement during urban redevelopment, and to house some particular government officials. Other low-income people, such as students and workers (especially immigrant students and workers), would not be supported at this time due to the constraint of finance. However, the city government indicated its general intention to provide incentives to private developers of LIH. 
The Programme contained some local initiatives on technical issues, such as the design of the apartment buildings. It predicted that the city would have policies to attract the participation from the private sector and to mobilise other financial sources. An estimated amount of 1,693 billion VND (equivalent to 105 million USD in 2005) would be needed to achieve the Programme's goals. About $50 \%$ of the total cost would come from the city budget while the rest was expected from other sources, such as the PIIP and private investors.

\subsubsection{Discussing detailed implementation}

Ten days after Decision 140 was enacted, the DNPCe required the DOC to prepare an implementation plan for the Having Housing Programme. On 19 October 2005, a Vice Chairwoman of the DNPCe chaired a meeting with participants from various departments and agencies to discuss the plan. This meeting was mainly about assigning responsibility for drafting regulations on incentives for the participation of private investors and the establishment of the HDF. Relevant departments were required to submit drafts of those regulations by the end of the year. Discussions in the meeting was mainly on requests for more time for these tasks.

One representative from the PIIP's management board suggested that the financial resource from the PIIP would not be available for the first period (2005-2007) because the project was planned to start in 2008. Furthermore, he warned that it would not be easy to mobilise finance from the World Bank's project:

- Please consider the time of investment by our Board [PIIP's Management Board] because we will not sign a contract with the World Bank until March 2007.

- [We] need to have reciprocal capital ${ }^{17}$ for the finance from the World Bank for housing improvement loans.

- When using the PIIP's capital, [we] need to comply with the World Bank's regulations on capital management and implementation solutions.

- The World Bank's policy on housing development is very strict, thus a plan to mobilise $25 \%$ of the total cost of the Programme [from the World Bank] needs to be carefully considered and reasonably explained. (D20)

Considering this suggestion, the DOC left the PIIP funding out of the first period's plan (2005-2007) of Decision 140. Instead, the official decision used the term 'other investors'

\footnotetext{
${ }^{17}$ Government co-financing.
} 
as a substitute. The PIIP was still expected to provide some finance for the second period of the programme (2008-2010) (107 billion VND) (D18).

The DOHA suggested prioritising government officials who were working for the government under the city's talent-attraction policy. It also requested a delay in collecting information on the housing requirements of other government officials. At this early stage of the implementation, some opinions were already raised regarding the potential problems of policy implementation, such as a need for proper procedures for choosing beneficiaries to avoid mistakes and opportunities for bribes as well as to ensure justice and transparency in allocating housing support, as suggested by the DOHA:

There should be some templates [guidelines] for considering and choosing beneficiaries. The procedures for choosing beneficiaries should be undertaken publicly at each agency. (D20)

and by the Ngu Hanh Son District PCe: "There is a need to have templates for choosing beneficiaries to apply in districts" (D20).

The worker's representative from the Management Board of Industrial Zones and Export Processing Zones called on the government to provide incentives on land-use rights for worker-housing projects. However, due to budget constraints, this idea got no support at the time.

As a current manager of state apartment units in the city, the HMC contributed a suggestion about having an effective and efficient mechanism for managing newly built apartment units and ways to collect rent on time in order to recover the capital for further investment:

There is a need to consider the efficiency of housing projects, particularly apartment projects, management procedures, capital recovery procedures. [We also] need a new policy and procedures for management. (D20)

The Company also envisaged a potential gap between supply and demand in implementing this policy and called for solutions:

There is a need to connect the information on housing demand to investment size to avoid waste of resources. (D20)

Further, the Company anticipated a need for some policies to sell apartment units to tenants and diversify the designs of apartment buildings for different demands. All these problems were later shown to be real after some years of implementation. However, at this point, no effective solutions were adopted. 


\subsubsection{The official plan}

After collecting these comments, the DOC submitted the revised draft of the plan to the DNPCe. The official implementation plan was issued in Decision 6109 dated 27 October 2005 (D86). The plan divided the implementation into two periods, as described in Table 8.1 .

The Plan assigned responsibilities to various government departments and agencies: the DOC was the standing agency of the Programme, responsible for assisting the DNPCe in directing, inspecting and reporting on implementation; choosing construction sites, making plans, and choosing apartment designs; supervising construction; collecting data about housing demand and reporting it to the DNPCe, and preparing the programme's further amendments. The DPI and the DOF were responsible for allocating the state budget to the programme; the DOF was responsible for the plan of mobilising finance for the Programme; and other departments and agencies for collecting data on housing demand and suggesting solutions for policy implementation (D86a).

Table 8.1: Policy goals and estimated cost of the implementation plan

\begin{tabular}{|c|c|c|}
\hline Plan & Period 1 (2005-2007) & Period 2 (2008-2010) \\
\hline Policy goal & $\begin{array}{l}\text { - } 170,000 \mathrm{~m}^{2} \text { of apartment } \\
\text { floorspace ( } 3,400 \text { units) } \\
\text { - } 30,000 \mathrm{~m}^{2} \text { one-storey } \\
\text { houses ( } 750 \text { units) } \\
\text { - } 40,000 \mathrm{~m}^{2} \text { row houses } \\
\text { (equal to } 330 \text { units) }\end{array}$ & $\begin{array}{l}-248,000 \mathrm{~m}^{2} \text { apartment } \\
\text { (4,970 units) } \\
-54,000 \mathrm{~m}^{2} \text { one-storey } \\
\text { houses ( } 1,350 \text { units), } \\
-71,600 \mathrm{~m}^{2} \text { row houses } \\
\text { ( } 596 \text { units), } \\
-10,000 \mathrm{~m}^{2} \text { villas ( } 50 \\
\text { units). }\end{array}$ \\
\hline Estimated cost & 368 billion VND & 582 billion VND \\
\hline $\begin{array}{l}\text { Estimated financial } \\
\text { sources }\end{array}$ & $\begin{array}{l}\text { - City budget: } 50 \% \\
\text { - PIIP: } 25 \% \\
\text { - Other economic sectors } \\
\text { [private investors, } \\
\text { dwelling owners, } \\
\text { donations]: } 25 \%\end{array}$ & $\begin{array}{l}\text { - Capital recovered from } \\
\text { period 1: } 30 \% \\
\text { - The city budget: } 35 \% \text {, } \\
\text { - The PIIP: } 17.5 \% \\
\text { - Other economic sectors: } \\
17.5 \%\end{array}$ \\
\hline
\end{tabular}

Source: D86 
It seems that the drafting team did not take into account the comments from relevant departments and agencies raised in the meeting on 19 October 2005. All the due dates were the same as in the previous draft: 20 December 2005. According to this plan, the DPI had to submit to the DNPCe a draft of "policies and procedures for attracting private investors and communities participating in housing development"; the DOF had to submit to the DNPCe a draft of "policies and procedures for providing loans for purchasing houses to different types of beneficiaries"; the DONRE had to submit to the DNPCe a draft of "policies and procedures on land-use rights, facilitating the participation of other economic sectors in housing development"; the HMC had to submit a draft of "regulations on housing management, use, repair, improvement, maintenance, as well as a capital recovery policy for further investment in order to establish an effective housing fund"; and other departments and agencies (DOLISA, DOHA, districts PCe) had to submit information regarding housing demand (D86).

Despite the removal, in Decision 140, of a reference to PIIP finance in period 1, the official plan contained an explicit forecast of PIIP funding in both periods of the programme. The drafting group (or in fact the policy decision-makers) might have remained genuinely optimistic about obtaining World Bank funding for the programme or they might have deliberately used this uncertain source to justify the ambitious policy goal.

Although only a part of the funding was envisaged to come from the city's budget, the plan anticipated that the government would award the construction contracts to state companies and agencies. This provision indicates that the policymakers were unsure about the possibility of mobilising finance from the PIIP and the private sector because the government would not be able to decide on contractors of private projects.

\section{Reporting to the city Party and the central government}

After the policy was enacted by the city's government, the city Party incorporated it into its next five-year plan in the political report presented at the $19^{\text {th }}$ City Party Congress in November 2005. Inclusion in the political report confirmed the policy as one of the city's most important political goals.

As stipulated in the implementation plan, the DOC was responsible for the task of reporting on policy implementation, including reporting to the central government (the MOC). Reports were made monthly, six monthly and yearly. Through these reports, the central government was informed that the city government was implementing policy initiatives relating to $\mathrm{LIH}$, which was also stipulated by the central government's Law on Housing 
(2005). However, the central government was still preparing guidelines for implementing these regulations. On 21 February 2006, the MOC in fact wrote to the DOC asking for the city's policy documents, to learn from the city's ideas and experiences to help with drafting the guidelines. The DOC sent the MOC a copy of Decision 140 and promised to report other policy ideas relating to housing ownership, housing use and management, housing transactions and state management later, after working with the DONRE (D24).

\subsubsection{First half of 2006: emerging problems in implementation}

Once the policy was actually implemented, some of the anticipated problems eventuated. In a six-month report prepared by the DOC to the DNPCe, the DOC raised the problem of finance, noting that "We have been unable to mobilise capital from the private sector and the PIIP" (D26).

The problem was confirmed again in a speech delivered by an official from the DOC to a workshop named 'Da Nang youth participate in the Having Housing Programme', organised by the Ho Chi Minh Communist Youth Union in Da Nang City in May 2006:

After 6 months of implementation, [we] have found that the biggest difficulty is finance... At the moment, we focus mainly on building apartments for relocated people. There is no housing stock for other people to rent or buy, [and] other types of housing such as row houses, separate houses, villas have not been built. (D16)

Another problem of policy implementation was the slow progress of some projects. To solve this problem, the DNPCe asked the DOC to suggest solutions for enhancing implementation of the Programme (Letter 45/2007). In response, the DOC suggested that the DNPCe should direct relevant agencies to speed up their construction works, allocate more of the city's budget for housing projects, and consider some potential solutions in mobilising finance. These solutions included issuing policies to mobilise the participation of private investors, selling allocated units to sitting tenants to recover capital, using revenue from lottery activities for building housing for poor people, issuing city government housing bonds, establishing a HDF, and mobilising capital from all sources, including the PIIP, the land-use rights, loans, donations, and from prospective users (D25).

\subsubsection{From 2007 to 2008: Further review and evaluation}

The DOC's suggestions showed that new policy ideas were constantly discussed within the system in the implementation stage. Many solutions were considered, but it took time and legal consideration for the government to adopt them. Enhancing the policy 
implementation also got the attention of the city Party. In February 2007, the Standing Committee of the city Party brought this issue into its monthly meeting with political social organisations. At this meeting, the Party Secretary ordered the DNPCe to investigate the housing situation of the city's citizens and to use the findings to improve implementation of the Having Housing Programme (D3). To implement this directive, further data on housing and housing demand was collected (D30).

When the first stage of the Programme was coming to an end, the DOC and relevant agencies were preparing for a preliminary summing-up report. The DOC participated in another broadcast of the Talk to Us programme at the beginning of 2008. The preparation notes for the Vice Director of the DOC says that the programme was to inform the public about the main content of Decision 140, the goals of the policy and its outcome after finishing the first period. The Vice Director was also expected to explain why a certain design of apartment building was chosen, where the finance for the policy came from and why the city was unable to mobilise finance from other economic sectors, and why there were difficulties in selling housing units to sitting tenants. Solutions for 22 state-owned apartment buildings in a deteriorated condition were also to be discussed (D29).

The preparation notes also discussed another significant financing problem: rental arrears.

The task of managing apartment buildings faced difficulties since its costs are paid from renting while many tenants delayed paying their rents. (D29)

The problem, as evaluated by interviewee $\mathrm{R} 1$, was an unpredictable challenge for policymakers. He recalled:

As we drafted the policy, we expected to recover $30 \%$ of the cost of the Period 1 for further investment of the Period 2. However, it turned out that we couldn't make it. Tenants didn't pay their rent. (R1)

\subsubsection{Policy evaluation in implementation stage}

A six-month report prepared by the DOLISA (D31) showed that central government regulations on housing for people in preferential categories and poor people were implemented at the same time as the Having Housing Programme. In accordance with central government regulations, the DOLISA was responsible for managing two funds: the 'For poor people Fund' provided housing support to poor households, while the 'Gratitude Fund' provided housing support to people in preferential categories. The DOLISA also received donations from SOEs and private companies to build houses for these 
beneficiaries. Housing units built in the Period 1 of the Having Housing Programme helped to increase the number of beneficiaries. In particular, in line with proposals from the Da Nang Relief Organisation of Women and Children, ${ }^{18}$ by June 2008, 38 row houses had been leased out to single mothers for 50,000-100,000 VND/month (3.1-6.2NZD).

After receiving reports from all relevant departments and agencies, the DNPCe organised a conference to review the first two years of implementing the 3-Haves campaign. In a speech delivered at this conference, the DOC's Vice Director recalled the purposes of the policy, presented its outcome after two years and offered an evaluation of the achievements as well as the pitfalls and challenges of the implementation. Again, the financial problems, the slow progress in some projects and difficulties in collecting rent were confirmed (D35). All this information was reported to the DNPCe, $\mathrm{DNPCl}$ and the city Party. The city Party, in its turn, reported to the central CPV (D5). In particular, in 2008, the CIEM sent a delegation to Da Nang to study the city's housing development experience. At this time the institute was drafting policies for real estate market development and regulations on a reform in state management of housing. Therefore, the city government shared its experiences with this research agency. Taking advantage of this opportunity, the city government suggested that the central government issue regulations on land incentives for the private sector's participation in housing development (D36).

Also in this year, the DOC was preparing a competition for selecting designs for low-, middle-, and high-income apartments. The move showed that, in addition to LIH, the city was expecting to extend the housing support to middle- and high-income people with the participation of the private sector (D39).

\subsubsection{Policy revisions in 2009}

By the end of 2008, there were reports in the media of some forthcoming actions by the central government relating to housing for low-income people. It was reported that the MOC was suggesting that the central government use the government's demand stimulus package for social housing and that the MOC planned to implement this policy initiative in two experimental cities: Ha Noi and Ho Chi Minh City (D45). From what we have learnt about the early stages of this housing policy process, we can infer that this information was discussed within the administrative system and probably was reported to the city Party. As

\footnotetext{
${ }^{18}$ This charity organisation, established and chaired by the city Party Secretary, aimed to provide support and protection to women and children in the city.
} 
a result, the city Party and government prepared for a new plan.

\section{Direction from the Party Secretary}

In a meeting with the DNPCe in March 2009, the Party Secretary ordered the DNPCe to direct and supervise the DOC to make a plan for building 5,000 housing units (D5). During this meeting, the Party Secretary also issued directives relating to the problems arising in the implementation stage of the policy, including violations in allocating housing apartments to beneficiaries, delays in rent payment, illegal sales and illegal occupancies of state-owned housing units.

Discussion within the administrative system and with the private sector for implementing new policy solutions

To follow the direction of the Party Secretary, the DNPCe issued a letter (No 1870 dated 30 March 2009) requesting that the DOC prepare a plan and estimated cost for 5,000 new housing units. While the DOC was sending the first draft of the 5,000-unit Programme to the DNPCe, the central government enacted Resolution 18 and decisions 65, 66, and 67. Two days after the enactment of Resolution 18 and two days before the issuance of the three decisions, the DNPCe organised a meeting with the DOC, relevant departments and agencies, and especially with VINCON (Real Estate and Finance Investment Joint Stock Company, renamed Vicoland in 2011, hereafter referred to as Vicoland). The meeting granted Vicoland the right to develop a LIH project - the first in the whole country. It also required the DOC to revise the draft of the 5,000-unit Programme.

\section{Making decisions}

On 24 May 2009, probably as a result of further discussions within the system on achieving the goals of the Having Housing Programme, the DNPCe issued Decision 3882 approving a Programme for building 7,000 housing units. This plan was made to achieve the goal of the 2005 policy. Thus, it did not need to be passed by the DNPCl. Apart from the policy goals and its cost estimate, the decision simply re-stipulated all recent central government regulations, mainly on incentives to private investors building LIH (D23).

The DNPCe wanted to attract other investors as well as Vicoland to participate in LIH development. Thus, the DNPCe directed the DOC to draft detailed instructions for the participation of those companies (D55). The DOC followed the standard procedure of another policy process, preparing the draft, getting it legally verified by the DOJ and submitting it to the DNPCe (D49). However, the draft was not enacted. It was likely that 
the drafting team could not suggest any new policies to add to those in Decision 3882.

\section{Implementation}

Thanks to the enactment of Decision 3882, the policy was further implemented. The city government invested more money in new housing projects and facilitated the participation of more private investors.

While implementing the current policy, the city government continued to seek support from central government for its housing policy. Towards the end of 2011, the DNPCe ordered the DOC to prepare another project to build a further 5,000 housing units for government officials by diverting budget from the government's fund for civil service salary reform. This project was submitted to the central government by the DNPCe, but the central government refused to give its approval.

During the implementation, there was more cooperation between the central and the city government as well as between the city government and the private sector. These activities will be reported in Chapters 10 and 12. One significant outcome of cooperation with the private sector was that in November 2011 the Party Secretary decided to buy some housing units developed by private investors in order to enable them to quickly recover their invested capital (D71). There was no specific central authority covering this sort of purchase: it was the city's own initiative in implementing the policy.

In another initiative in 2013, the city government enacted regulations on criteria for receiving and considering applications for state-housing tenancies in Da Nang City (D69). The regulation was an effort to deal with the problem arising in choosing beneficiaries and to make this service more transparent, and less susceptible to error and bribes.

As a result of the policy, by the end of 2013, about 8,000 apartment units had been built and more than 4,000 units were under construction, funded from the city budget or financed by private investors, plus one student dormitory funded by central government (D10). Thanks to this success, Da Nang was praised by the Deputy Minister of the MOC as one of the leading localities in providing public housing (Hai, 2013).

\subsubsection{Policy stage repeated}

As mentioned before, while the policy was implemented, some more policy ideas were further discussed. However, most of them did not reach the stage of approved policy. Some of the new policy ideas developed by the city government within the legal constraints set by the central government are described under the following headings: 


\section{* Policies and mechanism for mobilising the participation of the private sector in housing development from 2005 to 2009}

At the beginning of the policy process, policymakers expected the participation of the private sector. However, after two years of implementation, there was no sign of interest from private companies. According to the DOC, the reasons were that:

The demand from people who can afford to rent or buy houses developed by investors is small; potential profit is low for investors. (D29)

and

Land prices in Da Nang are lower than in other localities, thus, people prefer buying a plot of land to buying an apartment unit. (D29)

While LIH was not an attractive proposition for private investors without incentives from government, the lack of regulations from central government meant the city was quite limited in what it could offer them. To deal with the obstacle, the DNPCe directed the drafting of regulations on incentives for private investors participating in housing development. The DONRE submitted a draft of regulations on land incentives with some ideas such as:

- Housing projects (which develop housing apartments for rent) would be exempted from land rent for 10 years and investors would receive a $20 \%$ discount for prompt payment in the following years.

- Investors in other housing projects would receive a 10\% discount for prompt payment (within 30 days after receiving the land).

- Investors would be allowed to mobilise capital from other sources [loans, buyers' deposit] to invest in housing projects. (D29)

However, the regulations were not adopted. The reason, according to interviewee R11, was that there were no guidelines from the central government relating to incentives for the private sector participation at that time. In addition to the private sector, the draft could not suggest any new idea to mobilise more finance:

Firstly, there were no guidelines from the central government. Secondly, the suggested sources of finance were not new. Because you must have financial resources to do it. (R11)

Another interviewee remarked: "The city could not issue ultra vires policies. It could only 
provide clean land and facilitate the investment activities" (R1).

The idea of exempting payment for land-use rights was reported to the central government and possibly influenced its policies in Resolution 18 and Decrees 65, 66, 67 in 2009. The second policy idea, to reduce by $10 \%$ the fee of land-use rights if investors made their payments within 30 days of receiving the plot of land, was implemented by the city government for all investment projects. However, this policy was investigated later by the central inspection agency. In 2013, the central government alleged that the city government was responsible for the loss of 3,400 billion VND off the budget (D. Nguyen, 2013). The $10 \%$ reduction of land-use fees was among other local decisions that contributed to the loss. Mr Nguyen Ba Thanh (the city's former Party Secretary) and, unusually, the city government publicly rejected the allegation, claiming it was inaccurate (Minh Quang, 2013) and explained the legal basis of the reduction ${ }^{19}$ (D. Nguyen, 2013).

\section{* Selling apartment units to sitting tenants to recover capital for further investment}

As presented above, when discussing the implementation plan for the housing policy, a representative from Da Nang HMC suggested selling newly built apartment units to tenants. However, the suggestion was not considered at that time. One possible reason was that the urgent goals of policymakers were enacting the Having Housing Programme and implementing all available solutions for housing support. In that context, introducing a new policy, which was not stipulated by central government, was probably not a good idea. Policymakers needed more time to work on it. However, when the policy was being implemented, the financial issue became more problematic, and policymakers returned to this policy idea. The challenges of adopting it were discussed. For example, in its preparatory brief for a Talk to Us television programme, the DOC observed that:

Many [tenants] were very poor households, whose incomes were not enough for even paying the preferential monthly rent. Thus, they can hardly afford to buy those units. However, in the future, we [the government] will consider this idea to reduce the pressure on the local government's budget. (D29)

The key reason for caution was in fact that the proposal cut across central government's existing policy that state rental housing units were not for sale.

In February 2012 meeting, the Party Secretary decided to sell some state-owned apartment

\footnotetext{
${ }^{19}$ The city government argued that Decree 38 in 2000 (Clause 2, Article 14) had provided for a discount of 20\% for upfront payments of land-use rights. However, Decree 198 in 2004 rescinded Decree 38 but was silent on the question of discounts. Therefore, the city was entitled to assume that the Decree 38 provision for discounts continued.
} 
units to government officials and other beneficiaries by instalments:

- For government officials who are in really difficult housing situations, the city government will sell each person a housing unit; payment method: the payer must pay $50 \%$ of the unit's value at transaction time, the remaining amount will be paid off by instalments within 10 years.

- For other people, housing units will also be sold by instalments within 10 years or 20 years. (D7)

However, this decision could not be implemented immediately because there was no permission from the central government for such practices at that time. Faced with this legal constraint, the city government kept lobbying the central government to re-consider it. As a result, three years after that, Decree 34 (2013) cautiously left open the possibility of selling state-owned houses:

Regarding state-owned social houses which are under the management of ministries, central agencies and provincial PCes, if there is a need to sell these houses to recover capital for further development, the MOC takes the responsibility to study and submit regulations on policies and procedures for selling this type of housing to the Government for approval. (Article 25)

In August 2013, a delegation led by the Minister of the MOC discussed the state management of the construction sector with Da Nang City. On this occasion, the city Party and government asked the MOC to support the city in selling some state-owned housing units (Hai Chau, 2014; Luu Huong, 2014). Thus, in December 2014, the MOC suggested that the Prime Minister approve Da Nang City's plan to sell 846 state-owned housing units and the city gained the approval in April 2015 (Long, 2015; Nghi Loc, 2014; Ngoc Long, 2015). Possibly, the results of this pilot project were considered to make the central government's policy change in Decree 99 (October 2015), which allowed selling stateowned social housing units in a regulated procedure.

\section{* Establishment of a Housing Development Fund}

The idea of establishing a HDF in each province and city was, in fact, initiated by the central government in Decision 76 on National Housing Development Strategy. However, the central government did not provide guidance on the organisation and activities of a fund. Therefore, the DOF was assigned the task of preparing draft regulations for a city HDF. On 22/09/2006, the DOF completed the regulations and submitted them to the 
DNPCe. The draft proposed financing the Fund by issuing city government bonds and mobilising from organisations and individuals. It also planned to use the Fund's capital to invest in housing projects and to provide preferential loans to developers and beneficiaries of the city housing policy for repairing, upgrading, constructing and purchasing their houses.

The DOF also prepared a letter for the DNPCe to submit to the Ministry of Finance for central government approval of the Fund and another letter to the DNPCl for local authority approval (D97). However, the fund could not be established. One reason, according to interviewee R11, was that there was no legal framework from central government for the organisation and activities of the fund. In addition, the city established the DNIDF in 2007 according to guidelines from the central government. This Fund could undertake some functions of the HDF. The interviewee also remarked that, as was the case for incentives for the private sector's participation, the draft did not offer any new solutions for mobilising finance from the private sector. One innovative idea for financing the Fund was to transfer the ownership of all state-owned housing units to this Fund so that the Fund could sell those units to recover the capital for further development. This idea, however, ran counter to the central government prohibition on selling state-owned housing units. There would be little point in transferring ownership of existing housing to the Fund without the right to sell them. According to one interviewee:

For the HDF, it conflicted with the old Law on Housing [2005]. That law requires that the Prime Minister decides on the sale and the buyers of all state-owned housing units on the advice of the MOC; local governments were not authorised to make those decisions. Thus, the establishment of a Housing Fund was not accepted, according to the regulations at that time. We drafted, we discussed many times but could not make it because we got stuck with the MOC, with the Government. Recently when the new Law was not enacted yet, I suggested giving the DNIDF the responsibility to build social housing and to sell them without asking for permission from the central government ... We got stuck with the MOC [again] ... We still could not establish the housing fund. The new Law on housing [2015] does not allow the establishment of the HDF [the law assigns most of this fund's responsibilities to a state bank on social policies]. Now the DOC is still responsible for managing these houses and if there is any problem, we must consult the MOC. We still get stuck [on this issue], even now we can't establish the fund. (R11) 


\section{* New beneficiaries were considered}

\section{Single mothers were assisted in 2008}

Poor households were one category of prioritised beneficiaries of housing policy in 2005 . Single mothers are among poor households, but their lack of partner support makes their living conditions relatively more difficult. Therefore, the city government decided to prioritise this group of people in considering and approving applications for housing support. From July 2007, the city government assigned the task of building row houses for single mothers to the Da Nang Relief Organisation of Women and Children. One year later, in August 2008, 126 row houses were allocated to single mothers in the city. In November 2011, to further improve the housing condition of these beneficiaries, the city government granted the Organisation the right to invest in another apartment building project. These housing units were planned to relocate the 126 single mothers' families from the row houses.

\section{Leprosy community in Hoa Van village}

Hoa Van is an isolated village at the foot of Hai Van pass, on the shore of a bay opposite to the CBD of Da Nang City. It is the home to a community of lepers, who had to leave their hometowns because of the popular belief that the disease could be transmitted to other people in the same community. The isolated location caused many difficulties in these people's lives, including transportation, education and medical care. In 2012, the DNPCe, under the direction of the Party Secretary, decided to relocate this community into some row houses in the city centre so that these people and their next generations could integrate with society. This was how they became another group of beneficiaries of the housing policy. Rumour has it that there were unstated motives of this decision. Supposedly, the land of the village was planned to be used for tourism. However, this study will not focus on the motivations behind the decision.

\subsection{Summary}

The story of the LIH policy in Da Nang City started with the introduction of the Having Housing Programme in 2005 in a context when the city was undertaking its urban renewal process and promoting economic development. The story came to a turning point in 2009 with the participation of the private sector and ended in 2013 when new policy ideas were about to be adopted. The narrative in this chapter illustrates how the policy idea was put on the agenda, and was formulated, implemented and evaluated, as well as how policy cycles repeated during the implementation stage of the process. This policy process shows 
that policy outputs could be generated in different forms, including policy enactments, policy experiments and policy change. The narrative indicates that learning and policy experimentation was occurring, matters that will be taken up in the analysis to follow. It also suggests attention to the influence of the ongoing relationship between central and local government in the process. The next chapters $(9,10,11$, and 12) will focus on the meaning of each policy event to understand the influences on the process. 


\section{Chapter 9: The influences of the city's socio-economic conditions}

\subsection{Introduction}

This chapter focuses on the influences of historical, geographical, social and economic factors on the supply and demand sides of LIH in the Da Nang case, which ultimately affected the enactment, development and implementation of the LIH policy.

\subsection{Influences on the demand side of LIH}

\subsubsection{Housing demand from relocated people}

The requirements of resettlement dominated the city's housing planning over most of the case period. According to a DNPCe's report to the NA, the urbanisation renewal process resulted in a huge number of affected households (Table 9.1). With the city household's size about four people per household, the process had affected almost half of the city population (90,050 households) and required about $20 \%$ of the population to be relocated (41,282 households) during the period from 1997 to March 2012. Most of households, who had acquired residential land, were provided land where they could build their new houses (35,324 households); others moved to apartments. Thus, the city government needed a supply of housing to move them to, in order to quickly clear the sites. This was the primary force for the enactment of the city's housing programmes, including the Having Housing Programmes in 2005 and the 7,000-unit Programme in 2009.

This argument was supported by many interviewees:

The period from 2005 to 2009 is the peak period of urban renewal; [thus] the demand of resettlement was urgent. (R1)

The resettlement was massive; 100,000 households were affected. (R2)

The city acquired land from more than 100,000 households, which led to the high demand for housing. (R4)

At that time [2005], the city was developing; Mr Thanh prioritised infrastructure development to facilitate economic and tourism development. [That] led to more than 90,000 households being affected. Some of them were not relocated in [new] plots of land; rather they were moved to apartment units. (R5)

Da Nang was developed from a provincial district; thus, urban renewal was a primary task. This task affected the housing issue ... Urban renewal process required the clearance of slums and temporary houses. (R12) 
Table 9.1: Land acquisition and relocation in Da Nang

\begin{tabular}{|l|c|c|}
\hline \multicolumn{1}{|c|}{ Items } & 1997-2004 & $\mathbf{2 0 0 5 - 2 0 1 2}$ \\
\hline Number of projects & 300 & 1,000 \\
\hline Land area (ha) & 18,500 & 13,000 \\
\hline Number of households affected & \multicolumn{2}{|c|}{90,050} \\
\hline $\begin{array}{l}\text { Number of households that were acquired their } \\
\text { whole residential land }\end{array}$ & 21,282 \\
\hline $\begin{array}{l}\text { Number of households that were acquired a part of } \\
\text { residential land }\end{array}$ & 21,125 \\
\hline $\begin{array}{l}\text { Number of households that were acquired their } \\
\text { agricultural land }\end{array}$ & 20,333 \\
\hline $\begin{array}{l}\text { Number of households that were assigned land for } \\
\text { relocation }\end{array}$ & 35,324 \\
\hline
\end{tabular}

Source: D100

The city Party also confirmed this primary motivation of the housing policy in a report to the central CPV:

The implementation of the "Having Housing" policy has achieved important results, meeting housing demands of people, especially in a context when the city is carrying out many projects to improve the city image, which leads to the task of clearing, compensation and relocation. (D4)

The important role of housing demand for resettlement was reflected later in the outcome of the policy: by $2014,50 \%$ of the tenants of the city's LIH projects were relocated households; $10 \%$ were people in preferential categories; $20 \%$ were poor people, single mothers or people with disabilities; and the remaining were government officials (20\%) (D85).

The city furthermore achieved this impressive task of moving a great number of households to new areas with very little backlash, given that relocation and resettlement in Vietnam has not always been peaceful ('Vietnam Tightens Land Seizure Law', 2013). There was only one riot, in the case of relocating a Christian community in Hoa Xuan (D. H. Nguyen, 2014). Because of this achievement, the city was praised by the central government as being the most efficient locality in the country in performing the task of 
compensation and relocation (X. T. Nguyen, 2003).

\subsubsection{Housing demand from population increase and other beneficiaries}

With the support from the central government, including preferential financial and budgetary policies provided by Prime Minister's Decision 13 (refer to Section 7.2.2), job opportunities increased and made the city a more desirable destination for immigrants from neighbouring provinces, which increased the city's population and created more pressure on housing. Interviewee R12 remarked: "Socio-economic development led to an increase of immigrants and the urban renewal process increased the housing demand".

When designing Decision 140 on the Having Housing Programme, policymakers expected that the city's population would increase more than $12 \%$ in the following five years (from almost 765,000 people in 2004 to about 860,000 people in 2010) (D18). The estimate showed that more people were going to live in the city, leading to more demand on housing. Moreover, as a young city, Da Nang faced difficulties in competing with the two bigger urban centres of Ha Noi and Ho Chi Minh City to attract well-educated people to work for government agencies. The city government had accordingly introduced some incentives, including housing provision, to attract better-qualified applicants. Finally, housing support needed to be further considered to continue the job of supporting people who contributed to the revolution and to undertake poverty alleviation. Therefore, the large housing demand was waiting for solutions, as remembered by one interviewee:

The period from 2005 to 2009 is the peak period of the urban renewal; [thus] the demand of resettlement was urgent. In addition, the condition of state-owned apartment blocks deteriorated, the number of poor people and people in preferential categories in need of housing support was high. All the people were low-income people. (R1)

Data on housing situation in the city from a previous DOLISA survey was used to evaluate the requirements of the Programme. As presented in section 7.2.5.4, in 2004, there were about 5,000 households living in low-quality houses and in need of state housing support. The drafting team also aimed to relocate tenants who lived in 22 deteriorated state-owned apartment buildings (D2, D18). With some adjustments, the Having Housing Programme ended up with the housing demand of about 11,500 households (Table 9.2). Based on this demand, the DOC worked out a plan of developing 1,154,000m² (Table 9.3). 
Table 9.2: Housing demand 2005-2010

\begin{tabular}{|l|r|}
\hline \multicolumn{1}{|c|}{ Categories of beneficiaries } & $\begin{array}{r}\text { Number of housing } \\
\text { units in demand }\end{array}$ \\
\hline People in preferential treatment categories and poor people & 4,721 \\
\hline Government officials & 1,500 \\
\hline Relocated people + population increase & 5,000 \\
\hline High-ranking officials (public-service houses) & 250 \\
\hline Sub-total & $\mathbf{1 1 , 4 7 1}$ \\
\hline Students & 60,000 \\
\hline Workers & 70,000 \\
\hline
\end{tabular}

Source: D18

Table 9.3: Plan of LIH development 2005-2010

\begin{tabular}{|l|r|r|r|r|r|r|}
\hline & \multicolumn{2}{|c|}{ Period 1 } & \multicolumn{2}{c|}{ Period 2 } & \multicolumn{2}{c|}{ Total } \\
\hline & $\begin{array}{l}\text { Square } \\
\text { metres }\end{array}$ & Units & $\begin{array}{l}\text { Square } \\
\text { metres }\end{array}$ & Units & $\begin{array}{c}\text { Square } \\
\text { metres }\end{array}$ & Units \\
\hline Apartment units & 170,000 & 3,800 & 248,500 & 5,500 & 418,500 & 9,300 \\
\hline Town houses & 30,000 & 750 & 54,000 & 1,350 & 84,000 & 2,100 \\
\hline Row houses & 40,000 & 330 & 71,600 & 600 & 111,600 & 930 \\
\hline Villas & & & 10,000 & 50 & 10,000 & 50 \\
\hline Student dormitories & 50,000 & & 130,000 & & 180,000 & \\
\hline Worker dormitories & 50,000 & & 300,000 & & 350,000 & \\
\hline \multicolumn{1}{c|}{ Total } & $\mathbf{3 4 0 , 0 0 0}$ & $\mathbf{4 , 8 8 0}$ & $\mathbf{8 1 4 , 1 0 0}$ & $\mathbf{7 , 5 0 0}$ & $\mathbf{1 , 1 5 4 , 1 0 0}$ & $\mathbf{1 2 , 3 8 0}$ \\
\hline
\end{tabular}

Source: D19 


\subsection{Influence on the supply side of LIH}

\subsubsection{The city's budget situation}

Before it was separated from Quang Nam-Da Nang province, Da Nang had to share the provincial budget of about 400 to 500 billion VND with other 16 sub-province districts, which was just enough for recurrent expenditure (X. T. Nguyen, 2003). As a result, the budget for investment in the city during this time was very limited. When the city acquired separate provincial status in 1997, it could enjoy greater fiscal autonomy with sharp increases in both revenue and expenditure. The city's total revenue had gradually increased in the period from 1997 to 2002 (Da Nang Statistics Office, 1997-2013), but rocketed and reached a peak in 2011 before slowing down again (Figure 9.1). ${ }^{20}$ The sudden increase in the city budget revenue was the result of the city leaders' determination to increase revenue from land to invest in infrastructure systems, reflected in the city Party's principles of 'Exchange land for infrastructure' and 'Infrastructure as a priority' (X. T. Nguyen, 2003). This determination was supported by the enactment of the Law on State Budget in 2002, which gave more budgetary autonomy to local government.

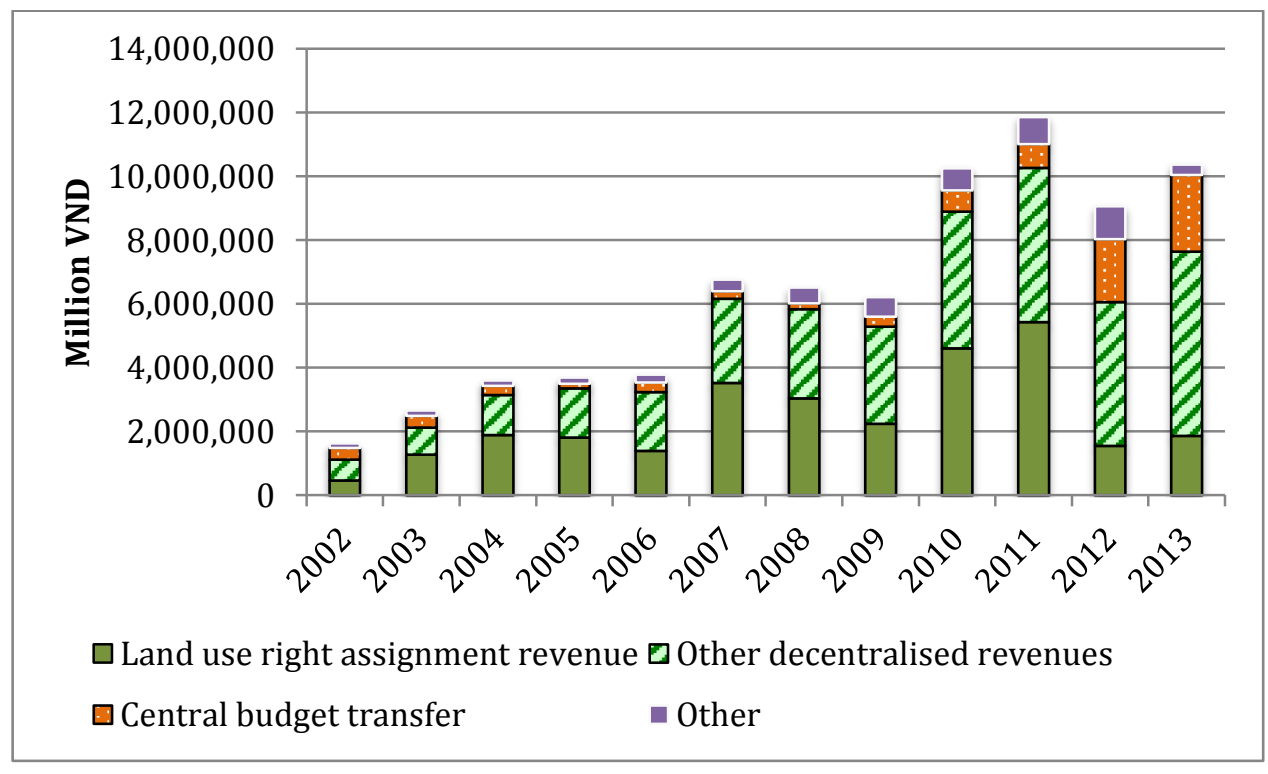

Figure 9.1: Da Nang's state revenues

Source: Calculated from Da Nang People's Committee (2002-2013) by excluding loans and revenues brought forward from previous years

\footnotetext{
${ }^{20}$ The DNPCe published its final account from 2002 to 2013 in legal documents (available on the Ministry of Finance's website and the city's Department of Finance's website. These data are official records of the city's budget.

The Da Nang Statistics Office also published data on the city's budget in Statistical Year Books from 1997 to 2013. However, these data are slightly different from the DNPCe's official records. Thus, they are mainly used to understand the general trend in the period from 1997 to 2002 when DNPCe's official records are not available.
} 
The city has received a large increase in revenue from assignment of land-use rights ${ }^{21}$ from 2003. This was the main local revenue and the main financial source for the city's infrastructure projects, including LIH development projects. Revenue from the land-use rights assignment amounted to about $47 \%$ of the city's decentralised revenues during the period from 2002 to 2013 (Figure 9.1).

In addition, the city also enjoyed a generous part of the shared revenue during this time. For the shared revenues, the central government set a fixed sharing rate for each province during a 'stability period'. This rate was set for Da Nang at 95\%, 90\%, and $85 \%$ respectively for the periods 2004-2006, 2007-2010, and 2011-2015. The comparative rates for Ha Noi were 32\%, 31\%, and $42 \%$ for the same periods (Truong, 2014). Da Nang was thus treated quite generously by this policy, indicating that the government regarded Da Nang as relatively in need of development. From 2002 onwards, shared revenues became an important contributor to the city budget revenues, reflecting the growing contribution of the private sector to the city economy (through various types of shared taxes) and cushioning the decline in revenue from the sale of land-use rights. The central government also transferred some central budget to invest in several important city infrastructure projects, which were identified in the Prime Minister's Decision 13 and to fund some national target programmes in the city.

Thanks to the increase in revenue, the city's expenditure was also increased correspondingly. The city particularly focused on investment and development expenditure. In the couple of years right after the city gained provincial status, its investment and development expenditure were much less than its recurrent expenditure. However, with the increasing revenue from land and the strong commitment to infrastructure development from 2000, its investment and development expenditure rose significantly and from then on exceeded its recurrent expenditure. Total investment and development expenditure was about $49 \%$ of the city's total expenditure during the period from 2002 to 2013 (Figure 9.2). Heavy investment in development expenditure meant that a great number of urban development projects were funded by the budget. In turn, these projects created demand for housing for relocated people and thus further demands on the budget for LIH. In this way, the demand for and supply of LIH continued to increase in the city during the last two decades.

\footnotetext{
21 'Assignment of land-use rights' is a politically-correct term of land sales. An individual or an organisation pays a oneoff payment to occupy a plot of land and enjoy rights like an owner.
} 


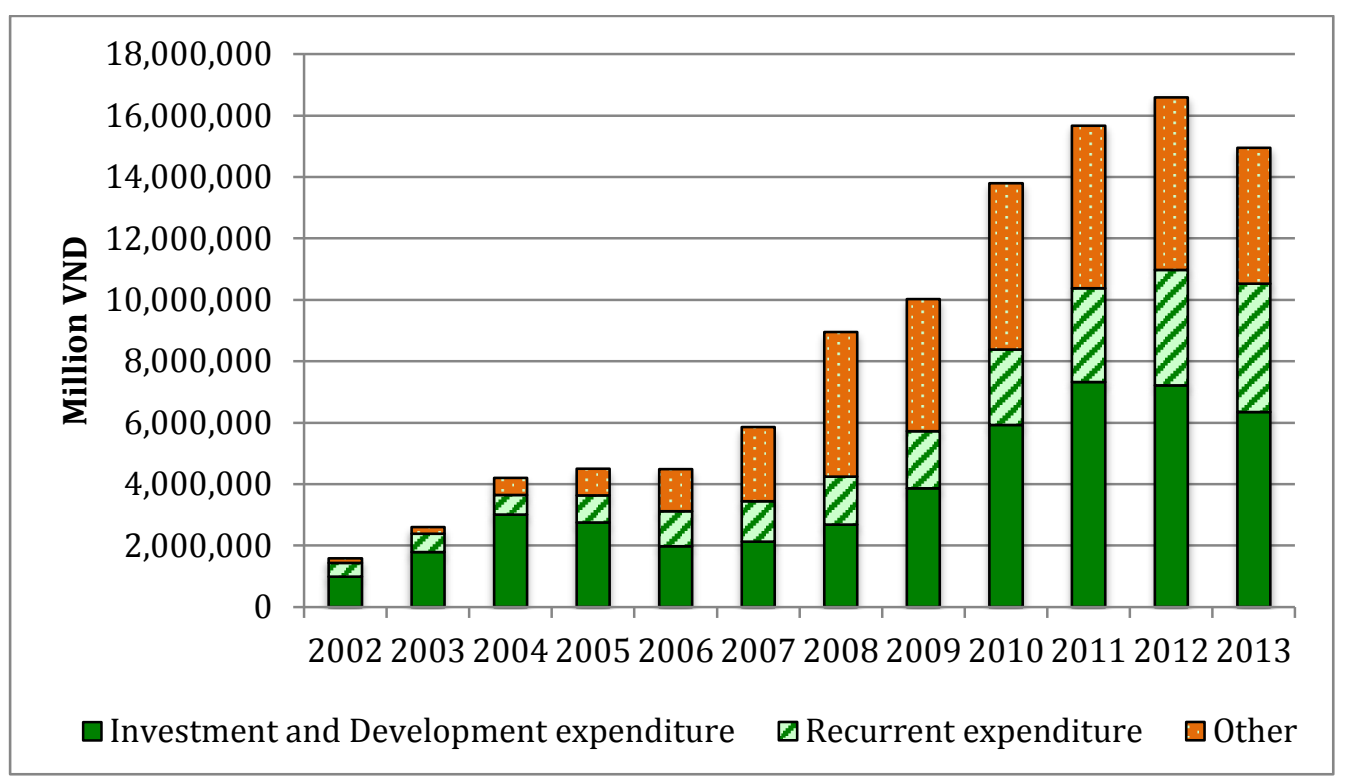

Figure 9.2: Da Nang's state expenditure

Source: Da Nang People's Committee (2002-2013)

In short, it can be said that after the year 2004, the city's revenues were continuing to increase. This pleasant prospect might have lent some confidence to the policymakers in designing the Having Housing Programme in 2005. Though other financial resources were much less assured, revenues from land could guarantee a significant source of finance for housing development. Some interviewees confirmed this influence:

The primary financial resource [of the programme] was from the exploitation of the land. (R1)

During the period from 2005 to 2012, the city's revenue from land was quite good. The city could earn money from land, thus, housing projects' progress was speeded up. After 2010, all projects' progress was getting slow due to the lack of finance. Therefore, the city was considering the solution of selling some state-owned housing units to gain money for further development. (R1)

That was the golden period ... Such a glut of money; our budget was strong ... We just used our own money for investment; we didn't lack money ... But things are getting difficult now. (R5)

When the Having Housing Programme was being implemented, economic forces once again profoundly affected the policy process in 2009 . When the international economy fell into recession in 2008 (Verick and Islam, 2010), the central government realised the need to encourage domestic demand, including housing demand via fiscal stimulus measures. 
Measures taken by the central government included tax cuts, public investment, interest subsidy and new regulations (Nguyen, Nguyen, Nguyen, and Bui, 2011). In particular, the enactment of Resolution 18 and three decisions (65, 66, and 67) enabled the enactment of the city's 7,000 housing units Programme in 2009 and facilitated the participation of the private sector. The introduction of Resolution 18 stated that the primary purposes of the Regulation were to respond to the economic crisis and to recover the economic development:

In order to solve the housing problem for those people [students, workers and lowincome earners in urban areas], to prevent the economic recession, to enhance manufacturing and business activities, to stimulate the investment activities and demand, and to ensure social security, the government decided ... (Resolution 18)

Those purposes were reconfirmed by the city Party in a report to the central CPV:

Building 7,000 housing units will solve housing problems for those people and achieve the objectives set by the Having Housing Programme; at the same time this programme can also support manufacture and sale activities as well as respond to the investment and demand stimulus measures, designed by the central government; ensuring the outcome of social security of the city and the national targeted programmes. (D13)

The policy adjustments by both the central and city governments received a positive response from private investors, because at that time they also faced difficulties in the highend housing market and in looking for another market segment.

\subsubsection{Finance from the World Bank}

When drafting the Having Housing Programme, the DOC planned to mobilise capital from the World Bank's PIIP (see Table 8.1). When asked why the team planned to use this fund and if there was any agreement between the city government and the World Bank relating to this plan, one interviewee admitted that the information was not very clear to the drafting team. They were simply informed that the World Bank would fund the PIIP in the city in the following years; and the city leaders required the drafting team to incorporate this financial source into the Programme's financial structure:

There was some information about the forthcoming project funded by the World Bank, and we expected to use some funds from this project for housing development. (R1) 
The DOC in fact mainly based its cost calculations on the estimated housing demand rather than on the available finance. Thus, the section on capital structure of the programme was quite vague, even to the drafting team (see Table 8.1). It is evident from the account of the policy process that only the contribution of the state budget could be forecast with reasonable confidence. The estimates of the rest of the assumed funding were effectively created to balance up with the forecast expenditure.

The city government might have worked (or delegated to the PIIP to work) with the World Bank about this plan. The World Bank published two research reports on LIH in Da Nang City (World Bank, 2006, 2007). Unfortunately, after conducting these two studies, the World Bank decided not to invest in housing for low-income people, explaining that this job should be taken by the private sector. The World Bank also raised a potential problem of LIH investment, that beneficiaries might not be low-income people. The PIIP, as its name implies, was directed at finance for infrastructure for urban development, and the Bank was unwilling to extend the scope of housing finance beyond households directly affected by the projects funded by the programme (World Bank, 2008). The Bank support included improving infrastructure in 14 low-income residential areas; developing three resettlement zones with about 200 housing units, one school and infrastructure systems; and establishing a micro-credit fund for housing loans (valued at 1 million USD) (D102).

In short, the influence of international organisations (in this case only the World Bank) was not significant in this case. The presence of the PIIP simply gave some encouragement to the policymakers, making them hope that the city's budget would not be the only financial resource for the housing programme. In reality, the contribution from the PIIP to LIH development was limited and the city leaders dealt with this issue by working with the central government and the private sector, as discussed in Chapters 10 and 12.

\subsubsection{Other sources of finance}

In addition to local revenue from land-use rights and the financial resources from the PIIP, policymakers also planned to mobilise finance from other sources, such as state-run lotteries activities, government bonds, loans, donations, prospective users and especially the private sector (D25). State-run lotteries, donations and tenants had contributed to finance the Having Housing Programme during the case's timespan, though there were not available data on the exact amount. The city had not issued any government bonds and loans were not significant during this period due to the bonanza of budget revenue. Influenced by the increasing importance of the private sector in the city's economy (refer 
to Figure 7.1), the policymakers expected to mobilise a significant contribution of 17.5$25 \%$ of the total estimated costs of the Programme (see Table 8.1) from this sector. The participation of the private sector will be presented in detail in Chapter 12.

\subsection{The indirect influences of historical and geographical features}

Studying the influences of the socio-economic conditions also draws attention to the effect of several historical and geographical factors. The city's ability to generate revenue from the sale of land-use rights was fundamentally made possible by the Doi Moi legal reforms, which secured individual rights to occupancy and use of land. This basic reform enabled the development of a real estate market. But it also pushed up the price of housing in urban areas, causing inequality in income and living standards. These could have threatened social stability, and thus drew the government attention to LIH policy. The separation of the city from Quang Nam province created a small, manageable city for policymakers to experiment with innovative policy ideas. Finally, the location of the city made it the hub for development of the Central region of Vietnam. Although these historical and geographical features did not directly influence the introduction of the Having Housing Programme, they conditioned the socio-economic situation to a point favourable for policy change.

\subsection{Conclusion}

Data on the city's development show that the introduction of the Having Housing Programme in 2005 and the policy adjustment in 2009 were affected by some socioeconomic factors. It can be said that housing demand for resettlement during the urban renewal process was the primary motivation for the enactment of the Having Housing Programme in 2005. Other socio-economic factors such as the increasing population (mainly due to immigration) and the housing demand of government officials, of people in preferential categories, and of vulnerable people also influenced the policymakers' decision but their weight was not as strong as the requirements of resettlement. In turn, the significant budget revenue from land exploitation made available thanks to the urban renewal process encouraged city leaders to adopt the policy idea in 2005 . It was the main financial source of the policy implementation during the timespan of the case. The initial plan of mobilising finance from other sources was unworkable when the policy was implemented. This forced the city leaders to experiment with other innovative policy ideas in the relationships with the central government and the private sector, which will be discussed in following chapters. When there were changes in international or national 
economic development, such as the international economic recession in 2008 , housing policy at both central and local levels was adjusted to meet the new economic condition. 


\section{Chapter 10: The central and local government relationship}

\subsection{Introduction}

This chapter discusses the influence of the relationship between central and local government in the LIH policy process in Da Nang City from 2005 to 2013. Its primary aim is to shed light on how the central government influenced the city government's policy process and whether the city enjoyed any autonomy in making its own policy choices.

\subsection{Evidence of the relationship throughout the case}

\subsubsection{Orientation of housing development set by the central government in May} 2004

As presented in Chapter 8, the introduction of Decision 76 approving the Housing Development Strategy through 2020 is the legal foundation for the introduction of the Having Housing Programme in Da Nang in 2005. The decision stipulated that the state would:

d) Implement a policy of investing in a housing fund for rent and for sale by instalments to people in preferential categories to improve their housing (hereafter called social housing fund);

đ) ${ }^{22}$ Encourage all economic sectors to participate in urban housing development in accordance with legal regulations;

e) Make efforts to achieve the goal of average housing space of $15 \mathrm{~m}^{2}$ per person by 2010 and $20 \mathrm{~m}^{2}$ per person by 2020 and to ensure the quality of urban housing meets the national standards.

To achieve those goals the decision set out some general and specific solutions. The general solutions were mainly focused on the need for revising and better implementing relevant legal regulations in housing development, such as to "study and enact regulations relating to housing standards and architecture management in urban areas" or to "improve the credit procedures to support households and individuals in housing loans". Particularly, the Decision encouraged the exploitation of land for housing development in urban areas. To implement these regulations, the decision assigned some specific objectives to local governments. Local responsibilities were, firstly, to enact a local housing development programme; secondly, to establish a HDF and to enact regulations on selling state-owned

\footnotetext{
${ }^{22}$ Vietnamese listing style based on Vietnamese alphabet
} 
houses by instalments and leasing houses to government officials and low-income people; thirdly, to collect data on housing demand of workers and students and suggest local housing support policies for them; and, finally, to allocate budget to housing development in accordance with legal regulations (Decision 76).

The city government fully applied the instruction from the central government when designing its Having Housing Programme. However, the Having Housing Programme was more than a faithful implementation of the central government's direction, in fact, it was a creative product of a local policy-making process that entailed significant effort to develop the central government's general policy idea into one suited to local conditions. The first example of local creativity was in the definition of policy beneficiaries. While supporting all prioritised people mentioned in Decision 76, Decision 140 also included relocated people, households living in highly dense and low infrastructure areas or government officials who worked for the city under the city's talent-attraction policy.

The housing demands of relocated people reflected Da Nang's urgent need for resettlement housing. The government officials working for the city under talent-attraction policy was also a beneficiary group unique to the city because, at that time, Da Nang was the only locality in the country issuing policies to attract well-educated people to work for city government agencies.

Decision 140 aimed broadly to support all low-income people in urban areas. In reality, while implementing the policy, due to budget constraints, the city government could only support specific categories: people who had contributed to the revolution, poor people, relocated people and some government officials. However, it also prioritised two more groups (single mothers and residents of a leprosy community), who were not mentioned in the central government's regulations.

The second example of the local government's initiatives was the technical solution. While the central government did not provide any instructions on the design and architecture of $\mathrm{LIH}$, the drafting team of Decision 140 made efforts to apply their expertise in construction based on the architecture of existing apartments, Vietnam's standards on construction, and probably suggestions from relevant agencies (R1) to come up with some regulations such as:

- Housing for low-income people should be five-story apartment buildings with average space of $50 \mathrm{~m}^{2} /$ unit and investment cost of about $1.8 \mathrm{VND}$ million $/ \mathrm{m}^{2}$.

- Dormitories should have five stories with average space of $30-40 \mathrm{~m}^{2} / \mathrm{room}$ and 
investment cost of 1.4VND million $/ \mathrm{m}^{2}$.

- Row houses should have two stories with average space of $120 \mathrm{~m}^{2} /$ unit and investment cost of about 1.2-1.3VND million $/ \mathrm{m}^{2}$.

- Public-service houses (villas) should have two stories with average space of 150$200 \mathrm{~m}^{2}$ and investment cost of about 2.2-2.5VND million $/ \mathrm{m}^{2}$.

- Housing for people in preferential categories and for poor households in rural areas should be one-story houses with average space of $40 \mathrm{~m}^{2}$ and investment cost of about $0.5 \mathrm{VND}$ million $/ \mathrm{m}^{2}$.

- For apartment buildings [investors] should just invest in building the frame of the houses and the front structure of the buildings [entire structure]. Tenants will invest in the interiors. (D18)

Normally, following general directions such as offered in Decision 76, local governments will wait for detailed guidelines before acting. A local government that wants to actualise a policy idea in the absence of the detail risks legal difficulties, (as happened in Da Nang in the cases of incentives for the private sector's participation or the establishment of the HDF; see section 8.2.14).

In fact, in the enactment of the Having Housing Programme in 2005, the city government effectively designed the entire programme on the strength of one important instruction from the central government that encouraged local governments to use revenue from land for housing development. Taking one general idea, the drafting team was able to design the detailed contents of the housing programme. How much of the local revenue would be used for housing development was a local decision and depended on the political priority for this policy in relation to other demands on the city's budget. When asked for memories of drafting Decision 140, one interviewee recalled that the drafting team tried to find a housing development programme or project from other localities but could not find any example to follow. Since there were no detailed instructions yet from the central government, they had to develop the detailed policy from their own knowledge, experience and leaders' ideas. The name of the Programme and its enactment within the 3-Haves campaign also indicated the creativity of the city government in producing this policy. The 3-Haves campaign was a product of policy consideration by the city leaders in discovering the best way to exercise their duties of governing the city. It seems to have been influenced by the previous 5-Nos campaign and reflected the city's distinctive leadership. There was no instruction from the central government for such a campaign. 
Therefore, it can be said that, although the Having Housing Programme was based on some general regulations from the central government about what local governments could do for their localities, the city government had some space to apply the central government's instructions creatively. However, it should be noted that this space was always limited by the legal framework set by the central government, as discussed in section 8.2.14 about the establishment of the HDF and the regulations on incentives for the private sector.

\subsubsection{The enactment of the Law on Housing in October 2005: facilitating the implementation of the city's Having Housing Programme}

In November 2005, one month after Decision 140 was issued, the Law on Housing was enacted by the central government. This law recognised the need to develop social housing. The law confirmed that the state encourages all economic sectors participating in housing development and will have policies to support social housing. It also provided a definition of the Social Housing Fund, a housing fund for government officials and workers in industrial zones and other groups specified by the Government. However, there were no guidelines on financing this fund and how they were to be used.

Other provisions in the law relating to the design and architecture of social housing were consistent with those in the city's Decision 140. For example, while Decision 140 stipulated that apartment buildings for low-income people should not be higher than five stories, the law provided that low-income apartments could be up to six floors.

Overall, the enactment of the Law on Housing (2005) encouraged the implementation of the Having Housing Programme, as the city policymakers were confident that they were on the right track and that more policies would be enacted to make their policy objectives feasible. In addition, the city's Decision 140 was still consistent with the national law and did not require amendment. In a report to the DNPCe, the DOC evaluated that the enactment of this law facilitated the implementation of Decision 140 (D26).

Ideas and experience sharing between the central and the city government

The consistency between the Law on Housing and the city's Having Housing Programme was probably a result of formal and informal communication between the central government (especially the MOC) and the city government during the preparation and discussion of the law contents. Governed by the dual accountability principle, the DOC had to report to the MOC about the enactment and implementation of Decision 140 in Da Nang City, as recalled by one interviewee: 
All these policies were reported to the MOC annually. We also reported to the MOC

in [national] conferences such as the [national] conference in Sa Pa in 2007. (R1)

The exchange of ideas between the MOC and the city government on guidelines for the Law on Housing (refer to section 8.2.9) indicated that the central government acknowledged that the city government was implementing some initiatives in social housing development (which was ahead of the central government guidelines) and that it expected to be able to learn from Da Nang's ideas and experience. (However, it should be noted that asking for suggestions and opinions from local governments and society is a normal activity in drafting any important legal document in Vietnam, reflecting the effect of the principle of democratic centralism, and the MOC might have sent this request to all provinces and cities in the country). It is not clear how much the central government applied Da Nang's policy and experience, but at least it is known that the central government took account of what the city was doing.

\subsubsection{Central government's regulations and local government policy complemented each other}

While implementing the Having Housing Programme by investing the city's budget in building apartment units for prioritised beneficiaries, the city government was also implementing some central government regulations on housing support for people who had contributed to the revolution and for poor people (see the results reported by the DOLISA in Boxes 10.1 and 10.2).

\section{Box 10.1: Housing support for people in preferential categories in the first six months of 2008 (D31)}

- Exemption from payment for land-use rights: 32 households

- Financial support for housing repairs: 159 households

- Houses of gratitude: two households

- Financial support for housing repairs for special beneficiaries: 65 households

- Rental of apartment units funded by the city's Having Housing Programme: 31 households 
The results showed that implementing the central government's regulations and the city's Having Housing Programme simultaneously helped the city to achieve its housing policy goals. At the summing-up conference in 2007, two years after implementing the 3-Haves campaign, a Vice Director of the DOC confirmed that the city's housing policy fitted the central government's orientation in housing and with the Law on Housing (D35). The match facilitated the implementation of the city's Having Housing Programme.

\section{Box 10.2: Housing support for poor people in the first six months of 2008 (D31)}

- Exemption from payment for land-use rights: 32 households

- Financial support for housing repairs: 57 households

- Houses of sympathy: 167 households

- Rental of apartment units funded by the city's Having Housing Programme: 19 households +38 single mothers

\subsubsection{The city government faced some legal constraints in enacting policies}

As presented in previous sections, from 2004, the central government encouraged local governments to enact policies to encourage the private sector's participation in LIH development. In particular, the Law on Housing (2005) stipulated that:

When individuals or organisations develop social housing projects, they would be exempted from the land-use levies or land rents for the land used for construction of social houses; be entitled to exemption from and/or reduction of relevant taxes according to the provisions of law. (Article 45)

On this legal foundation, the city government drafted regulations on incentives for private investors' participation in housing development. However, the draft was not approved and could not be enacted. A similar situation happened with the idea of establishing the HDF (see section 8.2.14). It also took the city government about ten years of going back and forth on the idea of selling apartment units to sitting tenants to recover capital for further 
investment until it gained support and approval from the MOC and the Prime Minister for a pilot project to sell some housing units (see section 8.2.14).

These three examples suggest that the space of policy innovation was constrained by the legal framework set by the central government. The city's room for manoeuvre could therefore be quite tight, but, in some circumstances, and with persistence and effort, as in the case of the pilot project to sell state housing units, the city leaders could persuade the central government to support its innovative policy ideas.

\subsubsection{New guidelines from the central government enabled the city government to further develop its housing policy}

To respond to the global financial crisis and deal with some other domestic economic problems, in December 2008 the central government adopted some urgent measures to prevent an economic downturn and ensure social stability. In particular, the government announced a stimulus package of US\$6 billion (which was later revised to almost US\$8 billion) providing tax cuts and interest subsidies as well as spending on infrastructure, housing, education and health care (Le, 2009; Nguyen et al., 2011). The CIEM's visit to the city in 2008 (see section 8.2.12) was an opportunity for the city government to suggest ideas about incentives for private investors as well as to collect information about forthcoming policies from the central government for housing issues (D36). In addition, through different channels, the city government was informed about the central government's plan to use the stimulus package for social housing, and prepared a programme of building 5,000 housing units to take advantage of the forthcoming policies.

The enactment of Resolution 18 and three guiding decisions started a new period for LIH development in Da Nang City with the introduction of the city's Decision 3882 launching a programme of building 7,000 housing units. From the perspective of policy ideas, Decision 3882 was merely a copy of the central government regulations without any local changes. However, thanks to the new regulations on incentives for private investors participating in LIH development, Da Nang could attract the first investor, to develop the first LIH project in Da Nang City.

\subsubsection{The city government persuaded the central government to provide financial support for LIH projects}

The 7,000 housing-unit Programme was used as an official basis for the city government to ask the central government for financial support. Two days after the decision was enacted, the DNPCe asked the Prime Minister for 850 billion VND (50\% of the total 
estimated cost of the programme) (D94). The DOC also asked the MOC to support the city's proposal (D22).

In response, the Prime Minister decided to assign 254 billion VND for Da Nang to invest in student dormitory projects over three years (2009-2011) (Decision 1808/QD-TTg dated 20 August 2009 and D51). However, the Prime Minister refused to provide finance directly for the city's LIH projects and asked the city government to use its own budget and investors' capital for this purpose (D48). Instead of providing finance directly to local governments for building houses, the central government decided to encourage the participation of private investors in LIH by offering preferential loans. In that situation, the city government adjusted its investment purposes. Instead of investing in housing development for low-income people, students and workers, the city decided to focus on LIH only and to use the finance from the central government mainly for student housing projects. Neither central nor local government provided finance for investment in housing for workers in industrial zones. The city was willing to provide cleared lands for worker housing projects, but there was not much interest from investors. One project was started but could not be completed. Meanwhile, the city government supported investors in LIH projects in accessing the central government's preferential loans (D52).

Despite the Prime Minister's refusal to fund LIH directly, the city government continued to seek central government support. In 2011, it submitted another project proposal for 5,000 housing units for government officials, to be wholly financed out of the central government's fund for civil service salary reform. This attempt did not succeed either. In November 2013, not discouraged, the DOC again suggested that the DNPCe submit yet another project to the central government to support its plan to build 14,000 units and to request access to the central government's preferential loans (D83). However, there is no evidence about the outcome of this suggestion.

These efforts showed that the city government did not passively wait for offers from the central government. Instead, they designed different projects, worked on convincing reasons and feasible funding, and then sought to persuade the central government to approve the projects. Although such efforts did not always bring about positive outcomes, they indicated the active role of the city government.

\subsubsection{Closer cooperation between central and city governments}

Apart from regular reports of housing policy outcomes from the DOC to the MOC, there is evidence that Ha Noi was taking a close interest in policy development in Da Nang. In 
September 2012, a delegation of the Central Steering Committee on Housing Policy and Real Estate Market visited the city to discuss solutions for achieving the objectives of the new National Housing Development Strategy (2011). During this visit, the Deputy Minister of the MOC praised Da Nang for leading the country in the public housing development. In return, the city government made some suggestions relating to LIH policy, including problems with preferential loans for LIH projects (D63, Da Nang Today, 2012; Ngoc Thuy, 2012). In a statement following this visit, the Central Steering Committee officially recognised the "outstanding results" (D72) of the city government's housing policy and praised the role of the city Party and the city government. It also noted that the central government would take into account the city's suggestions when revising a new decree about social housing management that the MOC was drafting. For other special policies that had not been specified by the central government and were beyond the mandate of the Committee, the Committee advised the city government to send reports to the government and relevant ministries for consideration. In particular, to support the city government in preferential loans for $\mathrm{LIH}$, the Committee undertook to meet with relevant ministries, the DNPCe and relevant banks to discuss solutions (D72).

The visit and its outcome indicated a closer relationship between the central government and the city. There were face-to-face discussions and plans for further cooperative action on social housing. The event also indicated that the central government listened to the local government's suggestions in drafting their regulations. This was also the first time the central government offered some official and very positive evaluations on the city's achievement as well as on the contribution of the city leaders.

Two months after this visit, the Committee organised a meeting with central government agencies (the Government Office, some ministries, and the State Bank of Vietnam), the DNPCe, investors developing LIH projects in Da Nang City, and two state-owned commercial joint stock banks, BIDV and VIETIN, to discuss solutions for ensuring finance for LIH projects in Da Nang City (30 November 2012).

The main purpose of this meeting was to allow the central government to play an intermediary role among some commercial banks, the city government and some investors to promote the loan process for LIH projects. The Committee advised that the city government should introduce and guarantee investors' loans at commercial banks. It also recommended that the two commercial banks (BIDV and VIETIN) should provide preferential credit packages to investors and buyers of LIH projects. In addition, it 
suggested that the State Bank issue special policies for social housing loans (D73). The actions showed the central government was becoming involved more deeply in the city's housing problems and cooperatively seeking suitable solutions. It was a starting point for further cooperation among the State Bank, commercial banks, investors and buyers of social housing, such as the Government's 30 trillion VND (1.4 billion USD) housing credit stimulus scheme in June 2013 (Thuy Vinh, 2015; VietnamPlus, 2015).

The cooperation between central and local government became especially strong when the city government and the MOC signed a collective action plan for implementing the National Housing Strategy in August 2013. Through this plan, the two parties resolved to establish a Working Group led by a Vice Chairman of the DNPCe and a Deputy Minister of the MOC, to coordinate some tasks such as collectively studying and developing procedures and policies on housing development and management, especially procedures and policies to develop social housing to suit the situation of the city; revising the city's Housing Programme to 2020; accelerating the formulation, evaluation and approval of zoning plans; mobilising financial resources for housing development, especially establishing a Saving and Development Housing Fund; and some other tasks (D84).

Among those tasks, the Deputy Minister of the MOC judged that the most important was cooperation between the two parties in studying, developing and revising housing policies. The two parties agreed that if there were any policy ideas beyond the competence of the MOC and the city government, the city would seek permission for a local pilot project, and then, on the strength of the success of this project, ask for official regulations to be enacted (Bo Xay dung, 2015; T. Ngoc and Ngoc Long, 2013). This was probably the foundation for the policy process the city government and the MOC went through to eventually gain approval from the Prime Minister for the pilot project of selling some state-owned housing units in 2015.

\subsubsection{Local-central relationship in the Party system}

Parallel to the relationship between the central and the city government, there existed another channel of communication between the city Party and the central CPV. For example, in 2006, the CPV requested municipal Party units to report on housing support for government officials. In response, the city Party reported to the CPV on the overall housing situation and all housing polices applied in Da Nang City (D2). These documents indicated that the central and local Party had a common concern about housing for government officials and they would direct the responsible governments to meet their 
housing requirements.

In 2013, in a report to the central CPV, the city Party claimed that the city Party and government had paid special attention to social security and set it as one important objective in the city's strategy of socio-economic development. The city Party considered the 5-Nos and 3-Haves campaigns as the city's "specific local policies" that covered many basic demands of vulnerable people (D9). In addition to reporting the results of the housing policy in the previous 20 years, the city Party also perceived a problem of housing for workers and asked the central Party to intervene in this issue. The Party involvement indicated that housing for workers was a problematic policy issue, partly because of their extremely low income and partly because of the lack of a suitable policy solution, which was later resolved effectively by the Binh Duong government in 2015 (Quynh Tran, 2017).

\subsubsection{Local government's initiatives overturned by the central government}

The evidence is thus that the city's policy creativity on housing was generally received favourably by both central government and Party. However, there were also times when the central government intervened to stop a city initiative. For example, in December 2011, the DNPCl approved Resolution 23, putting a temporary halt on permanent residence registrations of people who were unemployed or had criminal records and who sought to rent or share a house with locals in the city centre (Thanh Khe and Hai Chau Districts). The DNPCl claimed that, when approving these regulations, it was exercising its authority to distribute population within the city. This was a local effort to restrain the number of immigrants in the city with no housing of their own. Renting and sharing houses in the city centre would create more pressure on the limited infrastructure system and perhaps adversely affect the objective of average housing area in the city. However, the Legal Document Examination Department under the Ministry of Justice objected to the idea, arguing that "there is no article in the current laws which allows a provincial PCl to stop the effect of the Residence Law, which may prevent citizens from enjoying the legal interests given to them by the NA" (Nghe Nhan, 2012). Also in this resolution, the DNPCl ruled that from 2012, "the local authority will prohibit all sales of housing apartment". This was a city government's response to tenants who illegally sold their rental social housing units to third parties. However, the regulation caused confusion to readers because it did not distinguish the sales of state-owned social apartment units from the sales of private apartment units. As a result, the Legal Document Examination Department judged that the Resolution was ultra vires, and the MOJ asked the city government to abrogate those 
regulations (TuoiTreOnline, 2012).

The incident indicated that the city was always under the constraint of the legal frameworks set by the central government and its creative initiatives could always be prevented to ensure the consistency of the legal system. However, it was also a good example of how the city Party and government could manoeuvre in a limited legal space to make local policy. After being stopped by the central government, the Chairman of the DNPCl (also the Party Secretary) ordered all relevant government agencies and research institutes in Da Nang to undertake studies and suggest other solutions for population distribution. The DNPCe established a working group consisting of leaders of all relevant agencies with an assistant group consisting of professionals and officials to discuss the legal framework governing the issue, consider the city's situation and suggest acceptable solutions that could pass the examination of the central government, and which, at the same time, could achieve the city's goals in controlling the flow of immigrants and pressure on housing. As a member of the assistant group, I was informed that the central government supported the city's objective in controlling the population and understood the pressure on infrastructure and housing; while halting the city's resolution 23, the central government still encouraged the city to submit new solutions with firm evidence and strong legal backing for consideration.

The results of this process were Resolution 29 (2012) about population distribution and Resolution 48 (2013) regulating the average area per person in Da Nang City when considering applications for permanent residence registration for people who would be sharing or renting locals' houses. Based on the National Housing Strategy, which set out the minimum and average housing areas per person in cities, the DNPCl stipulated that when a person applied for permanent residence registration in the city, they had to prove that the average area per person of their house would meet the requirements of at least $20 \mathrm{~m}^{2}$ per person in Hai Chau and Thanh Khe districts and $15 \mathrm{~m}^{2}$ per person in other districts (D78, D79). This was an effective solution for the city to limit the number of immigrants and control the pressure on housing while still being able to defend itself from criticism from the central government and media.

\subsection{Conclusion}

In summary, over the period of this housing policy case, the relationship between central and local government in this housing policy case underwent significant changes. In the period from 2004 to 2009 , the relationship between the two was indirect and not very clear. 
At first, the general policy idea was initiated by the central government and then was creatively developed by the city to fit the local situation. In this period, there had been communications between the two to share policy ideas and experiences for further development of the general policy idea. However, the upward relationship was still limited mostly to reporting activities. While implementing its housing policy, the city government consistently applied all central government regulations. At the same time, however, it also interpreted them creatively to best fit local needs. Some of these initiatives succeeded but others did not. The period from 2009 witnessed a closer relationship with the continuing local effort to obtain financial support from the central government. The central government also became more active in cooperating with the city. Although there were times when the city's initiatives were overturned or its proposals denied, its efforts were always appreciated and praised by the central government. In a unitary state, the policymaking process in local government must be always limited by central government's legal framework to a certain extent. Thus, the power to overturn local policy was necessary to ensure the consistency of the legal system. Any creative implementation from local governments, such as using their own budgets for social housing development, should be within their authority. If the city government had any innovative policy idea, it was safe to report to and work with the central government to find acceptable solutions, as evidenced by the city government's action to sell some state-owned housing units. 


\section{Chapter 11: The role of the city Party and the Party Secretary}

\subsection{Introduction}

This chapter examines the role of the city Party and the Party Secretary throughout the policy process of the Da Nang case. Since the Party Secretary was the highest representative of the city Party, his actions will be considered as representing the Party policies and decisions. Therefore, the first section of this Chapter will examine the Party's and the Party Secretary's influences on the process. It is followed by a discussion on factors affecting the Party's influences. The third section will focus on the Party Secretary's influences as a key policy elite and a discussion on factors affecting his behaviour.

\subsection{The role of the Party and the Party Secretary}

\subsubsection{Agenda setting}

The first significant role of the city Party in the policy process was reflected in the Party Secretary's speech delivered on the $30^{\text {th }}$ anniversary of the city's independence. On this occasion, the idea of the 3-Haves campaign was first introduced as a policy solution for some urgent issues of the city. We have no evidence to identify the person who first raised the idea of the 3-Haves campaign. However, it is clear that the Party Secretary advocated the policy idea and took a strong public lead in promoting it. His support was crucial for the enactment and implementation of the 3-Haves campaign. As Kingdon (1995) notes, an attempt to pinpoint the single origin of a policy idea is fruitless because "if we try to track down the origins of an idea or proposal, we become involved in an infinite regress" and "People don't sit down and think up whole new approaches in a flash of insight. They borrow from somewhere else" (pp.72-76). Instead of trying to find 'the source' of the idea, we will investigate the 'climate' (Kingdon, 1995) in which the policy idea was raised, accepted and developed into legal regulations.

At the central level, the Political Bureau is the supreme policy-making body of the CPV; at the local level, the Standing Committee of the provincial Party unit holds a similar power. Thus, as noted by interviewee R11: "In our political system, all new policy ideas must be discussed and approved by the Party before being enacted in any legal regulations". The idea of the 3-Haves campaign was discussed within the city Party, especially by members of the Standing Committee. While the idea was discussed within the Committee, it is evident that the idea of the ' 3 -Haves' was influenced by the previous '5-Nos' campaign: 
Some members suggested finishing the 5-Nos campaign before commencing the 3 Haves campaign. After discussion, the Committee decided that the 5-Nos could not be completed because the time for it could not be limited to ten or fifteen years. For example, drug addiction is a common problem in most countries, and having no drug addicts in communities was actually an aspiration, an ideal desire. Thus, the Committee agreed that we need more time to work on the issue and it could not be finished at that time. Similarly, "no murder robbery crime" is also another difficult goal to achieve; even when there is just one case happening in a year. When we discussed the 5-Nos campaign, members of the Committee idealised [the goals], we aimed for a peaceful society. But then, our capacity and society management skills were not up to the expected level. Thus, such crime still happened. Those two examples show that there was a gap between what we aimed to achieve and the reality. Thus, when discussing, we agreed to continue the 5-Nos campaign, and start the new 3-Haves. (R11)

From this response, a common pattern can be found in the way the city leaders set out their policy goals. They advocated 'big dreams', then worked on them incrementally. People might argue that the goals sound like 'slogans' (Shankansky, 2002), utilised by the city leaders to create an attractive city image as well as to enhance their political profiles. However, the development of policies from 5-Nos to 3-Haves and the explanation from interviewee R11 show the city leaders' aspiration for better governance and society.

One local journalist remarked that: among the 3-Haves, the outcome of the Having Housing Programme would be measured easily by statistics and the success or failure of the policy could be demonstrated clearly. This would put the policymakers under heavy criticism if they failed (Ho Trung Tu's Facebook on 13 February 2015, used with the author's consent). However, the policymakers believed that the Having Housing Programme was the most feasible objective. Although the ultimate goal of housing for all would not be achievable in the short term, it should be possible to make measurable progress:

The three components of the 3-Haves campaign were equally important. However, members of the Committee, including myself, believed that the Having Housing Programme would achieve the goal earlier. Because unemployment and culture issues are very difficult and in fact we can never achieve the goals of those issues. Thus, Having Housing was a true desire ... I was happy; I believed that we could 
successfully undertake this programme. (R11)

Though there was a concern about the city's capacity in meeting the housing demand of increasing numbers of immigrants, the Committee decided to solve the problem step by step:

At that time, I worried about one thing: ensuring housing for all people. Because Da Nang was the centre of the Central Region, the number of immigrants increased every year. So, would we be able to meet the housing demand of all people, including immigrants? I took this matter up with the committee, and other members decided that we would focus on the housing demand of Da Nang's permanent residents first; [and] the demand of immigrants would be considered later. (R11)

In short, from the testimony of interviewee R11, the Standing Committee of the city Party discussed the necessity and feasibility of the housing policy. The discussions finally arrived at a decision in May 2005 by the city Party to enact the 3-Haves campaign (Letter 960).

It is noted that the policy idea was decided in May 2005, prior to the $19^{\text {th }}$ City Party Congress, which was held in November 2005. Therefore, the Congress's resolution was in fact a formal ratification of a policy decision which was already made by the Standing Committee of the city Party. The Committee also retained the power to approve the main contents of the 3-Haves campaign before passing them down to the DNPCl for official government resolution (D1). The approval by the $\mathrm{DNPCl}$ was an administrative procedure, rather than a decisive step in policy processes as described by the Law on PCl and PCe. Thus, it can be said that the most important policymakers were the members of the Standing Committee of the city Party.

After the policy was approved by this Committee, it was passed to the government for legalisation. The dual roles of some key decision-makers (the Party Secretary was the DNPCl's Chairman, his Deputy was the DNPCl's Vice-Chairman, two other members of the Standing Committee were Chairman and Vice-Chairman of the DNPCe, another member was the Head of the city VFF) facilitated this process and enabled the Party to impose its decision on the government. This setting might have explained the consensus atmosphere in the DNPCl's meeting to approve the 3-Haves campaign with no significant discussions relating to the policy idea. This fact is in accord with Dang Phong and Beresford's (1998) judgement: "[The CPV] is the body which decides policy as well as the institutional structure of the rest of the state apparatus. Its resolutions have the force of 
law" (p.46).

\subsubsection{Implementation}

After the policy idea was enacted, the city Party and the Party Secretary himself were continuously involved in its implementation. Party leaders participated in the programme's launching conference and the Party received administrative reports on its implementation. From time to time, the Party Secretary also participated in DNPCe meetings or met with administrative agencies to decide issues of implementation directly.

For example, the Party Secretary participated in the August meeting of the DNPCe's leaders with directors of the city departments and agencies preparing for a one-year report on the implementation of the 3-Haves campaign (D93). Then, in the Party's monthly meeting with representatives of its units and social organisations in February 2007, the Party Secretary asked relevant agencies to investigate citizens' housing situation and to use the findings to enhance the implementation of the Having Housing Programme (D3). In March 2009, the Party Secretary met with the DNPCe on management of apartment units (D5). Then in February 2011, he organised a meeting to make decisions on the exploitation of the land fund and plans for building apartments (D6); in November 2011, he ordered the DNPCe to take some initiatives in building social housing and student dormitories (D71); and in February 2012 he made decisions on building, allocating, using, and managing housing apartments units (D7).

\subsubsection{The Party Secretary made decisions on many important policy issues}

Through these meetings, the Party Secretary supervised the implementation of the housing policy and made many important decisions on the implementation and adjustment of the policy. For example, in the March 2009 meeting, he ordered that the DNPCe:

- Direct relevant agencies to check 102 relocated households that were allowed to stay temporarily in apartment units while waiting for allocation of land for resettlement, but then refused to vacate the units after being assigned their plot of land; [Relevant agencies have to] suggest solutions for each case, including the solution of forcing those tenants to move out. Due date of the task is 30/05/2009.

- Direct the HMC to collect rental payment due from third parties who bought apartments from policy beneficiaries (333 cases). If a third party is a city permanent resident, the payment is $100 \%$ of the debt. If a third party is an immigrant, the payment is $200 \%$ of the debt. (D5) 
Why did such an obvious solution as moving illegal tenants out of a housing unit need directions from the Party? Firstly, this Party intervention shows that all significant problems were reported to the Party and that the Party would direct the government how to respond. More importantly, it reflected the sensitive political atmosphere in Vietnam regarding one of the hottest political issues of urbanisation: moving people out of their legal houses and relocating them in new residential areas. It is commonly understood by Vietnamese people that relocated people suffer from the process and, although the CPV and the government promise to improve their lives in the new areas, there have been some riots relating to these land issues ('Vietnam Tightens Land Seizure Law', 2013; Nguyen, Zoomers, and Westen, 2015). Therefore, dealing with relocated people is always a sensitive issue. In the case of LIH in Da Nang City, some households affected by infrastructure development projects were allowed to stay temporarily in apartment units while waiting for allocation of land for resettlement, but then refused to vacate the units after being assigned their land. Although they illegally used those units, forcing them out was still a tough decision that the government tried to avoid. A case of forcing tenants to move out could easily turn into political trouble if there was any violence. That might have been the reason why the solution for those illegal tenants had to be approved by the Party before being implemented.

The second decision about the illegal transferrals of apartment units indicated another problem of the implementation of the policy. Some beneficiaries illegally sold their rental apartment units to third parties. Although the buyers acknowledged that they were buying a tenancy, not a title, they were willing to pay the upfront sublease payment because the rent rates were heavily subsidised and they could delay the rent payment for a while. At this point (2009), the Party Secretary (perhaps following the suggestions from the DNPCe) allowed these illegal transactions to continue and punished those buyers who were not permanent residents by imposing a higher rent. This decision was changed in 2012 when all these illegal transactions were strictly prohibited.

In the March 2009 meeting, the Party Secretary also made some more important decisions that foreshadowed changes in housing policy. For example, he ordered relevant agencies to make plans to sell some state-owned apartment buildings and requested the DNPCe to direct and supervise the DOC to draft a plan to build 5,000 housing units, which was increased to 7,000 units later in 2009 . He also decided to shift the responsibility for approving housing application forms to different agencies in an effort to deal with misconduct in allocating housing units to beneficiaries. 
When the policy was first implemented, there were many agencies responsible for considering and recommending beneficiaries. As remembered by one interviewee, at the beginning, housing application forms could be sent to "the Office of the DNPCe, the Office of the DNPCl, the Office of the city Party, the DOC, the DOLISA, the city Women's Union, the city Confederation of Labour" (R3).

The complex management system enabled some people to exploit their personal relationships to benefit from the policy, which led to unfairness in allocating housing units and harmed the prestige of the government officials as well as the intended outcome of the policy. Thus, in 2009, the Party Secretary decided to shift the responsibility to one single agency: the DNPCe, in order to better manage the process. He directed: "enhance the apartment management; all allocations must be recommended by only one agency: the Office of the DNPCe; and must be approved by the DNPCe" (D5). However, problems in allocating tenants continued. The Party Secretary was instrumental in further shifts in the responsibility, even for a time injecting himself directly into the approval process as recalled by one interviewee:

In 2012, to enhance the supervision of allocating tenants into apartment units, ensuring the allocation to the right people and satisfying the criteria of beneficiaries, Mr Nguyen Ba Thanh shifted the responsibility of approving application forms to the Office of Da Nang City NA's Delegation and the DNPCl. From 2012, all application forms were checked by a working team and then approved by the Party Secretary himself before being passed to the DNPCe for official decisions. This was also the time when the regulations on the criteria for approving the forms were issued because the number of the forms received was too big. From 2012 to 2014, we received about 10,000 forms. In 2014, Mr Thanh was transferred to Ha Noi and his positions in the city Party were replaced by a new Party Secretary; and the responsibility was shifted again. Now, the receiving point of the forms is the DOLISA; this department will check the criteria of the applicants and recommend to a newly established committee for approval. The approvals are subject to supervision by the Chairman of the DNPCl. ${ }^{23}$ (R3)

All issues addressed in the March 2009 meeting were supervised and overseen by the city Party and if any of them were not completely resolved, the Party Secretary would continue

\footnotetext{
${ }^{23}$ Also, the new Party Secretary.
} 
to issue directives. For example, in 2011, the Party Secretary again ordered relevant agencies to take further measures to deal with illegal transactions of apartment units:

- [Order the DOC] to move people who are illegally using state apartment units to some remote locations. Report on the results to the DNPCe by 10/03/2011;

- [Order] the HMC to take the responsibility to cooperate with relevant agencies to check and force people who are using apartment units illegally to move out to temporary houses. The task must be done by the end of quarter II of 2011. The DOC must follow up and supervise this task. (D6)

When the DNPCl's Resolution 23 faced objections from the central government and the media (refer to section 10.2.9), the Party Secretary re-stated this regulation in a Party meeting in 2012 and asked the DNPCe to implement it strictly:

- In cases where relocated households sold their apartment units to third parties before 2012, [the city government will] accept the situation and the third parties will be granted the right to rent those housing units providing they pay off all rental debts. Any sale after 2012 will be invalid. All sales of apartment units are prohibited and the HMC must publish these regulations in the media;

- Force relocated households who have been provided relocation land to move out of their temporarily relocated apartment units;

- The HMC must cooperate with other government agencies to check the occupancy situation at all state-owned apartment buildings and to ensure these regulations are applied strictly. (D7)

As a result of this determination, people who violated the regulations for using state-owned apartment units returned their units to the government or stopped violating the regulations (D. Nguyen, 2014). These cases were reported by the DNPCe to the Party and, in turn, the city Party reported this situation to the central Party:

There have been 141 tenants who violated regulations in using and managing apartment units. [Of these] 54 units have been retrieved, three units have been legalised [the third parties/buyers were officially allowed to rent those units], 62 tenants have proved that they had reasonable excuses for their violation and managed to settle back to the units, the other 22 units will be evicted. (D14)

Subsequently, the rules were better enforced. It is no longer common to find a policy beneficiary subletting his/her rental unit. 
It can be concluded that the Party Secretary would intervene in any aspect of the implementation of the policy if he believed the problem worth his attention and decision. In the 2011 meeting, he directed the DNPCe to buy some housing units developed by private investors (D71). This decision was to help the investors to recover their capital but also saved construction time for the city's public housing projects while still meeting the objective of supporting low-income people into housing. Assuming the rents were insufficient to cover the cost of the purchased units, this was a subsidy for low-income tenants out of public funds. When the Prime Minister approved a pilot project of selling some state-owned apartment units in Da Nang City, these units were put on sale at prices which would approximately recover the cost of purchase.

While helping those private investors in selling their units, the Party Secretary also directed the DNPCe to stop Vicoland investing in LIH in the city from 2011 because this company performed poorly in some LIH projects (to be discussed in detail in Chapter 12). At the same time, he gave his support to the DNPCe to grant more benefits to the 579-Duc Manh Joint Venture (to be presented in detail in Chapter 12). In another meeting in February 2012, it was the Party Secretary's decision to sell some state-owned apartment units to government officials and other beneficiaries by instalments, although the decision could not be implemented, as discussed in section 8.2.14.

Apart from those important decisions, the Party Secretary also decided on other new regulations to suit the real conditions of policy implementation in the meeting in February 2012. For example, when he was advised that many poor relocated people were unable to pay their rent on time, he decided to exempt all relocated people from paying rent from 1 January 2012 (D7). He also prioritised certain groups of beneficiaries in choosing their rental units because most social apartment blocks built before 2012 had no lifts and being allocated to level 1 was the most favourable location for tenants:

People in preferential categories and disabled people will be allocated into units on level 1 of apartment blocks. (D7)

There were always differences in the design and location of every unit in each apartment building. For example, there were $90 \mathrm{~m}^{2}$ units and $45 \mathrm{~m}^{2}$ units; units on levels 1 or 2 and units on levels 4 or 5 . Though there were differences in the rent rates of these units, the differences were quite small and thus all tenants wanted to rent large units at lower levels. The right to allocate a certain unit to a specific tenant remained with the HMC. Only the officials who supervised the blocks and the leaders of the company knew which units were 
still available. There were also no clear rules for choosing units for tenants. Therefore, in reality, from my personal experience and observation, it was likely that people who had a personal relationship with the company's officials, or government officials with quite highlevel positions in the Party and the government system, would be allocated favourable locations. The priority that the Party Secretary granted to people in preferential categories and people with disabilities was probably an effort to fill the gap in the regulations on this issue.

\subsubsection{The Party Secretary made decisions on the minutiae of policy implementation}

The Party Secretary also decided many detailed issues of policy implementation. For example, in the March 2009 meeting, he ordered the DNPCe direct relevant agencies to demolish some specific deteriorated apartment buildings:

Direct the DOC and the HMC to make plans for demolishing 14 deteriorated apartments and temporarily move sitting tenants to some other apartments. The cleared sites will be used for new high-rise apartments and relocating sitting tenants back. (D5)

He decided who would be allocated into which housing areas in some specific circumstances and forgave rent for some special tenants:

Let 264 households in Nai Hien Dong Ward, Son Tra District move temporarily into row houses. These row houses are not for sale; the tenants are exempted from rental payment $(20,000 \mathrm{VND} / \mathrm{month})$; direct the DOC to choose a location for building a new apartment building to relocate these people. (D5)

Or:

For specific cases of poor households and single mothers: 243 households in Son Tra District will be allowed to rent apartment units at the Fish Village condominiums in Nai Hien Dong Ward and Lot 4, Quang Man Bay Condominium; 80 households in Cam Le District will rent apartment units in Phong Bac - Hoa Tho; 219 households in Lien Chieu District will rent apartment units in Lien Chieu District (after construction is finished and put into use). (D7)

Because the process of approving an application form took a long time and there were always more eligible applicants than available units, some people came directly to the Party Secretary to ask for his approval on their application forms. If a case was reasonable, he 
would sign on the form to signal relevant agencies to prioritise that form (D. Nguyen, 2015b; Truong Trung, 2015). Two of my acquaintances had their form signed by the Party Secretary in this manner. However, this practice was not very common. Although the Party Secretary was known to frequently welcome people to his private house after working hours to discuss the city's issues and to receive petitions, in practice it was not easy for ordinary people to meet him in person and persuade him to decide on a specific case.

\subsubsection{Administrative agencies tried to avoid the Party Secretary's imposition}

The previous evidence illustrates how the Party Secretary could impose decisions on the government. In most cases, his decisions were implemented without question. As one informant explained, "once the city leaders made a decision, it was our responsibility to find solutions to get it done" (anonymous informant in personal communication-R18). However, in some cases, the administrative agencies would try to avoid his imposition if it became a burdensome task for the government.

For example, as mentioned above, the Party Secretary decided to buy $50 \%$ of the completed units developed by the 579-Duc Manh Joint Venture. However, it seemed that this decision was not well received by the administrative system, at least by the DOC. In November 2013, the DOC sent out a letter to the DNPCe suggesting that the city government should not buy these units due to the slow progress of the projects and the limited state budget (D76). This was quite a brave suggestion, given that the idea was already approved by the highest leader of the city. However, the company managed to bypass the obstacle, and in 2014 gained the DNPCe's approval to buy its units, although there was still some disagreement on the purchasing prices (D81, D82). In letters between the company, the DOC and the DNPCe (D81, D82), it is clear the DOC still did not support buying those units. It determined to set a quite low price to frustrate the company's effort to sell the units to the government.

[Explanation on the reasons for coming up the final price]. Thus, the DOC suggests that the DNPCe accept only the price of $5,700,000 \mathrm{VND} / \mathrm{m}^{2}$ for the Blue House project. If the company is not satisfied with this price, it is welcome to sell them to other customers. (D82)

In another document, the DOC suggested that within six months after the DNPCe officially announced the purchase price of these units, if the company could not complete the project, the city should cancel the purchase (D82b). However, the company successfully managed to sell 251 units to the city government at the price of $6,200,000 \mathrm{VND} / \mathrm{m}^{2}$ (" $\mathrm{Lien}$ doanh 
Duc Manh-579”, 2014). Most of these units were re-sold in the 2015 pilot project for sale of state-owned social housing units (Long, 2015).

The DOC was clearly not on the side of the decision to buy private investor's units. It is clear that within the administrative system as well as between the administrative system and the city Party, there were sometimes divergent opinions on some issues. However, they were all settled by the hierarchy of power and authorities; opposite opinions from lower agencies were considered but were not decisive. The leaders' will was the most important factor.

To sum up, the city Party clearly exercised detailed control over the development and implementation of the policy. Within the Party, the Party's Secretary evidently emerged as a key decision maker on matters of broad strategy down to the smallest implementation detail. In considering how he exercised that power, it can be assumed that he might not have thought up all the solutions himself. The ideas for his decisions possibly came from the administrative agencies. They could also have been raised during discussions between the Party Secretary and the government officials. Moreover, from what we learn about the agenda-setting stage of the process, we can infer that these issues might have been discussed within the Standing Committee of the city Party before the Party Secretary organised meetings with the administrative agencies to make final decisions. However, the fact that they all had to be approved by the Party Secretary before implementation indicated that the Party Secretary had almost absolute power in supervising and directing implementation of the policy. As an administrative procedure, all his orders on behalf of the city Party were sent to the DNPCe, and the DNPCe had to regulate them by government documents for implementation. Sometimes, he could also use his role as the Chairman of the DNPCl to make decisions and have them implemented.

\subsubsection{Other stages of the process}

There is not much evidence on the influence of the Party specifically on other stages of the process because, as presented in sections 8.2.11 and 8.2.12, the stages were not clearly separate from each other. The evaluation of the policy outcomes was conducted regularly through the reporting activities and meetings of city leaders and administrative agencies. By deciding how to respond to problems raised in these meetings, the Party showed its influence on the evaluation stage of the process.

During the implementation stage, the Party and the government also dealt with mistakes and violations of government officials and other people involved in the process. 
Information about these issues was not generally made public, except for some criminal cases reported in the media in 2013 and 2015. In 2013, one government official leaked the names of 135 people approved by the DNPCe to rent state-owned apartment units to their acquaintances, who used this information to ask the approved tenants for money, pretending they could influence the outcome of the applications. The con artists were put in jail, but there was no information on the consequences faced by the government official who leaked the information. In 2015, one con artist made false papers to trick poor people into thinking he could help them rent state-owned apartment units if they paid him. In this way, he tricked more than 30 people and got almost 2 billion VND. It is surprising that 21 out of those deceived people could use these fake papers to move into and live in this housing for several months. These cases were investigated and reported by the HMC to the police. The current Party Secretary commented that the HMC did not undertake the responsibility of managing those units: "The management is too weak, in other words, you did not manage anything at all” (Nhiet Bang, 2015). He also raised a problem that some officials of the Company even let their relatives use units without approval from the DNPCe. However, no information on the punishment that the Party and the government applied to these officials was made public.

\subsubsection{Overall assessment of the Party's role}

In general, the influence of the city Party on the LIH process in Da Nang City was commonly acknowledged, firstly from the lower agencies, such as the DOC: "This programme was implemented to realise the idea of the city Party and the DNPCl's Resolution 25 (2005) about the 3-Haves campaign” (D35).

The role of the city Party was also recognised by the central government. In particular, the MOC praised the contribution of the city leaders: "Da Nang is one of few localities where local leaders have particularly paid attention to social housing development” (D48).

The MOC stated that “... a key factor in social housing development is not financial or land issues but the local Party and government's concerns about low-income people's lives" (Ngoc Thuy, 2012).

The city Party itself also claimed that they initiated many creative policy ideas, including the Having Housing Programme:

Such policies as land exploitation for infrastructure development followed the philosophy of "State cooperates with people" as well as the tasks of clearing, compensation and resettlement, have been directed to be effectively implemented; 
showing the active and creative role of the city Party and the consensus from city's people. (D11, p.1)

And:

Thanks to such specific local policies as the 5-Nos and 3-Haves campaigns, social security has covered all people who were categorised as extreme poor households, poor households, patients in critical situation, and single mothers. (D9)

According to this self-evaluation, the 5-Nos and 3-Haves were local policies that were created by the active and creative leadership of the city Party. The Party's role and the support from the city's people were, as evaluated by the city Party, crucial factors affecting the successful implementation of those policies, including the housing policy.

\subsection{Underpinning factors of the Party influences}

The above section shows evidence of the Party and Party Secretary's influences on the policy process. This section will discuss the underpinning factors of the Party's involvement in this policy.

\subsubsection{Political ideologies}

Policies in Vietnam aim at an ultimate goal: the regime's legitimacy and stability (Dang, 2013; Datta and Pham, 2013; Lucius, 2009). Regime stability can be supported by the ability to create social consensus or harmony by providing better social welfare, enhancing living standards, and ensuring social equality. This understanding is constantly emphasised in Party documents, including those of the city Party. In a Political Report presented in the Party Congress in 2005, the city Party emphasised the need to undertake social policies to 'an dan'. The term 'an dan', when literally translated into English, means 'reassure the people', in this case of the legitimacy of the Party. The term has its origin from the feudal period, when kings ordered policies that aimed to develop the economy or improve the people's wealth. In Vietnamese people's minds, a king who pays attention to 'an dan' policies is a good king and will win support from the people. In a context of the singleparty state of Vietnam, borrowing the term from the past can probably help the Party in strengthening its legitimacy, as claimed in the Political Report:

Every Party member and cadre, every Party organisation must excellently perform the task of mobilising the support of the people, taking care of their legitimate interests; staying close to the people, listening to their opinions, solving their problems and all conflicts. Try best to reassure the people and build their trust in the 
Party. (Da Nang Party, 2005, p.81)

As listed in this Political Report, some of the 'reassure the people' policies that had been undertaken were the poverty alleviation programmes and the 5-Nos campaign (p.38). Presumably, the coming 3-Haves campaign was another opportunity for the Party to 'reassure the people' and to strengthen its legitimacy. The city Party considered the 3Haves campaign as a social security and management model which would be supported by the people and could be a lesson for other localities (Da Nang Party, 2005). The Having Housing Programme also claimed: "This is a breakthrough step in our city's policy of people assurance" (D18).

As acknowledged in the Political Report, the Party Secretary was the representative of the city Party in communicating the 'an dan' policies to the people: "The city Party leader had successfully implemented the 'reassure the people' policy of the city Party" (Da Nang Party, 2005, p.38).

The Party Secretary often presented himself as a kind leader, who cared for the people's lives. Media reported him providing money to motorbike taxi riders on Tet holidays, offering rental houses to single mothers, talking to juvenile delinquents about good and bad behaviour, advising husbands who were violent to their wives, or calling for donations to establish a hospital providing free treatment to poor cancer patients in the central region of the country (DVTV, 2010; Hoang Long, 2015; My Khanh and Khanh Hoa, 2012; D. Nguyen, 2015a; VietnamNews, 2009). These activities helped him earn support from the people for himself and for the Party. They were unarguably kind decisions and policies; however, it seems that they were also politically motivated. In 2003, when he talked to 1,500 government officials, he revealed his 'four biggest fears'. First was the fear of losing opportunities; he explained that it was an opportunity for Da Nang to become the driving force of the central region when it was separated from Quang Nam province, and the city would miss this opportunity if the government did not strengthen their efforts. Second was the fear of losing government officials due to their bad performance or corrupt behaviour. Third was the fear of losing the people's support due to the decline in the quality of government officials. This danger led to the fourth fear: "if we lose the people's support, we would lose the regime". "This is the most painful loss we might endure" (Hai Chau, 2013). The fourth fear indicated that the ultimate ends of his political career as well as of the whole Party and government system should be the legitimacy of the Party. His commitment to poor people might have been founded in his personal sympathy, but his 
policy decisions must have taken into account the ultimate consequences for the legitimacy of the Party. The LIH policy could therefore be seen as an opportunity that the city Party had taken to strengthen its legitimacy.

Although the legitimacy of the Party was the underpinning ideology of all social policies, it is rarely expressed clearly in the Party's and government's official documents. Instead, it was often expressed through other important purposes, such as strengthening the leading role of the Party or ensuring political and social stability, as articulated in the $20^{\text {th }}$ City Party Congress's Resolution for the period from 2010 to 2015:

Continue to speed up the reform; enhance the leading capacity and fighting strength of the city Party; maintain the political stability; promote democracy and the strength of the people's unity; develop the economy rapidly and sustainably; build up the city to become a big urban centre of the country, a socio-economic centre of the Central Region ... (D11) (emphasis added)

These ultimate goals were affirmed by the CPV in its Resolution 25 (2012) about social policies:

Those [social] polices are the objectives and motives of sustainable development, political and social stability, and expressing the good nature of our regime ... contributing to consolidating the people's trust [in Party and government] and political-social stabilities. (D64)

This Resolution also drew some lessons for the CPV in leading the state in social policies, such as strengthening the leading role of the Party and creating social consensus by providing good social policies (D64).

When it came to expressing the specific goals of the LIH policy, the city Party explicitly explained that the Having Housing Programme was implemented to achieve social stability: "Housing is an urgent demand of people; implementing good housing policy will generate social stability" (D2).

The claim showed that the LIH policy was actually a "reassure the people" policy which aimed to gain support from the people for the leading role of the Party. In addition to the goal of maintaining social stability, the city Party also mentioned another objective of this policy. It explained that government officials were provided housing support, because their "salaries are low, thus it is difficult for them to build or buy houses. This situation will affect working productivity" (D2) (emphasis added). In other words, they believed that 
encouraging the government officials by providing them housing assistance would lead to better performance of government duties.

While always aiming to ensure its legitimacy, the Party itself and the Party chief often expressed this underpinning ideology by claiming the nature of the Party as a ruling Party that is close to the people, by the people and for the people. Serving the people has become a famous slogan in the country and even been regulated in the constitution:

The Socialist Republic of Vietnam is a state of the people, from the people, for the people. All state power belongs to the people and is based on an alliance between the working class, the peasantry, and the intelligentsia. (Constitution 1992)

This principle was drawn from the past when the people played a critical role in the victory of the CPV in the wars. Then, it was referred to constantly in official documents of the Party, both at central and local levels:

Of them, the most important lesson is replying on people, being accountable to people, promoting the strength of people's unity to carry out all strategies and policies; all for the interests of the people. That is the first and everlasting lesson, a lesson for all times and all things, the greatest and biggest lesson of our Party during the past years. Those four lessons have created the distinctive qualities and features of our Party: active, creative, daring to think and daring to do, knowing how to make things done, and taking responsibility; once [we have] chosen right breakthrough directions, [we] will put great efforts and resources to achieve the goals. (D12)

The outcomes of social policies are usually presented as the evidence of this principle and the LIH policy was an excellent example in communicating this message.

To sum up this discussion of ideology, the ultimate purpose of any social policy in Vietnam is the legitimacy of the Party, political and social stability, social consensus, and sustainable development of the country. These goals would be achieved partly by creating an image of a ruling Party that serves the people. In the Da Nang case, they would be achieved through undertaking a policy that provided benefits to less fortunate people in the city.

\subsubsection{Humanitarian value}

In addition to those political ideologies, the city leader also accorded special value to 'humanitarianism' (nhan van), that the city leaders expected to become the signature 
feature of the city: "It [the housing policy] not only contributed to the socio-economic development, but also implied humanitarian value" (D35).

The humanitarian value was mentioned many times in the city Party's Political Reports. In 2010, for example, the Party's objectives of developing the city from 2010 to 2015 were to build Da Nang as a city:

... having civilised urban environment and rich in humanity, with fresh nature and high standard of cultural life, being prosperous by development of a knowledge economy; to be a harmonious, friendly, and peaceful city; an attractive and worthliving urban area. (D11) (emphasis added)

This Report also set "implementing humanitarian social policies" as one of five breakthrough strategic directions for the socio-economic development of the city. It can be said that the 5-Nos and 3-Haves campaigns were primary components of solutions that the city leaders took to build up this feature for the city.

\subsubsection{Aspiration for the city's development}

Da Nang is an urban centre of the Central Region of Vietnam. Both the central Party and Government expected the city would become one of the first industrialised and modernised cities of the whole country (D12) and the moving force of the poor central region, "an economic, culture, science and technology centre of the Central Region and High Land area" (D35). To support the city in these objectives, the Politburo and Secretariat of the CCOM visited the city and issued the Resolution 33 (2003) to lay the foundation for the city development. This was a pivotal and "historical" resolution, as evaluated by the Party Secretary (D92). Due to this high expectation from the central government and the ambitious goals of the city leaders, the city Party always set high objectives in developing the city.

For example, in his speech on the $30^{\text {th }}$ anniversary of the city's independence in 2005 , the Party Secretary expressed an aspiration to make Da Nang "a modern city, strong in economy and bright in culture, a harmonious city of people and nature" (D92), though he admitted that these goals would take long time to accomplish (D92). To realise this aspiration, the city enacted and implemented many ambitious policies, such as the 5-Nos and 3-Haves. The policymakers acknowledged that those were ambitious goals and difficult to achieve but they still made the decisions in the hope to accomplish them in the future. As admitted by one interviewee: “... there is a gap between what we aimed to achieve and the reality" (R11). In that policy environment, although the Having Housing 
Programme sounds ambitious, it still got on the agenda and was adopted.

\subsubsection{The influences of previous and similar policies}

\subsubsection{The previous subsidised housing policy applied in the centrally planned economy}

As presented in Chapter 2, the subsidised housing policy was implemented in Vietnam before Doi Moi. Thus, when designing the initial framework for this research, it was assumed that this policy might have affected the city's policymakers in considering the Having Housing Programme in 2005. However, evidence from documents and interviews showed that the subsidised housing policy affected the policymakers in an unexpected way. It was not that they learnt from this experience in the past and tried to reproduce a similar one. Rather, the subsidised housing policy was considered one of the barriers to implementing the new housing policy. While discussing the draft of the Having Housing Programme in 2005, policymakers anticipated that the new housing policy might be misunderstood as just a new version of the subsidised housing policy. In a discussion at the DNPCl about this policy, the Party Secretary constantly repeated that the city government would not provide housing to people for free; instead housing units would be leased out at preferential prices as a social welfare policy.

The city VFF and other organisations must provide information to people so that they can understand the city's policy. Solving the housing issue does not mean that the city government will subsidise housing for people. We will lease housing units out at different prices to different beneficiaries. (D87)

The emphasis of this matter showed that policymakers did recall past policy but in the sense that they worried that people would expect free housing from the government. This misunderstanding might lead to the risk that policy beneficiaries would have an attitude of relying on the state for their housing problem. This worry was explicitly expressed in the document of the Having Housing Programme:

To attract individuals and organisation participating in housing development business, which would meet the society's housing demand and decrease the pressure on the state budget, [we] need to eliminate the subsidised housing policy; the state budget should only be used for special/urgent beneficiaries, in addition, there should be a policy to encourage households and individuals to build their own houses and a policy on land use to encourage different economic sectors participating in housing development. (D18) 
The city government envisaged that leasing out housing units could generate a financial return for further investment (see Table 8.1). In a speech prepared for a Vice Director of the DOC to present at a conference on the implementation of the Having Housing Programme (28 October 2005), there was a suggestion to the HMC to improve rent collection to change tenants' attitude of 'relying on the government': "Step by step, eliminate the notion of subsidised housing; and solve the problem of delaying in paying rent in some apartments in our city" (D21).

The Vice-Director repeated this idea in another speech delivered at the conference summing up two years of implementing the 3-Haves campaign (D35).

In reality, the job of collecting rent was relatively difficult because there were tenants who had not paid their rent for several years. There are some explanations for this delay in rent payment. First, prior to the enactment of the Having Housing Programme, people who were allocated a housing unit according to the subsidised housing policy did not pay their nominal rent due to poverty. Secondly, the city government was not enthusiastic in rent collection or housing maintenance. As a result, many people thought that once they could move into a state housing unit, they could delay their payment for years without any serious consequences. Thirdly, most tenants had been relocated. They believed that the city government had the responsibility to provide them with shelter. An apartment unit was considered the state's compensation for the loss they suffered from moving out of their old place. Even though they signed a rent contract, most of them believed that the unit was their property and were not willing to pay rent. Many government officials called this 'attitude of relying on the government'. Apart from this attitude, there were actually some very poor households who could not afford even a very cheap rent rate. When asked about the influences of the subsidised housing policy in the past, one interviewee commented:

There was influence. When the Programme was enacted, it brought about many benefits. We created a good fund of housing. However, it also created the attitude of relying on the subsidy policy. Mr Pham Sy Liem ${ }^{24}$ used to say: "we had fallen in the trap of the subsidised housing policy". It was because some beneficiaries were in a very difficult situation and could not pay the rent even when the city government had offered some reduction. People had the 'attitude of relying on the government'. In reality, many relocated people did not pay their rent. Thus, we did not have the money for re-investment. When building a policy, we need to focus on three big

\footnotetext{
${ }^{24}$ Vice President of Vietnam's Construction Association.
} 
matters: the general orientation, the detailed target, and the management of use. However, the management of use was not properly paid attention when drafting this policy. When the policy was implemented, this problem arose. When we enacted this policy, we did not intend to provide a subsidised housing policy. (R1)

Some people argued that there was no difference between the previous subsidised housing policy and the LIH policy, because under both policies, the state used its budget to build housing to lease out to government officials (Pham, 2012). In fact, the difference was the policymakers' intention to generate a significant financial resource from these state-owned housing units for further development.

In short, at the beginning of the research, it was expected that the previous subsidised policy was an example for policymakers to design their LIH policy. Evidence shows that policymakers' original intention was in fact not to pick up any experience from the past; rather to have a new policy that would generate enough surplus for further housing development. In practice, the previous subsidised housing had an unexpected consequence. It created the habit and the misconception of delay in rent payment. Hence, from the perspective of policymakers, the subsidised housing policy was not a good memory to draw from but a barrier for the implementation of the new housing policy:

It might have been the vestige of the subsidised housing policy previously applied in the city. People still hoped that they could live in those units for free, just like before.

\subsubsection{The influence of housing policies applied before 2005}

Though evidence did not support the proposition that the previous subsidised housing policy served as an example for policymakers to learn from, it proved that the housing policy introduced in 2005 was partly based on the experience of existing housing policies for people in preferential categories and poor people.

Central regulations on housing support for these people in preferential categories have been consistently applied in Da Nang since 1997. The city issued about six decisions, providing detailed guidelines for implementing this policy from 1998 to 2005. According to one of those local documents, the Da Nang government implemented all types of housing support suggested by the central government, using funding from state budget, the city Gratitude Fund, donations by individuals and organisations, and other sources. In addition, the city provided housing assistance to poor people. The results are presented in Box 11.1. 
The influence of these existing policies was confirmed by two interviewees: interviewee R1 noted that there was a housing fund for poor households in Da Nang City prior to 2005 and interviewee R2 claimed that the new housing policy in 2005 was developed based on the successful results of these existing polices.

As one interviewee remarked, before 2005, there were housing support policies in Da Nang, following national policies. The Having Housing Programme marked a point when local government found the need to reorganise the existing housing support and issue a new programme to concentrate all available resources for a better housing policy. The existing housing policies and their implementation served as examples for the city's policymakers to envisage how the Having Housing Programme would be implemented. Also, those two groups of beneficiaries (people contributing to the revolution and poor people) continued to be primary targets of the Programme, along with other new beneficiary groups arising along the implementation, such as government officials (started from 1998), single mothers (from 2008) and residents of a leprosy community (in 2012). Thus, it can be said that these policies had some influence on the decisions in the Having Housing Programme.

\section{Box 11.1: Housing support for people under preferential treatment categories and poor people (DOLISA)}

For people under preferential treatment categories

\begin{tabular}{|l|c|c|}
\hline \multicolumn{1}{|c|}{ Housing support } & $\mathbf{1 9 9 8 - 2 0 0 5}$ & $\mathbf{2 0 0 5}-\mathbf{2 0 0 9}$ \\
\hline Number of households & 10,321 & 10,668 \\
\hline Assistance worth (million VND) & 146,632 & 252,868 \\
\hline
\end{tabular}

For poor people from 2001 to 2004: 3,206 units (80\% total temporary houses)

\subsubsection{The influences of the 5-Nos and 3-Haves}

It is also worth noting that the city government adopted the 5-Nos campaign from 2000, aiming to make Da Nang a city free of poverty, illiteracy, begging, drug use and robbery. The 3-Haves campaign in 2005 could be considered as an extension of social policies covered by the 5-Nos. While discussing the policy ideas, policymakers considered both 
the value of the 5-Nos and the 3-Haves (see quotation in section 11.2.1). Additionally, the three components of the 3-Haves could complement each other to solve some key social problems in the city.

\subsubsection{Policies from other localities}

As presented in section 8.2.3, when drafting the Having Housing Programme, the DOC looked to other localities in the country for ideas. However, there were no specific policy lessons available at that time. They also studied Singapore's and South Korea's housing policies but were unable to make use of them.

In 2009, the city government sent officials to Ho Chi Minh City, Ha Noi and Can Tho to gain practical experience but the outcome was not significant because those localities were just starting their LIH projects (R1).

\subsection{The role of individual policymakers}

\subsubsection{The role of the Party Secretary}

As stated at the beginning of this chapter, it is difficult to separate the role of the Party Secretary and the Party in this policy process because the Party leader always acted on behalf of his political organisation. However, as will be evident from the numerous examples of his direct personal involvement in decision-making, it is impossible to deny the influence of his personal characteristics on the policy's enactment and implementation. For example, the way the housing policy was introduced in the 3-Haves campaign reflected his distinctive approach to communicating policies to people and outsiders, which also can be found in the 5-Nos campaign, the 4 Big Fears or the 4 Lessons Learnt from the Past. Though most of my interviewees were generally reluctant to directly discuss the role of any individual, they all agreed that the Party Secretary made a special contribution to the city, including the enactment and implementation of the Having Housing Programme. As noted by two interviewees: "He played the primary role" (R1), and: "The idea was Mr Nguyen Ba Thanh's, but the policy must have been decided by the collective city Party" (R8).

Another interviewee commented on the role of individual in the Vietnamese political atmosphere:

In the Vietnamese political system, collective decision is important. All policies must be collectively decided. However, in some localities, if the teams are not strong enough, the role of individuals can be superior. Da Nang City's Party Secretary at that time had strong political will. He initiated many policy ideas and especially, he 
had the ability to rhetorically persuade other people to accept his initiatives. He was capable of overcoming any criticism from other policymakers in order to make his ideas become policies. And he was very patient in pursuing his goals. Even when there was criticism, he would persuade until those critics gave up. (An anonymous interviewee)

The interviewee's comment on Mr Thanh suggested that even though the idea of Having Housing was quite ambitious, the Party Secretary persuaded other policymakers that it was feasible, and no criticism could bar the enactment and implementation of that policy idea once it got his support.

Mr Thanh's policy leadership in the city was in fact extensively and unusually cited following his death in 2015. A former Chairman of the DNPCe, Mr Huynh Nam said in a reported interview: "In this city, now, we can never tell enough about the contribution of Brother Thanh" (TuoitreOnline, 2015). And:

Our city thanks the contributions of the leaders and the people. Among them, Brother Thanh is the biggest and the most special contributor. He was a pioneer; he created new things, decided right and breakthrough policies, generated good value for the city to become like this. (TuoitreOnline, 2015)

In particular, Mr Bui Van Tieng, former Head of the Organisation Department of the Da Nang Party Committee recalled Mr Thanh's contribution: “The biggest heritage that $\mathrm{Mr}$ Nguyen Ba Thanh left for Da Nang is the 5-Nos and the 3-Haves campaigns" (D. Nguyen, 2015a).

In a memorial speech delivered at Mr Thanh's funeral, Mr To Huy Rua, Politburo member, Secretary of the CCOM and Head of the Party Central Organisation Commission, recognised Mr Thanh's achievements:

Comrade [Thanh] was the person who initiated the 5-Nos and 3-Haves campaigns of the city ... This was a period of development with many proud achievements of the city Party and the people, and closely attached to the prestige of Nguyen Ba Thanh. (To, 2015)

With this recognition, it is difficult to reject the special influence of the Party Secretary on the LIH policy process in Da Nang City. Nevertheless, in a conversation with one informant, when I asked for his opinion about the role of policy elites in the policy process, he interrupted with a response that I should not discuss the role of individuals in 
Vietnamese political environment. This response reflected the fact that appraising an individual politician in Vietnam was sometimes considered a taboo by some people in the system. Gueorguiev and Schuler (2016), discussing career paths of Chinese and Vietnamese Communist Party members, suggest that an exceptionally high public profile might be harmful for promotion prospects. In this political context, the Party Secretary still emerged as the key figure in the policy process and his role was commonly acknowledged by his colleagues and other policy actors. The next section will discuss the underpinning factors affecting the Party Secretary's decisions in the policy process.

\subsubsection{Underpinning factors affecting the Party Secretary's leadership: ideologies, personal characteristics, and personal interests}

Mr Nguyen Ba Thanh (1953-2015) was appointed the Chairman of DNPCe in 1996. He had served as the Chairman of the DNPCe for seven years, and was then elected city Party Secretary in 2003. He was the city leader for the next nine years before being appointed Head of CPV's Central Internal Affairs Commission in December 2012. He was also the Chairman of the DNPCl during most of his time as the city's Party Secretary. With sixteen years in top political positions, Mr Thanh's career and reputation was closely associated with the development of the city.

\subsubsection{Political ideologies}

Nguyen Ba Thanh was a communist. He had been engaged in revolutionary activities since he was thirteen years old (Thai, 2015). His father was a martyr in the war. Holding important positions in local government as well as in the Party system, his political decisions should be connected to the ideologies of the CPV. As discussed in the section about the underpinning political ideologies of the city Party, Mr Thanh might have worked for the ultimate goal of the legitimacy of the CPV in Vietnam. As a member of the postrevolution generation, his political mission should be to contribute to maintain the Party legitimacy of good economic and social management.

\subsubsection{Personal characteristics}

In addition to being driven by political ideologies, Mr Thanh also had many special personal characteristics that might have affected his political decisions. While politicians in Vietnam were perceived as "not open to public, having colourless appearance, showing no different characteristics, and lacking legendary stories about their love of the country" (Phan, 2006), Mr Thanh was a different case. The author of the above comment about Vietnamese politicians remarked: "Uhm, in the country of the blind, the one-eyed man is 
king. Thanh is interesting, anyway" (Phan, personal communication, 13 March 2015, cited with the author's consent).

While other Party senior cadres tend to cultivate a common image of boring, dark-suited conventionality in public, Thanh made himself prominent as a local leader with a strong personality, as described by The Economist:

Mr Thanh made his name as the long-serving Communist Party boss of Danang. He was unusually charismatic, at least by the standards set by the one-party state. Most Vietnamese bureaucrats hew to a colourless status quo, but Mr Thanh made himself famous for firing subordinates and settling land grievances in public (The Economist, 2015).

From the great amount of information about him in the media, it seemed that he earned the support and admiration from the people by publicly showing his characteristics as an aspirational, determined, initiative-supporting and warm-hearted politician.

Mr Thanh, firstly, built up an image of an aspirational man. In a talk to 4,500 city government officials in 2012, he constantly stated a requirement of government officials, that they should have aspiration. He emphasised that this was "aspiration, but not greedy ambition". Then he explained: "Greedy ambition is setting expectations that you cannot achieve, and the expectations are for your own interest, while aspiration is setting reachable goals for the public cause and working for them" (D. Nguyen, 2015a). His greatest expressed goal was to make Da Nang become Vietnam's Singapore. One Vietnam-watcher commented on this ambition: "He is also quite megalomaniacal, saying he will transform Da Nang into a new Singapore. And when you know the two cities, there is quite a long way to go" (Timberland, 2011). To realise this ambitious goal, he undertook many challenging initiatives including building Da Nang as the city of 5-Nos and 3-Haves. When he first explained the idea of 5-Nos, many expressed their doubt of its feasibility, including the then Prime Minister (Tran, 2005). However, this doubt did not discourage him, as in his claim: "Don't care how far you can go with your aspiration, you must have an aspiration first" (T. Nguyen, 2012).

His public speeches contributed to building an image of a politician who "dares to think, dares to do, knows how to do, and dares to take responsibility" (D12, To, 2015), and is "a man of action" (ThanhNienNews, 2013). It can be said that he was interested in initiating or encouraging new policy ideas and mobilising his political resources to put them on the agenda and into reality. "He thinks of new jobs and puts pressure on himself and his staff", 
said Mr Bui Van Tieng (D. Nguyen, 2015a). Mr Tieng also confirmed some common compliments about him: "He gets things done" and "He was never satisfied with what he has done" (D. Nguyen, 2015a). Jonathan London judges Mr Thanh's characteristics: "He was a rare commodity in Vietnamese politics: an entrepreneurial and pragmatic political conservative with a strong record of experimentation and achievement" (London, 2015). One interviewee recalled:

Brother Thanh is a determined person. It's his characteristic. Sometimes he scared other people. He did what he said and he got things done. Sometimes it was not that people agreed with him, but they were just scared of him. Objection was unacceptable. Implementation must be serious otherwise you'd get punished. The role of this individual was extremely great. You see, only he could establish the cancer hospital [offering free treatments to poor people]. Some people found that it's a good idea but not many dared to do it, not many had resources to do it. (R5)

One of the reasons he earned the support of the city's people was that he publicly showed his concern for the lives of poor people in the city. This strategy won him support from locals as well as people in the whole country. It is worth noting that the media is censored by the Party and government in Vietnam and almost every locality has its own state newspaper and television channel. Therefore, he might have mobilised the local media for reporting these activities. The interesting thing here is that other localities' leaders had similar resources but no other politician could create a similar phenomenon. According to propositions by Gueorguiev and Schuler (2016), it might be that his peers were not competent or charismatic enough to earn that reputation or he just could not help himself from being famous or perhaps he intentionally garnered the public attention.

He frequently sent out a message that he ruled the city by love and his lasting commitment to the development of the city and the better lives of the people. For example, in his concluding speech to a city Party's congress he claimed:

[I] have had 15 years serving and binding to this city, [I] understand the trust from Party members, the love and protection of the city people. I perceive them not only as an encouragement but also my responsibility to devote myself for the development of the city. I promise that my contribution to the city is not in mere words but in real actions, with support from the whole city Party, we will bring the city to development and the people to better lives in this beloved land. (D12)

This characteristic was recalled by one of his trusted assistants: 
Our beloved Comrade Nguyen Ba Thanh is a leader who followed the principle of "for the people" throughout his revolutionary life. That principle was not only expressed in his sayings, speeches, and meetings but also reflected in every single action that he took with a deep love for his people. (Phan, 2015)

Some other politicians might have had the same concern for the poor, but Mr Thanh had an effective way to express it publicly. He showed it naturally and in a persuasive way. His blunt but effective speaking style was complimented by Jonathan London: he had the ability to "speak at very great length - sometimes as long as three hours - but in a disarmingly free-wheeling, often persuasive, and consistently playful and humorous way that made his public speeches and pronouncements a spectacle, winning him additional admiration among his fans and begrudging respect among his skeptics" (Wilson, 2015).

He also earned the support of the people by expressing his commitment to anti-corruption. He described government officials who undertake their duties only if people have bribed them as the animals on show in a circus; he spent time working outside his office to understand the city situation. He pointed out faults in city management. He publicly criticised many directors of line departments for their management faults. There were rumours that he was involved in corruption himself but no firm evidence has ever emerged. The people who alleged that he committed corruption were brought to a court and punished. There was a rumour about his intervention in this juridical decision, but again this was an unsubstantiated allegation. What could be observed was that he was promoted by the highest leader of the CPV to the position of the Head of the Central Internal Affairs Commission, an important Party agency responsible for anti-corruption. Despite all the doubts, when he was transferred to Ha Noi for that position, he had carried along hope for anti-corruption work in Vietnam. Many expected that he could make a difference for the country. However, the fact that he failed to become a member of the Politburo and passed away while he was quite young (61) dashed the hope.

Thanks to these down-to-earth actions and policies as well as a popular public image, he earned great support from the people of Da Nang and somehow become an "unusually charismatic" leader (The Economist, 2015), a "widely admired senior figure" (Wilson, 2015) and one of Vietnam's most charismatic local politicians (Gueorguiev and Schuler, 2016). He was regarded as a hero by many people (The Economist, 2015). That's why his death was mourned by many in the city and in the wider country (AFP, 2015; The Economist, 2015). Giving the fact that praise of individuals is quite rare, if not a taboo, in 
the Vietnamese political environment, Mr Thanh appeared a special figure in the policy environment of Da Nang City.

Understanding his personal characteristics and public profile helps explain why he had the ability to push challenging policy ideas on the city's agenda. In addition, it provides indirect evidence to understand his political power to make his policy ideas come true without dealing with fiercely opposite opinions from his colleagues in the DNPCl or other government officials. When asked if there was any protest from city government officials relating to the idea of the 3-Haves campaign, particularly the Having Housing Programme, one interviewee recalled: "There might have been opposing opinions but they were discussed outside meeting rooms and had no value" (R3). Mr Thanh would have been aware of this and mobilised political resources to get his ideas accepted, as commented by the anonymous interviewee about Thanh's capacity to bypass criticism from other policymakers. Mr Thanh, however, would explicate this as support from the Party and the people (D12). More generally, if there was opposition to the LIH policy, it was quite muted.

Due to his ability as Party Secretary to impose his will on the system, some critics called Thanh a 'dictator' or 'benevolent dictator' (Timberland, 2011), others named him 'King of Da Nang" (Wilson, 2015). However, other members of the DNPCl also facilitated this practice by not effectively using their power to debate his decisions. They were probably afraid of the risk that raising opinions against the Party Secretary might negatively affect their political careers, or they might have believed that their isolated opposition would be unlikely to make a difference; in other words, they did not have the political resources to oppose him. Also, in Vietnamese politics, it is almost impossible for the government to reject a policy idea when it has been approved by the Party. Therefore, it is common to see no public controversies. The one-party government system aims to reach consensus on all aspects of policy. The city's political atmosphere gave the Party Secretary plenty of opportunities to initiate and implement his policy ideas.

\subsubsection{Personal interest}

The Party Secretary served the city for about 16 years, holding many important positions. During such a long time in power, inevitably, there were questions as to whether he sought any personal benefits. This matter will never be definitively resolved because only he knew fully what he sought. However, one interviewee cautiously noted: "Anyone can see that the housing policy can easily win the people's support" (An anonymous interviewee). 
When I asked if he meant that the housing policy was a kind of 'reassure the people' policy, he corrected: "It was not only a 'reassure the people' policy by the city Party, it could also be perceived as a policy to earn people's support for leader(s)" (An anonymous interviewee).

So, from the perspective of one of Mr Thanh's colleagues, it is possible that the Party Secretary aimed to win popular support, which could be an important factor in his political career. It could also have been his personal goal in life. A Vietnamese proverb says that letters on a gravestone would fade away after one hundred years but rumour about one person would still spread after thousand years. The proverb reflects a desire of Vietnamese people to avoid bad rumours and to establish a good reputation. Mr Thanh might have sought to burnish his reputation and to achieve the sense of pride for his political career. He once mentioned this feeling in a speech: "Each of us has a right to take pride of our city" (D12).

However, none of those assumptions about his personal interests can ever be proved. People who knew him well were not willing to discuss these issues. Only one interviewee commented: "There was no personal desire. It's because he wanted to do and dared to do. He had the streak of leadership ... determined and responsible. Those were rare and precious attributes" (R5).

Given that this interviewee was a friend of Thanh, it is not clear if he spoke mainly out of veneration for his friend. Thus, a fair and true evaluation of his contribution might be unachievable. A journalist commented:

As a city leader, Mr Thanh was a true star in the Vietnamese political firmament. However, if there were press freedom, what he had done would be fairly evaluated. I'm sorry to say this when he just passed away. (Trung Bao Nguyen's Facebook, 14 February 2015, cited with the author's consent)

In summary, evidence shows that the Party Secretary played a significant role in all stages of the LIH policy process. There were some underpinning factors that probably affected his decisions, namely his political ideologies, his political will and characteristics, as well as personal interests. Driven by the ultimate goal to strengthen the CPV's legitimacy, he advocated a policy that could contribute to a good image of the ruling Party, such as the LIH policy. His ambition and determination encouraged him to make an "ambitious policy" which might sound "megalomaniacal" (Timberland, 2011) to other people. He had a strong personal drive to control and dominate the process and his personal charisma 
allowed him to do so. His personal sympathy to the poor people's lives might have acted as a motive for his interventions to the policy. Though there was no clear evidence of his personal interest in making the policy decisions, it is possible that he aimed to win popular support for his political career and to achieve his personal desire of being valued and respected for his achievements.

\subsection{Conclusion}

This chapter has analysed evidence on the leadership of the city Party and especially of the Party Secretary during the timespan of the case. Clearly, the Standing Committee of the city Party was at the centre of the whole process, where key decisions were made and approved. Among top politicians, the Party Secretary emerged as the central figure who had almost absolute power in introducing policy ideas, making policy decisions and dealing with the private sector. The power of the Party Secretary suggested another approach to the consensus-based feature of policymaking in Vietnam: in certain situations, an individual could take control of the collective bodies and impose his will on the whole apparatus. Evidence from the case also suggests that policymakers were affected by underpinning political ideologies and previous housing policies. In addition, the top leader's strong political will and personal characteristics played a significant role in his decision-making. 


\section{Chapter 12: Other influences on the policy process}

\subsection{Introduction}

This chapter examines evidence on the developing relationship between the state and private sector in LIH in the Da Nang case. In addition, it also scans data on other influences on the process to complete the whole picture of the story.

\subsection{The role of the private sector and its relationship with the state}

\subsubsection{From 2005 to 2009}

The idea of calling for investment from the private sector in housing development was mentioned in the National Strategy for Housing Development from 2004. To implement this idea, when designing the Having Housing Programme, the drafting team looked for experience from other localities and came up with a conclusion that they mainly relied on the private sector, rather than using their own budgets:

... Lessons from some localities such as HCM City, Ha Noi, Dong Nai show that housing development mainly relies on the participation of enterprises with support from banks and financial agencies; state budget expenditure on housing development in these localities are very limited.

... Lessons show that if policies and procedures on land-use rights are reasonable, they will facilitate the participation of other economic sectors. (D21)

From this experience, the city's policymakers expected that housing development in Da Nang should also be buttressed by the private sector. At that time, there were some commercial housing projects developed by private investors in the city. These projects gave hope for the forthcoming flow of financial resources for housing development.

The need for the private sector's participation was clear but solutions to getting them involved were not. The drafting team was unable to present any specific policy lessons from other localities while there was no guidance from the central government. Thus, in the meeting of the $\mathrm{DNPCl}$, one delegate pointed out the need to issue policies on incentives for the private sector's participation:

We have no policies to attract private investors like other localities, [I suggest that] we have policies about land-use rights and incentives for manufacturers of construction materials to participate in [housing development]. (D87)

The expectation was officially expressed in Decision 140 issuing the Having Housing 
Programme. However, the document did not detail specific solutions. The Decision provided only that the city government would offer land incentives in some form:

... there will be policies on land-use rights to encourage the private sector to participate in housing development (commercial housing).

... For workers and students' housing, the state only provides support in land-use rights so that the private sector can develop housing for these people. (D18)

Although policies on incentives for the private sector were not clear, the policymakers still expected to mobilise a significant contribution from this sector (see Table 8.1). As presented before, the city departments were assigned the task of designing the policy of attracting the private sector and people to participate in housing development. However, both the DONRE's and DOF's drafts were not adopted (see section 8.2.14). Manoeuvering within the legal constraints set by the central government, the city assigned the DNIDF to undertake some responsibilities of the HDF. In addition, the city decided to exempt $10 \%$ of the land-use fees for investors who paid their land-use fees within 30 days from the date they received a certificate of land-use rights.

Probably due at least in part to the limited incentives, no project was developed by the private sector during the period from 2005 to 2009. The DOC repeatedly reported this problem to the DNPCe (D25, D26), pointing out that this was "the biggest challenge in implementing the programme" (D25). The problem was also reported to the central CPV by the city Party in 2008 :

The implementation [of the Having Housing Programme] is slow and far behind the planned objectives ... The reason was that the finance from the government budget was guaranteed but other resources from the private sector and the PIIP could not be mobilised. (D4)

The DOC constantly suggested that the DNPCe adopt policies suggested by the DONRE and the DOF and encourage investors who were developing commercial housing projects in the city to speed up the progress of their projects so that there would be more housing units for use (D25).

The problem was also mentioned in a live television programme, Talk to Us, on DVTV (D29), and in the conference summing-up two years of implementing the 3-Haves campaign (D35). 


\subsubsection{From 2009 to 2013}

\subsubsection{The first LIH project}

As the implementation evolved, several factors combined to put more pressure on the city to increase private sector involvement. These included the growing pressure on the city budget, the much-reduced expectations of funding from the World Bank, the distinct lack of interest from the private sector in the existing 'investment climate', the greater profit opportunities in the upper segments of the market, residents' preferences for separate houses rather than apartment units and the limited scope of the incentives offered to developers by the city. The city came to realise that to achieve the ambitious objectives of the Having Housing Programme it would need a greater involvement of private developers and that to get this participation it would have to offer more incentives.

At the beginning of 2009 , the city was informed about the forthcoming regulations from the central government on incentives for the private sector participating in LIH projects. Simultaneously, one private investor (Vicoland) contacted the city leaders and the city government to propose the first LIH project in Da Nang City. There must have been previous discussions between the two parties, because only two days after the central government issued Resolution 18 and two days before the enactment of Decisions 65, 66, and 67, the city government issued a statement about LIH projects developed by Vicoland. The city government's statement said that Vicoland would be allowed to develop four projects (1,000 units) from May 2009 to January 2010 and more projects after that. The first project was located in a central district of the city, which added more value to the investment. While other investment projects had to wait for a long time and complete a complicated procedure to access clean land, the DNPCe directed relevant agencies to quickly provide clean land for Vicoland to commence the projects. The statement also applied regulations from the central government to require that the company must sell completed units at regulated prices and to be paid by instalments:

The investor will use its financial resources to build the apartments; the average selling price per unit must be about 200,000 million VND; buyers can pay by instalment for 13 years with the first payment set at about $25 \%$ of the unit's value; the investor can use the first level of the apartments for service purposes [such as shops]. (D56)

This statement was issued when the central government's regulations had not yet been further guided by local regulations raises a question. It is possible that the private company 
was urging the city government to accept its investment application. Meanwhile, the city was probably eager to welcome the first investment from the private sector to accomplish its housing policy goals, given that it was coming to the end of the second period of the Having Housing Programme and the policy outcome was not reaching the planned objectives. The DNPCe manoeuvred within existing central government regulation to support Vicoland. It is plausible that they received instructions to do so in one of the regular weekly meetings with the city Party.

\subsubsection{Other investors participate and the ongoing relationship between the state and the private sector}

After facilitating the participation of Vicoland, the city government also sought and persuaded other investors to take part. In 2009, there were three companies participating in LIH projects in the city, namely Vicoland, 579-Duc Manh Joint Venture and Hung Phu Ltd.

When the private investors developed some first projects, they found difficulties in selling their products, often because, rather than buying an apartment unit, people preferred renting a LIH unit while saving for their own separate houses. In addition, the cost of land in Da Nang was lower than in some other cities such as Ho Chi Minh City or Ha Noi while the prices of LIH units were quite similar (R1). The fact was reinforced by another interviewee: "People prefer renting to buying social housing units because they have to borrow from banks to buy" (R11). This situation led the city Party and government to decide on buying units developed by private investors and then leasing them out to lowincome tenants:

1. About housing units invested by Vicoland:

... Da Nang City government agrees to buy 100 units... at the price of 5,000,000 $\mathrm{VND} / \mathrm{m}^{2}$; these units will be allocated to government officials. Assign the task of signing contract and buying the units to the DNIDF. All jobs must be done by November 2011. Financial resource (for this contract) is from the DNIDF. The down payment will be made in November 2011, the rest will be paid off in December 2011...

2. About housing units developed by the 579-Duc Manh Joint Venture:

Approve a solution of buying 50\% of completed units developed by this company. (D71) 
The city government also had to deal with problems from private developers. After building some projects, Vicoland was criticised for its low-quality products and being dishonest in doing business, causing protests from tenants and buyers. Consequently, it was prohibited from developing more LIH projects in the city:

1. About housing units invested by Vicoland:

- Vicoland must speed up its construction progress and hand over completed units to buyers by $31 / 12 / 2011$.

- Da Nang City government agrees to buy 100 units...

- Allow the company to continue to sell the remaining stock of housing (178 units) to buyers approved [by the city government].

- Stop granting new social housing projects to Vicoland. (D71)

The relationship deteriorated further. One interviewee stated that the city government was taking steps to sue Vicoland because it did not fully transfer 100 units to the city government as committed after receiving payment from the city government (R11).

Duc Manh-579 Joint Venture ${ }^{25}$ seemed to have had a better relationship with the city government. One interviewee remembered that the city leaders persuaded this company to participate in LIH development because the owner of this company had a good reputation in doing business in the city (R11). In the November 2011 meeting, the Party Secretary and the city government decided to:

- Approve granting the cleared land site in Thanh Loc Dan-Hoa Minh (along Nguyen Tat Thanh street) to this company in order to build nine-story social housing apartment blocks ... provided that the company starts the project at the beginning of 2012 and completes it at the end of the year; the company is also allowed to continue other approved social housing projects.

- Allow the 579-Duc Manh Joint Venture and Vicoland to participate in limited tenders for construction tasks in social housing projects.

\footnotetext{
${ }^{25}$ Duc Manh was a private limited company established in 2001. It developed a very successful commercial housing project in the centre of Da Nang from 2004 to 2007. In 2009, the company cooperated with the 579 Investment and Construction Joint Stock Company to establish the 579-Duc Manh Joint Venture to invest in LIH. In fact, both companies had the same owner.
} 
- Granting the right to use and exploit the completed student dormitories to the 579-

Duc Manh Joint Venture and the 579 Company; request these companies to design regulations on using and managing these complexes and to submit [a report] to the DNPCe in November 2011. (D71)

The decision about granting the right to use and manage the completed student dormitories to the two companies got a negative comment from an informant:

It's ridiculous. Why has a private company got the right to manage state-invested dormitories? It (the 579-Duc Manh Joint Venture) must have special relationship with the city leaders. (An anonymous informant in personal communication).

Furthermore, in 2012, Duc Manh-579 Joint Venture managed to borrowed 10 billion VND from DNIDF for social housing projects (Trieu Tung, 2012).

The contrast of the relationships between the city government and the two companies indicated that once the city lost trust in a company, it would be unable to seek new investment opportunities in the city. In contrast, if a company was trusted, more opportunities would be offered. That meant the city government not only sought, welcomed, and facilitated the participation of private investors, but it also selected suitable ones.

The benefits enjoyed by the 579-Duc Manh Joint Venture also suggest why the private sector was interested in LIH projects, though the profit was limited to $10 \%$ by law. That was because investors could enjoy some implicit benefits, such as the right to participate in limited tenders in some state-owned projects or to borrow from the DNIDF at low interest rates. In addition, the company's capacity of bypassing the objection from the DOC to sell more than 200 units to the city government indicated a special relationship between this developer and local leaders.

The Hung Phu Investment and Construction Joint Stock Company was also a private investor, developing a housing project for workers in 2009. However, the project was not completed due to lack of finance.

After the central government offered the 30 trillion VND credit package in 2013, more real estate developers invested in LIH in Da Nang, including Phu My Ltd, Sai Gon XanhThuan Phuoc, Trung Nam Joint Stock Company and Sun Group (So Xay Dung, 2015). All of them are private investors. 


\subsubsection{The city government controlled LIH projects developed by the private sector}

Social housing developed by the city budget was mostly allocated to limited groups of beneficiaries such as people in preferential categories, poor people whose income was less than the poverty line set by the city government (less than $300,000 \mathrm{VND} / \mathrm{month}$ ), and certain government officials. LIH projects developed by private investors aimed at a more extended scope of beneficiaries. According to the central government's regulations, they must have: 1) been employed in the city or relocated people, 2) had housing difficulties, 3) received no housing support from the state, 4) been a permanent resident in the province or the city where the project was located, and 5) a monthly income, stable and high enough to pay off the rent or the value of the units but not above the local average level of income calculated by the provincial PCe. ${ }^{26}$ Applications to buy or rent a LIH unit would be considered on a points system based on these criteria. The DNPCe held the right to approve the lists of buyers and tenants of all LIH projects in the city.

In addition to managing the lists of buyers and tenants, the city government was also responsible for approving the design of low-income projects developed by investors. There were some regulations from the central government to follow, such as that the size of each LIH unit had to be equal to or less than $70 \mathrm{~m}^{2}$. Thus, Vicoland and 579-Duc Manh Joint Venture had to send their designs to the DNPCe for approval (D41, D42, D46).

The investors were also required to report on the progress of their projects regularly to the DOC and the DNPCe. In these reports, they could make some suggestions to the local government for their projects. For example, Vicoland suggested that the DNPCe allow the company to increase the selling prices of its units or to let this company start selling units before construction finished but after it completed five or six floors of a seven-storey apartment (D54a). Moreover, they must make sure that the maximum profit rate of their projects was equal to or less than $10 \%$ and satisfied regulations on selling by instalment or leasing out these units (Article 4, Decision 67).

\subsubsection{Incentives offered by the government to investors}

LIH projects were under close control of the city government because investors benefited from many incentives provided by both central and local government. At the central level, the government issued laws, decisions and circulars, regulating incentives on land, tax, loans and other benefits.

${ }^{26}$ Circular 36 (2009) by the MOC. 
At the local level, the city government supported investors by recommending them for preferential loans provided by the central government. For example, in October 2009, the DOC sent a letter to the MOC to suggest that the MOC should support the 579-Duc Manh Joint Venture, Vicoland and Hung Phu Ltd in accessing preferential loans for their LIH projects in the city (D52). In 2012, the city government cooperated with the central government to offer more preferential loans (see section 10.2.7). Developers could also borrow from the DNIDF at low interest rates. The city also offered financial support by buying some of their housing units.

In addition, the local government provided developers with technical support, including free design and technical solutions for construction. Finally, they were supported with good infrastructure systems around their projects. Investors highly appreciated the infrastructure support and the offer of clean land at good locations. This assistance made the products more attractive to buyers and reduced the investment cost for developers:

... the advantage of investing in Da Nang was that the city's plan was clear with wellinvested infrastructure systems, especially infrastructure systems for social housing projects; and the city assigned some good locations for social housing projects. These areas were connected with good infrastructure systems, which facilitated the construction works and enabled the units to be put in use easily. (R6)

The support from the city government was very important; the city provided us land in good locations. Particularly, Mr Nguyen Ba Thanh [the Party Secretary] directed Mr Tran Van Minh [the Chairman of the DNPCe] to give our company clean land. His determination was invaluable. (R7)

Investors also appreciated the welcoming atmosphere provided by the city Party and government:

In terms of accessing the investment opportunities, our company was supported by the city government in receiving clean land. When the projects were in progress the city also supported investors in implementing Decision 67 and Circular 36 about criteria of buyers. In general, information access was good for enterprises. (R6)

Our company chose Da Nang because it was the hometown of our director. Also, we were supported by the city's departments and the DNPCe. That's the decisive factor for us to develop LIH projects. (R7)

The support from other agencies was important too, for example, the support from 
the DOC, when there was no detailed guideline [for LIH development], we still got the investment certificate. The infrastructure was very good; power and water supply were sufficient. (R7)

Both private sector interviewees (R6 and R7) appreciated the support from the local government for their projects. This support was also recognised by the central government, reflected in this recommendation from the MOC:

We suggest that the city government continue to implement such policies and procedures that encourage investors in speeding up the projects' progress, including offering clean land with good infrastructure. (D73)

In addition to those explicit incentives from central and local government, investors also enjoyed some implicit advantages offered by the city leaders as mentioned in previous sections.

\subsubsection{Housing for workers: an unsuccessful effort by both the private sector and the city government}

When the Having Housing Programme was adopted in 2005, the city government had intended to support workers with housing. However, due to the limited budget, the city government announced that it could only support workers in terms of land while the construction must rely on their employers and the private sector's resources (D18). The Programme estimated that there would be 70,000 workers in housing need, which meant (based on the city's floor space standards) that the city needed $280,000 \mathrm{~m}^{2}$ dormitory housing for this group. In 2007, the DOC submitted a list of eight suitable locations and developers for worker housing projects. Then the DNPCe approved six out of those eight projects (D37).

At this time, the central government did not issue any guidelines on incentives for worker housing projects. Hence, the city government planned to apply the current regulations, plus providing some reduction in land-use fees for developers (D37). However, none of these projects could start (D48). After receiving the land from the city government, an employer, Mabuchi Motor, conducted a survey to collect workers' opinions on whether they wanted to rent the company's accommodation at the price of $500,000 \mathrm{VND} / \mathrm{month}$ or not. Most of the responses said no. The company returned the land to the city government and cancelled the project (Thu Phuong, 2012).

In 2009, the city handed an unfinished project to Hung Phu Ltd to build houses for workers, 
but the construction was stopped after some first floors were built because the developer ran out of finance. The project was later converted to a student dormitory funded by the central government (Nhiet Bang and Huu Long, 2015; Thu Phuong, 2012; Tieu Yen, 2015). Many failed projects made the city government lose trust in the private sector in building housing for workers. The city government reported this issue to the central government (D22). The main reasons cited were that investors had weak financial capacity and workers preferred to live independently in rental houses rather than in condominiums (D22). The city Party also mentioned this issue to the central Party. However, the city was unable to implement a specific policy for workers' housing until 2013 when two projects (3.500 units) were started by Sai Gon Xanh-Thuan Phuoc company and Trung Nam Joint Stock Company, backed by the credit package from the central government (D98). In addition, the city had more LIH projects developed by the private sector, which could be sold to workers as well.

In summary, before 2009, when the central government had no guidelines on incentives for the private sector participating in $\mathrm{LIH}$, there were no housing projects developed by private investors. After 2009, LIH became more attractive to investors thanks to the incentives on land, tax, loans and other implicit advantages. Free land and preferential loans were the two important motivations for private investors in developing LIH. Thanks to these incentives, from 2009 the private sector began to contribute significantly to the city's housing development. By 2013, the free land policy motivated investors to build and put in use about 1,000 housing units, or about $11 \%$ of the total LIH units completed by 2013 in the city. With the launch of the 30 trillion VND credit package offered by the central government, more projects have been started. According to data from the DOC, by June 2013, the private sector was building or preparing for another 5,000 housing units, or about $33 \%$ of the total units under construction stage (D98). Da Nang's LIH policy has not been without difficulties: housing for workers. However, the difference in the outcomes of LIH policy before and after the participation of the private sector provided a great lesson that, given sufficiently generous incentives, LIH policy could mobilise significant private investment rather than relying only on government finance.

\subsection{Other influences}

\subsubsection{The role of media}

As media has been strictly controlled in a single party state, there was not much evidence about the influence of this actor in the policy process, although there were many newspaper 
articles about this policy. Collected data show that the media's role could be summarised in three forms: (i) media mobilised to inform people about the policy; in other words, it performed the propaganda job for the city government; (ii) media as a channel for the people to raise questions to the city government about implementation of the policy; and (iii) media offering warnings relating to problems arising in the implementation stage of the policy.

\section{(i) Propaganda job}

Before the Having Housing Programme was enacted, the Talk to Us programme was used by the city Party and government to explain the main content of the forthcoming 3-Haves campaign to the people. Since this was a live television programme, people could raise questions via this programme to the policymakers. However, from media reports available on the Internet, the televised programme was used mainly for the Party Secretary and the Standing Vice Chairman of the DNPCe to explain the policies to the people (Tran, 2005). In response, people could express their concerns to the policymakers through their representatives in the $\mathrm{DNPCl}$ or to the city VFF. However, there was little evidence that they made use of this opportunity. Evidence showed that leaders' ideas and technical advice were the two main contributors for the policy's enactment and public feedback played very little part in the policy process. At the meeting of the DNPCl about the Having Housing Programme, the Director of the DOC reported that his department organised one press conference about the draft of the policy (D87), but he did not report any questions or opinions collected from that press conference.

While the policy was being implemented, the media continued to convey city leaders' directions to the people. For example, the media was mobilised to inform the people about policies on illegal sales of public housing (D7) and about criteria for housing applications (D69).

This role was confirmed by an interviewee who was a local journalist, and specialised in investment and construction matters:

Responsibilities of media and journalists (are) to provide information about housing policies of both central and local government ... To publish articles constantly, to support the propaganda work for the housing policy content and housing policy outcome. (R12) 


\section{(ii) A channel for public feedback}

An unpublished document showed that the DOC received a list of questions from a television channel, raised by people about the housing policy. The document also contained the answers for those questions from the DOC. They were mainly information about the policy contents and explanations for a forthcoming plan, for the quality problems at some apartment units and the design of a student's dormitory (D57).

\section{(iii) Reports of problems arising in the implementation stage of the policy}

It is however easy to find a large number of newspaper articles about housing policy implementation in Da Nang City, especially articles about the slow progress and quality problems in some LIH projects developed by private investors ("Lien doanh Duc Manh579”, 2014; Phuong Tra and Trieu Tung, 2012a, 2012b; Trieu Tung, 2014; Trong Huy, 2013) or about illegal activities in the policy implementation (D. Nguyen, 2014; Nhiet Bang, 2015; Phan, 2013). One interviewee noted this role of the media: "[media] supervised the implementation stage, ensuring the housing programme provided houses to the right beneficiaries" (R12). When evaluating his personal contribution to the housing policy in the city, this interviewee, as a journalist, claimed that he contributed to the job of ensuring housing quality, the fair allocation of housing units, the management capacity of government agencies and raising problems in the policy implementation such as the accessibility of LIH and loan support for buyers (R12). Evaluating the role of media, another Party Secretary of the city (Mr Tran Tho) noted: "Media has influenced the minds of leaders at different government levels of Da Nang City in policymaking, in directing the policy implementation, in spotting and solving problems" (Hai Chau, 2015).

\subsubsection{The people and the city's mass organisations}

The people appeared in the policy process mainly as beneficiaries of the policy, who the government tried to please as the ultimate political purpose of a social policy. 'A government of the people, by the people, and for the people' has always been a slogan for Vietnamese government. This housing policy was unarguably an opportunity for the Party and the government to prove this nature of the regime to the people. Thus, it is easy to find the city Party and government's claims about the importance of the people in documents relating to the housing policy as well as in other general documents with various phrases, such as "the support from people" or "the consensus from the city's people", "relying on people, being accountable to people, promoting the strength of people's unity to carry out all orientations and policies; all for the interests of the people", "the absolute support and 
encouragement of the city's people", or "this is a breakthrough step in our city's policy of reassuring people" (D9, D11, D12, D18). The people were often cited as one factor that contributed to the successful implementation of this policy because of their consensus, and their support for the policy. It is possible that through interactions between the people and the Party Secretary, the idea of providing housing support to low-income people was established.

However, there was little evidence of the people as policy actors who could influence the policy content except the information about the press conference organised before the policy was enacted and some Talk to Us television programmes. As mentioned before, there was little evidence on issues raised directly by the people on this policy for discussion by policymakers. There was no mechanism for the people to discuss the policy content directly, such as by commenting on a policy draft. They could, instead, raise their opinions through some mass organisations such as the city VFF, the Youth Union or the Women's Union. The VFF, as described by R11, is the representative of the people, voicing the people's view, and thus should play an important role in making this policy. The Chairman of the city VFF was a member of the Standing Committee of the city Party and did in fact participate in some Party and government meetings on this policy. However, the role of the VFF and its members in this case was not very clear. There was one occasion when the city's Women's Union influenced the Party Secretary to prioritise single mothers in accessing state apartment units (R5). In other cases, these organisations were mainly used for propaganda tasks (D16, D87). These organisations also have the right to supervise policy implementation on behalf of the people. For example, in 2013, the city VFF cooperated with the DISED to organise a workshop about the implementation of the LIH policy. However, in general, times they could intervene in policy implementation were relatively limited.

In addition, the people could also affect the policy process through their representatives at the DNPCl. The most important opportunity for them to decide the policy content was when the draft was discussed and approved by the DNPCl. However, as discussed in Chapter 8, the DNPCl, could not do much in terms of deciding the technical aspects of the policy, or indeed whether the policy should be enacted, given that it had already been approved by the Party.

The DNPCl is also responsible for supervising the implementation of the policy by questioning administrative systems at its meetings. For example, the DOC received some 
questions from the DNPCl about (i) why housing for workers has not achieved any good outcome, (ii) why one investor was rejected by the DNPCe for a worker housing project, (iii) how many housing units had been built and used, and (iv) illegal occupancy at some apartment blocks and solutions for that problem (D66a, D66b).

In summary, citizens of Da Nang were the target of the LIH policy rather than an active policy actor. They could affect the policy process indirectly through their representatives at the DNPCl and through mass organisations who were under the overarching control of the city Party.

\subsubsection{The research community}

As presented in Chapter 8, while drafting the Having Housing Programme, the drafting team looked for lessons from other jurisdictions but came up with not many useful ones. From local knowledge, one reason for that might be the limitation on capacity of policy research and the unavailability of references. After the Programme was enacted, there has been some research into housing. In April 2006, the city government paid for a study of housing development strategy in Da Nang City through 2020 (Dang, 2006). The report provided rich information on housing and architecture in the city prior to 2005 ; it also examined socio-economic and cultural factors that can exert influences on housing and housing policy, as well as studying the city's situation of land and infrastructure. This information, as claimed by the authors, was used to identify the housing situation and housing demand and back the researchers' suggestions on a strategy for housing investment and development in Da Nang City.

While the Having Housing Programme was being implemented, the DPI undertook another study (Department of Planning and Investment, 2012) (perhaps with assistance out-sourced to a research institute, inferring from the language used in the draft of the report). This study was completed in 2012, aiming to develop a programme for supervising investment in social housing projects in Da Nang.

At the same time, the DISED also cooperated with the city Fatherland Front on another study of LIH in Da Nang City (Le, 2012). This study also evaluated the LIH and LIH policy in Da Nang City and suggested some solutions for housing development.

In addition, the World Bank commissioned two reports $(2006,2007)$ on LIH in Da Nang City, which led to the Bank's decision not to invest in LIH except for building some housing for households affected by the PIIP. 
Overall, these studies were conducted after the enactment of the Having Housing Programme. Therefore, they did not help the policymakers with their policy decisions in 2005. As confirmed by interviewees:

In 2005? Not yet, not yet, there was no study at that time. When the policy idea was initiated, discussed, and then enacted, there was no study. (R11)

We searched for information on the Internet but there was not much. There was no Housing Programme like that, perhaps Da Nang was the vanguard. (R1)

However, the content of the 2006 report on housing strategy indicates that it could have been an important source of information for policymakers in understanding the housing situation in the city. Hence it might have been helpful for policymakers while implementing the Having Housing Programme as well as while experimenting with innovative housing policy ideas after 2005. More importantly, the fact that report was commissioned by the city government showed that the city acknowledged the role of research assistance in making policy decisions. The report was completed in April 2006 with the content structure similar to the Having Housing Programme in 2005 but with more detailed and rich information. This suggests that, while the policy was decided in a rush in 2005 (probably to serve the city Party's Congress in 2005), the policymakers might have recognised a need for further study of the issue. In Da Nang City, a certain amount of local budget is spent on research activities annually (about $1-2 \%$ of the city's recurrent expenditure). The city government can call for proposals on issues that need to be studied or it can also approve proposals from the research community. One author of the 2016 report refused to participate in a face-to-face interview but agreed to answer some questions via email. The responses suggest that the authors proposed the study and received funding for it from the city budget. The respondent could not tell whether policymakers referenced the report when making policy decisions because no one contacted the authors after it was submitted. However, the respondent presumed that policymakers might have read the report because it was subsequently made publicly available (R15).

The content of the policy proposals in the 2006 report suggests that they were probably used by the DOF in drafting the regulations on the organisation and activity of the HDF, and by the DONRE in drafting the incentive policies for private sector participation. However, the fact that this report did not develop into an official Housing Development Strategy also indicates the limited influence of research communities on the final decisions. Authors of other studies refused to comment on their research's influence on policymakers, 
which may simply mean they do not know what influence it had. One of the policymakers commented:

I knew that there were some studies conducted by some researchers at the Science Technologies Associations, line departments, institutes, but I don't know much about them, I don't know any specific study ... From my point of view, the studies were not completed, not thorough. (R11)

This interviewee admitted not having read any of the studies. Based on my personal experience, it is likely that he did not trust research reports in general, perhaps based on having read some of them. It also reflects the limitation of the procedures of science management in the city. Although the city government spends money on research activities, the Department of Science and Technologies, which has quite a limited role in most policy discussions, was administratively responsible for receiving and storing the research findings. Not many of the reports were made available in easily-readable forms to policy leaders and thus few of them were read by policy leaders or had any influence.

It is worth noting that the role of research community has been evolving from 2008 after a policy research institute was established in Da Nang City.

\subsubsection{International organisations}

The World Bank was the only international development agency involved in the city's housing development. However, there was no official discussion between the government and the World Bank about the Having Housing Programme. The PIIP, as suggested before, just gave hope for policymakers about other possible sources of finance.

\subsection{Conclusion}

This chapter examined the role of societal actors in the policy process, including the private sector, the people and their mass organisations, the media, the research community and non-government organisations. In general, the efforts of the city government to attract private sector participation in LIH development resulted in its having quite a significant influence on the development and implementation of the policy, as the central and city governments found a mix of incentives that would encourage private investment. The role of other actors was quite limited. 


\section{Chapter 13: Discussion and conclusion}

This chapter discusses the data findings to highlight the contribution of this study to the literature on public policy and policymaking in Vietnam. It also points out the limitations of the research and makes suggestions for further studies.

\subsection{Discussion}

\subsubsection{The policy process}

This case study illustrates a specific policy process in local government in Vietnam. Empirical evidence shows that policy stages did not occur in a linear order: stages repeated within other stages. Especially, policy formulation and decision-making occurred again and again within the implementation phase of a continuous case from 2005 to 2013. Still, the stages heuristic's disaggregation is useful for recognising key features of each stage in the process.

\section{Agenda setting}

Kingdon's (1995) multiple streams model is a classical and often-used model to explain the agenda setting stage of policy processes. It is not difficult to identify three distinctive streams in this case, as well as the activities of a policy entrepreneur.

The problem stream can be traced to the high demand for housing in the developing city of Da Nang in the early 2000s. Housing demand came from slum dwellers, poor people, people in preferential categories, immigrants, and young poorly paid government officials. More importantly, huge housing demand came from households affected by the urban renewal process. At this point, the problem of housing for people in urban areas came to the attention of the city government and housing affordability was determined as the key issue. In Kingdon's words, the stream of policy problem was identified.

Meanwhile, in May 2004 the stream of solutions appeared when the central government enacted the National Housing Development Strategy, signalling that housing for lowincome people was going to be one of its national policy priorities and encouraging local initiatives in response. In addition, central government suggested using land as part of a possible solution for the problem.

The streams of problem and solution came together at a time when the city's financial condition was favourable. The Law on State Budget (2002) gave more financial autonomy to local governments, particularly in collecting and using revenue from land for state investment. Meanwhile the city had just started its urban renewal and had plenty of land 
for exploitation. It fact, the sudden increase in revenue from land made the policymakers feel confident in enacting and implementing the housing policy.

This time was also a decisive point in local politics when the city Party was preparing for a new five-year plan to be launched at the $19^{\text {th }}$ Party Congress in late 2005 . The previous five-year plan was characterised by a 5-Nos campaign, which had elevated the city's status in the media as 'trendy' in local governance. The time was ripe for a new campaign for the coming five-year period, from 2005 to 2010. Moreover, the next plan was expected to enhance the city's status. It can be said that the plentiful revenue from land and the $19^{\text {th }}$ Party Congress in late 2005 opened the window of opportunity for the streams of problem and solution to meet the stream of politics and to push the policy idea on to the agenda. Although there is no solid evidence to tell who initiated the idea of the 3-Haves, the city's Party Secretary took the opportunity to introduce the idea for the first time. With the Party Secretary's advocacy, the policy idea was passed easily through meetings of the Standing Committee of the city Party. In addition, the 3-Haves campaign was strongly supported because it met the city government's tendency of using slogans in enacting and implementing policies. The policymakers might have expected the 3-Haves would win the same public notice as the 5-Nos. In this political context, with the advocacy of the Party Secretary, the 3-Haves campaign officially got on the government's agenda when the Standing Committee of the city Party asked the DNPCe to prepare drafts for these policies.

While Kingdon's model is helpful to view the process at a broad level, Hofferbert offers a more specific model to understand the influences of this particular case. Hofferbert's funnel of causality model can help capture all influential factors on the agenda-setting stage of the process and place them in suitable relationships. Furthermore, this model enables policy development and implementation to be seen as a dynamic process. For example, rather than stretching the 'window of opportunity' to encompass the relatively long-lasting financial situation, Hofferbert's model places it squarely in the 'socio-economic conditions' factor along with other factors reflecting the demand side of the housing policy. This financial condition would continue to influence the LIH policy in the city later, especially when revenue decreased due to the decline of the land fund, which forced the city government to turn to the private sector for a more sustainable financial resource. Moreover, Hofferbert's 'institutional arrangement' factor can help to emphasise the important role of the central-local government relationship in this case. Studying this relationship not only identifies the necessary legal foundation laid by the central government but also highlights the local initiative in enacting the 3-Haves campaign, 
which was unique in the whole country and reflected the city's creativity in governance. In other words, Hofferbert's model can help to underline the combination of influences from the central government's housing strategy and the local discretion in producing the unique 3-Haves campaign. Meanwhile, this model also stresses the importance of the policy elite in mobilising the network of policy actors in pushing the policy idea on the agenda. One final merit of Hofferbert's model is that its influential factors were not only valuable in the agenda-setting stage but would also maintain their roles during the other stages of the process.

In short, the socio-economic conditions interacted with the institutional arrangements to give impetus to the policy elites' intentions to advance the policy idea. The most distinctive feature in this stage was the discussions within the city Party, where a consensus was reached before the policy idea officially got on the government's agenda. Although there was concern about the financial feasibility of the Having Housing Programme, no evidence indicates that there was fierce competition among factions within the Party. If there was any dissension on the policy, it was subsumed in the dominant and forceful role of the Party Secretary. The agenda-setting stage also indicated that policymaking in this case followed the mobilisation model (Cobb et al., 1976), in which political leaders initiated a policy idea and then required public support for implementation.

\section{Policy formulation}

Once the city Party asked the DNPCe to prepare the drafts for the 3-Haves campaign, the administrative branch of the government invested all available resources to form the content of the policy. Policy problems and solutions were identified and discussed among relevant actors, with consideration of technical and political constraints, as presented in the literature on policy formulation (Howlett, 2011; Howlett and Ramesh, 2003). Technical issues included legal aspects in identifying the policy beneficiaries, the design and architecture of LIH units as well as financial resources available at that time. Political constraints included the consistency with central regulations and people's support.

In this stage, policy actors included societal and state actors, who will be discussed in Section 13.1.2.3. During this stage, the DOC was the crucial actor, responsible for collecting data, organising discussion on the content of the policy, and presenting proposals to key policymakers for their final decision-making.

This policy formulation stage consisted of many activities mentioned in the literature, such as appraisal, dialogic, assessment, and consolidation (Howlett, 2011). With reference to 
policy tools in the literature (Howlett et al., 2015; Turnpenny et al., 2015), in this case, the main analytical tools included brainstorming, consultation exercises, scenario analysis, and financial impact analysis.

However, it worth noting that, the 'financial analysis' was decidedly limited by lack of information and expertise. It was also heavily affected by city leaders' will. As a result, the policy was decided with over-optimistic assumptions about financial resources and open room for further policy development in the implementation stage.

\section{Decision-making}

As discussed in the agenda-setting stage, there was no political rival who could force policymakers to come to a bargain or a compromise in this case. However, evidence shows that policymakers had to make decisions under many constraints (information, time, finance, and policy experience and expertise). In connection with the literature on decisionmaking (Forester, 1984; Howlett and Ramesh, 2003; Simon, 1955), the final decision under these constraints can be characterised as a bounded rational choice and was the subject of further development.

Another important feature of this stage was that although the policy was enacted in the form of a DNPCl resolution and a DNPCe decision, its actual decisive point was in the Standing Committee led by the Party Secretary. In fact, the content of the policy was approved by this unit before passing through the legislative and administrative authorities, just for formal legislative procedures.

\section{Policy implementation}

A plan for the implementation of the 3-Haves campaign was prepared by the DOC at the same time as the policy itself. Some potential problems were anticipated at that time; however, due to the constraints of time, information and experience they were left unsolved. The policy was implemented in a top-down pattern at the beginning. However, the anticipated problems soon became clear right after the policy was implemented. To resolve those problems, policy actors engaged in a process of experimentation, when different policy solutions were tried during the implementation.

The implementation showed that the policy was not simply transferred from policymakers to implementers for carrying out, but rather policy was regularly revised and adjusted during the stage with active participation by actors in the whole government system. There were some failed efforts, some instances of 'trial and error' and some successful policy 
experiments that led to policy changes. They indicated that the policy was not complete at the time it was enacted. Implementation could be seen as a learning process where lessons became feedback for further policy development.

This stage also shed light on the relationship between politicians and administrators. This is not only an example of the principal-agent relationship mentioned in the literature, that administrators had to faithfully implement the policy made by the politicians. It is also a case when politicians can be deeply involved in the implementation process. Meanwhile, administrators also had chances to enjoy minor discretion in implementing the policy. However, whenever an implementation issue came to the attention of politicians, administrators did not have much room to manoeuvre. If there were counter opinions between politicians and administrators, the one on top of the hierarchy of power would make the final decision. These observations did not diminish the fact that the politicians listened to suggestions from administrators before making decisions. They mainly confirmed the almost absolute power of the politicians in the policy implementation.

\section{Policy evaluation}

As stated before, this policy process did not occur in a linear pattern, thus evaluations were conducted periodically during the implementation and produced feedback for repeated policy cycles within the process.

\subsubsection{Influences on the policy process}

\subsubsection{Socio-economic conditions}

As presented in Chapter 8, socio-economic conditions defined the demand and supply sides of LIH and led to the introduction of the Having Housing Programme in 2005. Furthermore, a significant policy change in 2009 was associated with a sharp change in economic conditions because of the international economic recession. As stated by Hoffebert (1974), these socio-economic conditions were the consequences of the previous historical and geographical conditions. Studying this influence suggested that in the face of rapidly rising demand, LIH development depended critically on the supply side of the market. In this case study, although the generous revenue from land promoted the introduction of the Having Housing Programme, it also proved to be an unsustainable source. Thus, LIH development needed to be financed by state, private sector and home owners and tenants.

\subsubsection{Institutional arrangements}




\section{The effect of the principle of democratic centralism}

This study showed that the relationship between central and local government was crucial in the policy process. In this relationship, the principle of democratic centralism played an important role. Its effect was showed in the impact of the central government regulations on the city's policy changes in 2005 and 2009 as well as in the city's failed efforts presented in section 10.2.1. These failed experiments supported Fritzen's (2006) suggestion that the democratic centralisation principle is the primary force constraining the autonomy of local governments in unitary Vietnam. These examples also indicated that the room for manoeuvre by the local government was not as substantial as claimed by Arkadie and Mallon (2003), Datta and Pham (2013), Fritzen (2006), and Lucius (2009). Rather it was relatively limited when it came to adopting innovative policy ideas. The legal constraint set by the central government could be considered one of factors leading to the incremental feature of the policy-making process because local innovative policy ideas needed time and great effort to be officially legalised.

\section{Room for local creativity and autonomy}

Nevertheless, despite the bounds on local autonomy set by the central government, this case is also evidence of some local creativity and discretion at play particularly in the introduction of the unique Having Housing Programme (refer to section 10.2.1) and in the local effort to assist the private sector (refer to section 11.2). In these situations, the city's autonomy mainly came from the financial decentralisation that allowed the city to decide its expenditure by using revenue from land. This finding is in accord with the observations of Arkadie and Mallon (2003), Fritzen (2006), and Nguyen and Schroeder (2010) that provincial governments in Vietnam enjoy significant discretion in fiscal decision-making. More importantly, the city's discretion in this case also shows that the bounds set by the central government created the opportunities for the city's leaders to demonstrate their creativity and charismatic leadership in taking advantage of the ambiguity of the central government's regulations to venture innovative policy ideas.

The city's relative autonomy in implementation and its limited room for policy innovation are congruent with Lucius's (2009) argument that local authorities enjoy discretion in the decision-making process in some situations (when solving local issues by using local finance). However, they cannot move ahead of the central government in most situations. Although many of the city's innovative policy ideas could not be realised, Da Nang City still demonstrated its significant creativity and active engagement in policy innovation. 
While Teets (2015) proposes that career promotion and meeting local needs can be two key underlying incentives for local policy innovation in China, this case suggests that local needs and a distinctive local leadership drove the city's innovation. Evidence from this case also offers an explanation for Vu's (2015) question about why some provincial governments demonstrate a strong commitment to local development while others might follow rent-seeking strategies. The answer from this case is probably that distinctive local leadership combined with available resources could help a local government to pursue development-oriented policies. This proposition is similar to the argument of Malesky (2004) and Fritzen (2006) that leaders in better-off provinces might have more opportunities to assess innovative policy ideas and be more active in using them for making policy changes. It is also in agreement with Shanks et al.'s (2004) observation that style of local leadership and local budget capacity are among factors affecting the diversity in policy interpretation and implementation at local levels in Vietnam. This argument does not rule out any possible rent-seeking that might have occurred along with the dedication for the city's development.

\section{Cooperation between central and local government}

Evidence shows that on occasion there was cooperation between central and local government in housing policy development and implementation. The cooperation existed in the policy ideas exchange, financial support and other cooperation presented in detail in sections 10.2.6 and 10.2.7. It was also evident in the mutual efforts to realise the idea of selling state housing units to sitting tenants.

These interactions between the central and the city government indicated that fencebreaking activities no longer acted as a primary force for policy change in this period as in the past and particularly in the development of Doi Moi. With the introduction of the Having Housing Programme, the city government did not go against central rules. Rather, it worked out a suitable way to implement the not-yet-clear directions from the central government. Similarly, other local adjustments were also within the city's decentralised authority. In contrast, when the city government's policy idea was clearly in breach of central regulations, as in the case of the immigrant restriction, the city was immediately overruled. With lessons learned from this case, when the city government wanted to sell some state housing units to sitting tenants to recover capital for further investment, it had to negotiate with and persuade the central government to allow a pilot project. In this 
situation, the city did not break the fence; rather, it asked for, and eventually gained, permission to experiment with an innovative policy idea.

To put it another way, policy experiment and learning were still an effective way to change policy at both central and local levels in this case, but it occurred in different ways, with negotiation and bargaining between the central and local levels. This adjustment might have been the result of the change in reception at both levels. On the one hand, the central government recognised that local experiments had been a good source of lessons for national policy changes in the beginning of Doi Moi, so that it was not totally forbidden at the time of the case, especially when the capacity of policymakers in Vietnam was still limited. On the other hand, the central government also wanted to be able to re-assert its authority at any time, and preserve the effect of the democratic centralisation principle. Thus, listening to local initiatives and offering permission for experiments might help to maintain the power of the central government while mobilising local initiatives for better policymaking and implementation. In other words, the central government's elasticity and tolerance for local experiment can be considered as an effective strategy to maintain and enhance its authority and legitimacy. Local government officials, in this case, might also have been aware of the risk of adopting innovative policy ideas, since the central government had moved to stop fence-breaking in other cases (such as the case of immigrant restriction in the city and other cases in other localities [Vu et al., 2007]). A more cautious approach would be safer for their political careers while still giving them opportunities to demonstrate their creativity in local governance.

In addition to central-local government relations, this case also offers evidence to understand how the government agencies worked together in reality. All steps in the city's policy process complied with legal regulations that policy ideas must be discussed and approved by the DNPCl and implemented by the DNPCe and its agencies. The actual process, however, showed that the decisive points were in fact located mostly in the city Party. This finding is similar to McCarty's (2001) observation that in Vietnam the government apparatus is an instrument to implement Party policy. The deep involvement of the Party Secretary in the policy enactment, implementation and adjustment indicated that he was in charge of the whole process, not the Chairman of the DNPCe. This result is contradictory to the Party's claim of retreating from the day-to-day business of the government to focus only on setting general principles for policy. It is also different from Vasavankul's (2002) and Gainsborough's (2005) observations on the changes in Party leadership style and the increasingly important role of the NA and PCls. This case can 
support Gainsborough's (2005) note that elite political culture continued to be a key feature of politics in Vietnam. Although all policy actors understood that the real policy choice was made by the Party, the formalities still had to be undertaken firstly to paint a lacquer of legitimacy on the Party decision. The formal procedures also helped further develop the Party's decision into detailed legal regulations. Finally, formalities were at work because some institutions in Vietnam, especially mass organisations, were content with their formal role regardless of their actual contribution to the efficiency of policy-making process.

\subsubsection{Policy actors}

This case study sheds light on a network of policy actors participating in a policy process at provincial level in Vietnam. The policy network included societal and state actors with different degrees of influence on the process.

The first societal actor, the people, participated in the process mostly as a target group rather than as an influential actor who could affect the policy output. As regulated by law, mass organisations (the VFF and its members) were the official representatives of the people, responsible for protecting their interests in the process. The city VFF participated in all stages of the process, in its formal role of speaking for the people. Meanwhile, it also acted as the state's propaganda instrument to mobilise the people's support for the policy. In this case, the city's Women's Union played a more active role in influencing the Party Secretary to offer special support for single mothers.

Media were mobilised by the city government to inform the people of policy and acted as an intermediary to convey the people's concerns about policy to the government, especially in the implementation stage. In addition, media also participated in monitoring implementation and pointing out violations. Taking into account this contribution, media, at least in this case, play a more important role than Lucius (2009) and Data and Pham (2013) observed, that the press plays the role of public informer and Party supporter, and is not in the position of gathering public opinions to change policy or affect the policymaking process or that media are the mouthpieces of the CPV and the propaganda and mobilisation tools of the state.

The World Bank was apparently the only international financial institution to a play a limited role in the city's housing policy. Its only part in the Having Housing Programme was to provide a largely illusory balancing item for the financial projections.

This case study indicated that policymakers made some limited use of the research community. There was a demand for information about relevant policies in other localities 
and countries. However, due to the unavailability of relevant studies and consultants as well as perhaps the lack of research capacity, the research community had no role in the policy formulation and decision-making stages. From 2006 to 2013 some studies had been undertaken to provide some relatively objective evaluations of the policy outcome as well as to offer some policy suggestions. Nevertheless, there was very little evidence on the impact of these studies on the policy process.

Among societal actors, the private sector seemed to have a more significant role, which will be discussed in the next section; other societal actors appeared or participated in the process but did not create significant changes.

State actors played much more important roles in the process. The first important group was technical and legal advisors who worked at the DNPCe's divisions, departments and agencies. These government officials influenced the technical content of the policy. As implementers, they knew how the policy was applied in reality, as well as its problems and suitable solutions.

The DNPCl, as the city's formal law-making body, was required to assent to the legal requirements of the policy. In reality, this case showed that the DNPCl was no more than a rubber stamp of the Party policy. Key administrative leaders, such as the Chairperson or Vice Chairpersons of the DNPCe, were also overshadowed by the paramount leadership of the Party Secretary. Their significant roles in policymaking were as members of the Standing Committee of the city Party, where important decisions were made. However, as admitted by one of them, sometimes the collective decision-making body of the Standing Committee of the city Party could also be overruled by the absolute power of the Party Secretary. This finding on the limited role of the DNPCl is in agreement with previous studies about PCls by Vasavakul (2014), United Nations (2004) and Wit (2007). It also shows what 'the gap' between the legal stipulation of powers and actual practice (Vasavakul, 2014) looks like in reality.

\section{Policy elites}

Among the state actors, the Party Secretary emerged as the key figure of the process. Evidence showed that he could make many important policy decisions during different stages of the process. The absolute power of this individual in this case challenged the conventional wisdom of the consensus-based feature of policymaking in Vietnam mentioned in the literature (Arkadie and Mallon, 2003; Dang, 2013; McCarty, 2001; Rama, 2008; Shanks et al., 2004; Vu et al., 2016). This case supports an argument that while 
collective leadership and consensus-based decision-making were prescribed in formal rules and regulations the process might be more complicated inside the apparatus. At first glance, the process seemed to occur in a democratic manner with all relevant parties participating: there was public 'opinion collecting' (Arkadie and Mallon, 2003), cooperation was mobilised among departments and agencies, a consensus was reached by representatives of the $\mathrm{DNPCl}$, and collective discussions were undertaken within the Standing Committee of the city Party. However, they were more or less a 'managed democracy' (McCarty, 2001). In fact, the decisive points of the whole policy process were mostly in the hands of the Party Secretary.

Meanwhile, opposing opinions were raised weakly and not addressed soundly. The decisive role of the Party Secretary in the city suggested another approach to the consensusbased feature of policymaking in Vietnam: in certain situations, an individual could take control of the collective bodies and impose his will on the whole apparatus to make key decisions, as long as he demonstrated his loyalty to the Party's ideology and remained committed to the people's welfare. This finding, coupled with the case of signing the USVN BTA in Dang's (2013) study, supports an argument that the consensus-based feature in policymaking in Vietnam is very nuanced and can be exercised differently in different situations. Public unity might follow one group's victory in a contestation between factions within the Party, which can lead to the acquiescence of others. It can also be evidence that the will of a single individual can be imposed on the whole apparatus. This observation leads to a proposition that if senior Party cadres are innovative politicians, policy change can happen more easily. Meanwhile, it also imposes a requirement for the CPV to identify and implement rules that can hold leaders accountable when making decisions.

Studying the Party Secretary's performance in this case and other relevant situations indicate that he was influenced by the overarching political ideology, which aimed to maintain the Party's legitimacy by offering good social welfare policies. This finding is in agreement with Dang's (2013), Datta and Pham's (2013) and Lucius's (2009) observations about the core/enduring values that need to be protected in policymaking in Vietnam, namely political stability, the absolute leadership of the CPV, and social harmony. In addition, the Party Secretary's political will and special personal characteristics also affected the way he made decisions. It seems that he liked issuing slogans in governing the city, regardless of the feasibility of the policy goals. However, he had sufficient political resources to get his policy ideas implemented, except when there was opposition from the central government, where he had no control. Policymakers are often unwilling to move 
beyond the status quo, but this policy elite was fond of policy innovation. This distinguishing characteristic helps explain why he advocated policy change. There were hints that he pursued a personal interest of being supported by the people, which was an important factor for his political career, a motive that was mentioned in the literature (Genieys and Smyrl, 2008). There is no available evidence to support this proposition, though it is plausible that he deliberately burnished his reputation. Grindle and Thomas's suggestion of examining personal and professional values as well as policy elites' serious concern for public interest and social welfare provides a useful tool for evaluating what policymakers have done in this case. It is a counter argument for the tendency in other theories and models to explore the underlying self-interest that may have driven policymakers.

The influences of previous subsidised housing policies in the centrally planned period, the existing housing policies prior to 2005, as well as the 5-Nos and 3-Haves campaigns show that policymakers looked at their own context and examined previous policy successes and failures, then looked at foreign political systems, particular those of established innovators (Singapore and South Korea) for lessons, as suggested by Benson (2011). Due to the unavailability of lessons, policy transfer did not occur, instead policymakers in this case had to rely on trial and error to experiment with policy innovation and draw policy lessons. Nevertheless, this case suggests there is an increasing demand for policy transfer and great opportunities for epistemic communities, think tanks and other actors to exert influences on public policy in Vietnam.

\section{The relationship between the state and private sectors}

Studying the participation of the private sector in this process from 2009 offered some interesting findings. Evidence showed that the 'public and private partnership' could only happen when the private sector was able to seek profit. Even with the $10 \%$ discount on prompt payment of land-use fees, the city was still unable to attract any private LIH projects in the period from 2005 to 2009.

More incentives from both central and local government from 2009 and the difficulties in the high-end housing market led to the private sector's participation. The timing and location of the first private LIH project in the city suggests that the city government was closely involved in facilitating the project. The relationship between the city government and the private sector indicated a developing relationship in which the city government 
experimented with different policy ideas to encourage the profit-driven private sector's participation as well as to deal with their dishonest business practices.

This case also bears evidence of a situation when a private investor could exert influence on the top local leaders' decisions regardless of the opposition from technical advisors and administrators. The unclear relationship between politicians and private investors has been raised by other scholars, such as Gainsborough (2012) and Vu (2015) and discussed in formal forums (H.G, 2015). Discussions between the city government and private investors on housing developments took place mostly behind the scenes, so we will never know exactly how they proceeded. But it was clear that both the private sector and city government were learning how to negotiate and collaborate, and what to expect from each other. It was also clear to investors, officials, and no doubt others in the Da Nang case, that the Party Secretary's role was central to the eventual decisions and that he had significant room for manoeuvre in negotiation with the private sector.

The difference in the outcomes of LIH policy before and after the participation of the private sector provided a great lesson that LIH policy should rely on the private sector's participation with appropriate state incentives rather than only on government spending.

\subsubsection{Conclusion}

The collected data have proven that Hofferbert's model, with modifications based on insights from various approaches, is a useful lens to understand influences on the policy process in the Da Nang case. All influences were important and interacted in ways described in this discussion. The context background still consists of socio-economic conditions, which decided the demand and supply sides of the housing policy. These socioeconomic conditions were shaped by some elements of the city's 'historic and geographic conditions'. The institutional arrangements with a focus on the central and local government relationship are an important factor, affecting many aspects of the enactment and implementation of the policy. In this relationship, the principle of democratic centralism served as the primary principle, though local initiatives and creativity were also significant. Evidence also shows that intergovernmental cooperation did help explain some policy changes. The policy network includes some less important societal groups and important actors such as technical and legal advisors, the private sector, administrative leaders, and the most important players: political leaders and especially the Party Secretary. Most importantly, while Hofferbert's model was originally designed to explain the adoption of one policy and does not deal with other stages after the adoption, my modified 
framework embraces multiple policy cycles within one main policy process. The policy output at the end of the funnel can be defined as policy enactment, policy experimentation and policy change. Lessons learned from implementation and experimentation, which can be drawn from cooperation and negotiation among policy actors, as Weible et al. (2012) postulate, could be feedback for another policy cycle to occur again. Thus, the model will be slightly changed at the two end points of the funnel, the institutional arrangements and policy actors (Figure 13.1).

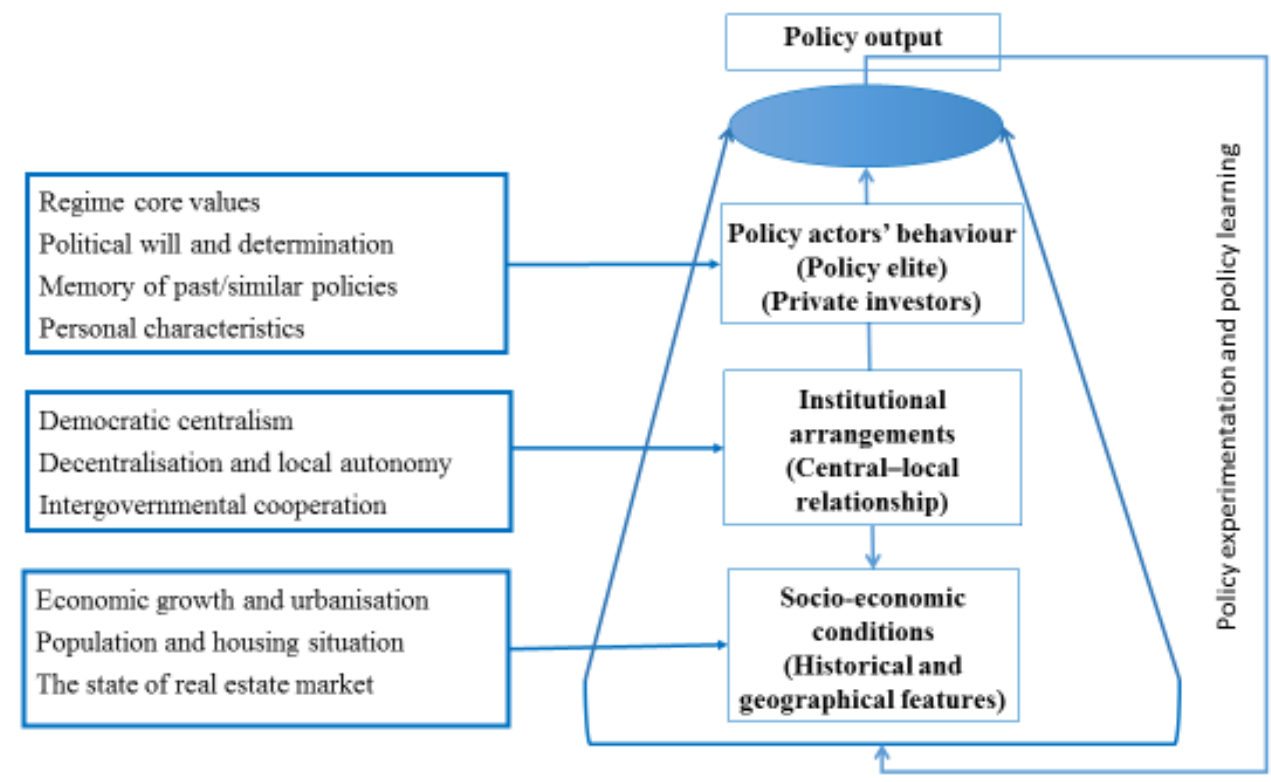

Figure 13.1: A framework of influences on the policy process in the case of LIH policy in Da Nang City

The data confirm Hofferbert's (1974) suggestion, that "the determinants of public policy would be to begin with elite behaviour and work backwards through factors conditioning them" (p.229). In this case, policymakers were conditioned by socio-economic conditions, constrained by the relationship with the central government and affected by the private sector in making decisions. Figure 13.2 further elaborates the above framework. 




Figure 13.2: Influences on the policy process in the case of LIH policy in Da Nang 


\subsection{Contributions and limitations of the research}

\subsubsection{Contributions}

As set out in Section 1.2, this study targeted one primary research question: What are the critical influences on the policy process in local government in the one-party state of Vietnam? In doing so, it has addressed some sub-questions: 1) How has LIH policy process evolved in Da Nang City? Which policy actors have been involved in the process? and, 2) During that process, what factors influenced policy actors? How and why are those factors important?

To answer the first question, collected data have been analysed and interpreted to construct a narrative of the process from 2005 to 2013 . This is the first study that offers insights into a policy process in Vietnam with rich information on policy discourses and conversations which were considered 'behind the scenes' activities in policy studies in Vietnam. Studying the policy process in this case contributes to the literature on public policy and the policy process in Vietnam in two ways:

Firstly, it reinforces a claim that the policy process occurs in a non-linear pattern with stages repeating within other stages. Policy evaluation can be undertaken while policy is being implemented to provide feedback for policy adjustment. Moreover, the policy process in this case shows that policy can be relatively general when it is first adopted and will be further developed while it is implemented.

Secondly, close examination of the policy process sheds light on the ways that and the extent to which the CPV intervened in and controlled the organisation and activities of the government apparatus at the local level. It also clarifies the role of the local PCl and PCe in decision-making and policy implementation.

While answering the second question, the findings of the study show that it is possible to combine elements from different theoretical approaches to understand public policy and that the policy process, in this case, was affected by a combination of different sets of influences, namely the broad socio-economic conditions shaped by some historical and geographical features, the institutional arrangements focused on the central-local government relationship, and the behaviour of policy actors centred on policy elites. Other related policies had some impact on the policy process but the degree of influence was not significant. 
More specially, this study contributes to the literature in three ways. Firstly, it sheds light on the scale of local autonomy enjoyed by local government in Vietnam and suggests that, although space for policy innovation was constrained by the principle of democratic centralism, the city government in fact enjoyed significant autonomy in policy implementation and the central-local government relationship had room for policy experimentation and learning. This proved to be an effective way to change policy at both central and local levels.

Secondly, the study offers a different lens on the use and limitations of consensus in policymaking in Vietnam and shows that, at least in this case, an individual could have a critical role in making and implementing policy. While this leader may have been an exceptional individual, the case shows that trying to understand what goes on behind the collective and consensus-based face of Vietnam's politics, difficult as that may be, is worth the effort.

Lastly, this study also sheds light on the developing relationship between the state and private sector in low-cost housing development. Data from the case show that LIH development should work alongside the private sector rather than rely solely on state funding. In this relationship, the government needs to direct its focus on incentives to encourage the private sector's participation as well as measures to manage this profitdriven actor.

Understanding these influences offers some implications for actors, such as donors and international organisations, who want to exert influence on the policy process in Vietnam. If Shank et al. (2004) suggest an approach to the broad network of policy actors, this study shows that a focus on key figures in the network might be more useful in certain situations. This study is also useful for insiders who wish to improve the quality of policymaking, policy implementation and policy evaluation at both central and local levels. The knowledge enhances their appreciation of key influences on the policy process, especially the central-local relationship, policy elites and external actors. It also highlights the need for procedures to assist policymakers in making policy as well as to keep them accountable.

\subsubsection{Limitations and future research}

Despite the above contributions, this study still has some limitations. First, it uses a single case to comprehend the actual policy process in local government in Vietnam. The key advantage of this research design is that it offers deep and detailed knowledge about the case and thus allows a thorough analysis of the impact of influences on the policy process. 
However, the disadvantage is that it cannot be known if elements of the policy process are common to other policy domains and other local governments in Vietnam. This limitation suggests ideas for further research, including broader studies on influences on policy processes in local and central government Vietnam. Broader and deeper research that focuses on one or two key influences of the policy process such as the central-local government relationship or the role of leadership in making policy in Vietnam could also be a fruitful avenue for further studies.

Another limitation was that the study relies on interview and documentary data of past policy events. That means the researcher did not have opportunity to observe the actual process, an experience that might yield more nuanced comprehension of the process and its influences. Moreover, this study could not collect perspectives of all participants in the process, especially the most desired participant: the Party Secretary. As a result, some data were missed and some research problems were not fully resolved, such as the extent of personal interests underpinning the Party Secretary's inclination to policy innovation in this case. Similarly, there are still some unpublished documents that could not be accessed. Further studies could offer more insights into the policy process if researchers have opportunities to observe or participate in the process or have chances to gain access to top policymakers.

\subsection{Conclusion}

This study has addressed questions about influences on the policy process in local government in Vietnam by examining empirical evidence from the case of LIH policy in Da Nang City from 2005 to 2013. It offers a close look at what happened in a policy process in a local government, which reinforces the non-linear pattern of policy process and sheds light on the actual roles of politicians, legislatures and administrators in public policy. More importantly, it proves that Hofferbert's funnel of causality model, appropriately adapted, is a useful lens to understand the relationship among pre-existing socio-economic conditions, institutional arrangements and behaviour of policy actors in determining public policy in local government in Vietnam. 


\section{References}

Abuza, Z. (2001). Renovating politics in contemporary Vietnam. London, United Kingdom: Lynne Rienner Publishers.

AFP. (2015). Popular Vietnamese communist party official dies. http://www.dailymail.co.uk/wires/afp/article-2952132/Popular-Vietnamesecommunist-party-official-dies.html

Airey, D., \& Chong, K. (2010). National policy-makers for tourism in China. Annals of Tourism Research, 37(2), 295-314.

Airey, D., \& Chong, K. (2011). Tourism in China: Policy and development since 1949. New York, NY; Abingdon, United Kingdom: Routledge.

Anderson, J. E. (1975). Public policy-making. New York, NY and Washington, DC: Praeger Publishers.

Arkadie, B. V., \& Mallon, R. (2003). Vietnam: A transition tiger? Canberra, Australia: Asia Pacific Press at The Australian National University.

Baumgartner, F., \& Jones, B. (1991). Agenda dynamics and policy subsystems. The Journal of Politics, 53(4), 1044-1074.

Bennett, C. J., \& Howlett, M. (1992). The lessons of learning: Reconciling theories of policy learning and policy change. Policy Sciences, 25, 275-294.

Benson, D., \& Jordan, A. (2011). What have we learned from policy transfer research? Dolowitz and Marsh revisited. Political Studies Review, 9, 366-378.

Berg, A. V. D. (2001). The social sciences according to Bunge. Philosophy of the Social Sciences, 31(1), 83-103.

Bernard, H. R., \& Ryan, G. W. (2010). Analyzing qualitative data: Systematic approaches. Thousand Oaks, CA: SAGE Publications, Inc.

Berry, F. S., \& Berry, W. D. (2007). Innovation and diffusion models in policy research. In P. A. Sabatier (Ed.), Theories of the policy process. Boulder, CO: Westview Press.

Blessing, A. (2015). Public, private, or in-between? The legitimacy of social enterprises in the housing market. Voluntas, 26, 198-221.

Blomquist, W. (2007). The policy process and large-N comparative studies. In P. A. Sabatier (Ed.), Theories of the policy process. Boulder, CO: Westview Press.

Bo Xay dung. (2015). Bo Xay dung va UBNDTP Da Nang ky ket Chuong trinh phoi hop hanh dong trien khai thuc hien Chien luoc phat trien nha o den 2020, tam nhin den 2030 [The Ministry of Construction and Da Nang People's Committee signing a collective action plan to implement the National Housing Development Strategy to 2020, a vision to 2030]. Retrieved 14 September 2015 from http://www.xaydung.gov.vn/en/trang-chi-tiet/-/tin-chi-tiet/Z2jG/63/192127/boxay-dung-va-ubnd-tp-da-nang-da-ky-ket-chuong-trinh-phoi-hop-hanh-dong-trienkhai-thuc-hien-chien-luoc-phat-trien-nha-o-den-nam-2020-va-tam-nhin-den-nam2030.html

Borras, S. (2001). State-society relations in land reform implementation in the Philippines. Development and Change, 32, 545-575. 
Bui, T. T. H., Mirzoev, T., \& Mukhopadhyay, M. (2015). Shaping the health policy agenda: The case of safe motherhood policy in Vietnam. International Journal of Health Policy and Management, 4(11), 741-746.

Bui, X. D. (2013). Gop y hoan thien quy dinh ve to chuc chinh quyen dia phuong [Some recommendations for the amendment of the regulations on local government] Retrieved 1 March 2016 from http://lyluanchinhtri.vn/home/index.php/thuctien/item/450-gop-y-hoan-thien-quy-dinh-ve-to-chuc-chinh-quyen-diaphuong.html

Chan, A. L. (2010). Power, policy and elite politics under Zhao Ziyang. The China Quarterly, 203, 708-718.

Chandola, H. (1977). New economic zones. Economic and Political Weekly, 12(4), 83-85.

Chen, J., Yang, Z., \& Wang, Y. P. (2014). The new Chinese model of public housing: A step forward or backward? Housing Studies, 29(4), 534-550.

Cima, R. J. (1987). Vietnam after 1975 Vietnam: A country study. Washington, D.C.: The U.S Library of Congress.

Cobb, R., Ross, J-K., \& Ross, M. H. (1976). Agenda building as a comparative political process. The American Political Science Review, 70(1), 126-138.

Crotty, M. (1998). The foundations of social research: Meaning and perspective in the research process. Sydney, Australia: Allen \& Unwin Pty Ltd.

Da Nang Home Affairs Department. (2012). Draft of the Population Distribution Scheme.

Da Nang Party. (2005). Political Report.

Da Nang People's Committee. (2002-2013). Yearly final account.

Da Nang People's Committee. (2010). Da Nang City's Master Plan on Socio-Economic Development to 2020.

Da Nang Statistics Office. (1997-2013). Statistics Year Books.

Da Nang Today. (2012). Housing policy has positive results. Retrieved 11 September, 2015, from http://www.baodanang.vn/english/society/201209/Housing-policyhas-positive-results-2192671/

Dahl, R. A. (1958). A critique of the ruling elite model. The American Political Science Review, 52(2), 463-469.

Dang, H. V. (2013). A new approach to explain policy reforms in Vietnam during Doi Moi by developing and validating a major policy change model for Vietnam. $\mathrm{PhD}$ Dissertation), Portland State University, USA.

Dang, H. V. (2016). Xay dung Luat Dat dai dap ung nhu cau hoi nhap quoc te [Designing the Law on Land to response to international integration]. Retrieved 6 January 2016 from

http://land.hcmunre.edu.vn/Files/QLDD/05_Vo.pdf?AspxAutoDetectCookieSupp ort $=1$

Dang, P., \& Beresford, M. (1998). Authority relations and economic decision-making in Vietnam: An historical perspective. Copenhagen: Nordic Institute of Asian Studies.

Dang, V. D. (2006). Xay dung chien luoc phat trien nha o thanh pho Da Nang den nam 2020 [Building a housing development strategy in Da nang City to the year 2020]: Da Nang Science Association of Construction Technology 
Darbi, W., \& Hall, C. M. (2014). Elite interviews: Critical practice and tourism. Current Issues in Tourism, 17(9), 832-848.

Datta, A., \& Pham, L. H. (2013). Not just a beautiful flower? Knowledge, information and economic policymaking in Vietnam: Overseas Development Institute. Retrieved 18 December 2013 from https://www.odi.org/sites/odi.org.uk/files/odiassets/publications-opinion-files/8429.pdf

Department of Housing Management and Real Estate Market. (2013). Social housing in Vietnam.

Department of Planning and Investment. (2012). De an giam sat dau tu cac chung cu nha o xa hoi thanh pho Da Nang [A programme for supervising investment in social housing projects in Da Nang].

Dinh, X. T. (2013). To chuc chinh quyen dia phuong - Kinh nghiem quoc te va thuc tien Viet Nam [Local government organisation - International experiences and Vietnam's situation]. Retrieved 1 March 2016 from http://yluanchinhtri.vn/home/index.php/thuc-tien/item/447-to-chuc-chinh-quyendia-phuong-kinh-nghiem-quoc-te-va-thuc-tien-viet-nam.html

Dolowitz, D., \& Marsh, D. (1996). Who learns what from whom: A review of the policy transfer literature. Political Studies, 44(2), 343-357.

Dolowitz, D. P., \& Marsh, D. (2000). Learning from abroad: The role of policy transfer in contemporary policy making. Governance, 13(1), 5-23.

Drew, H. (2014). Overcoming barriers: Qualitative interviews with German elites. Electronic Journal of Business Research Methods, 12(2), 77-86.

DVTV. (2010). Ong nguyen Ba Thanh be mac ky hop HĐND khoa VII 2010 [Mr Nguyen $\mathrm{Ba}$ Thanh's speech to closes the People's Council meeting 2010]. Retrieved 24 February 2015 from https://http://www.youtube.com/watch?v=iuc4rIvlXXs

Dye, T. R. (1984). Understanding public policy. New Jersey, NJ: Prentice-Hall, Inc., Englewood Cliffs.

Dye, T. R., \& Robey, J. S. (1980). "Politics versus economics": Development of the literature on policy determination. In T. R. Dye \& V. Gray (Eds.), The determinants of public policy. Lexington, Massachusetts: LexingtonBooks, D.C. Heath and Company.

Fontana, A., \& Frey, J. H. (1994). Interviewing: The art of science. In N. K. Denzin (Ed.), The Handbook of Qualitative Research. Thousand Oaks, CA: Sage Publications.

Forbes, D. (1996). Urbanization, migration, and Vietnam's spatial structure. Journal of Social Issues in Southeast Asia, 11(1), 24-51.

Forester, J. (1984). Bounded rationality and the politics of muddling through. Public Administration Review, 44(1), 23-31.

Fritzen, S. (2000). Decentralization and local government performance: A comparative approach with application to social policy reform in Vietnam. (PhD Dissertation), Princeton University, USA. (9957095)

Fritzen, S. (2006). Probing system limits: Decentralisation and local political accountability in Vietnam. Asia-Pacific Journal of Public Administration, 28(1), $1-24$. 
Gainsborough, M. (2005). Rethinking Vietnamese politics: Will the real state please stand up. $\quad$ Retrieved $11 \quad$ February 2014 from https://www.scribd.com/document/109651171/Gainsborough-RethinkingVietnamese-Politics

Gainsborough, M. (2012). Elites vs reform in Laos, Cambodia, and Vietnam. Journal of Democracy, 23(2), 34-46.

Genieys, W., \& Smyrl, M. (2008). Elites, ideas, and the evolution of public policy. New York, NY: Palgrave Macmillan.

Gerston, L. N. (2004). Public policy making: Process and principles. New York, NY: M. E. Sharpe, Inc.

Giang, D., \& Low, S. P. (2015). Infrastructure investments in developing economies. Singapore: Springer Science and Business Media.

Gilbert, J., \& Howe, C. (1991). Beyond "state vs. society": Theories of the state and new deal agricultural policies. American Sociological Review, 56(2), 204-220.

Goodlad, R., \& Atkinson, R. (2004). Sacred cows, rational debates and the politics of the right to buy after devolution. Housing Studies, 19(3), 447-463.

Gough, K., \& Tran, H. A. (2009). Changing housing policy in Vietnam: Emerging inequalities in a residential area of Hanoi. Cities, 26(4), 175-186.

Grindle, M. S., \& Thomas, J. W. (1991). Public choices and policy change: The political economy of reform in developing countries. London, United Kingdom: The Johns Hopkins University Press.

Guba, E. G., \& Lincoln, Y. S. (1994). Competing paradigm in qualitative research. In N. K. Denzin \& Y. S. Lincoln (Eds.), Handbook of qualitai research (pp. 105-117). Thousand Oaks, CA: SAGE.

Gueorguiev, D. D., \& Schuler, P. J. (2016). Keeping your head down: Public profiles and promotion under autocracy. Journal of East Asian Studies, 16(1), 87.

H.G. (2016). Muon thanh dai gia, phai duoc "uu dai ngam, quan he than tin"... [To be successful in doing business, must have "underground incentives, closed relationship"...], Infornet. Retrieved 30 March 2016 from http://infonet.vn/muonthanh-dai-gia-phai-duoc-uu-dai-ngam-quan-he-than-tin-post194651.info

Ha Noi People's Council. (2013). Ha Noi tong ket thi hanh Hien phap 1992 [Ha Noi's report on the implementation of the Constitution 1992]. Retrieved 1 March 2016 from http://duthaohienphap.hoabinh.gov.vn/index.php/67-ha-n-i-t-ng-k-t-vi-c-thihanh-hi-n-phap-nam-1992

Hai Chau. (2013). Cau chuyen chan dong cua ong Nguyen Ba Thanh 10 nam truoc [Mr Nguyen Ba Thanh's shocking story 10 years ago]. Infonet. Retrieved 27 February 2016 from http://infonet.vn/cau-chuyen-chan-dong-cua-ong-nguyen-ba-thanh-10nam-truoc-post53377.info

Hai Chau. (2014). Da Nang xin ban dut nha o xa hoi do ngan sach dau tu [Da Nang asks for permission to sell state-invested social housing]. Retrieved 8 September 2015 from http://infonet.vn/da-nang-xin-ban-dut-nha-o-xa-hoi-do-ngan-sach-dau-tupost140031.info

Hai Chau. (2015). Bi thu Da Nang: Bao chi da tac dong den tu duy cua lanh dao thanh pho [Da Nang Party Secretary: Media affect the city leaders' minds], Infonet. Retrieved 
7 April 2015 from http://infonet.vn/bi-thu-da-nang-bao-chi-da-tac-dong-den-tuduy-cua-lanh-dao-thanh-pho-post157765.info

Hall, P. (1993). Policy paradigms, social learning, and the state: The case of economic policymaking in Britain. Comparative Politics, 25(3), 275-296.

Heilmann, S. (2008). From local experiments to national policy: The origins of China's distinctive policy process. The Chinese Journal, 59, 1-30.

Ho Chi Minh City People's Committee. (2013). Bao cao Tong ket Luat nha o 2005 (Draft) [Report on the implementation of the Law on Housing 2005].

Ho Tuong. (2016). Su that ve Chu Hoa va 30,000 ngoi nha o Sai Gon [The truth about Uncle Hoa va 30,000 town houses in Sai Gon], Tuoi Tre. Retrieved 9 February 2016 from http://tuoitre.vn/tin/ban-doc/20160126/su-that-ve-chu-hoa-va-30000ngoi-nha-o-sai-gon/1044766.html

Hoang Long, (2015). Chuyen ong Nguyen Ba Thanh dep nan an xin, cham lo Tet cho xe om, ba gac [Mr Nguyen Ba Thanh eliminates beggars and provides assistance to motorcycle taxi riders on Tet holiday], Nguoi Dua Tin. Retrieved 24 February 2015 from http://www.nguoiduatin.vn/ong-nguyen-ba-thanh-qua-doi-ong-thanh-chamlo-tet-cho-xe-om-a170883.html

Hodder, I. (1994). The interpretation of documents and material culture. In N. K. Denzin \& y. S. Lincoln (Eds.), Handbook of qualitative research. Thousand Oaks, CA, London, United Kingdom, New Delhi, India: SAGE Publications.

Hofferbert, R. I. (1974). The study of public policy. New York, NY: The Bobbs-Merrill.

Hoffman, A. v. (2012). History lessons for today's housing policy: The political processes of making low-income housing policy: Joint Center for Housing Studies of Harvard $\begin{array}{lllll}\text { University. } & \text { Retrieved } & 29 & \text { August } & 2016\end{array}$ http://www.jchs.harvard.edu/research/publications/history-lessonstoday\%E2\%80\%99s-housing-policy-political-processes-making-low-income-0

Housing New Zealand Corporation. (2004). Building the future: Towards a New Zealand housing strategy. Wellington, New Zealand: Housing New Zealand Corporation.

Howlett, M. (2011). Designing public policies: Principles and instruments. London, United Kingdom, New York, NY: Routledge.

Howlett, M., McConnel, A., \& Perl, A. (2017). Moving policy theory forward: Connecting multiple stream and advocacy coalition frameworks to policy cycle models of analysis. Australian Journal of Public Administration, 76(1), 65-79.

Howlett, M., \& Ramesh, H. (2003). Studying public policy: Policy cycles and policy subsystems. [City?], Canada: Oxford University Press.

Howlett, M., Tan, S. L., Migone, A., Wellstead, A., \& Evans, B. (2015). Policy formulation, policy advice and policy appraisal: The distribution of analytical tools. In A. J. Jordan \& J. R. Tumpenny (Eds.), The tools of policy formulation: Actors, capacities, venues and effects. Retrieved 21 June 2016 from http://www.elgaronline.com/view/9781783477036.00020.xml.

Huu Kha. (2016). Dai bieu Quoc Hoi la bi thu, chu tich it dam phat bieu, vi sao? [Why do National Assembly's deputies, who are [Provincial] Party Secretary and Chairmen of People's Committee, rarely raise opinions?], Tuoi Tre Newspaper. Retrieved 22 March 2016 from http://tuoitre.vn/tin/chinh-tri-xa-hoi/20160321/dai-bieu-quochoi-la-bi-thu-chu-tich-it-dam-phat-bieu-vi-sao/1071085.html 
Huy Duc. (2013a). Giai phong in Ben Thang Cuoc [Liberation in The Winning Side] CreateSpace Independent Publishing Platform. Retrieved 15 April 2016 from http://www.vinadia.org/ben-thang-cuoc-huy-duc-quyen-i-giai-phong/

Huy Duc. (2013b). Quyen binh in Ben Thang Cuoc [The Power in The Winning Side] (Vol. 2). CreateSpace Independent Publishing Platform. Retrieved 9 February 2016 from http://www.vinadia.org/ben-thang-cuoc-huy-duc-quyen-ii-quyen-binh/

Ives, M. (2016). In One-Party Vietnam, Independents Vie for Assembly Seats, The New York Times. Retrieved 22 March 2016 from http://www.nytimes.com/2016/03/22/world/asia/vietnam-election-mai-khoi.html

Jenkins, W. I. (1978). Policy analysis: A political and organizational perspective. New York, NY: St. Martin's Press.

John, P. (2013). New directions in public policy: Theories of policy change and variation reconsidered. Paper presented at the International Conference on Public Policy, Grenoble.

Jones, B., \& Baumgartner, F. (2012). From there to here: Punctuated equilibrium to the general punctuation thesis to a theory of government information processing. Policy Studies Journal, 40(1), 1-20.

Kempen, R. v., \& Priemus, H. (2002). Revolution in social housing in the Netherlands: Possible effects of new housing policies. Urban Studies, 39(2), 237-253.

Kingdon, J. W. (1995). Agendas, alternatives, and public policies. New York, NY: Longman.

Koh, D. (2001). Negotiating the socialist state in Vietnam through local administrators: The case of Karaoke shops. SOJOURN: Journal of Social Issues in Southeast Asia, 16(2), 279-305.

Kwon, S-W., Choi, S. O., \& Bae, S-S. (2013). Effects of political institutions on punctuated equilibrium in local emergency management policy processes: Examination of county governments in Florida, U.S. Lex Localis, 11(2), 193-211

Labbé, D., \& Musil, C. (2014). Periurban land redevelopment in Vietnam under market socialism. Urban Studies, 51(6), 1146-1161.

Lambert, T. (2015). A brief history of Vietnam. Retrieved 05 Jan 2016 from http://www.localhistories.org/viethist.html

Lampton, D. M. (2014). Following the leader: Ruling China, from Deng Xiaoping to Xi Jinping. London, United Kingdom: University of California Press.

Le, T. T. H., \& Sajor, E. E. (2010). Privatization, democratic reforms, and microgovernance change in a transition economy: Condominium homeowner associations in Ho Chi Minh City, Vietnam. Cities, 27, 20-30.

Le, T. T. V. (2009). Vietnam's policy response to the financial crisis: East Asian Institute. $\begin{array}{lllll}\text { Retrieved } & 18 & \text { September } & 2015 & \text { from }\end{array}$ http://www.eai.nus.edu.sg/publications/files/Vol1No2_LeThiThuy.pdf

Le, V. D. (2012). Xay dung chinh sach nha o cho ho thu nhap thap tren dia ban thanh pho Da Nang [Designing housing policy for low-income earners in Da Nang City]: Da Nang Institute for Socio-Economic Development. 
Le, V. (2016). Tai sao biet thu Phap lai mat va tru tinh? [Why are French-style villas cool and romantic]. Retrieved 2 February 2016 from http://www.dhxd.edu.vn/do-hoaxay-dung-kien-truc/835-tai-sao-biet-thu-phap-lai-mat-va-tru-tinh-.html

Lieberthal, K., \& Oksenberg, M. (1988). Policy making in China: Leaders, structures, and processes. New Jersey, NJ, Oxford, United Kingdom: Princeton University Press.

"Lien doanh Duc Manh-579". (2014). Lien doanh Duc Manh-579: Dau tu hay xi cho chiem phan [Duc Manh Joint Venture: Investment or Speculation]. Retrieved 21 October 2015 from http://bizlive.vn/du-an/lien-danh-duc-manh-579-dau-tu-hay-xi-chochiem-phan-163378.html

Lincoln, Y. S., \& Guba, E. G. (1985). Naturalistic inquiry. Thousand Oaks, CA: SAGE Publication, Inc.

London, J. (2014). Politics in contemporary Vietnam. In J. London (Ed.), Politics in contemporary Vietnam: Party, state, and authority relations. Retrieved 18 January 2016 from http://ebookcentral.proquest.com/lib/vuw/detail.action?docID=1699408

London, J. (2015). Nguyen Ba Thanh. Retrieved 25 February 2015 from http://blog.jonathanlondon.net/

Long, N. (2015). Da Nang chinh thuc ban nha o xa hoi thuoc so huu nha nuoc [Da Nang sells state-owned social housing units]. Retrieved 8 September 2015 from http://www.baoxaydung.com.vn/news/vn/bat-dong-san/da-nang-chinh-thuc-bannha-o-xa-hoi-thuoc-so-huu-nha-nuoc.html

Lucius, C. (2009). Vietnam's political process: How education shapes political decisionmaking. Florence, KY: Routledge.

Luu Huong. (2014). Da Nang tien phong trong xay dung nha o xa hoi [Da Nang leading in social housing development]. Retrieved 8 September 2015 from http://baochinhphu.vn/Hoat-dong-dia-phuong/Da-Nang-tien-phong-trong-xaydung-nha-o-xa-hoi/205787.vgp

Malesky, E. (2004). Leveled mountains and broken fences: Measuring and analysing de facto decentralisation in Vietnam. European Journal of Asian Studies, 3(2), 307336.

Malesky, Edmund, Abrami, Regina, \& Zheng, Yu. (2008). Institutions and Inequality in Single-Party Regimes: A Comparative Analysis of Vietnam and China. Comparative Politics, 43(4), 401-419.

Marshall-Cavendish. (2007). World and its peoples: Eastern and southern Asia (Vol. 6). New York, NY: Marshall Cavendish.

Marshaw, C., \& Rossman, G. B. (2006). Designing qualitative research. Thousand Oaks, CA: Sage Publications, Inc.

McCarty, A. (2001). Governance institutions and incentive structures in Vietnam. Paper presented at the Building Institutional Capacity in Asia, Jakarta.

McGinnis, M. D. (2011). An introduction to IAD and the language of the Ostrom workshop: A simple guide to a complex framework. The Policy Studies Journal, 39(1), 169-183.

McNew-Birren, J. (2015). 'All policy is local': punctuated equilibrium theory and the politics of US lead regulation. Environmental Politics, 24(5), 681-702. 
Mei, C., \& Liu, Z. (2014). Experiment-based policy making or conscious policy design? The case of urban housing reform in China. Policy Sciences, 47(3), 321-337.

Mikecz, R. (2012). Interviewing elites: Addressing methodological issues. Qualitative Inquiry, 18(6), 482-493.

Minh Q. (2013). Da Nang 'phan phao' [ Da Nang 'rejected'], TuoiTre. Retrieved 28 October 2016 from http://tuoitre.vn/tin/chinh-tri-xa-hoi/20130119/da-nang-phanphao/530653.html

Moses, J., \& Knutsen, T. (2007). Ways of knowing: Competing methodologies in social and political research. Hampshire, United Kingdom, New York, NY: Palgrave Macmillan.

Munira, S. L., \& Fritzen, S. (2007). What influences government adoption of vaccines in developing countries? A policy process analysis. Social Science \& Medicine, 65, 1751-1764.

My Khanh, \& Khanh Hoa. (2012). City helps anti-social juveniles. Retrieved 25 February 2015 from http://www.baodanang.vn/english/society/201207/City-helps-antisocial-juveniles-2178669/

Myers, M. (2009). Qualitative research in business and management. Los Angeles, CA, London, United Kingdom: SAGE.

Nathan, A. J. (2016). Who is Xi?, The New York Review of Books. Retrieved [date] from http://www.nybooks.com/articles/2016/05/12/who-is-xi/

Nghe Nhan. (2012). Decentralization mechanism: provinces make decisions, the nation suffers. $\quad$ Retrieved $15 \quad$ September 2015 from http://english.vietnamnet.vn/en/special-report/21388/decentralization-mechanism-provinces-make-decisions--the-nation-suffers.html

Nghi Loc. (2014). Da Nang mo co che nha o [Da Nang has new housing policy]. Retrieved 8 September, 2015, from http://thoibaonganhang.vn/da-nang-mo-co-che-nha-o29140.html

Ngoc Long. (2015). Da Nang chinh thuc ban nha o xa hoi thuoc so huu nha nuoc [Da Nang sells state-owned social housing units]. Retrieved 12 December 2016, from http://www.baoxaydung.com.vn/news/vn/bat-dong-san/da-nang-chinh-thuc-bannha-o-xa-hoi-thuoc-so-huu-nha-nuoc.html

Ngoc Thuy. (2012). Da Nang la mot trong nhung dia phuong dan dau ca nuoc trong viec thuc hien nha o xa hoi [Da Nang among localities leading the country in social housing development]. Retrieved 11 September 2015 from http://www.danang.gov.vn/portal/page/portal/danang/chinhquyen/tin_tuc?p_pers_ id=42058\&p_folder_id=39013\&p_main_news_id=19758116

Nguyen, D. (2013). 'Da Nang that thoat 3.400 ty dong nhung dan duoc loi' [Da Nang lost 3,400 million VND but the people gained the benefit], VNExpress. Retrieved 28 October 2016 from http://vnexpress.net/tin-tuc/thoi-su/da-nang-that-thoat-3-400ty-dong-nhung-dan-duoc-loi-2883961.html

Nguyen, D. (2014). 116 cong chuc Da Nang vi pham su dung chung cu gia re [116 government officials violated regulations on using apartment units]. Retrieved 30 September 2015 from http://vnexpress.net/tin-tuc/thoi-su/116-cong-chuc-da-nangvi-pham-su-dung-chung-cu-gia-re-3006487.html 
Nguyen, D. (2015a). Di san Nguyen Ba Thanh trong long nguoi dan Da Nang [Nguyen Ba Thanh's heritage in Da Nang people's heart], VnExpress. Retrieved 23 February 2015 from http://vnexpress.net/tin-tuc/thoi-su/di-san-nguyen-ba-thanh-trong-longnguoi-dan-da-nang-3147869.html

Nguyen, D. (2015b). Nguoi Da Nang thuong tiec ong Nguyen Ba Thanh [Da Nang people mourning $\mathrm{Mr}$ Nguyen $\mathrm{Ba}$ Thanh]. Retrieved 9 October 2015 from http://vnexpress.net/tin-tuc/thoi-su/nguoi-da-nang-thuong-tiec-ong-nguyen-bathanh-3147783.html

Nguyen, D. H. (2014). 10 nam Da Nang xay dung va phat trien: Van dung sang tao, phu hop cac co che, chinh sach, tao su phat trien dot pha [10 years of Da Nang's development: creatively implemented policies for breakthrought development]. $\begin{array}{lllll}\text { Retrieved } & 11 & \text { November } & 2015 & \text { from }\end{array}$ http://canbotre.danang.vn/home/view.php?t=3293

Nguyen, H. P., \& Schroeder, L. (2010). An analysis of quasi-decentralized budgeting in Vietnam. International Journal of Public Administration, 33, 698-709.

Nguyen, H. H. (2014). Grassroots democracy and inequality reduction in rural Vietnam: The case of Thai Binh in 1997 and now. Asian Journal of Political Science, 22(1), 71-92.

Nguyen, M. P. (2013). Thuc trang phan cap, phan quyen va van de tu quan dia phuong tai Viet Nam [Decentralisation and local autonomy in Viet Nam]. Paper presented at the To chuc chinh quyen dia phuong o Viet Nam: Nhung van de ly luan va thuc tien [Local government in Viet nam: Theory and Impirical issues], Ninh Thuan, Viet Nam. Retrieved 1 March 2016 from http://duthaoonline.quochoi.vn/DuThao/Lists/DT_TAILIEU/Attachments/1188/0 2-Phanquyen-PhuongNM.pdf

Nguyen, N. A., Nguyen, D. C., Nguyen, D. N., \& Bui, T. H. (2011). Fiscal issues in Vietnam economy: Assessment on the impact of stimulus, fiscal transparency and fiscal risk. In T. Ito \& F. Parulian (Eds.), Assessment on the impact of stimulus, fiscal transparency and fiscal risk. (pp. 249-282): ERIA.

Nguyen, N. T. (2015). Mot chang duong cua Quoc Hoi qua trai nghiem cua mot dai bieu [A milestone of the National Assembly reflected in a deputy's experience]. Paper presented at the Quoc Hoi 70 nam [70 years of The National Assembly]. Retrieved 22 March 2016 from http://vietstudies.info/kinhte/NNgocTran_TraiNghiemDaiBieu.pdf

Nguyen, Q., \& Kammeier, H. D. (2002). Changes in political economy of Vietnam and their impacts on the built environment of Hanoi. Cities, 19(6), 373-388.

Nguyen, Q. P., Zoomers, A., \& Westen, A. C. M. v. (2015). Compulsory land acquisition for urban expansion: A study of farmer's protest in peri-urban Hue, Central Vietnam. Paper presented at the Land grabbing, conflict and agrarian environmental transformations: perspectives from East and Southeast Asia, Chiang Mai University.

Nguyen, T. (2012). Bi thu Thanh uy Nguyen Ba Thanh noi chuyen voi can bo lanh dao, quan ly cac cap: can bo phai co to chat va khat vong" [Party Secretary Nguyen Ba Thanh talking to local leaders: government officials must have capacity and aspiration]. $\quad$ Retrieved $\quad 9 \quad$ October 2015 from http://baodanang.vn/channel/5399/201202/bi-thu-thanh-uy-nguyen-ba-thanh-noi- 
chuyen-voi-can-bo-lanh-dao-quan-ly-cac-cap-can-bo-phai-co-to-chat-va-khatvong-2154255/

Nguyen, T. B. (2016). Nghi tu phong trao "tung ca" ong Dinh La Thang hien nay [Some thoughts about the "praising Mr Dinh La Thang" movement at the moment $\begin{array}{lllll}\text { Retrieved } 9 & \text { March } & 2016 \text { from }\end{array}$ studies.info/kinhte/NTrongBinh_TungCaDinhLaThang.htm

Nguyen, X. T. (2003). Danang: Policy options for investment and economic development: Central Institute for Economic Development, Asia Foundation, Fulbright Economics Teaching Program.

Nhiet Bang. (2015). Vu lua dao chung cu rung dong du luan Da Nang: Cong ty quan ly chang quan ly gi [A shocking deceit: The Housing Management Company fails its job]. Retrieved 12 October 2015 from http://laodong.com.vn/xa-hoi/vu-lua-daochung-cu-rung-dong-du-luan-da-nang-cong-ty-quan-ly-chang-quan-ly-gi352276.bld

Nhiet Bang, \& Huu Long. (2015). Nha o cho cong nhan tai Da Nang: Sau nhieu nam van roi vao... "ngo cut" [Housing for workers: Got stuck after years]. Retrieved 21 October 2015 from http://laodong.com.vn/cong-doan/nha-o-cho-cong-nhan-tai-danang-sau-nhieu-nam-van-roi-vao-ngo-cut-382384.bld

NZHistory. (2016). State housing. Retrieved 31 August 2016 from http://www.nzhistory.net.nz/culture/state-housing-in-nz

Olsen, W. (2012). Data Collection. New Delhi, India: SAGE Publications India Pvt Ltd.

Orlikowski, W., \& Baroudi, J. J. (1991). Studying information technology in organizations: Research approaches and assumption. Information System Research, 2(1), 1-28.

Ostrom, E. (2007). Institutional rational choice: An assessment of the institutional analysis and development framework. In P. A. Sabatier (Ed.), Theories of the policy process (2nd ed.). Boulder, CO: Westview Press.

Painter, M. (2005). Public administration reform in Vietnam: Foreign transplants or local hybrids? In J. Gillespie \& P. Nicholson (Eds.), Asian socialism and legal change: The dynamics of Vietnamese and Chinese reform. Canberra, Australia: Australian National University E Press.

Parsons, W. (1995). Public policy: An introduction to the theory and practice of policy ananlysis. Cheltenham, United Kingdom: Edward Elgar Publishing Limited.

Peshkin, A. (2000). The nature of interpretation in qualitative research. Educational Researcher, 29(9), 5-9.

Pham, S. L. (2012). Bai toan tai chinh ve nha o xa hoi [The problem of finance for social housing], Vietnam Architecture Magazine. Retrieved 29 December 2015 from http://kienviet.net/2012/06/11/bai-toan-tai-chinh-ve-nha-o-xa-hoi

Pham, T. (2016). Phong vien bi "gat ta vao ma": Quan chuc Quoc Hoi de nghi Bo Cong An xu ly nghiem [Journalist "brushed on cheek": A National Assembly Deputy suggests a strict punishment. Retrieved 13 October 2016 from http://www.vtc.vn/phong-vien-bi-gat-tay-vao-ma-quan-chuc-quoc-hoi-de-nghibo-cong-an-xu-nghiem-d279670.html

Pham, V. T., \& Parenteau, R. (1991). Housing and urban development policies in Vietnam. Habitat International, 15(4), 153-169. 
Phan, B. Q. A. (2013). Da Nang: Xet xu nhieu doi tuong lua dao "chay" chung cu [Da Nang: Con artists in apartment housing cases are brought to court]. Retrieved 19 October, 2015, from http://antg.cand.com.vn/Kinh-te-Van-hoa-The-Thao/DaNang-Xet-xu-nhieu-doi-tuong-lua-dao-chay-chung-cu-306798/

Phan, C. T. (2014). Doi song thoi bao cap: Nha o tap the [Life in the subsidised time: apartment housing], The Thao va Van hoa. Retrieved 2 February 2016 from http://thethaovanhoa.vn/van-hoa-giai-tri/doi-song-thoi-bao-cap-bai-3-nha-tap-then20140508151612478.htm

Phan, N. D. H. (2006). "Thuong hieu" lanh dao [Leaders' "brand name"]. Retrieved 7 October 2015 from http://tuoitre.vn/tin/ban-doc/20060422/thuong-hieu-lanhdao/134038.html

Phan, T. L. H. (2012). Reforming local government in Vietnam. Lessons learned from Japan. (PhD Dissertation), Nagoya University. Graduate School of Law, Japan.

Phan, V. T. (2015). Tam long thuong dan sau nang [A heart for people]. Retrieved 18 February 2015 from http://www.tienphong.vn/xa-hoi/ong-nguyen-ba-thanhtamlong-thuong-dan-sau-nang-824003.tpo

Phe, H. H., \& Nishimura, Y. (1991). Housing in Central Hanoi. Habitat International, 15(1), 101-126.

Phuong Tra, \& Trieu Tung. (2012a). Ky 2: Cham dut viec chuyen nhuong chung cu trai phep [Part 2: Illegal transactions of apartment units stopped], Bao Da Nang. Retrieved $\quad 31 \quad$ December 2015 from http://www.baodanang.vn/channel/5407/201203/rac-roi-nha-chung-cu-ky-2cham-dut-viec-chuyen-nhuong-chung-cu-trai-phep-2155887/

Phuong Tra, \& Trieu Tung. (2012b). Rac roi nha chung cu-Ky 1: Vo mong nha thu nhap thap [Problems of apartment housing - Part 1: Unfulfilled dreams of low-income housing], Bao Da Nang. Retrieved 31 December 2015 from http://www.baodanang.vn/channel/5407/201203/rac-roi-nha-chung-cu-ky-1-vomong-nha-thu-nhap-thap-2155701/

Przeworski, A. (1990). The state and the economy under capitalism. Chur, Switzerland: Harwood Publishers GmbH.

Punch, K. F. (2014). Introduction to social research: Quantitative \& qualitative approaches (3rd ed.). London, United Kingdom: SAGE Publications Ltd.

Quynh Tran. (2017). Cuoc song trong khu nha 100 trieu dong o Binh Duong [Life in 100million-VND apartment units in Binh Duong], VnExpress. Retrieved 20 February 2017 from http://vnexpress.net/photo/thoi-su/cuoc-song-trong-khu-nha-100-trieudong-o-binh-duong-3539076.html

Rama, M. (2008). Making difficult choices: Vietnam in transition. Washington, D.C.: WorldBank.

Rose, R. (1991). What is lesson-drawing? Journal of Public Policy, 11(1), 3-30.

Rowley, J. (2002). Using case studies in research. Management Research News, 25(1), 1627.

Rozbicka, P. (2013). Advocacy coalitions: Influencing the policy process in the EU. Journal of European Public Policy, 20(6), 838-853. doi: $10.1080 / 13501763.2013 .781820$ 
Rubin, H., \& Rubin, I. (2004). Qualitative interviewing: The art of hearing data. doi: http://dx.doi.org/10.4135/9781452226651.n1

Rubin, H., \& Rubin, I. (2012). Qualitative interviewing: The art of hearing data. London, United Kingdom: SAGE Publications Ltd.

Sabatier, P. A. (1986). Top-down and bottom-up approaches to implementation research: A critical analysis and suggested synthesis. Journal of Public Policy, 6(1), 21-48.

Sabatier, P. A. (2007a). Fostering the development of policy theory. In P. A. Sabatier (Ed.), Theories of the policy process. Boulder, CO: Westview Press.

Sabatier, P. A. (2007b). Theories of the policy process (2th ed.). Boulder, CO: Westview Press.

Sabatier, P. A., \& Weible, C. M. (2007). The advocacy coalition framework: Innovations and clarifications. In P. A. Sabatier (Ed.), Theories of the policy process. Boulder, CO: Westview Press.

Samad, T., Hoang, H. T., Brhane, M., Mcvitty, J. E., Nguyen, H. M., Harrison, D. H.,... Tran, T. C. N. (2015). Vietnam - Affordable Housing: A Way Forward. Washington, DC: World Bank Group.

Sanderson, I. (2002). Evaluation, policy learning and evidence-based policy making. Public Administration, 80(1), 1-22.

Schubert, G., \& Heberer, T. (2015). Continuity and Change in China's "Local State Developmentalism". Issues \& Studies, 51(2), 1-38.

Shankansky, I. (2002). Politics and policy making: In search for simplicity. Boulder, CO: Lynne Rienner Publishers.

Shanks, E., Luttrell, C., Conway, T., Vu, M. L., \& Ladinsky, J. (2004). Understanding propoor political change: The policy process. London, United Kingdom: Overseas Development Institute.

Sharaput, M. (2012). The limits of learning: Policy evaluation and the Ontario Ministry of Research and Innovation. Canadian Public Administration, 55(2), 247-268.

Shester, K. L. (2011). American public housing's origins and effects (PhD Dissertation). Vanderbilt University, Nashville, TN. (3479848)

Shih, V., Shan, W., \& Liu, M. (2010). Gauging the Elite Political Equilibrium in the CCP: A Quantitative Approach Using Biographical Data. The China Quarterly, 201, 79103.

Silverman, D. (2011). Qualitative Research (3rd ed.). London, United Kingdom: SAGE Publications Ltd.

Simon, H. (1955). A behavioral model of rational choice. The Quarterly Journal of Economics, 69(1), 99-118.

Simons, H. (2009). Case study research in practice. London, United Kingdom: SAGE.

Skocpol, T. (1985). Bringing the state back in: Strategies of analysis in current research. In P. Evans, D. Rueschemeyer \& T. Skocpol (Eds.), Bringing the state back in. Cambridge, United Kingdom: The Press Syndicate of the University of Cambridge.

So Xay Dung. (2015). Da Nang cong khai thong tin nha o xa hoi va thuong mai duoi 15 trieu dong/m2 [Da Nang publishes information about social housing and commercial 
housing that costs less than 15million/m2] Retrieved 21 October, 2015, from http://www.sxd.danang.gov.vn/nha-o-xa-hoi?articleId=32974

Stake, Rob E. (2009). The case study method in social enquiry. In R. Gomm, M. Hammersley \& P. Foster (Eds.), Case study method (pp. 18-27). London, United Kingdom: SAGE Publications Ltd.

T. Ngoc, \& Ngoc Long. (2013). Bo Xay dung va UBNDTP Da Nang ky ket Chuong trinh phoi hop hanh dong trien khai thuc hien Chien luoc phat trien nha o den 2020, tam nhin den 2030 [Ministry of Construction and Da Nang People's Committee signed a collective action plan for implementing the National Housing Strategy through 2020, a vision to 2030]. Retrieved 14 September 2015 from http://ictdanang.vn/index.php?option=com_content\&view=article\&id=7755:boxay-dung-va-ubndtp-da-nang-ky-ket-chuong-trinh-phoi-hop-hanh-dong-trienkhai-thuc-hien-chien-luoc-phat-trien-nha-o-den-2020-tam-nhin-den2030\&catid=109: dong-hanh-cung-doanh-nghiep \&Itemid=2

Tanner, M. S. (1995). How a bill becomes a law in China: Stages and processes in lawmaking. The China Quarterly, 141(Special Issue: China's Legal Reforms).

Teets, J. C. (2015). The politics of innovation in China: Local officials as policy entrepreneurs. Issues \& Studies, 51(2), 79-109.

Thai, B. L. (2015). Cuoc tron mat vu thoi tieu hoc cua Nguyen Ba Thanh [Nguyen Ba Thanh's narrow escape from secret agents], Tuoi Tre Newspaper. Retrieved 27 February 2015 from http://tuoitre.vn/tin/chinh-tri-xa-hoi/20150217/cuoc-tron-matvu-ngoan-muc-thoi-tieu-hoc-cua-nguyen-ba-thanh/711792.html

ThanhNienNews. (2013). Jury out as Da Nang's populist leader takes on "tough" anticorruption task. $\quad$ Retrieved 7 October 2015 from http://www.thanhniennews.com/society/jury-out-as-da-nangs-populist-leadertakes-on-tough-anticorruption-task-3599.html

The Housing Shareholders Advisory Group. (2010). Home and Housed: A vision for Social Housing in New Zealand. Retrieved 30 August 2016 from http://www.baybuzz.co.nz/wp-content/uploads/2010/08/vision-for-socialhousing-nz.pdf

Thomas, G. (2011). A typology for the case study in social science following a review of definition, discourse, and structure. Qualitative Inquiry, 17(6), 511-521.

Thu Phuong. (2012). Nan giai nha o cho cong nhan [Wicked problem of housing for workers]. $\quad$ Retrieved 21 October 2015, from http://www.danang.gov.vn/portal/page/portal/danang/chinhquyen/diem_bao?p_pe rs_id=\&p_folder_id=9370276\&p_main_news_id=15012132

Thuy Vinh. (2015). Ngan hang cho vay bat dong san: Goi 30.000 ty dong o dau [Real estate loans: Where has the 30.000 billion package gone]. Retrieved 14 September, 2015, from http://tinnhanhchungkhoan.vn/tien-te/ngan-hang-cho-vay-bat-dong-san-goi30000-ty-dong-o-dau-114899.html

Tieu Yen. (2015). Du an xay dung nha o cho cong nhan: van chua den dich [Housing for workers: unachieveable]. Retrieved 21 October 2015 from http://www.baodanang.vn/channel/5433/201508/du-an-xay-dung-nha-o-chocong-nhan-van-chua-den-dich-2433807/ 
Timberland, I. (2011). Vietnam's controversial "dictator" cut red tape. Retrieved 25 February 2015 from http://zeenews.india.com/news/world/vietnams-controversialdictator-cuts-red-tape_700466.html

To, H. R. (2015). Dieu van (Memorial speech at Mr Nguyen Ba Thanh's funeral). Retrieved 7 October 2015 from http://vtc.vn/dieu-van-truy-dieu-ong-nguyen-bathanh.2.541190.htm

Tran, Q. B. (2013). Qua trinh bien doi kien truc nha o thi dan Ha Noi thoi Phap thuoc [The architecture change in urban housing in $\mathrm{Ha}$ Noi in the French colonial era]. Retrieved 2 February 2016 from http://mag.ashui.com/chuyenmuc/kien-truc/9618qua-trinh-bien-doi-kien-truc-nha-o-thi-dan-ha-noi-thoi-phap-thuoc.html

Tran, Q. V. (1993). Do Thi Co Vietnam (Vietnam's ancient urban areas). In Q. V. Tran (Ed.), Trong coi. California, CA: Tram Hoa Publisher. Retrieved 27 January 2016 from http://vanhoahoc.vn/nghien-cuu/van-hoa-hoc-ung-dung/van-hoa-dothi/1338-tran-quoc-vuong-do-thi-co-viet-nam-.html

Tran, T. T. (2015). Xây dựng và phát triển nhà ở xã hội tại Thành phố Hồ Chí Minh [Building and developing social housing in Ho Chi Minh City]. Retrieved 13 February 2016 from http://www.constructiondpt.hochiminhcity.gov.vn/web/guest/phat-triennha;jsessionid=0AA7EE91CDC516857FADF5625E3F08D2?p_p_id=EXT_ART ICLEVIEW\&p_p_lifecycle=0\&p_p_state=normal\&p_p_col_id=column-eightyright\&p_p_col_count $=1 \&$ _EXT_ARTICLEVIEW_struts_action $=\% 2 \mathrm{Fext} \% 2 \mathrm{Farti}$ cleview\%2Fview\&_EXT_ARTICLEVIEW_groupId=10217\&_EXT_ARTICLEV IEW_articleId=765009\&_EXT_ARTICLEVIEW_version=1.0\&_EXT_ARTICL EVIEW_i=4\&_EXT_ARTICLEVIEW_curValue=1\&_EXT_ARTICLEVIEW_re direct $=\% 2$ Fweb $\% 2$ Fguest $\% 2$ Fphat-trien-nha

Tran, T. (2005). "5 khong" va "3 co" o Da Nang ["5-Nos" and "3-Haves" in Da Nang, Tien Phong Newspaper. Retrieved 31 August 2015 from http://www.tienphong.vn/xahoi/5-khong-va-3-co-o-da-nang-13824.tpo

Tran, V. D., \& Bao Tram. (2013). Ba thap ky doanh ngiep tu nhan Viet [Three decades of Vietnam's private enterprises], Dat Viet Online. Retrieved 6 January 2016 from http://baodatviet.vn/kinh-te/thi-truong/ba-thap-ky-doanh-nghiep-tu-nhan-viet2345558

Trieu Tung. (2012). Mong cho chung cu [Waiting for apartment units], The Da Nang Times. $\quad$ Retrieved 4 January 2017 from https://danangtimes.wordpress.com/2012/06/20/tin-tuc-da-nang-mong-doi-chung$\mathrm{cu} / \mathrm{amp} /$

Trieu Tung. (2014). Du an nha o xa hoi: Suy giam niem tin [Social housing projects: deteriorating belief], Bao Da Nang. Retrieved 31 December 2015 from http://baodanang.vn/channel/5404/201408/du-an-nha-o-xa-hoi-suy-giam-niemtin-2354721/

Trinh, D. L., Nguyen, Q. V., Wiesman, B., \& Leaf, M. (2000). Urban housing. In P. Boothroyd \& X. N. Pham (Eds.), Socioeconomic renovation in Vietnam: The origin, evolution and impact of Doi Moi. International Development Research Centre and Institute of Southeast Asian Studies, Retrieved 26 January 2016 from http://library.umac.mo/ebooks/b11681834.pdf

Trong Huy. (2013). Bat cap o chung cu thu nhap thap [Problems in low-income housing apartments], Bao Da Nang. Retrieved 31 December 2015 from 
http://www.baodanang.vn/channel/5428/201305/bat-cap-o-chung-cu-thu-nhapthap-2240882/

True, J. L., Jones, B., \& Baumgartner, F. (2007). Punctuated-equilibrium theory: Explaining stability and change in public policymaking. In P. A. Sabatier (Ed.), Theories of the policy process. Boulder, CO: Westview Press.

Truong, B. T. (2014). Fiscal decentralisation in Vietnam: Outcomes and the way forward. Paper presented at the Asian Regional Seminar on Public Financial Management, Phnom Penh.

Truong Tung. (2015). Xom phu nu don than khoc thuong ong Nguyen Ba Thanh [Single mother village mourning Mr Nguyen Ba Thanh]. Retrieved 9 October 2015 from http://tuoitre.vn/tin/chinh-tri-xa-hoi/20150215/xom-phu-nu-don-than-khocthuong-ong-nguyen-ba-thanh/712083.html

TuoiTreOnline. (2012). Nghi quyet 23 cua Da Nang trai luat [Da Nang's Resolution 23 is illegal]. Retrieved 15 September 2015 from http://tuoitre.vn/tin/chinh-tri-xahoi/20120301/nghi-quyet-23-cua-da-nang-trai-luat/480098.html

TuoitreOnline. (2015). Nguoi dan Da Nang tiec thuong ong Nguyen Ba Thanh [Da Nang people mourning Mr Nguyen Ba Thanh]. Retrieved 6 October 2015 from http://tuoitre.vn/tin/chinh-tri-xa-hoi/20150214/nguoi-da-nang-tiec-thuong-ongnguyen-ba-thanh/711672.html

Turnpenny, J. R., Jordan, A. J., Benson, D., \& Rayner, T. (2015). The tools of policy formulation: An introduction. In J. R. Turnpenny \& A. J. Jordan (Eds.), The tools of policy formulation: Actors, capacities, venues and effects. Retrieved 21 June 2016 from http://www.elgaronline.com/view/9781783477036.xml.

United Nations. (2004). The Socialist republic of Vietnam: Administration Country Profile: The United Nations. Retrieved 2 March 2016 from http://unpan1.un.org/intradoc/groups/public/documents/un/unpan023247.pdf Vasavakul, T. (2002). Rebuilding authority relations: Public administration reform in the era of Doi Moi. Ha Noi, Vietnam: Asian Development Bank.

Vasavakul, T. (2014). Authoritarianism reconfigured: Evolving accountability relations within Vietnam's one-party rule. In J. London (Ed.), Politics in contemporary Vietnam: Party, State, and Authority Relations. Retrieved 18 January 2016 from http://ebookcentral.proquest.com/lib/vuw/detail.action?docID=1699408

VCCI, \& USAID. (2015). PCI - Chi so nang luc canh tranh cap tinh [PCI - Provincial Competitiveness Index]. Retrieved 11 November, 2015, from http://www.pcivietnam.org/bang-xep-hang?f2=0\&index=0\&year=2012

Verick, S., \& Islam, I. (2010). The great recession 2008-2009: Causes, consequenses and policy responses. Germany: Institute for the Study of Labor. Retrieved 8 April 2014 from http://ftp.iza.org/dp4934.pdf

Vietnam General Statistics Office. (1999). Population and Housing Census in Vietnam. $\begin{array}{lllll}\text { Retrieved } & 27 & \text { February } & 2017 & \text { from }\end{array}$ https://www.gso.gov.vn/default.aspx?tabid=407\&idmid=4\&ItemID=1346

Vietnam General Statistics Office. (2006). Result of the Vietnam Household Living Standards Survey 2006. Retrieved 22 December 2015 from: https://gso.gov.vn/default_en.aspx?tabid=515\&idmid=5\&ItemID=8183 
Vietnam General Statistics Office. (2009). Population and Housing Census in Vietnam. $\begin{array}{lllll}\text { Retrieved } & 27 & \text { February } & 2017 & \text { from }\end{array}$ https://gso.gov.vn/default.aspx?tabid=512\&idmid=5\&ItemID=10798

Vietnam General Statistics Office. (2011). Migration and Urbanisation in Vietnam: Paterns, Trends, and Differentials. Retrieved 28 January 2016 from http://asiapacific.unfpa.org/sites/default/files/pub-pdf/7_Monograph-MigrationUrbanization.pdf

Vietnam General Statistics Office. (2012). Result of the Vietnam Household Living Standards Survey 2012. Retrieved 22 December 2015 from https://http://www.gso.gov.vn/default.aspx?tabid=417\&idmid=4\&ItemID=13886

VietnamNews. (2009). City chief slams abusive husbands. Retrieved 25 February 2015 from http://vietnamnews.vn/society/190657/city-chief-slams-abusive-husbands-.html

VietnamPlus. (2015). Housing credit package disbursement pushed forwards. Retrieved 14 September 2015 from http://en.vietnamplus.vn/housing-credit-packagedisbursement-pushed-forwards/77261.vnp

"Vietnam Tightens Land Seizure Law". (2013). Vietnam tightens land seizure law after farmers protest, Bloomberg News. Retrieved 19 February 2017 from https://http://www.bloomberg.com/news/articles/2013-12-08/vietnam-tightensland-seizure-law-after-protests-southeast-asia

Vu, T. T. A. (2012). Phân cấp quản lý kinh tế ở Việt Nam: Nhìn tù góc độ thể chế [Decentralization in Vietnam from Institutional Perspectives]: Background Paper prepared under the Request of the Vietnamese National Assembly's Committee of Economic Affairs.

$\mathrm{Vu}, \mathrm{T} . \mathrm{T}$. A. (2015). The political economy of industrial development in Vietnam: The global economic governance programme - University of Oxford. Retrieved 13 April $2016 \quad$ from http://www.geg.ox.ac.uk/sites/geg/files/WP_107\%20The\%20Political\%20Econo my\%20of\%20Industrial\%20Development\%20in\%20Vietnam\%20Tu\%20Anh\%2 0Vu\%20Thanh.pdf

Vu, T. T. A., Dapice, D., Nguyen, X. T., \& Do, T. A. T. (2016). A retrospective on past 30 years of development in Vietnam: WorldBank. Retrieved 29 February 2016 from https://www.scribd.com/document/319848986/A-Retrospective-on-Past-30Years-of-Development-in-Vietnam

Vu, T. T. A., Le, V. T., \& Vo, T. T. (2007). Provincial extralegal investment incentives in the context of decentralisation in Vietnam: Mutually beneficial or a race to the bottom: UNDP Policy Dialogue Paper. Retrieved 18 April 2016 from http://www.vn.undp.org/content/vietnam/en/home/library/poverty/provincialextralegal-investment-incentives-in-the-context-of-de.html

Vuong, H. Q. (2014). Vietnam's political economy in transition (1986-2016). Retrieved 5 January 2016 from https://www.stratfor.com/the-hub/vietnams-political-economytransition-1986-2016

Vuving, A. L. (2016). Why Trong's re-election doesn't spell the end for reform in Vietnam. EastAsiaForum. $\quad$ Retrieved $11 \quad$ April 2015 from http://www.eastasiaforum.org/2016/04/05/why-trongs-re-election-doesnt-spellthe-end-for-reform-in-vietnam/ 
Wang, Y. P., \& Murie, A. (2000). Social and spatial implications of housing reform in China. International Journal of Urban and Regional Research, 24(2), 397-417.

Wang, Y. P., \& Murie, A. (2011). The new affordable and social housing provision system in China: Implications for comparative housing studies. International Journal of Housing Policy, 11(3), 237-254.

Weaver-Hightower, M. B. (2014). A mixed methods approach for identifying influence on public policy. Journal of Mixed Methods Research, 8(2), 115-138.

Weible, C. M. , Heikkila, T., deLeon, P., \& Sabatier, P. A. (2012). Understanding and influencing the policy process. Policy Sciences, 45(1), 1-21.

Whitehead, C., \& Scanlon, K. (2002). Fiscal instruments for the provision of affordable housing. Paper presented at the European Network for Housing Research Conference, Vienna, Austria.

Wilson, D. (2015). Vietnamese's "King of Da Nang" mourned by all, ASIA South China Morning Post. Retrieved 24 February 2015 from http://www.scmp.com/news/asia/article/1714203/vietnams-king-danang-nguyenba-thanh-mourned-all

Wit, J. d. (2007). Decentralisation, local governance and community participation in Vietnam. Upgrading the Capacity of Local Authorities in Planning and Managing Social - Economic Development in Rural Vietnam: Institute of Social Studies, The Hague, The Netherlands. Retrieved 25 February 2016 from https://repub.eur.nl/pub/32795/metis_168543.pd

World Bank. (2006). An assessment of housing for low-income groups in Danang (Phase 1). $\quad$ Retrieved 18 January 2013 from https://openknowledge.worldbank.org/handle/10986/12927

World Bank. (2007). An assessment of housing for low-income groups in Danang (Phase 2). $\quad$ Retrieved 18 January 2013 from https://openknowledge.worldbank.org/handle/10986/12926

World Bank. (2008). Project Appraisal Document: WorldBank. Retrieved 17 January 2015 from http://documents.worldbank.org/curated/en/845281468329997432/VietnamDa-Nang-Priority-Infrastructure-Investment-Project

World Bank. (2011). Vietnam Urbanisation Review. Ha Noi: WorldBank. Retrieved 5 February $2016 \quad$ from http://documents.worldbank.org/curated/en/225041468177548577/Vietnamurbanization-review-technical-assistance-report

World Bank. (2015a). GDP growth. Retrieved 10 November 2015 from http://data.worldbank.org/indicator/NY.GDP.MKTP.KD.ZG

World Bank. (2015b). Vietnam: Overview. Retrieved 7 January 2016 from http://www.worldbank.org/en/country/vietnam/overview

Yin, R. K. (2014). Case study research: Design and methods (5th ed.). Los Angeles, CA: SAGE.

Yip, N-m., \& Tran, H. A. (2008). Urban housing reform and state capacity in Vietnam. The Pacific review, 21(2), 189-210.

Zang, X. (2006). Elites, social change and policy-making in China: An introduction. Policy and Society, 25(1), 1-8. 
Zheng, H., Jong, M. D., \& Koppenjan, J. (2010). Applying policy network theory to policymaking in China: The case of urban health insurance reform. Public Administration, 88(2), 398-417. 


\section{APPENDICES}

\section{APPENDIX 1: INFORMATION SHEET FOR RESEARCH PARTICIPATION}

Title of research: Factors affecting the policy process in local government in Vietnam. The case of housing policy for low-income people in Da Nang City.

Researcher: Nguyen Thi Ha Vy, School of Government, Victoria University of Wellington, New Zealand.

I am a PhD student in Public Policy at Victoria University of Wellington. To complete my degree, I am undertaking a research project about factors affecting the policy process in local government in Vietnam, using the case of housing policy for low-income people in Da Nang City. This research project has received approval from the Victoria University Human Ethics Committee.

I am inviting interviews from a range of people who have been involved in the LIH policy process. Participants will be drawn from the city Party, DNPCl, DNPCe, relevant departments, construction companies, the research community, labour organisations, and international organisations. With some tailoring for participants' area of expertise, the interviews will cover the following themes: how the policy process happened; what were their roles in the policy process; what influenced them in making policy decisions and the reasons why those influences were important. Ultimately, I expect to find how socioeconomic conditions, the relationship between central and Da Nang City's governments, the role of local policymakers and other important influences interact to produce the LIH policy in Da Nang City. Where relevant, I will also ask participants for copies of documents related to this topic for documentary analysis.

I expect the interviews will require about one hour, and will be arranged at a time and place convenient to you. If you agree, I will audio-record the interview, to assist me to make an accurate record. Participation in this research is voluntary and participants have the right to withdraw from the research without having to give reasons at any time before my data collection is finished on 15/01/2014.

To keep participants' confidentiality, references to participants will be by pseudonym or role description only. When quotes from interviews are reported, best efforts will be made to avoid conveying the personal identity of the participant. 
Collected data will be analysed and put into a written thesis. The thesis will be submitted for marking to School of Government, Victoria University of Wellington, and deposited in the University Library. Research findings may be used for one or more articles, which will be submitted to scholarly journals. Findings may also be presented at academic or professional conferences. The information gathered will be securely stored and then destroyed five years after the end of my doctoral study.

All collected data will only be accessed by the researcher and supervisors and used for this research purpose only.

Feedback of the interview and a summary of the final thesis will be sent to participants who request them. 


\section{APPENDIX 2: GUIDEPOST INTERVIEW QUESTIONS}

\section{PART 1: To ask people involved in the policy process}

\section{A. To understand the policy process}

1. Can you tell me about your organisation's and personal role in the LIH policy process in Da Nang from 2005 to 2013 ?

2. Can you please describe more about the policy process within your organisation? How was your organisation's role related to the whole policy process?

3. What main matters were discussed during the LIH policy process?

4. What kind of information did you use to consider the policy issue and policy solutions?

5. Who did you consult to make relevant decisions?

\section{B. To understand the role of socio-economic conditions}

6. Were there factors that made LIH an important policy issue and what were they?

7. Could you please tell me about the socio-economic conditions that facilitate or obstruct the LIH policy?

\section{To understand the central-local government relationship}

8. Could you tell me where the idea of the 3-Haves campaign came from? Who brought the idea to the agenda?

9. How do you evaluate the importance of the central government's regulations in making LIH policy in Da Nang?

10. What were the differences between the central government's regulation and the city's policy? Why were there differences?

11. Can you explain why the city government made changes in housing policy for lowincome people in 2009 ?

12. Where did the finance resource for LIH come from? Was there any constraint?

13. Can you tell me about the city's financial situation regarding LIH in 2005 and 2009 ?

\section{To understand the role of policymakers and other actors}

14. How has the LIH policy received the approval of the Party? To what extent and at what level was it debated in the Party/the Committee/the Council? 
15. From your point of view, what is the main meaning of LIH policy to the people, and to the government?

16. What do you think about the role of: the state, the central vs. local government, and the public vs. private sector in housing for low-income people? How have government views on these roles changed in the last 20-30 years?

17. Were you involved in housing sector before 1986? What did the housing sector in Da Nang look like at that time? What policy was applied? How was the housing situation of people in Da Nang at that time?

18. Was there any experience from that time that you think was useful for policymakers when they made LIH policy in 2005 and 2009?

19. Were you influenced by any similar policy experience in making this policy (from other cities, countries or international organisations)?

20. Was there any distinguishing feature of LIH policy in Da Nang in comparison with other localities?

21. What conditions enabled the city to enact those differences?

22. What were the most important decisions made?

23. Who do you think were the most significant people involved in those decisions?

24. Were there any particular reasons/incentives for those people to make the decisions?

\section{E. To find out other relevant factors}

25. Was there any influence from low-income people/constituents/other organisations and the private sector in making this policy?

26. Have you got any feedback from low-income people/constituents/other organisations/the private sectors about LIH policy? What was the feedback? How did you respond?

27. How do you evaluate the role of private companies in building low-income houses and in influencing government policy?

28. Did you ask for donor's participation in LIH? What was the outcome? How do you evaluate their roles?

29. What were the role of the press; research community; consultative exercises; and the system of checks and balances in this policy process? 


\section{PART 2: To ask witnesses and knowledgeable informants}

\section{Construction companies:}

- Can you tell me about your participation in LIH development in Da Nang City?

- When did you start to notice the segment of LIH? Did you perceive it as a promised investment activity at the beginning? Were you asked for your opinion by local government about expected incentives for investors of LIH? Did you try to influence policymakers in making policy for LIH investors?

\section{International organisations:}

- Is LIH one of your organisation's concerns?

- Were you asked for your opinion by local government about LIH? Did you have any influence on policymakers regarding LIH?

\section{Labour organisations:}

- How is housing situation of the majority of workers in Da Nang City?

- How do you evaluate Da Nang City's LIH policy in relieving workers' housing difficulty?

- Were you involved in the process of making housing policy for workers? 


\begin{tabular}{|l|l|}
\hline \multicolumn{1}{|c|}{ Organisation } & \multicolumn{1}{|c|}{ Pseudonym } \\
\hline City Party & R9, R11 \\
\hline DNPCl & R3, R4, R16, R10 \\
\hline DNPCe & $R 5$ \\
\hline Departments and other administrative agencies & R1, R2, R13, R14, R17, R18, R20 \\
\hline Private sector & R6, R7 \\
\hline International agencies & R19 \\
\hline Mass organisation & $R 21$ \\
\hline Media & R8, R12 \\
\hline Research community & R15, R22 \\
\hline
\end{tabular}




\section{APPENDIX 4: CODING OF DOCUMENTS}

D1. Letter 960-CV/TU dated 12/05/2005 from the city Party to the DNPCe

D2. Report 26-BC/TU dated 30/08/2006 by the city Party to the CCOM of CPV

D3. Statement 54/TB-TU dated 05/03/2007 by the city Party about the Standing Committee's conclusion in a monthly meeting among Party agencies and political social organisations in February 2007

D4. Report 50-BC/TU dated 15/08/2008 by the city Party

D5. Statement 121-TB/TU dated 20/3/2009 by the city Party

D6. Statement 23-TB/TU dated 25/02/2011 by the city Party about Mr Nguyen

$\mathrm{Ba}$ Thanh's conclusion in a meeting about the exploitation of land fund and plans for building apartments in the city

D7. Statement 93-TB/TU dated 13/02/2012 by the city Party

D8. Action plan 19-CTr/TU dated 29/10/2012 by city Party on implementing Resolution 15 dated 01/06/2012 by the CPV about social security

D9. Report $163-\mathrm{BC} / \mathrm{TU}$ dated $30 / 9 / 2013$ by the city Party to the Central Economic Committee of CPV on the result of social security policy in Da Nang City from 1997 to 2013

D10. Report $165-\mathrm{BC} / \mathrm{TU}$ dated $02 / 10 / 2013$ by the city Party to the Central Economic Committee of CPV on building a comprehensive infrastructure system on way to build our country to become a modern industrialised country

D11. The $20^{\text {th }}$ city Party Congress' Resolution for the period from 2010 to 2015

D12. Concluding speech to the $20^{\text {th }}$ city Party Congress (presented by $\mathrm{Mr}$ Nguyen Ba Thanh)

D13. (Draft) Report dated May 2014 by the city Party to the CCOM of CPV about restructuring the economy

D14. (Draft) Report dated May 2014 by the DNPCe about socio-economic development plan for the period from 2016 to 2020

D15. Report dated 2013 by the DOLISA about the 5-Nos and 3-Haves campaigns 
D16. A proceeding presented by Mr Tran Van Nam in a workshop named "Da Nang youth participate in the Having Housing Programme organised by the Ho Chi Minh Communist Youth Union in Da Nang City (05/05/2006)

D17. (Draft) Submission by the DOC to the DNPCe about the enactment of the Having Housing Programme created on 28/09/2005

D18. Decision 140/2005/QD-UB dated 03/10/2005 by the DNPCe about the enactment of the Having Housing Programme for people in Da Nang City from 2005 to 2010

D19. (Draft) Plan for policy implementation (this document was prepared by the DOC and submitted with the draft of the Decision 140)

D20. (Draft) Submission by the DOC to the DNPCe about plan for the implementation of the Having Housing Programme created on 24/10/2005 D21. A speech prepared for Mr Tran Dinh Hong, Vice Director of the DOC in a conference on the implementation of Having Housing Programme (28/10/2005)

D22. (Draft) preparation for a video conference between the MOC and local governments (05/2009) to report about the implementation of Resolution 18 and three decrees $65,66,67$ by the Government relating to housing for workers, students and low-income people.

D23. Decision 3882/QD-UBND dated 24/05/2009 by the DNPCe about approving the Programme of building 7,000 housing units to implement the Having Housing Programme

D24. Letter (draft) dated March 2006 by the DOC to the Housing Management Committee of the MOC about providing documents for the guidelines of implementation of the Law on Housing

D25. Letter (draft) dated January 2007 by the DOC to the DNPCe reporting solutions for enhancing the 3-Haves campaign.

D26. Report (draft) dated 04/04/2006 by the DOC reporting the implementation of the Having Housing Programme (6 month report)

D27. Decision 184/QD-UB dated 19/11/2004 by the DNPCe enacting a Poverty Reduction Programme in Da Nang City from 2005 to 2010

D28. Letter (draft) dated September 2006 by the DOC to the DOF commenting on 
the draft of the regulations of organisation and activities of HDF

D29. Preparation for 'Cung chung toi doi thoai' Programme on DVTV (by Mr Tran Van Nam for Mr Tran Dinh Hong - Vice Director of DOC)

D30. Information of enterprises in Da Nang City

D31. Report (draft) by the DOLISA dated June 2008 (6 month report) about implementation of Having Housing Programme in the first half of 2008

D32. Report (draft) dated 17/06/2008 by a Division of the DOC to the Office of the DOC

D33. Report (draft) dated 11/07/2008 by the DOC to the DNPCe

D34. Letter (draft) dated 21/05/2008 by the DOC to relevant departments and agencies requesting for six-month reports

D35. A speech delivered by Mr Tran Van Hong at a summing-up conference of two years of implementing the 3-Haves campaign

D36. Information prepared for discussion with the DPI (as requested by the DPI at Letter 102 dated 15/01/2008 about reporting on two years of implementation of the 3-Haves campaign) and also for a meeting with the CIEM about policies for the development of real estate market and reform in state management in housing in cases of new urban zones, apartments, and offices for rent

D37. Some information relating to housing for workers

D38. Letter dated December 2008 by the DOC to its units (Housing Management Company, investors in housing, Management Board of Projects)

D39. Letter dated December 2008 by the DOC to the DNPCe about organising a design competition in order to choose better designs for low-income apartments, middle-income apartments and high-income apartments

D40. Preparation for a video conference with the MOC (May 2009)

D41. Report by the DOC to the DNPCe about apartment designs used for the 5,000 housing unit programme (May 2009)

D42. Statement (draft) dated 28/12/2009 by the Chairman of the DNPCe about the meeting on building apartments for the social housing programme

D43. Letter (May 2009) by the DOC to the DNPCe about preparing sites for lowincome housing projects 
D44. Letter (April 2009) about a plan for building 5,000 housing units

D45. An article dated 10/12/2008 on Lao Dong Newspaper about the MOC's Submission $(08 / 12 / 2008)$ to the government about using state budget for social housing project (used by an official of the DOC)

D46. Letter (draft) by the DOC to the DNPCe about the list of people who registered to buy low-income housing units invested by Vicoland

D47. DOC's report of September 2009

D48. DOC's report of October 2009

D49. DOC's report of November 2009

D50. DOC's report of December 2009

D51. Letter dated February 2010 by the DOC to the DPI about financial source for government bond

D52. Letter by the DOC to the MOC relating to capital for private companies investing in LIH in Da Nang City

D53. Report dated 30/03/2010 by the DOC to the DNPCe about all housing projects in the city

D54a. DOC's report of June 2010

D54b. Draft of regulations on criteria in choosing tenants, buyers and procedures relating to leasing and selling social housing (16/12/2010)

D55. Statement 91 dated 22/07/2009 by the DNPCe about plan for social housing programme

D56. Statement 103 dated 22/04/2009 by DNPCe about the 5,000 housing units programme

D57. Answers for question from a television programme

D58. Reports of some months of 2011

D59. Submission (September 2011) by the DOC to the DPI about approving a project of building apartments for government officials in Da Nang city

D60. DOC's report of November 2011 about the progress of social housing projects D61. DOC's report of November 2011 about the progress of the 7,000 housing unit programme

D62. A document prepared for an event (a meeting or a conference) by the DOC 
D63. The DNPCe's report to a delegation from the MOC led by Deputy Minister Nguyen Tran Nam, working with Da Nang City about housing development strategy to 2020 , a vision to 2030

D64. Resolution 15-NQ/TW dated 01/06/2012 by the XI Central Committee of the CPV at its $5^{\text {th }}$ congress, about some social policy issues in the period from 2012 to 2020 D65. DOC's report of November 2012

D66a\&b. Answers for questions by constituents

D67. Report dated 13/11/2012 by the DNPCe to a delegation from the MOC about inspecting the implementation of resolutions for real estate market management (prepared by the DOC)

D68. Some suggestions for social housing development (06/11/2013)

D69. The DNPCl's statement 25/TB-HDND dated 22/05/2013 about criteria for receiving and considering applications for rent in Da Nang City

D70. Data from the DOLISA

D71. Statement 149/TB-UBND dated 23/11/2011 about the meeting of city leaders about implementation of social housing and student dormitories in Da Nang City D72. Statement 37/TB-BCDNO\&TTBDS-VPTT dated 05/10/2012 by the Central Steering Committee on Housing Policy and Real Estate Market about the result of the visit to Da Nang City

D73. Statement 48/TB-BCDNO\&TTBDS-VPTT dated 30/11/2012 by the Central Steering Committee on Housing Policy and Real Estate Market about the result the meeting on 09/11/2012 about financial resource for social housing development of Da Nang City

D74. Letter 9602/UBND-QLDTh dated 15/11/2012 by the DNPCe about selling 100 units at Bach Dang Dong Street (Vincoland's project)

D75. Letter 1871 dated 19/11/2012 by the DOF about guaranteeing for Vicoland to borrow money for the project at Bach Dang Dong Street

D76. Letter 4303/SXD-QLN dated 23/10/2013 by the DOC reporting about housing projects invested by 579-Duc Manh Joint Venture (Duc Manh Joint Stock Company and 579 Investment and Building Company)

D77. Resolution 23 dated 24/12/2011 by the DNPCl about solutions for socio- 
economic development

D78. Resolution 29/2012/NQ-HDND dated 05/12/2012 by the DNPCl about population distribution

D79. Resolution 48/2013/NQ-HDND dated 12/12/2013 by the DNPCl regulating the average area person in Da Nang City applied when considering applications for permanent residence registration for people who will be sharing or renting locals' houses

D80. Letter 5477/SXD-QLXD dated 23/12/2013 by the DOC to the DNPCe

D81. Letter 30-14 dated 26/03/2014 by 579-Duc Manh Joint Venture to the DNPCe about prices of housing units

D82. Letter 1661/SXD-QLN dated 04/04/2014 by the DOC about prices of units invested by 579-DucManh

D83. Letter 4576/SXD-QLN dated 08/11/2013 by the DOC to the DNPCe about low-income housing projects

D84. Joint letter 1843/LT/BXD-UBNDTPDN dated 06/09/2013 between the MOC and the DNPCe about a Joint Action Plan to implement the National Housing Strategy to 2020, a vision to 2030

D85. Draft of a decision on selling state-funded social housing in Da Nang City (2014)

D86. Decision 6109/KH-UBND dated 27/10/2005 by the DNPCe about the plan of implementing the Having Housing Programme

D87. Meeting minutes dated 25/07/2005 by the DNPCl

D88. Resolution 25 (2005) by the DNPCl about the 3-Haves campaign

D89. Submission 4753/TTr-UBND dated 24/08/2005 by the DNPCe to the DNPCl asking for opinions about the 3-Haves campaign's enactment

D90. Letter 4883 dated 15/9/2005 by the Office of the DNPCe to the Director of the DOJ

D91. Letter 1248 dated 21/09/2005 by the DOJ to the Office of the DNPCe about verification of legal document drafts

D92. A speech delivered by Mr Nguyen Ba Thanh on the $30^{\text {th }}$ anniversary of the city's independent day

D93. Statement 209 dated 31/08/2006 by the DNPCe announcing the conclusion of 
the monthly meeting between city leaders and leaders of departments, agencies, districts in August 2006

D94. Submission $3189 / \mathrm{TTr}-\mathrm{UBND}$ dated $26 / 05 / 2009$ by the DNPCe to the Prime Minister about the 7,000 housing units Programme

D95. Letter 269/TT-HDND dated 08/09/2005 by the DNPCl answering the DNPCe's Submission 4753

D96. The $19^{\text {th }}$ City Party Congress' documents (for the period from 2005 to 2010)

D97. Draft of regulations on the organisation and activities of the city's HDF

D98. Report on the progress of building social housing apartments and students housing

D99. Excel sheets: Da Nang socio-economic conditions

D100. Report 55 dated 21/03/2012 by the DNPCe to the NA about solving relocated people's difficulties in resettlement areas

D101. Report dated January 2013 the DNPCe about infrastructure investment from state budget in ten years from 2002 to 2012

D102. Decision 1800 dated 28/02/2008 by the DNPCe approving the PIIP project D103. Resolution 33 (2003) by the Politburo about developing Da Nang in industrialisation and modernisation period. 